\title{
Molecular regulation of vascular calcification
}

Citation for published version (APA):

Dhore, C. R. (2005). Molecular regulation of vascular calcification. [Doctoral Thesis, Maastricht

University]. Universiteit Maastricht. https://doi.org/10.26481/dis.20050603cd

Document status and date:

Published: 01/01/2005

DOI:

$10.26481 /$ dis.20050603cd

Document Version:

Publisher's PDF, also known as Version of record

\section{Please check the document version of this publication:}

- A submitted manuscript is the version of the article upon submission and before peer-review. There can be important differences between the submitted version and the official published version of record.

People interested in the research are advised to contact the author for the final version of the publication, or visit the DOI to the publisher's website.

- The final author version and the galley proof are versions of the publication after peer review.

- The final published version features the final layout of the paper including the volume, issue and page numbers.

Link to publication

\footnotetext{
General rights rights.

- You may freely distribute the URL identifying the publication in the public portal. please follow below link for the End User Agreement:

www.umlib.nl/taverne-license

Take down policy

If you believe that this document breaches copyright please contact us at:

repository@maastrichtuniversity.nl

providing details and we will investigate your claim.
}

Copyright and moral rights for the publications made accessible in the public portal are retained by the authors and/or other copyright owners and it is a condition of accessing publications that users recognise and abide by the legal requirements associated with these

- Users may download and print one copy of any publication from the public portal for the purpose of private study or research.

- You may not further distribute the material or use it for any profit-making activity or commercial gain

If the publication is distributed under the terms of Article $25 \mathrm{fa}$ of the Dutch Copyright Act, indicated by the "Taverne" license above, 


\section{Molecular regulation of vascular calcification}


(C) C.R. Dhore

ISBN 90-6464-262-1

Vormgeving: Karin Faber, IXO-vormgeving

Druk: Ponsen \& Looijen b.w. 


\title{
Molecular regulation of vascular calcification
}

\author{
Proefschrift \\ ter verkrijging van de graad vall doctor \\ aan de Universiteit Masstricht, \\ op gezag van de Rector Magnificus, \\ Prof. mr. G.P.M.F. Mols, \\ volgens het besluat van het College van Decanen, \\ in het openbaar te verdedigen \\ op vrijdag 3 juni 2005 om 12.00 uur \\ door \\ Cherida Rachel Dhore \\ Geboren op 29 jull 1971 te 's Gravenhage.
}


Promotor

Prof. dr. M.A.A.P. Daemen

Co-Promotor

Dr. J.P.M. Clewtjens

Beoordelingscommissie

Prof. dr. K.M.L. Leunissen (voorzitter)

Prot. dr. F.W.H.M. Bär

Prof. dr. V. Everts (Universiteit van Amsterdam)

Prot. dr. P.P.M.M. Geusens

Dr. C. Vermeer

Financial support by the Netherlands Heart foundation (NHF 97.113) and the Dr. Ir. van de Laar Stichting for the publication of this thesis is gratefully acknowledged. 


\section{List of abbreviations}

AC-LOL acetylated low density lipoprotein

ALP

allkaline phosphatase

ApoE

ASMA

BAP

BCIP

$B C-2$

apolipoprotein $\mathrm{E}$

$\alpha$-smooth muscle actin

bone alkaline phosphatase

BMP

5-bromo-4-chloro-3'-indolylphosphate p-toluidine salt

BSP

Cbfa 1

B-cell leukemia 2

CFDP-1

bone morphogenetic protein

Cktsfl-bl

bone sialoprotein

CRTL-1

core binding factor alpha subunit 1

DIG

craniofacial developmental protein 1

cysteine knot superfamily 1

cartilage linking protein 1

DNA

ECM

EVG

Gla

digoxigenin

deoxyribonucleic acid

extracellular matrix

HE

Elastica von Giesson

$\gamma$-carboxyglutamate

HDL

$\mathrm{kiDa}$

$\mathbb{L D L}$

MGP

hematoxylin and eosin

high density lipoprotein

kilo dalton

low density lipoprotein

MM-LDL

matrix Gla protein

MRNA

minimally modified low density lipoprotein

MS

messenger ribonucleic acid

NBT

OC

Mönckeberg's sclerosils

nitro-blue tetrazolium chloride

osteocalcin

OPN

osteopontin

ON

osteonectin

OPG

OPGL

OXLDL

osteoprotegerin

PBS

pfu

PTHIP

osteoprotegerin ligand

oxidized LDL

RANK

RANKL

RGD

RNA

phosphate buffered saline

plaque forming unit

parathyroid hormone related peptide

receptor activator of nuclear factor- $1 \mathrm{~B}$

receptor activator of nuclear factor-кB ligand

Arg-Gly-Asp

RTPCR

ribonucleic acid

SEM

SMC

reverse transcriptase polymerase chain reaction

SPARC

TRAP

TBS

TGF $\beta$

TNF

standard error of the mean

smooth muscle cell

secreted protein, acidic and rich in cystein

tartrate resistant acid phosphotase

tris buffered saline

transforming growth factor $\beta$

tumor necrosis factor

VSMC

wascular smooth muscie cell 



\section{Contents}

Chapter 1 General introduction

1 Atherosclerosis

1.1 Pathogenesis of atherosclerosis

1.2 Atherosclerotic classification (Virmani)

1.3 Atherosclerotic calcification

2 Osteogenesis and vascular calcification

3 Atherosclerotic calcification \& osteoporasis

4 Atherasclerotic calcification \& lipids

5 Regulation of calcification

6 Hypothesis.

$7 \quad$ This thesis

8 References

Chapter 2 Differential expression of bone matrix regulatory proteins in human atherosclerotic plaques

Chapter 3 increased expression of bone matrix regulatory proteins in leaflets of patients with aortic valwe stenosis

Chapter 4 BMP-2 induces atherosclerotic calcification and fibrosis in carotid artery wein grafting in hypercholesterolemic ApoE3* Leiden mice

Chapter 5 A third generation bisphosphonate, risedronate has no effect on the development of atherosclerosis in ApoE $\%$ mice in doses that affect bone density

Chapter 6 General Discussion

Summary

Samenwating

Dankwoord

Curriculum vitae

Full color figures 

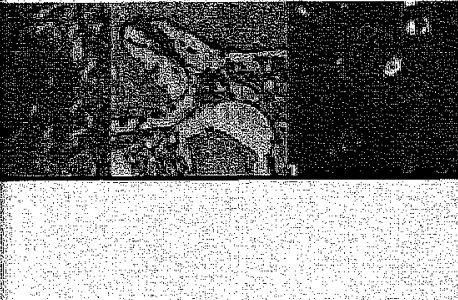

\title{
Chapter 1
}

\author{
General introduction
}




\section{Atherosclerosis}

\subsection{Pathogenesis of atherosclerosis}

Atherosclerosis is a disease of the large arteries, and is the primary cause of myocardial infarction, stroke and ischemia of the extremities. In the USA, Europe and Japan, it is the underlying cause of about $50 \%$ of all deaths. Risk factors for atherosclerosis can be grouped into factors with a genetic compound, and those that are largely environmental?. Factors with a genetic compound are elevated levels of low-density lipoprotein $(\mathrm{LDL})$ and very low-density lipoprotein $(\mathrm{VLDL})^{3}$, reduced levels of high-density lipoprotein (HDL)", elevated lipoprotein (a) , elevated blood pressure (hypertension) ${ }^{36,}$ elevated homocysteine?, family history" , diabetes mellitus and obesity" elevated haemostatic factors (e.g. fibrinogen) " depression", behavioral traits", gender (male) ${ }^{10}$, systemic inflammation" and metabolic syndrome ${ }^{12}$. Environmental risk factors are high-fat diet", smoking ${ }^{3}$. low anti-oxidant levels ${ }^{13}$. lack of exercise ${ }^{3}$ and infectious agents ${ }^{\text {\#. }}$. Among these genetic and environmental risk factors, elevated levels of serum cholesterol are probably unique in being sufficient to drive the development of atherosclerosis in humans and experimental animals, even in the absence of other known risk factors ${ }^{15}$.

Atherosclerosis starts silently at the first decade of life, progresses with age and mainly affects large arteries. Large arteries consist of three layers (fig. 1.1), the tunica intima, tunica media and tunica adventitia and atherosclerosis manifests in the inner layer (intima) of these large arteries, It is a progressive disease characterized by several stages.

Atherosclerosis begins with activation of the endothelium of the normal vessel wall, including an alteration in its permeability. Low-density lipoproteins become entrapped

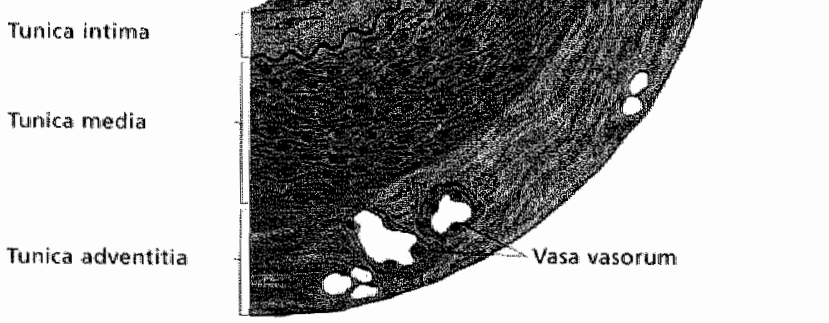

Figure 1.9 morphological charcteristics of the vessel wall 
within the vesse: wall and undergo oxidative modification. Meanwhile, activated endothelial cells produce molecules to attract inflammatory cells.

Monocytes are recruited from the bloodstream and become macrophages. These macrophages are responsible for the uptake of oxidized lipids to form foam cells: a characteristic feature of the early lesion, the intimal xanthoma or fatty streak. A subpopulation of smooth muscle cells (SMCS) with a synthetic phenotype migrates towards the intina. where they increase in number, produce extracellular matrix components and form a fibrous cap. Highly oxidized LDL has been shown to be toxic to macrophages: With the death of some macrophages, lipid droplets are released and phagocytized by smooth muscle cells, producing smooth muscle foam cells". Both macrophage and smooth muscle cell derived lipid filled foam cells have the ability of undergoing necrosis and apoptosis. These necrotic or apoptotic cells can form a nidus for calcification. When the fibrous cap becomes thinner, the plaque is more vulnerable for rupture and thrombosis which may cause acute and near-total occlusion leading to acute clinical complications of myocardial infarction and stroke ${ }^{15.18 .19}$.

Whether the presence of calcification in atherosclerotic plaques increases the appearance of plaque rupture is until now not clear. Recently, two major discussions have dominated the field of vascullar calcification. The first focuses on the effect of calcification on plaque stability, the second on the question whether vascular calcification is a passive or an active regulated process. In this thesis we will concentrate on the molecular regullation of vascular calcification and thus on the latter theme.

\subsection{Atherosclerotic classification (Virmani)}

In this thesis we use the plaque classification proposed by Virmani et al. ${ }^{20}$. This is a rather simple classification that is consistent with the classification proposed by the American Heart Association (AHA)", containing categories of plaque types that are easy to use, and deal with a wide array of morphological wariations. Typical examples of these lesions are given in figure 1.2 (adapted from Virmani et al.) ${ }^{\text {* }}$

Intimat thickening (fig. 1.2a)

This lesion type may occur already soon after birth. The intima becomes thicker mainly due to smooth muscle cells in a proteoglycan rich matrix. Intimal thickening is a pre-atherosclerotic lesion that is able to regress.

Intimal xanthoma or fatty streak (fig. 1.2b)

Like intimal thickening, intimal xanthoma (also known as fatty streak) may occur soon after birth and is known to regress. "Xanthoma" is a general pathological term that describes the accumulations of fat-laden macrophages. Intimal xanthoma primarily 
consist of accumulations of macrophage-derived foam cells, T-lymphocytes, and varying degrees of smooth muscle cells in the intima of a large artery.

\section{Pathological intimal thickening (fig. $1.2 \mathrm{C}$ )}

Pathological intimal thickening is a poorly defined entity sometimes referred to as an "intermediate lesion". True necrosis is not apparent, and there is no evidence of cellular debris. Some lipid may be present deep in the lesion, but dispersed. The fibrous cap overlying areas of lipid is rich in smooth muscle cells in a proteoglycan-rich matrix. Some scattered macrophages and lymphocytes may also be present in the fibrous cap.

\section{Fibrous cap atheroma (fig. $1,2 d$ )}

The core of this lesion is true necrotic, containing cholesterol esters, free cholesterol" phospholipids, and triglycerides. The fibrous cap consists of smooth muscle cells in a proteoglycan-collagen matrix, with a variable number of macrophages and lymphocytes. The media underneath the plaque is often thin.

Thin fibrous cap atheroma (fig. 1.2e)

This lesion is a look-a-like of the fibrous cap atheroma, but contains a thin fibrous cap infilltrated by macrophages and lymphocytes with rare SMCs.

Plaque rupture (fig. 1.2f)

Ruptured plaques are thin fibrous cap atheromas with luminal thrombi. These lesions contain an extensive necrotic core with large numbers of cholesterol crystals and a thin fibrous cap infiltrated by foamy macrophages and some T-lymphocytes. The fibrous cap is thinnest at sites of rupture and consists of a few collagen bundles and some smooth muscle cells. The luminal thrombus is in communication with the lipid-rich necrotic core.

Calicified nodule (rig. 1.2g)

Calcified nodules are plaques with luminal thrombi showing callific nodules protruding into the lumen through a disrupted thin fibrous cap. There is absence of endothelium at the sites of the thrombus, and inflammatory cells (macrophages, Thymphocytes) are absent.

Fibrocalcific plaque (fig. 1.2h)

Fibrocalcific plaques are referred to as "stable" lesions in the literature. These lesions are predominantly composed of dense collagen containing a few scattered smooth muscle cells and inflammatory cells. When present, the necrotic core is small. These lesions are often heavily calcified and previous hemorrhage and/or thrombosis is difficult to determine. 

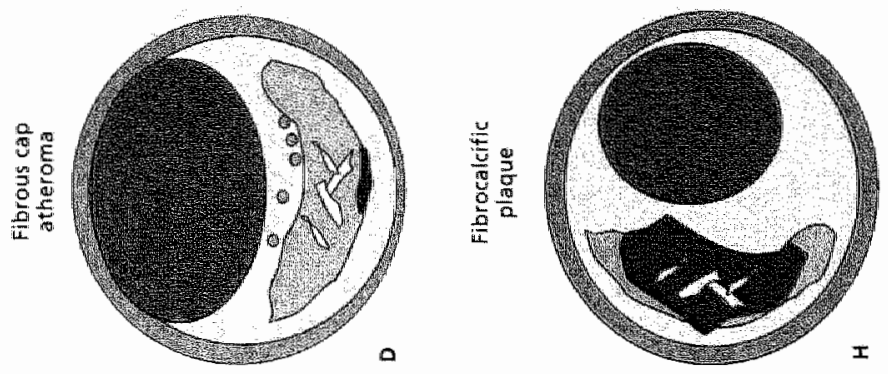


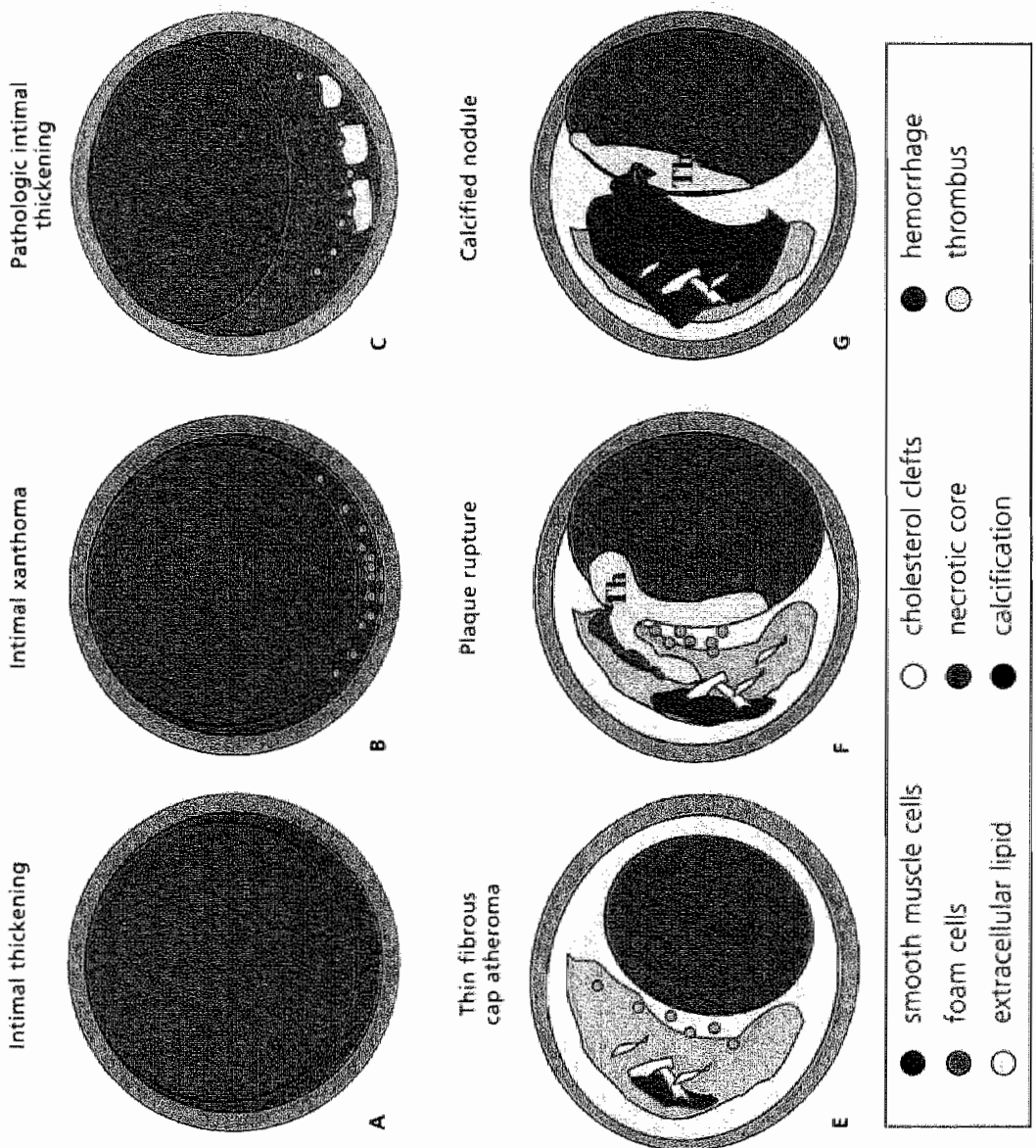

Figure 1.2 Classification of atherosclerotic plaques. Full color fiqures see page 141 


\subsection{Atherosclerotic calcification}

Vascular calcification

Vascular calcification refers to the deposition of calcium phosphate mineral, most often hydroxyapatite, in the vessels of many different tissues. Vascullar calcification often occurs in patients with chronic renal failure (kidney), Alzheimer disease and Down syndrome (brain), chronic hemodialysis patients (kidney), and in cardiac patients (heart valves). Vascular calcification in large arteries occurs at two anatomic sites, in the intima or in the mediall layer of these vessels. Calcification of the media is referred to as Mönckeberg's sclerosis (MS) and occurs commonly in aged and diabetic individuals ${ }^{2 ?}$ and in patients with chronic kidney disease ${ }^{23}$ (table 1). Mönckeberg's sclerosis appears to be a strong predictor of cardiovascular mortality in diabetic patients ${ }^{2 x}$, and is independent of atherosclerosis ${ }^{3 t_{2}}$. However, vascular calcification in the intima is invariably associated with atherosclerosis. Disturbances in lipid metabolism, male sex, and hypertension aggravate atherosclerotic calcification (table 1). Atherosclerotic calcification is not restricted to large arteries, and can also occur in the leaflets of aortic valves.

\section{Atherosclerotic calcification}

Calcification is a prominent feature of advanced atherosclerosis and is located in the intima of the large arteries. Calcification in atherosclenotic plaques decreases vessel elasticity, augments plaque brittleness, and leads to increased plaque rupture during angioplasty procedures ${ }^{26.29}$. Although atherosclerotic calcification has been associated with increased risk of stroke, myocardial infarction and death ${ }^{26,35}$, other reports described the opposite ${ }^{31, y 2}$.

The main controversy is whether calcification stabilizes or destabilizes the plaque. Demer et al argued that the presence of a soft plaque, with a point of weakness induced by inflammation adjacent to an area of calcification, predisposes the plaque to rupture.

Table 1. Risk factors of vascular cakification.

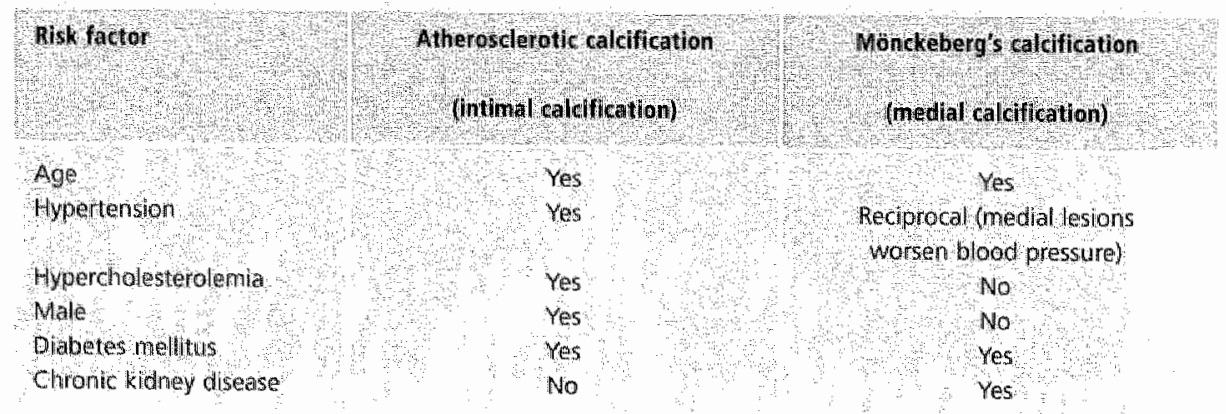


Plaque rupture occurs mainly at the interfaces of rigid and compliant structures such as between calcium mineral deposits and the normal arterial wall or the fibrous plaque ${ }^{\text {s. }}$. However, Virmani et al. described that calcified area is greatest in healed ruptures, followed by fibro-atheroma, thin cap atheroma, plaque hemorrhage, fibrous plaque, plaque rupture and total occlusion. Although calcification is associated with a large lipid core size, calcification is more often seen in areas overlying collagenous plaques:

Although its association with atherosclerosis has been noted for centuries ${ }^{35.35}$ "the regulation of vascular calcification has been largely ignored, because of the prevailing view that it was merely a degenerative, passive process of calcium phosphate precipitation that only accurs in end-stage atherosclerosis and simply signifies dying cells.

Recently, by the discovery that bone-associated genes can be expressed in the vessel wall, it has become clear that vascular calcification may not be a passive process, but may be actively regulated ${ }^{37.39}$. Early lesions of young adults have been found to already contain small aggregates of crystalline calcium within the lipid core ${ }^{21, n g}$. The regulation of atherosclerotic plaque calcification has been suggested to share similarity to skeletogenesis. This hypothesis has partly been corroborated by the presence of osteogenic features in plaques ${ }^{32,4}$.

\section{Aortic valve calcification}

Calcification of the tricuspid aortic valve is the most common cause of aortic valve disease in older patients, and is located in the fibrotic layer of aortic valve leaflets. The cause of aortic valve calcification is largely unknown, but typical morphological characteristics associated with calcification in aortic valves are associated with atherosclerotic calcification ${ }^{42}$. Vascular calcification is considered to be a risk factor for valvular calcification ${ }^{43}$ and recently published data indicate that aortic valve calcification is indeed associated with increased risk of cardiovascular events including stroke and cardiac death ${ }^{43.45}$. Moreover, valvular and vascular calcifications are both considered to share similarities with skeletal bone formation ${ }^{46}$.

The composition of a calcified plaque

According to the Virmani classification ${ }^{20}$, atherosclerotic plaques containing calcium mineral deposits or other osteogenic structures are classified as calcified nodule or as fibrocalcific plaque. The osteogenic elements in calcified plaques can be bone cells, cartilage, calcium mineral, lamellar bone, nucleation sites (matrix vesicles) and bone matrix regulatory proteins. Also, collagen fibrils, mitochondria, and lipids are present in the vessel wall ${ }^{2 n, A ? d a}$.

Calcium mineral within atherosclerotic plaques is known to be hydroxyapatite $\left[\mathrm{Ca}_{10}\left(\mathrm{PO}_{4}\right)_{6}(\mathrm{OH})_{2}\right]$, which is the same mineral as is found in bone ${ }^{n .50}$. Also in the plaque 
osteogenic cells like osteoblasts, osteccytes, chondrocytes and osteoclasts are necessary for the formation and degradation of calcium mineral, cartilage and lamellar bone. The origin of these cells in the plaque is not clear. One of the theories is that they are derived from differentiation of vascular cells into chondrogenic and/or osteogenic cells ${ }^{33}$. One of the most widely used bone differentiation markers is the bone specific isoenzyme alkaline phosphatase (BAP) ${ }^{\text {is } 5 \text { ? }}$, and the expression of this marker is enhanced in calcified atherosclerotic plaques ${ }^{5}$. BAP in osteoblastic differentiation is believed to caralyze the hydrolysis of monophosphate ester at sites of mineralization. The cleaved ionic phosphate groups are incorporated into calcium phosphate in the form of hydroxyapatite mineral ${ }^{5 \mathrm{~A}}$. During and after osteoblastic differentiation these cells produce several bone matrix regulatory proteins to induce or inhibit mineralization, cartilage and bone formation. It is well established that lipids are associated with mineralization in bone and other calcified tissues ${ }^{55.57}$. It has been postulated that lipids are involved in the nucleation of hydroxyapatite mineral. This nucleation is accomplished by specialized structures termed matrix vesicles. Matrix vesicles are membrane bound vesicles that are produced by budding from chondrocytes, osteoblasts, and odontoblasts and contain the necessary calcium-binding proteins and phosphatases for nucleation of hydroxyapatite. Like skeletal bone, human calcified atherosclerotic plaques contain matrix vesicles, which are key elements in organized calcium phosphate crystal formation ${ }^{43}$. Matrix vesicles are thought to initiate calcification by forming bone and mineralizing cartilage ${ }^{58}$. Initial hydroxyapatite crystal deposition occurs along the inner surface of these matrix vesicles $^{\text {s9 }}$. Matrix vesicles-like structures have also been found in calcified arteries and heart valves $5^{17.60 .62}$. Kockx et al $l^{63}$ showed that in advanced carotid atherosclerotic plaques, matrix vesicles are derived form vascular smooth muscle cells. They contain $B A X$, a pro-apoptotic protein of the $\mathrm{BCl}-2$ family. suggesting that they may be remnants of apoptotic cells. It is thought that cell death may lead to matrix vesicle generation ${ }^{5.64}$, and Hashimoto ${ }^{65}$ recently demonstrated that also chondrocyte apoptotic bodies have similarities with matrix vesicles. The cytotoxicity of oxidized lipids, which causes cell membrane "blebbing" might induce formation of matrix vesicles ${ }^{56}$.

\section{Osteogenesis and vascular calcification}

Mineralization of bones and teeth is an exquisitely regulated, cell-mediated process in which the tissue extracellular matrix is embedded in crystalline calcium phosphate deposits. This process gives rise to hard tissues endowed with the mechanical properties required for their normal physiological functions. In contrast, mineralization of soft tissues occurs under pathological conditions. 
Fetal bone has a woven structure, which is replaced by a highly ordered structure called lamellar bone. Two mechanisms of bone formation are intramembranous and endochondral ossification. Intramembranous ossification is seen in the craniofacial skeleton, where mesenchymal cells directly become bone matrix producing osteoblasts that form trabecular bone. In contrast, endochondral ossification is a multiple step process. Mesenchymal cells become chondroblasts. These chondroblasts form a hyaline cartilage precursor in the shape of the finally formed bone. Other mesenchymal cells differentiate and make a perichondrium. Central cartilage cells become hypertrophic and no longer divide. The surrounding matrix becomes basophilic and then calcifies. This mineralization may be triggered by the seeding action of calcium-rich matrix vesicles released form chondrocytes. Perichondral cells become bone-matrix producing osteoblasts. Finally, cartilage is replaced by lamellar bone surrounded by a layer of osteoid (non-mineralized matrix). Both mechanisms of ossification, intramembranous and endochondral are able to induce lamellar bone formation within the atherosclerotic plaque. Even within the same plaque, both processes can occur.

The major extracellular matrix protein of bone is type I collagen. The main mineral is hydroxyapatite. The mineral phase comprises $60 \%$ of the total bone weight. Glycosaminoglycans, collagen, lipids, cells, and water are the remaining constituents of bone.

Mesenchymal stromal cells have the ability to acquire characteristics of several more differentiated cells, like osteoblasts ${ }^{67}$, and are also able to transdifferentiate to myofibroblasts in vitro ${ }^{6,69}$. In the intima of mice with arterial atherosclerosis SMC-like cells, originating from hemopoietic stem cells were identified ${ }^{20,71}$ which suggests that osteogenic cells are derived from stem cells.

Active calcification can only occur in the presence of bone matrix regulatory proteins. A series of reports provided evidence that several osteogenic bone matrix regulatory factors are expressed in atherosclerotic lesions ${ }^{33,2 x, 73}$ and that the process resembles embryonic bone dievelopment $t^{46,4}$.

The first osteo-inductive protein found in atherosclerotic plaques was BMP- $2^{n}$. Since then, several groups described bone matrix regulatory proteins in atherosclerosis, and there is evidence that different cell types present in the plaque are able to produce these proteins ${ }^{37,73}$. These cell types are vascular smooth muscle cells, macrophages, mast cells or pericytes. They are able to produce matrix Gla protein (MGP): osteopontin

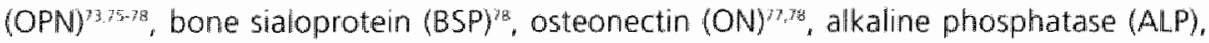
tumor necrosis factor- $\alpha$ (TNF $\alpha)^{79}$, bone morphogenetic protein 2 (BMP-2)

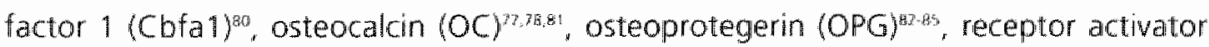
of NF KB ligand (RANKL) 


\section{Atherosclerotic calcification \& osteoporosis}

Osteoporosis is characterized by a reduced bone mass and disturbed microarchitecture, which increases the susceptibility to fractures". Osteoporosis mainly occurs in postmenopausal women and in elderly women and men. Bone loss is caused by a relative excess of bone resorption over bone formation.

Epidemiologically osteoporosis is associated with both atherosclerosis and vascular

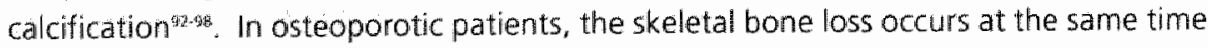
as the formation of bone in the atherosclerotic arterial wallg". In rodents, wascular calcfication and osteoporosis co-exist under at least three conditions: deficiency of osteoprotegerin ${ }^{100}$, deficiency of dietary essential fatty acids ${ }^{43}$ and hyperlipidemia ${ }^{99}$. The factors that are responsible for this apparent paradox of promotion of wascular calcification and bone formation and osteolysis of bone are still unclear.

Another similarity between atherosclerosis and osteoporosis is found in the working mechanism of the drugs used in the treatment of osteoporosis (bisphosphonates) and atherosclerosis (statins). Both drugs act on the mevalonate pathway (fig. 1.3), by inhibiting different steps in the pathways that branch from the synthesis of cholesterol from acetyl COA. Statins act early in the mevalonate pathway by inhibiting 3-hydroxy-3-methylglutaryl coenzyme A (HMG COA) reductase, which blocks the conversion of HMG COA to mevalonate. Mundy and colleages ${ }^{10 \%}$ described the bone forming potential of statins, by showing that statin treatment increases the synthesis of BMP-2, causing osteoblast proliferation, maturation and bone formation. Treatment with statins reduces the progression of coronary artery calcification and in atherosclerotic patients, statins reduce cardiovascular events and increase plaque stability ${ }^{103}$. Previous observations in bone tissue ${ }^{10 t}$ and in murine embryonic stem cells have shown that statins can induce BMP-2 expression, while Emmanuele et al. showed that statins induce BMP-2 expression in human VSMC ${ }^{105}$. Although statins induce BMP-2 expression, treatment with statins has been shown to reduce vascular calcification

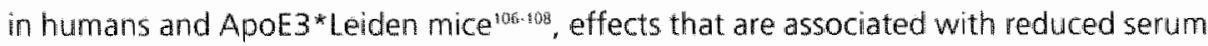
lipid levels. Bea et al. showed a significant reduction in the frequency of calcification in innominate arteries of ApoE-/- mice independently of lipid lowering ${ }^{103}$. Aortic valve calcification can also be reduced by statin treatment as described by Shavelle et al.: Four mechanisms of action of statins can be used to explain the paradox of the induction of BMP-2 and the reduction of vascular calcification. Lipophilic statins can directly increase the production of BMP-2 and thus induction of osteoblast differentiation. These effects of statins are not equal on bones and plaques because of their different sensitivity for BMP-2. This is also true for the second mechanism of action where statins imhibit G-protein prenylation in the mevalonate pathway resulting in a reduction of both osteoclast activity and osteoblast apoptosis. The third and fourth mechanism 


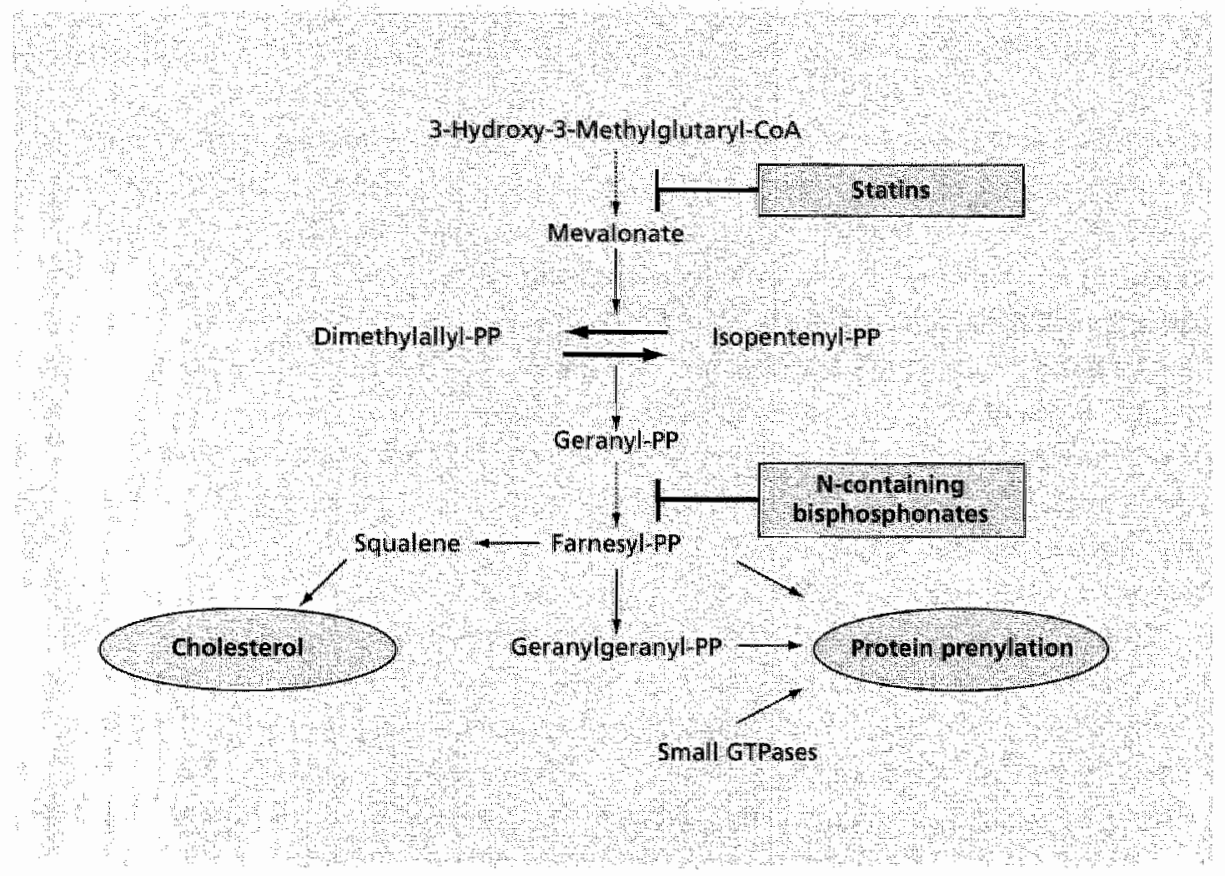

Figure 7.3. Mewalonate pathway. Adapted from Cummings et al.

of action both has effect on the progression of atherogenesis, e.g. reduced LDL cholesterol and markers of inflammation in the circulation. The reduced progression of atherogenesis in a experimental set up with controls that develop advanced atherosclerotic plaques, results in a reduction of vascular calcification.

Further, the currently approved statins for lowering cholesterol are not the most effective drugs for increasing bone mass. High doses might stimulate bone formation more effectively"'.

Nitrogen containing bisphosphonates interfere with protein prenylation (attachment of a lipid prenyll groups to a protein) by inhibiting the synthesis of farnesyl pyrophosphate (geranylgeranul-PP). Prenylation is necessary for the proper function of small glutamyl transpeptidases (GTPases) in the osteoclast. These signaling proteins, when anchored in the osteoclast membrane by a lipid prenyl group, regulate osteoclast cell processes, including cytoskeleton organization, vesicle transport, membrane ruffling, and apoptosis.

Although statins and bisphosphonates act in the same general pathway, they may have different effects on bone. By inhibiting osteoclast function, bisphosphonates reduce bone resorption and do not stimulate bone formation ${ }^{1 / 2}$. Conversely, statins seem to increase bone formation, although the effect of statins on bone resorption is not known. 


\section{Atherosclerotic calcification \& lipids}

Lipids are associated with mineralization in bone and other tissues ${ }^{55,57}$. Lipid accumulation is clearly associated with atherosclerotic calcification ${ }^{113}$. Calcification colocalizes with cholesteral crystals in human atherosclerosis ${ }^{14}$, is present in the intima of cholesterol-fed rabbits"s or in ApoE-/ mice" and vascular calcification co-exists with hyperlipidemia.

Lipids have been postulated to be involved in the nucleation of hydroxyapatite mineral, accomplished by matrix vesicles (phospholipid-enriched membrane bound organelles found in the extracellular matrix of calcified tissues) ${ }^{59}$. Cholesteral is present in calcified granules in atherosclerotic plaques, suggesting a potential role for cholesterol and other associated lipids in the nucleation of apatite within these lesions ${ }^{\text {t: }}$. Also high tissue lipid content facilitates mineralization "." Watson et al. demonstrated that hydroxycholesterol stimulates vascular cell-mediated calcification in vitro" ${ }^{118}$. Hsu showed that cholesterol directly enhanced the ability of vesicles to calcifiy, providing additional mechanisms of cholesterol-induced vascular calcification" "However, the exact role of lipids in the mineralization process is unknown ${ }^{120}$.

Coronary calcification and aortic valve calcification progress more rapidly in subjects with levels of LDL $>130 \mathrm{mg} / \mathrm{dL}^{43}$, and successful lowering of cholesterol levels with lipid-lowering agents significantly reduces the progression of coronary calcification Oxidized LDL (OxLDL) and acetylated LDL. (ACLDL) induce calcification of vascular cells in vitro, by inhibiting their phagocytosis potency ${ }^{2}$. HDL is capable of reducing mineralization even when this mineralization is induced by minimally madified LDL (MM-LDL) or cytokines. However, when minimally modified, HDL (MM-HDL) can induce mineralization of vascular cells ${ }^{2 z}$.

\section{Regulation of calcification}

Bone morohogenetic proteins

The idea that the regenerative capacity of bone may resides within the bone itself came from the work of Urist ${ }^{23}$. He demonstrated that isolated adult bone extracts are able to induce ectopic endochondral bone formation in rats. Urist called this extract bone morphogenetic protein, although it was not clear which proteins were responsible for the osteonductive activity.

It is now evident that bone morphogenetic proteins (BMPs) belong to the large multigene transforming growth factor $\beta$ (TGFB) super family. Members of the BMP subfamily consist of seven conserved cysteine residues in the mature carboxy-terminal portion of the protein, where the BMPs have their active site. Mature BMPs are 
synthesized as large intracellular precursor molecules that are processed to $30 \mathrm{kDa}$ molecular weight dimers before secretion. Although the osteoinductive capacity of many BMPs has been proven, BMP-2, $-4,-7$, and -9 have been shown to be bone inductive molecules. Interestingly heterodimers of $\mathrm{BMP}-2 / 7$ and $4 / 7$ were found to be more potent at inducing bone and cartilage formation than the corresponding homodimers ${ }^{124: 235}$. Bone morphogenetic proteins are known to be potent bone inducers that act through specific BMP receptors located on the cell surface of responding mesenchymal ceils and promote proliferation and differentiation of these cells into the osteoblastic lineage ${ }^{1 / 25: 28}$, and initiate endochondral bone formation.

BMP-2 strongly stimulates adipogenic differentiation of murine mesenchymal precursor cells, and is found in breast tumor cells. Recombinant human BMP-2 has the potential to be used to stimulate bone gap healing in the craniofacial complex in dogs, and induces cell-cycle arrest in the $G \mathbb{1}$ phase and apoptotic cell death of mouse hybridoma cells.

BMP-4 plays an important role in the onset of endochondral bone formation in humans, and a reduction in expression of BMP-4 has been associated with a variety of bone diseases such as fibrodysplasia ossificans. BMP-4 can be stimulated by anti-estrogens, but not by estrogens or other steroid hormones. BMP-4 is expressed in human fetal osteoblast cells. The mRNA of BMP-4 is increased during differentiation of ameloblasts and odontoblasts in tooth. It is also present in bone tissue.

\section{BMP receptors}

BMP receptors are members of the serine/threonine receptor kinases. These include the receptors for TGF $\beta$, activin and inhibining. BMP receptors consist of two types, type I and $\mathrm{II}$, and both receptor types are required for signal transduction ${ }^{130}$. The type I receptors are characterized by the presence of a highly conserved cysteine rich extracellular domain and a unique GS box (characteristic repetition of serines and glycines) of 30 amino acids, preceding the intracellular serine/threonine kinase domain. Type II receptors have a different extracellular cysteine domain, and lack the intracellular GS box. Ligand studies have shown that type II serine/threonine receptors for acitivin are able to bind BMP-2 and -7, however the binding affinities for BMPs are lower than for activins.

\section{BMP signaltransduction}

Signal transduction for BMPs requires both type ! and type II receptors. Outside the cell BMP binds to the type II receptor. This type II receptor becomes phosphorylated, binds to and activates the type I BMP receptor (fig. 1.4). The receptor complex is internalized and inside the cell this receptor-complex transduces the signal via a group of proteins called Smads. These Smads $(1,5$ and 8$)$ are phosphorylated by type II receptor kinase, bind to 5 mad 4 and translocated into the nucleus, where they regulate the 


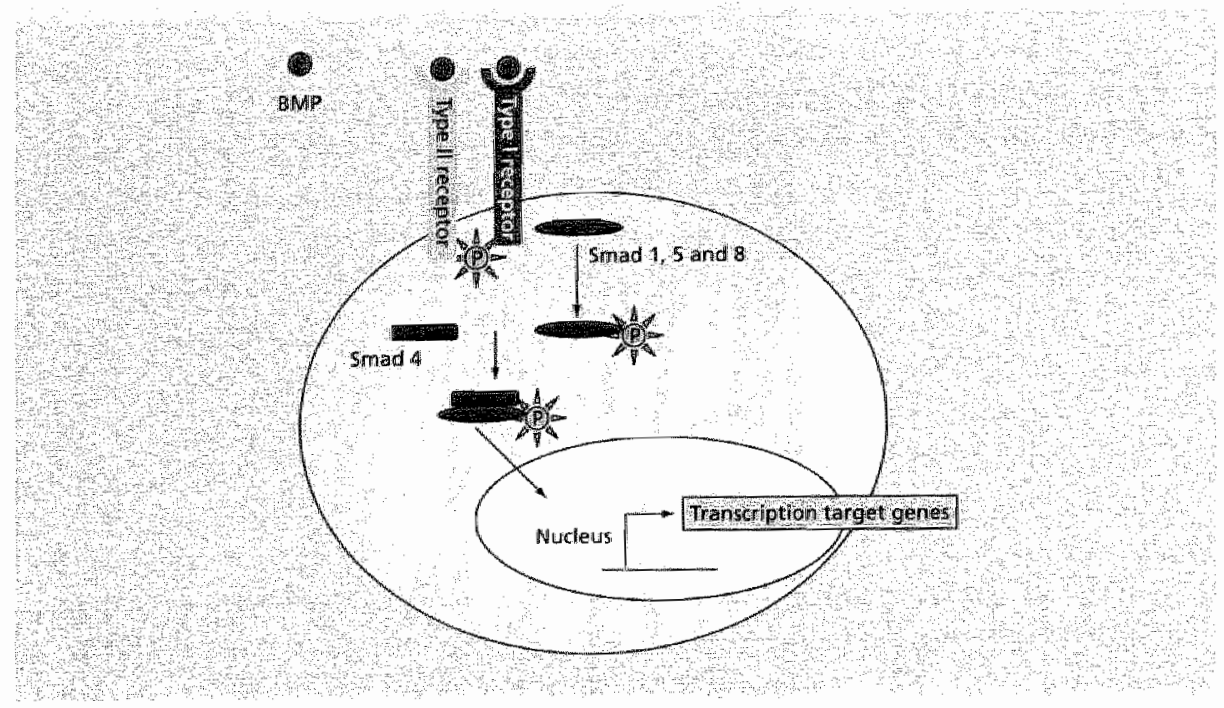

Figure 1.4 BMP signaltransduction

transcription of target genes. In addition, a number of negative regulators of BMP action exist within the nucleus such as noggin, chordin and follistatin. It is evident that the positive and negative regulation of bone formation cause a tightly controlled and self-limiting mechanism.

\section{Other bone matrix proteins}

BMPs are not the only bone matrix regulatory proteins involved in calcification. Other bone matrix proteins include the gamma carboxy glutamic acid (Gla) containing proteins (matrix Gla protein \& osteocalcin), RGD containing glycoproteins (bone sialoprotein \& osteopontin), the glycoprotein osteonectin, the tumor necrosis factor receptor family member osteoprotegerin and its ligand receptor activator of nuclear factor-kB ligand.

Matrix Gla protein (MGP) and osteocalcin (OC) contain 5 and 3 Gla residues respectively. MGP is an inhibitor of cartilage mineralization and has a role in regulating chondrocyte maturation and ossification. MGP- - mice develop severe aortic calcification, and die due to vessel wall rupture. MGP is found in bone, in serum, the normal and atheroselerotic vessel wall, and in patients with diabetes.

Serum $O C$ is used as an early marker in bone turnover. $O C$ is cleaved by plasmin. and found primarily in bone, but also in patients with chronic arthritis and prostate cancer. OC deficient mice have increased bone formation ${ }^{134}$. 
The OPN gene encodes a protein of 55-65 kDa with a preserved integrin binding RGD (Arg-Gly-Asp) tripeptide ${ }^{13}$. RGD-mediated cell adhesion and proliferation via OPN and $B S P$ is proposed to act through the integrin $\alpha_{w} \beta_{3}^{13}$. Inhibition of calcification by OPN requires phosphorylation of the protein. OPN can act as both a cytokine and an extracelluiar matrix protein. It is expressed by chondrocytes, and is found in several tissues such as brain and heart, in calcified and non-calcified arterial lesions, synovial fibroblasts, mitral valves and in psammoma bodies. Also, OPN is able to attenuate atherosclerosis in female ApoE- $/$ - mice ${ }^{134}$. Numerous factors are known to stimulate osteopontin expression at the RNA level in osteoblasts. These factors include ascorbic acid, TGFB, retinoic acid, endothelin, BMP, and vitamin D. Several of these factors are also known to induce alkaline phosphatase and presumably, elevate phosphate levels.

Bone sialoprotein (BSP) is expressed in highly proliferating bone marrow stromal cells. It is present during angiogenesis and might be implicated in the preferential seeding and growth of metastatic cells in bone. BSP is also present in calcified lesions developed at visceral sites including liver "thyroid, lung and adrenal glands, in tooth and in proliferating neoplastic epithelium in buccal pouches of hamsters. Cementoblasts express BSPis.5 and elevated serum BSP is found in patients with ankylosing spondylitis ${ }^{136}$

Osteonectin (ON), Sparc and BM-40 are different names for the same protein. ON is expressed at high levels in bone tissue, is widely distributed in other tissues and cell types ${ }^{137}$, and is generally associated with tissue remodeling e.g., tissues undergoing morphogenesis, mineralization, angiogenesis, and pathological responses to injury and tumorigenesis. ON deficient mice develop osteopenia, decreased bone formation ${ }^{139}$ and severe cataract formation ${ }^{139}$. After cleavage of the signal sequence, $\mathrm{ON}$ is a $32 \mathrm{kDa}$ protein ${ }^{\${ }^{50}}$. The secreted form is $43 \mathrm{kDa}$, in part due to the addition of carbohydrates ${ }^{5 ! 1}$. The human protein is divided into three distinct domains. The first domain has been implicated in the mineralization of cartilage and bone. This domain can act as an amine acceptor. ON is a predominant glutaminyl substrate (amine acceptor) in the chondrocyte matrix and is co-expressed with transglutaminase in maturing cartilage ${ }^{\text {stz }}$. ON is also found in the basement membrane: ${ }^{1 / 3}$ where it presumably binds to type $\mathrm{N}$ collagen. This is followed by a second domain, rich in cysteine, that shows sequence homology with cysteine-rich domains. The third domain is the extracellular calcium-binding domain (residues 138-286). It is largely $\alpha$-helical and contains a two EF-hand motif high affinity calcium binding site. A EF-hand motif is a helix-loop-hellix structural motif which is capable of binding calcium ions in the loop region. This thind domain also has a binding epitope of moderate affinity for types I and IV collagen ${ }^{\text {i4 }}$. Binding to cytokines is a major characteristic of $O N$. TGFB, which is associated with the rapid remodeling of connective tissues and has been shown to regulate the expression of extracellular 
matrix proteins:s, was demonstrated to augment ON MRNA levels via a posttranscriptional mechanism in human fibroblasts ${ }^{14}$. Specific interactions between ON and collagens could result in the remodeling of extracellular matrix. Cells from ON null mice produce significantly diminished levels of type I collagen in comparison to cells from wild-type mice ${ }^{\text {tas }}$.

Osteoprotegerin (OPG) is a member of the tumor necrosis factor receptor superfamily (TNFR). OPG was isolated independently by two laboratories, and synonyms such as osteoclastogenesis inhibitory factor (OCIF). TNF receptor-related molecule-1 (TR1), or follicular dendritic cell-derived receptor (FDCR-1) have been coined. According to the American Society for Bone and Mineral Research Committee, the term OPG is now recommended. The human OPG gene is a single-copy gene that spans $29 \mathrm{~kb}$ and is located on chromosome 8. The secreted glycoprotein exists in both a $60 \mathrm{kDa}$ monomeric form and a disulfide-linked homodimeric form of $120 \mathrm{kDa}$. Both OPG forms were indistinguishable in their specific activity to inhibit osteoclastogenesis. Osteoclast formation is completely inhibited by OPG. OPG is present in bone marrow stromal cells, osteoblast like cells and osteosarcoma cells, in odontoblasts, ameloblasts and pulp cells in teeth, in pre-osteoblasts, osteoblasts and lining cells in bone, in endothelial cells and occasionally in osteocytes and bone marrow. OPG expression is regulated by the osteoblast-specific transcription factor core binding factor 1 (Cbfa1) ${ }^{\text {a9 }}$, and decreased by parathyroid hormone related peptide (PTHrP).

Osteoprotegrin ligand (OPGL), now called receptor activator of nuclear factor-KB ligand (RANKL), is a membrane-bound ligand expressed by bone marrow stromal cells and is a stimulator of osteoclastogenesis. In bone, osteoblasts and bone marrow stromal cells regulate osteoclast formation by the production of cytokines like OPG and RANKL. Estrogens suppress RANKL induced osteoclas: differentiation, while prostaglandin EZ induces expression of RANKL. RANKL binds to receptor activator of NF $\sim \mathrm{KB}$ (RANK), a transmembrane receptor on hemopoietic osteoclast precursor cells RANKL is present in bone marrow stromal cells, osteosarcoma cells, odontoblasts. ameloblasts, pulp cells, in tumors associated with bone lysis and is patients with rheumatoid arthritis and Paget's disease.

Fetuin-A $\left(\alpha_{2}\right.$-Heremans-Schmid glycoprotein (Ahsg $)$ is a high molecular weight, negatively charged member of the cystatin superfamily of cysteine protease inhibitors. This $62 \mathrm{kDa}$ glycoprotein is synthesized in the iver (hepatocytes) and is ubiquitously present in the extracellular space. Ahsg is a systemic inhibitor of ectopic calcification. acts in all extracellular fluids, is not locally restricted and has a high affinity for 
hydroxyapatite. The underlying mechanism involves a direct interaction with the mineral phase and the prevention of large crystal formation, since Ahsg is the major protein of a high molecular weight complex including calcium, phosphate and MGP in serum ${ }^{\text {ss }}$. Ahsg has been shown to antagonize TGFS and BMPs "it "it can act as an

opsonin ${ }^{152}$ and quenches the oxidative burst associated with the uptake of apatite crystals by neutrophils. It forms antibody complexes involved in the removal of apoptotic neutrophils ${ }^{13}$. Strikingly, Ahsg deficient mice have no obvious abnormalities although some female Ahsg deficient mice revealed the existence of soft tissue calcification (unpublished obervation) $)^{154}$. Vascular calcification is the most prominent underlying pathological finding in patients with uraemia, and is a predictor of mortality in this population. In serum of patients on haemodialysis, Ahsg concentrations are significantly lower ${ }^{155}$. Ahsg reduction is associated with inflammation and links vascular calcification to mortality in patients on dialysis.

\section{Hypothesis}

As described in the previous paragraphs atherosclerosis is a disease characterized by several stages. One of these stages is the calcified plaque. In this thesis we focus on the question whether vascular calicification is a passive or an active regulated process and how vascular calcification is regulated. Our main hypothesis is that vascular calcification in a tightly regulated process within the vessel wall.

Due to the presence of osteogenic cells, osteogenic structures (like matrix vesicles, cartilage and full-fledged bone) and the discovery that two bone matrix regulatory proteins, $\mathrm{OPN}$ and BMP-2 were present in human atherosclerotic plaques, it is known that atherosclerotic calcification has high similarity with bone calcification (e.g. mineralization). Since bone calcification is regulated by more bone matrix proteins than only the two proteins mentioned above, we hypothesized that several other bone matrix proteins are present in atherosclerotic calcification. Furthermore, it has been suggested that aortic valve stenosis is a disease characterized by the presence of atherosclerotic plaques in its leaflets, including plaques in the calcified stage, and that both atherosclerosis and aortic valve scierosis are different manifestations of the same disease. Based on these data we hypothesized that several different bone matrix regulatory proteins are present in atherosclerotic calcification in both the aortic wall and aortic valve leaflets.

Since BMP-2 is a highly osteo-inductive protein and one of the first bone matrix proteins described in atherosclerotic plaques our third hypothesis was that this protein is an active regulator of calcification in atherosclerotic plaques. 
Based upon the observed correlation of osteoporosis and calcified atherosclerotic plaques and the observation that bisphosphonates inhibit bone resorption and are used in the treatment of osteoporosis, we hypothesized that bisphosphonates will reduce atheroscleratic calcification.

\section{This thesis}

In chapter 2 and 3, we describe that several bone matrix regulatory proteins are present in human atherosclerosis in the intima of large arteries and in the fibrotic layer of aortic valve leaflets, where they contribute to the active regulation of calcification. Chapter 4 describes fast advanced atherosclerotic calcification in a murine vein graft model induced with BMP-2 adenowiral delivery and shows that atherosclerotic calcification is induced by BMP-2. In chapter 5 we use a nitrogen containing bisphosphonate for intervention in the atherosclerotic calcification process, since osteoporosis and atheroscleratic calcification are correlated. We found that bisphosphonates have no influence on vascullar calcification when given in a dose that

enhances bone density. In chapter 6 we summarize and discuss the data presented in the experimental chapters and provide some novel thoughts on the regulation of vascular calcification and on possibilities to intervene in this process. 


\section{References}

1. Ross $\mathbb{R}$. The pathogenesis of atherosclerosis: a perspective for the 19905. Nature. 1993;362:801-809.

2. Lusis AJ. Atherosclerosis. Nature, 2000;407:233-41.

3. Assmann $G$, Cullen $\mathbb{P}$, Jossa $F$, et al. Coronary heart disease: reducing the risk: the scientific background to primary and secondary prevention of coronary heart disease. A worldwide view. International Task force for the Prevention of Coronary Heart disease. Arterioscler Thromb Vasc Biol 1999;19:1819-24.

4. Gordon DJ Rifkind BM. High-density lipoprotein--the clinical implications of recent studies. N Engl I Med. 1989;321;1311-6.

5. Kronenberg $F_{0}$ Kronenberg MF, Kiechl S, et al. Role of lipoprotein(a) and apolipoprotein(a) phenotype in atherogenesis: prospective results from the Bruneck study. Circulation. 1999;100:1154-60.

6. Luft FC. Molecular genetics of human hypertension. I Hypertens. 1998; $46: 1871-8$.

7. Gerhard GT, Duill PB. Homacysteine and atherosclerosis. Curr Opin Lipidol. 1999:10:417-28.

8. Goldbourt U, Neufeld HN. Genetic aspects of arteriosclerosis. Arteriosclerosis. 1988;6:357-377.

9. Glassman AH, Shapiro PA. Depression and the course of coronary artery disease. Am I Psychiatry, 1998:155:4-11.

10. Nathan L, Chaudhuri G. Estrogens and atherosclerosis. Annu Rev Pharmacol Toxicol. $1997: 37: 477-515$.

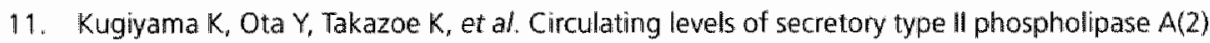
predict coronary events in patients with coronary artery disease. Circulation. 1999:100:1280-4.

12. Lusis AJ, Weinreb A, Drake TA. Textbook of Cardiovascular Medicine. Philadelphia: Lippincott-Raven; 1998.

13. Steinberg D. Witztum JL. Molecular Basis of Cardiovascular Disease Philadelphia: Saunders; 1999.

14. Hu H. Pierce $G N$, Zhong $G$. The atherogenic effects of chlamydia are dependent on serum cholesterol and specific to Chlamydia pneumoniae. J Clin Invest. 1999;103:747-53.

15. Glass CK. Witztum Jl. Atherosclerosis. The road ahead. Cell. 2001;104:503-16.

16. Reid VC. Mitchinson MJ. Toxicity of oxidised low density lipoprotein towards nouse peritoneal macrophages in vitro. Atherosclerosis. 1993;98:17-24.

17. Wolfbauer G, Glick JM, Minor $L K_{\text {, }}$ et al. Development of the smooth muscle foam cell: uptake of macrophage lipid inclusions. Proc Natl Acad Sci U S.A. 1986,83:7760-4.

18. Ross R. Aterosclerosis. An inflammatory disease. The New England Journal of Medicine. 1999;340:115-126

19. Steinberg D. Witztum UL. Lipoproteins, lipoprotein, Oxidation, and Atherogenesis. Philadelphia: Saunders; 1999.

20. Virmani R, Kolodgie FD, Burke AP, et al. Lessons from sudden coronary death. A comprehensive morphological classification scheme for atherosclerotic lesions. Arteriosclerosis. Thrombasis and Vascular Biology. 2000;20:1262-1275. 
21. Stary $H C$, Chandier $A B$, Dinsmore $R E$, al. $A$ definition of advanced types of atherosclerotic lesions and a histological classification of atherosclerosis. A repart from the Committee on Valscular Lesions of the Councll on Arteriasclerosis. American Heart Association. Arteriosclerosis Thrombosis and Vascular Biology. 1995; 15:1512-1531.

22. Edmonds ME. Medial arterial calcification and diabetes mellitus. Zeitschift fur Kardiologie. 2000,89:11 101-104.

23. Goodman WG, London $G$, Amann $K$, et al. Vascular calcification in chronic kidney disease. Am J Kidney Dis. 2004;43:572-9.

24. Letho $S$, Niskanen $L$, Suhonen $M_{\text {, }}$ ef al. Medial artery calcification: a neglected harbinger of cardiowascular complications in non-insulin-dependent diabetes mellitus. Arterioscler Thromb Vasc Biol. 1996;16:978-983.

25. Shanahan CM, Cary NRB, Salisbury IR, et al. Mediall localization of mineralization-regulating proteins in association with mönckeberg's sclerosis. Evidence for smoath muscle cell-mediated vascular calcification. Crculation. 1999;100:2168-2176.

26. Fitzgeralld PI, Ports TA, Yock PG. Contribution of localized calcium deposits to dissection after angioplasty. An observational study using intravascular ultrasound. Circulation. $1992 ; 86 ; 64-70$.

27. Rumberger JA, Schwartz RS, Simons $\mathrm{DB}_{\text {, }}$ et al. Relation of coronary calcium determined by ellectron beam computed tomography and lumen narrowing determined by autopsy. Am $J$ Cardiol. 1994:73:1169-73.

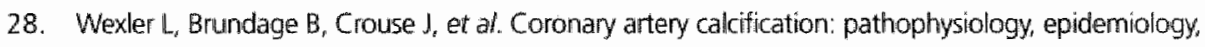
imaging methods, and clinical implications. Circulation. 1996:94:1175-1192.

29. Sharma $5 \mathrm{~K}$, Israel DH, Kamean $\mathrm{L}$. et al. Clinicall, angiographic, and procedural determinants of major and minor coronary dissection during angioplasty. American Heart Journai. $1993: 126: 39447$

30. Beadenkopf WG. Daoud AS, Love BM. Calcification in the coronary arteries and its relationship to arteriosclerosis and myocardial infarction. American Journal of Rontgenology. $1964: 92: 865-871$.

31. Doherty TM, Detrano RC. Coronary arterial calcfication as an active process: a new perspective on an old problem. Cakified Tissue international. 1994:54:224-230.

32. Hunt Ill, Fairman R, Mitchell ME, et al. Borne formation in carotid plaques a clinicopathological study. Siroke. 2002:33:1214-9.

33. Demer L, Watson KE, Bostrom K. Mechanism of calcification in atherosclerosis. Trend's in Candiovascular Medicine. 1994:4:45-49.

34. Virmani R, Burke AP, Farb A, et al. Pathology of the unstable piaque. Prog Cardiovasc Dis. $2002: 44: 349-56$.

35. Virchow R. Cellular Physiology. As Based upon Physiological and Pathological Histology. New York: Dover; 1863.

36. Yu SY. Calcification processes in atherosclerosis. Adv Exp Med Biol 1974;43:403-425. 
37. Shanahan CM, Cary NR, Metcalfe JC, et al. High expression of genes for calcification-regulating proteins in human atherosclerotic plaques. Journal of Chical Investigation. 1994:93:2393-2402.

38. Demer $L$, Tintut Y. Osteopontin. Between a rock and a hard plaque. Circulation Research. $1999 ; 84: 250 \cdot 25: 2$

39. Giacheli CM. Ectopic calcification: gathering hard facts about soft tissue calcification. Am J Pathol. 1998:154:671-675.

40. Burke AP, Taylor A, Farb A, et al. Coronary calcification: insights from sudden coronary death victims. Zeitschrift fur Kardiologie. 2000;89:11 49-53.

41. Jeziorska M, McCollum C. Wooley DE. Observations on bone formation and remodeling in advanced atherasclerotic lesions of human carotid arteries. Virchows Arch. 1998:433:559-565.

42. Mohler ER, 3id. Are atherosclerotic processes involved in aortic-value calcification? Lancet. 2000;356:524-525.

43. Pohle K, Maffert $R$, Ropers $D$, et al. Progression of aortic valve calcification. Association with coronary atherosclerosis and cardiovascular risk factors. Circulation. 2001;104:1927-1932.

44. Otto CM, Lind BK, Kitzman DW, et al. Association of aortic-valve sclerosis with cardiovascular mortality and morbidity in the elderly. The New England Joumal of Medicine. 1999;341:142-147.

45. Rosenhek $R$, Binder $T$, Porenta $G$, et al. Predictors of outcome in severe, asymptomatic aortic stenosis. The New England Journal of Medicine. 2000;343:611-617.

46. Mohler III ER, Gannon F, Reynolds $C$, et al. Bone formation and inflammation in cardiac walwes. Circulation. 2001:103:1522-1528.

47. Tanimura A, McGregor DH, Anderson HC. Matrix vesicles in atherosclerotic calcification. Proc Soc Exp Biol Med. 1983:172:173-177.

48. Hirsch $D_{\text {, Azoury }} \mathrm{R}$, Sarig $S$, et al. Colocalization of cholesterol and hydroxyapatite in human atherosclerosis lesion. Calcified Tissue International. 1993:52:94m98.

49. Anderson HC. Calcific diseases. A concept. Arch Pathol Lab Med. 1983;107:341-8.

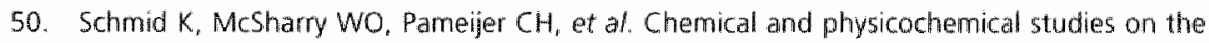
mineral deposits of the human atherosclerotic aorta. Atherosclerosis. 1980;37:199-210.

5\%. Stein GS, Lian IB, Stein ML. Transcriptional control of osteoblast growth and differentiation. Physiol Rev. 1996;76:593-629.

52. Zernik J, Twarog K, Upholt WB. Regulation of alkaline phosphatase and aipha 2(1) procollagen synthesis during early intramembranous bone formation in rat mandible. Differentiation. $1990 ; 44: 207-215$.

53. Shanahan $\mathrm{CM}$, Proudfoot $\mathrm{D}$, Tysan $\mathrm{KL}$, et al. Expression of mineralisation-regulating proteins in association with human vascular calcification. Zeitschrift fur Kardiologie. 2000;89:11 63-68.

54. Mody $N_{\text {, Tintut }} Y_{\text {, Radcliff }} K$, et al. Vascular calcification and its relation to bone calcificalion: possible underlyng mechanisms. I Nucl Cardiol. 2003;10:177-83.

55. Shapiro M. Wuthier RE, Irving IT. A study of the phospholipids of bovine dental tissues. 1. Enamel matrix and dentine. Arch Oral Biol. 1966;11:501-12

56. Enlow DH, Conklin IL, Bang S. Observations on the occurrence and the distribution of lipids in compact bone. Clin Orthop. 1965;38:157-69. 
57. Conklin LL. Enlow DH, Bang S. Methods for the demonstration of lipid applied to compact bone. Stain Tectinol. 1965;40:183-91.

58. Anderson HC. Molecular biology of matrix vesicles. Clin Orthop. 1995;314:266-280.

59. Ali SY. Analysis of matrix vesiches and their role in the calcification of epiphyseal cartilage. Fed Proc 1976:35:135-42.

60. Kim KM. Calcification of matrix vesicles in human aortic valve and aortic media. Fed Proc. $1976,35: 156-62$.

61. Tanimura A, McGragor DH, Anderson HC. Calcification in atherosclerosis, 1. Human studies. Joumat of Experimental Pathology. 1986;2:261-273.

62. Anderson HC. Vesicles assaciated with calcification in the matrix of epiphyseal cartilage. I Cell Biol. 1969:41:59.72.

63. Kockx M, DeMeyer GRY, Muhring l, et ah. Apoptosis and related proteins in different stages of human atherosclerotic plaques. Circulation. 1998;97:2307-2315.

64. Kirn KM. Apoptosis and calcification. Scanning Microscopy. 1995;9:1137-1178.

65. Hashimoto 5, Ochs RL, Rosen $F$, et al. Chondrocyte-derived apoptotic bodies and calcification in articular cartillage. Proc Natl Acad Sci U S A. 1998;95:3094-3099.

66. O"Brien KD, Reichenbach DD, Marcovina SM, et al. Apolipoproteins B, (a), and E accumulate in the morphologically early lesion of "degenerative' valvular aortic stenosis. Arterioscier Thromb Vasc Biol. 1996;16:523-32.

67. Pereira RF, Halford KW, O'Hara MD, et al. Cultured adherent cells from marrow can serve as long-lasting precursor cells for bone, cartilage, and lung in irradiated mice. Proc Nat/ Acad Sci U S A. 1995:92:4857-61.

68. Campbell GR, Campbelf JH. Vascular smooth muscle and arterial calcification, Zeitschrift fur Kardiologie. 2000;89:11 54-62.

69. Bonanno E, Ercoli L. Missori $P$, et al. Homogeneous stromal cell population from normal human adult bone marrow expressing alpha-smooth muscle actin filaments. Lab invest. $1994: 71: 308-15$

70. Han Cl, Campbell GR, Campbell $\mathrm{JH}$. Circulating bone marrow cells can contribute to neointimal formation. J Vasc Res. 2001;38:113-9.

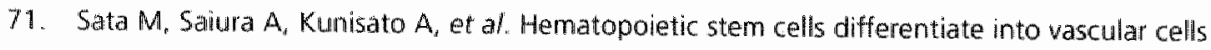
that participate in the pathogenesis of atherosclerosis. Nat Med. 2002;8:403-9.

72. Bostrom $\mathrm{K}$. Watson KE, Horn S, et al. Bone morphogenetic protein expression in human atherosiderotic lesions. Journal of Clinical Investigation. 1993;91:1800-1809.

73. Giachelli $C M, B a e N$. Almeida $\mathrm{M}_{\text {s }}$ et al. Osteopontin is elevated during neointima formation in rat arteries and is a novel component of human atherosclerotic plaques. Journal of Clinical Investigation. 1993:92:1686-1696.

74. Canfield $A E_{i}$ Doherty MI, Kelly $V_{x}$ et al. Matrix gla protein is differentially expressed during the deposition of a calcified matrix by vascular pericytes. Federation of European Biochemical Societies. 2000;487:267-271. 
75. Hirota $S_{n}$ Imakita $M$, Kohri $K_{*}$ et al. Expression of osteopontin messenger RNA by macrophages in atherosclerotic plaques. American Joumal of Pathology. 1993; 143:1003-1008.

76. Ikeda $T$, Shirasawa $T$. Esaki $Y$, et al. Osteopontin mRNA is expressed by smooth muscie-derived foam cells in human atherosclerotic lesions of the aorta. Joumal of clinical inwestigation. $1993 ; 92: 2814-2820$.

77. Severson ER, lngram RT, Fitzpatrick LA. Matrix proteins associated with bone calcification are present in human vascular smooth muscle cells grown in vitro. In vitro cellular Developmental Biology-Animal. 1995;31:853-857.

78. Doherty MJ, Ashton BA, Walsh S, et al. Vascular pericytes express osteogenic potential in witro and in wivo. Journal of Bone and Mineral Research. 1998;13:828.838.

79. Tintut $Y$, Patel J, Parhami $F_{\text {n }}$ et al. Tumor necrosis factor-alpha promotes in vitro calcification of vascular cells via the CAMP pathway. Circulation. 2000:102:2636-42.

80. Engelse $M A_{x}$ Neele $J M, B$ ronckers $A L_{x}$ et al. Vascular calcification: expression patterns of the osteoblast-specific gene core binding factor alpha-1 and the protective factor matrix gla protein in human atherogenesis. Cardiovasc Res. 2001:52:281-9.

81. Fleet $J$. Hock IM. Identification of osteocalcin MRNA in nonosteoid tissue of rats and humans by rewerse transcription-polymerase chain reaction. Journal of Bone and Mineral Research. 1994:9:1565-1573.

82. Hofbauler LC. Schoppet M. Osteoprotegerin: a link between osteoporosils and arterial calcification? The Lancet. 2001;358:257-258.

83. Min H, Morony S, Sarasi I, et al. Osteoprotegerin Reverses Osteoporosis by Inhibiting Endosteal Osteoclasts and Prevents Vascular Calcification by Blocking a Process Resembling Osteociastogenesis. J. Exp. Med. 2000;19:2:463-474

84. Price PA, June $H H$, Buckley $J R$, et al. Osteoprotegerin inhibits artery calcification induced by warfarin and by vitamin D. Arterioscier Thromb Vasc Biol. 2001:21:1610-6.

85. Zhang J, Fu M, Myles D, et al. PDGF induces osteoprotegerin expression in vascular smooth muscle cells by multiple signal pathways. FEBS Lett. 2002,521:180-4.

86. Schoppet $M$. Preissner KT. Hofbauer LC. RANK Ligand and Osteoprotegerin: Paracrine Regulators of Bone Metabolism and Vascular Function. Arterioscler Thromb Vasc Biol. $2002: 22: 549-53$.

87. Rekhter MD, Zhang $K$, Narayanan $A S$, et al. Type I collagen expression in human atherosclerosis. localization to specific plaque regions. American Joumal of Pathology. 1993,143:1634-1648.

88. Murata K, Motoyama T. Collagen species in various sized human arteries and their changes with intimal proliferation. Artery. 1990;17:96-106.

89. Watson $K E$, Parhami $F$, Shin $V$, et al. Fibronectin and collagen I matrixes promote calcification of vascular cells in vitro, whereas collagen IV matrix is inhibitory. Arteriosclerosis and Thrombosis. 1998;18:1964-1971.

90. Faber $B C$, Cleutiens $K B$. Niessen $R L$, et al. identification of genes potentially involved in rupture of human atherosclerotic plaques. Circ Res. 2001;89:547-54. 
91. Melton U, Atkinson E, O'Fallon WM, et al. Lomg-term fracture prediction by bone mineral assessed at different skeletal sites. J Bone Miner Res. 1993;8:1227-1233.

92. Sugihara $N$, Matsuzaki $M$. The influence of severe bone loss on mitrat annular calcification in postmenopausal ositeoporosis of elderly Japanese women. 1993.

93. Jie $K-\$ G$, Bots $M L$, Vermeer $C$, el al. Vitamin $K$ status and bone mass in women with and without aortic atherosclerosis: a population-based study. Calcified Tissue International. $1996,59: 352-356$.

94. Boukhris R. Becker KL. Calcification of the aorta and osteoporosis. A roentgenographic study. Jama. 1972,219:1307-11.

95. Larache M, Povilles JM, Ribot $C$, et at. Comparison of the bone mineral content of the lower limbs in men with ischaemic atherosclerotic disease. Clin Rheumatol 1994;13:611-4.

96. Ouchi $Y$, Akishita M, de Souza AC, et al. Age-related loss of bone mass and aorticlaortic valve calcification--reevaluation of recommended dietary allowance of calcium in the elderly: Ann N Y Acad 5ci. 1993;676:297-307.

97. Kiel DP, Kauppila LI, Cupples LA, et al. Bone loss and the progression of abdominal aortic calcification over a 25 year period: the Framingham Heart study. Calcif Tissue Int. 2001:58:271.6.

98. Hak AE, Pols HA, van Hemert AM, et al. Progression of aortic calcification is associated with metacarpal bone loss during menopause: A population-based longitudinal study. Arteriosclerosis Thrombosis and Vascular Biology. 2000;20:1926-1931.

99. Demer LL. Vascular calcification and osteoporosis: inflammatory responses to axidized lipids. hternational Journal of Epidemialogy. 2002;31:737-741.

100. Bucay $N$. Sarosi I. Dunstan $C R$, et al. Osteoprotegerin-deficient mice develop early onset osteoporosis and arterial calcification. Genes and Development. 1998;12:1260-1268.

101. Murdy $G$, Garrett R, Harris $S$, et al. Stimulation of bone formation in vitro and in rodents by statins. Science. 1999:286:1946-1949.

102. Achenbach $S$, Ropers D, Pohle $K$, et al. Influence of lipid-lowering therapy on the progression of coronary artery calcification: a prospective evaluation. Circulation. 2002;106:1077-82.

103. Libby $\mathbb{P}_{*}$ Aikawa M. Stabilization of atherosclerotic plaques: new mechanisms and clinical targets. Nat Med. 2002:8:1257-62.

104. Phillips BW, Belmonte $N$, Vernochet $C$, et al. Compactin enhances osteogenesis in murne embryonic stem cells. Biochem Biophys Res Commun. 2001;284:478-84.

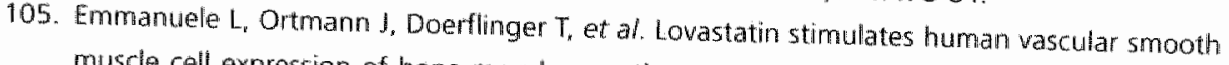
muscle cell expression of bone morphogenetic protein-2, a potent inhibitor of low-density lipoprotein-stimulated cell growth. Biochem Biophys Res Commun. 2003;302:67-72.

106. Callister TQ. Raggi $P_{1}$ Cooil $B_{2}$ et at. Effect of HMG-COA reductase inhibitors on coronary artery disease as assessed by electron-beam computed tomography. $N$ Engl I Med.
$1998 ; 339: 1972-8$.

107. Budoff MJ, Lane KL, Bakhsheshi $H_{\text {s }}$ et al. Rates of progression of coronary calcium by electron beam tomography. Am $\&$ Cardiol. 2000;86:8-11. 
108. van de Poll SW, Romer TI, Volger OL, et al. Raman spectroscopic evaluation of the effects of diet and lipid-lowering therapy on atherosclerotic plaque dewelopment in inice. Arterioscler Thromb Vasc Biol. 2001:21:1630.5.

109. Bea $F$, Blessing $E$, Bennett $B$, et al. Simvastatin promotes atherosclerotic plaque stability in apoE-deficient mice independently of lipid lowering. Arteriascier Thromb Wasc Biol. 2002:22:1832-7

110. Shavelle DM, Takasu ע, Budoff MI, et al. HMG CoA reductase inhibitor (statin) and aortic valwe callium. Lancet. 2002;359:1125-6.

111. Cummings $S R_{x}$ Bauer $D C$. Do statins prevent both cardiovascular disease and fracture? Jama: 2000:283:3255-7.

112. Russell $R G$, Rogers MJ. Frith $J C$, et at. The pharmacology of bisphosphonates and new insights into their mechanisms of action. J Bone Miner Res. 1999;14:53-65.

113. Stary HC. Lipid and macrophage accumulations in arteries of children and the development of atherosclerosis. Am J Clin Nutr. 2000;72:12975-13065.

114. Sarig S, Weiss TA, Katz $\|_{r}$ et al. Detection of cholesterol associated with calcium mineral using confocal fluorescence microscopy. Laboratory Investigation. 1994;71:78:2-787.

115. Kramsch DM Chan CT. The effect of agents interfering with soft tissue calcification and cell proliferation on calcific fibrous-fatty plaques in rabbits. Circ Res. 1978;42:562-71.

116. Qial $\mathrm{JH}_{\text {, Xie }} \mathrm{PZ}$, Fishbein MC, et al. Pathology of atheromatous lesions im inbred and geneticlaly engineered mice. Genetic determinatin of arterial calcification. Arteriosclerosis and Thrombosis. 1994:14:1480-1497.

117. Rokita $E$, Cichocki $T$, Heck $D$, et al. Calcification of aortic wall in cholesterol-fed rabbitts. Atherosclerosis. 1991;87:183-93.

118. Watson KE, Bostrom $K$, Ravindranath $\mathbb{R}_{n}$ et al. TGF-B 1 and 25-Hydroxycholesterol stimulate asteoblast-like vascular cells to calcify. Journal of Clinical Investigation. 1994:93:2106-2113.

119. Hsu $\mathrm{HH}$. In vitro effect of cholesterol on calcifying activity of vesicles isolated from rabbit aortas. Biochim Biophys Acta. 2003:1638:235-40.

120. Demer LL, Tintut $Y$. Mineral exploration: search for the mechamism of vascular calcification and beyond: the 2003 Jeffrey M. Hoeg Award lecture. Arterioscler Thromb Vasc Biol. 2003;23:1739-43. Epub 2003 Sep 4.

121. Proudfoot $D$, Davies JD, Skepper JN, et al. Acetylated low-density lipoprotein stimulates human vascular smooth muscle cell calcification by promoting asteoblastic differentiation and inhibiting phagocytosis. Circulation. 2002;106:3044-50.

122. Parhami $F$, Basseri $B$, Hwang J, et al. High-density lipoprotein regulates callcification of vascular cells. Circ Res. 2002;91:570-576.

123. Urist MR. Bone: formation by autonduction. Science. 1965;150:893-9.

124. Aono $A$, Hazama $M$, Notoya $K$, et al. Potent ectopic bone-inducing activity of bone morphogenetic protein-4/7 heterodimer. Biochem Biophys Res Commun. 1995;2 10:670-7.

125. Israel DI, Nove I, Kerns KM, et al. Heterodimeric bone morphogenetic proteins show enhanced activity in witro and in wivo. Growth Factors. 1996:13:291-300 
126. ten Dijke $P_{n}$ Yamashita $H$, Sampath $T K$, et al Identification of type I receptors for asteogenic protein 1 and bone morphogenetic protein-4. I Biol Chem. 1994;269:16985-8.

127. Urist MR, Delange RJ. Finerman GA. Bone cell differentiation and growth factors. Science. 1983:220;680-6.

128. Vargas SI. Naprta $A_{x}$ Glaccum $M$, et al. Interleukin-6 expression and histomorphometry of bones from mice deficient in receptors for interleukin"1 or tumar necrosis factor. J Bone Miner Res. 1996:11:1736-44.

129. Massague J, Attisano L. Wrana JL. The TGF-beta family and its compasite receptors. Trends Cell Biol. 1994:4:172-8.

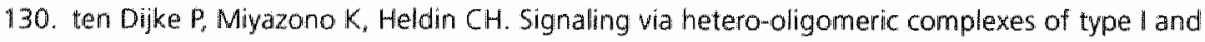
type Il serine/threonine kinase receptors. Curr Opin Cell Biol. 1996:8:139-45.

131. Ducy P, Desbois C, Boyce B, et al. Increased bone formation in osteocalcin-deficient mice. Neture. 1996;382;448-452.

132. Bautista DS, Xuan JW, Hota $C$, et al. A monoclonal antibody against osteopontin inhibits RGD-mediated cell adhesion to osteopontin. Ann N Y Acad Sci. 1995;760:309-311.

133. Sung V, Stubbs JT, 3rd, Fisher L, et al. Bone sialoprotein supports breast cancer cell adhesion proliferation and migration through differential usage of the alpha(V)beta3 and alpha(V)beta5 integrims. J Cell Physiol 1998;176:120-156.

134. Matsui $Y$, Ritting SR, OKamoto $H$, et al. Osteopontin deficiency attenuates atherosclerosis in female apolipoprotein Endeficient mice. Arterioscler Thromb Vasc Biol. 2003;23:1029-34.

135. MacNeil RL, Berry J, D'Errico J, et al. Role of two mineral-associated adhesion molecules, osteopontin and bone sialoproteim, during cementogenesis. Connective Tissue Research. 1995; 33:323-32.

136. Acebes $C$, de la Piedra C. Traba ML, et al. Biochemical markers of bone remodeling and bone sialoprotein in ankylosing spondylitis. Clinica Chimica ACta. 1999;289:99-110.

137. Maillard C. Malaval L. Delmas PD. Immunological screening of SPARCrOsteonectin in nonmineralized tissues. Bone. 1992;13:257-64.

138. Delany AM, Amling M, Priemel $M$, et al. Osteopenia and decreased bone formation in osteonectin-deficient mice. Joumal of clinical investigation. 2000;105:915-923.

139. Gilmour DT, Lyon G, Carlton MBL, et al. Mice deficient for the secreted glycoprotein SPARC/ osteonectin/ BM40 develop normally but show severe age-onset cataract formation and disruption of the lens. The EMBO Journal. 1998;17:1860 1870.

140. Mason 11. Taylor A, Williams JG, et al. Evidence from molecular cloning that SPARC, a major product of mouse embryo parietal endoderm, is related to an endothelial cell 'culture shock' glycoprotein of Mr 43,000. Embo \$. 1986:5:1465-72

141. Sage $H$. Tupper J. Bramson R. Endothelial cell injury in vitro is associated with increased secretion of an Mr 43,000 glycoprotein ligand. I Cell Physiol. 198:6;127:373-87.

142. Aeschlimann D, Kaupp $O$, Paulsson M. Transglutaminase-catalyzed matrix cross-liriking in differentiating cartilage: identification of osteonectin as a major glutaminyl substrate. J Cell Biol. 1995:129:881-92. 
143. Mann $K$, Deutzmann $R_{x}$ Paulsson $M_{x}$ et al. Solubilization of protein BM-40 from a basement membrane tumor with chelating agents and evidence for its identity with osteonectin and SPARC. FEBS Lett. 1987;218:167-72.

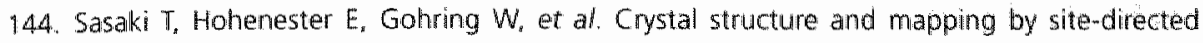
mutagenesis of the collagen-binding epitope of an activated form of BM-40/SPARC/ osteonectin. Embo l. 199:8;17:1625-34.

145. Kingsley DM. The TGF-beta superfamily: new members, new receptors, and new genetic tests of function in different arganisms. Genes Dev. 1994;8:133-46.

146. Reed MJ, Vernon RB, Abrass IB, et al. TGF-beta 1 induces the expression of type I collagen and SPARC, and enhances contraction of collagen gels, by fibroblasts from young and aged donors. J Cell Physiol. 1994;158:169-79.

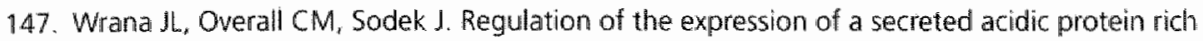
in cysteine (SPARC) in human fibroblasts by transforming growth factor beta. Comparison of transcriptional and post-transcriptional control with fibronectin and type 1 collagen. Eur J Biochem. 1991;197:519-28.

148. Francki A, Bradshaw AD, Bassuk JA, et al. SPARC regulates the expression of collagen type 1 and transforming growh factor-beta1 in mesangial cells. J Biol Chem. 1999;274:32145-52.

149. Thirunavukkarasu $K T$, Halladay $D L$, Miles RR, et al. The osteoblast-specific transcription factor Cbfal contributes to the expression of osteoprotegerin (OPG), a potent inhibitor of osteoclast differentiation and function. The Journal of Bialogical Chemistry. 2000:275:25163-25172.

150. Price PA, Thomas GR, Pardini AW, et al. Discovery of a high molecular weight complex of calcium, phosphate, fetuin, and matrix gamma-carboxyglutamic acid protein in the serum of etidronate-treated rats. I Biol Chem. 2002;277:3926-34.

151. Dernetriou $M$, Binkert $C$. Sukhu $B$, et af. Fetuin/alpha2-HS glycoprotein is a transtorming growth factor-beta type il receptor mimic and cytokine antagonist. The Journal of Biological Chemistry. 1996:271:12755-12761.

152. Wang $H$, Zhang $M$, Bianchi $M$, et al. Fetuin (alphaz-HS-glycoprotein) opsonizes cationic macrophagedeactivating molecules. Proc Nat Acad Sci U S A. 1998:95:14429-34.

153. Jersmann HP, Dransfield I. Hart SP. Fetuinzalpha2-HS glycoprotein enhances phagocytosis of apoptotic cells and macropinocytosis by human macrophages. Clin Sci (Lond). 2003;105:273-8

154. Jahnen-Dechen W. Schinke T, Trindi $A_{\text {s }}$ et al. Cloning and targeted deletion of mouse fetuin gene. The lournal of Biological Chemistry. 1997;272:31496-31503

155. Ketteler M. Bongartz $P$, Westenfeld $R$, et al. Association of low fetuin-A (AlHSG) concentrations in serum with cardiovascular mortality in patients on dialysis: a cross-sectional study. Lancet. $2003 ; 361: 827-33$ 


\section{Chapter 2}

\section{Differential expression of bone marrix regulatory proteins in human atherosclerotic plaques}

Cherida R Dhore, Jack PM Cleutjens, Esther Lutgens, Kitty BJM Cleutjens, Piet PMM Geusens,

Peter JEHM Kitslaar, Jan HM Tordoir, Henri MH Spronk. Cees. Vermeer and Mat JAP Daemen.

Published: Arteriosclerosis Thrombosis and Vascular Biologie 2001;21:1998-2003 


\section{Abstract}

In this chapter, we examined the expression of regulators of bone formation, and osteoclastogenesis in human atherosclerosis because accumulating evidence suggests that atherosclerotic calcification shares features with bone calcification.

The most striking finding of this study was the constitutive immunoreactivity of MGP, OC and BSP in non-diseased aortas and the absence of BMP-2, BMP-4, OPN and ON in non-diseased aortas and early atherosclerotic lesions. When atherosclerotic plaques demonstrated calcification or bone formation, BMP-2, BMP-4, OPN, and ON were upregulated. Interestingly, this upregulation was associated with a sustained immunareactivity of MGP, OC and BSP. The two modulators of osteoclastogenesis (OPG and RANKL) were present in the non-diseased vessel wall and in early atherosclerotic lesions. In advanced calcified lesions, OPG was present in bone structures, whereas RANKL was only present in the extracellular matrix surrounding calcium deposits.

The observed expression patterns suggest a tight regulation of the expression of bone matrix regulatory proteins during human atherogenesis. The expression pattern of both OPG and RANKL during atherogenesis might suggest a regulatory role of these proteins not only in osteoclastogenesis, but also in atherosclerotic calcification. 


\section{Introduction}

Calcification of the vessel wall is one of the features of atherosclerosis and is by itself considered to be a risk factor for plaque rupture ${ }^{\text {t.k. }}$. Although recent studies indicate that atherosclerotic calcification is an organised process, exact regulatory mechanisms remain unclear ${ }^{12.7}$. Increasing evidence suggests that atherosclerotic bone formation and calcification shares features with skeletal bone formation and calcification "such as chondrocyte and osteoblast differentiation, mineralisation, bone matrix deposition, and bone resorption.

Several proteins are involved in the regulation of skeletal bone formation, such as matrix Gla protein (MGP), osteocalcin (OC), also called bone Gla protein, bone sialoprotein (BSP): bone morphogenetic protein-2 and 4 (BMP-2, BMP-4), osteopontin $(O P N)$, and osteonectin (ON). Although the immunolocalisation of some of these proteins in the human vessel wall has been described before, the avallable data are rather incomplete and restricted to advanced stages of atherosclerosis. Immunoreactivity of two proteins involved in osteoclastogenesis, osteoprotegerin (OPG) and its ligand OPGL, also named RANKL (receptor activated nuclear factor-kappa $B$ ligand), has not been described before in the human atherosclerotic vessel wall. In the present study we examined the protein expression pattern of 7 regulators of bone formation, and 2 modulators of osteoclastogenesis in all stages of human atherosclerotic lesions to provide an inventory of the expression of regulators of bone turnover in human atherogenesis.

\section{Methods}

\section{Patients' characteristics and tissue preparation}

Atherosclerotic plaques from abdominal aortas $(n=42)$ were collected from autopsy (Department of Pathology. Academic hospital Maastricht) $(n=29)$ and from patients undergoing vascular surgery (Department of Generall Surgery, Academic hospital Maastricht) $(n=13)$. Autopsy specimens were obtained from adult men and women aged 55 to 59 years. The cause of death was diverse (e.g. cardiovascular disease and cancer). Surgical specimens were obtained from patients (4 women, 7 men, aged 51 to 78 years) undergoing vascular surgery, all of whom had symptoms of vascular occlusion. Specimens were processed routinely and embedded in paralfin.

Plaque subtypes ( 5 to 8 per subgroup) were determined according to the classification proposed by Virmani et al.3. Lesion morphology was evaluated on hematoxylin and eosin stained sections. 


\section{Calcification}

Von Kossa staining was used to assess calcification in specimens from all stages of plaque development. This staining was performed by the standard procedure.

\section{Western blotting}

Validation of all antibodies occurred by Western blotting. Proteins were isolated by the urea method (Ready Prep TM Sequential Extraction Kit, Instruction Manual, Bio-Rad Laboratories, CA, USA). A 15\% SDS-page gel with $50 \mu \mathrm{g}$ whole cell extract protein per sample was electrophoresed. Proteins were transferred to a nitrocellulose membrane at 30 Volts. After 1 hour of blocking with $3 \%$ bovine serum albumine (Sigma-Aldrich, Zwijndrecht, The Netherlands) in $10 \mathrm{mM}$ Tris-buffered saline pH 7.5 (TBS), $100 \mathrm{mM}$ $\mathrm{NaCl}$ and $0.1 \%$ Tween, blots were incubated with antibodies directed to either MGP (1:200), OC (1:800, Anawa Trading SA, Wangen, Zürich, Switzerland), ESP (1:500)", BMP-2 (1:350, santa Cruz Biotechnology, Inc., Santa Cruz, CA, USA), BMP-4 11:350, Santa Cruz Biotechnology, Inc. Santa Cruz, CA, USA), OPN (1:500), ON (1:1000, Zymed laboratories, Inc., San Francisco, CA, USA)', OPG (1:1000), or RANKL (1:1000). Antimouse, horseradish peroxidase (HRP) (1:1000, Dako, Denmark) labelled, anti-rabbit HRP (1:2000, Cell Signaling Technology, a New England Biolabs company, UK) and anti-goat HRP (1:2500, Dako, Denmark) were used as the secondary antibodies. Specific antibody binding was visualised with enhanced chemiluminiscence (ECL) Western blotting detection reagents (Amersham Pharmacia Biotech Benelux, Roosendaal, The Netherlands).

\section{Immunohistochemical staïning}

Paraffin sections ( $4 \mu \mathrm{m}$ ) were deparaffinized and washed three times in Tris-buffered saline (TBS) (5 mM Tris-HCl pH 7.5, $140 \mathrm{mM} \mathrm{NaCl).} \mathrm{Parallel} \mathrm{sections} \mathrm{were} \mathrm{stained} \mathrm{with}$ mouse monoclonal antibodies against MGP (1:25), BMP-2 (1:20, Genetics Institute, inc. Cambridge, MA, USA), goat polyclonal antibodies against BMP-4 (1:25), OPN (1:125). OPG (1:100). RANKL/OPGL (1:75), rabbit polyclonal antibodies against $O C$ $(1: 50)$. ON (1:400) and BSP (1:25). For the mouse monoclonal antibodies, biotinylated sheep anti-mouse $\operatorname{lgG~(1:250,~Amersham,~Life~Science,~Little~Chalfont,~Buckinghamshire,~}$ Uk) was used as the second antibody, while biotinylated rabbit anti-goat lgG $(1: 200$, Dako, Glostrup. Denmark) or sheep anti-rabbit IgG (1:1000, Dako) were used as secondary antibody for the polyclonal antibodies. After incubation with an alkaline phosphatase-coupled avidin-biotin complex (ABC complex, Dako), antibodies were visualised with an alkaline substrate kit I Vector SK-5100, Vector Laboratories, Inc. Burlingame, CA, USA). Sections were counterstained with hematoxylin and mounted with coverslips. In negative controls incubation with primary antibody was omitted.

Since immunohistochemical results of specimens derived from autopsy and surgery did not differ, the data are presented as one group. 


\section{Immunophenotyping}

Double immunohistochemistry was performed using CD68 (Dako, mouse monoclonal antibody) to identify macrophages, and $\alpha$-smooth muscle actin (ASMA, Dako, mouse monoclonal antibody) to identify vascular smooth muscie cells.

First, MGP, OC, BSP, BMP-2, BMP-4, OPN, or ON were localised with the above described protocol for immunohistochemical staining. Subsequently, the sections were treated with $0.1 \%$ pepsin (Boehringer Mannheim GmbH, Mannheim, Germany) and incubated for $45 \mathrm{~min}$, with ASMA or CD68, both diluted 1:500. Biotin-labelled sheep anti-mouse IgG (1:250, Amersham, Life Science) was used as secondary antibody. The avidin-biotin alkaline phosphatase (1:200, Dako) complex in combination with fast blue substrate $(0.2 \%$ w/v fast blue-BB-salt (Sigma Chemical CO. St. Louis, MO, USA) was used as chromogen. No counterstaining was performed and sections were mounted. Negative controls were treated accordingly without both primary antibody incubation steps.

\section{In situ hybridisation}

Sense and antisense digoxygenim (DIG)-llabeled RNA probes for MGP, BMP-2, BMP-4, OPN, and ON mRNAs were transcribed from the T7 promoter of pGEM3Z. Hybridization of $4 \mu \mathrm{m}$ paraffin embedded sections, and visualization with alkaline phosphatase-coupled anti-DIG antibodies and indolylphosphate-nitroblue tetrazolium: (BCIP/NBT) substrate were performed as described earlier". Parallel sections were hybridised with anti-sense and sense probes. In the negative controls the probe was not added to the hybridisation mixture.

\section{Results}

\section{Validation of antibodies}

Western blotting (fig. 2.1) showed that BSP protein (35 kDa) was present in early atherosclerotic plaque but was not detectable in calcified atherosclerotic lesions. BMP-2 and BMP-4 both form dimers ( $30 \mathrm{kDa}$ ) and were slightly upregulated in the fibrous cap atheroma and fibrocalcific plaques. OPN western blotting resulted in a $67 \mathrm{kDa}$ band in early atherosclerotic plaque. The $43 \mathrm{kDa}$ ON was upregulated in the fibrocalcific atherosclerotic lesion. Whereas OPG (46 kDa) was upregulated in the fibrous cap atheroma and fibrocalcific plaque, its ligand RANKL (35 kDa) was only detected in the early lesion. Western blotting of both Gla containing proteins (MGP and OC) was not satisfactory because of the highly insolubility of these proteins. MGP (10 kDa) was detected in a sample of synthetic MGP, and was faintly wisible in the protein lysates of the atherosclerotic plaques. OC could not be detected with this protein isolation method, probably due to the insolubility of the protein. 

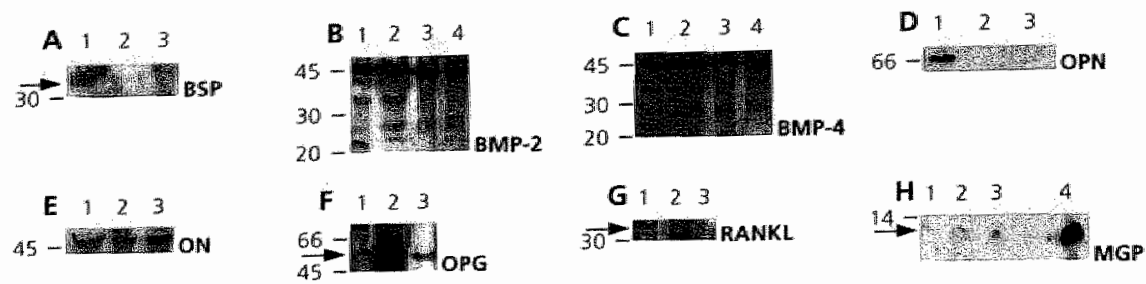

Figure 2. 1. Western blotting analysis with antibodies directed to bone matrix proteins. Lane 1: intimal xanthorna, lane 2: fibrous cap atheroma and tane 3: fibrocalcific plaque. Fig. 2.1 a: blot stained with ox-BSP. Fig. 2.1b: blot stained with o-BMP-2. Note: lane $4=$ fibrocalcific plaque. Fig. 2 .1c: blor stained with $\alpha-B M P$. A. Wote: ane $4=$ fibrorakific plaque. Fig. 2.1d: blot stained with o-OPN. Fig. 2.1e: blot stained with a-ON. Fig. 2.1f: blot stained with $\alpha$-OPG. Fig. 2.1g: blot stained with $\alpha$-RANKL. Fig. 2.1h: blot stained with MAGP antibady. Note: lane $4=$ synthetic $M G P$.

Human heart, liver and lung tissue was used as negative controls for immunohistochemistry of antibodies directed to MGP, OC and BSP (ffig. 2.2). MGP was absent in the hepatocytes, but the vessels in the liver did contain MGP. OC and BSP were absent in human heart.

Pre-treatment of calcified control sections with $3 \%$ citric acid resulted in an equal pattern of protein localisation as non pre-treated sections indicating the lack of a-specific binding of the antibodies to calcium deposits.

\section{Non-diseased aorta}

Five bone matrix proteins, MGP, OC, BSP, BMP-4, and OPG were present in the non-diseased aorta (fig. 2.3). MGP (fig. 2.4a) and BSP were present throughout the intima and media, including endothelial cells, SMC and elastic fibres. BMP-4, ON, and OPG proteins were highly expressed, but only in the medial SMC. RANKL immunoreactivity was very weak, and confined to the medial SMC, a pattern that was comparable to OPG. OC, which like MGP, is a Gla containing protein, was only expressed in the endothelial cells lining the lumen. Two bone matrix proteins, BMP-2 and OPN (fig. 2.4b) were absent in the non-diseased aorta.

The adventitia showed immunoreactivity for six bone matrix proteins MGP, OC, BSP, BMP-2, BMP-4, and ON. MGP, BSP, and ON were present in the adventitial vessels, OC throughout the whole adventitia except for the vessels, and BMP-2 and BMP-4 only in the polymorphonuclear cells. 


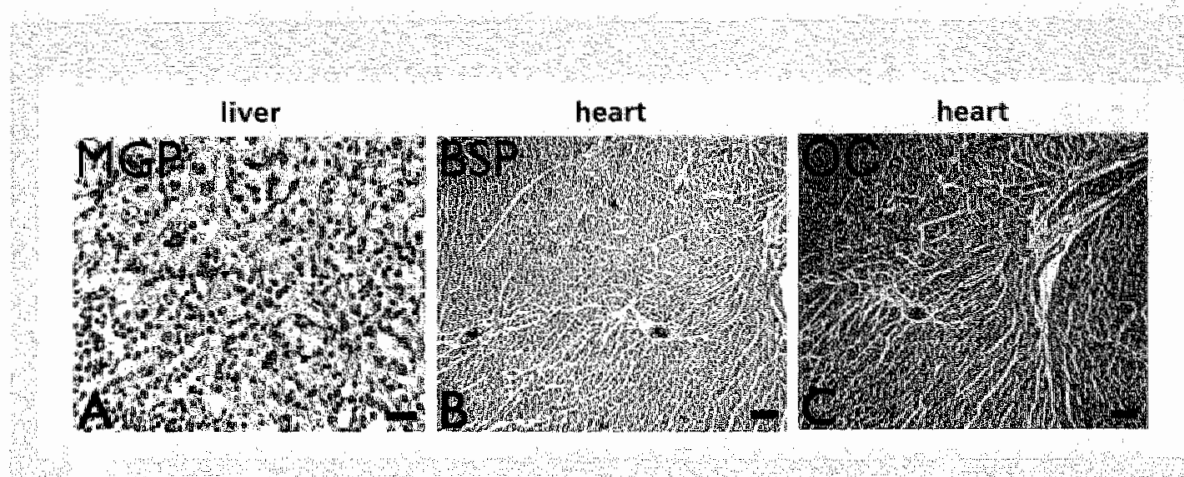

Figure 2.2. Immunohistochemical staining. Negative controls for the antibodies directed to MGP: $O C$ and $B S P$. Fig. 2.2a: human liver stained with $\alpha-M G P$. Fig. $2.2 b$ and $c$. human heart stained with respectively $a-O C$ and a-BSP. Note: positive staining is red. Scale bars in figure 2 represent 50 um. Full color figures see page 142.

\section{Intimal xanthoma or fatty streak}

Characteristic of this type of early lesion is the accumulation of macrophage derived lipid filled foam cells in the intima (fig. 2.3). In intimal xanthoma lesions MGP, BSP, BMP-4, and ON expression was localised in the medial SMC. The intima showed immunoreactivity of six bone matrix regulatory proteins. MGP and BSP were present in the intimal SMC. Macrophage derived lipid filled foam cells expressed MGP, BSP (fig. 2.4c) and $O C$ protein, whereas BMP-2, BMP-4 (fig. 2.4d), OPN, ON, OPG, and RANKL were absent. Endothelial cells, lining the lumen expressed OC, BMP-4, OPG and RANKL.

\section{Fibrous cap atheroma}

The fibrous cap atheroma is the lesion type in which a collagenous-proteoglycan matrix containing fibrous cap is covering the large lipid core (fig. 2.3). Cells present in these lesions are smooth muscle cells (SMC) in the shoulder region of the plaque, foam cells, T-cells and endothelial cells.

Medial smooth muscle cells, underlying the fibrous cap atheroma, showed expression of MGP, BSP, and ON. All nine proteins investigated, showed immunoreactivity in the intima of these lesions. However, the localization of the proteins was diverse. BSP, BMP-2, BMP-4 (fig. 2.4e), $O N$ and $O P G$ were expressed by the intimal SMC present in the shoulder regions. Expression of MGP, BSP, OC, BMP-4, OPN, and ON was prominent in the foam cells in the lipid core. Some specimens contained cells that can best be described as chondrocyte-like cellis that reside in small spaces in the intercellular substance. These cells were mainly localized at the borders of the lipid core, and showed high expression of MGP and ON (fig. 2.4f) protein, and moderate BSP and BMP-4 immunoreactivity. 

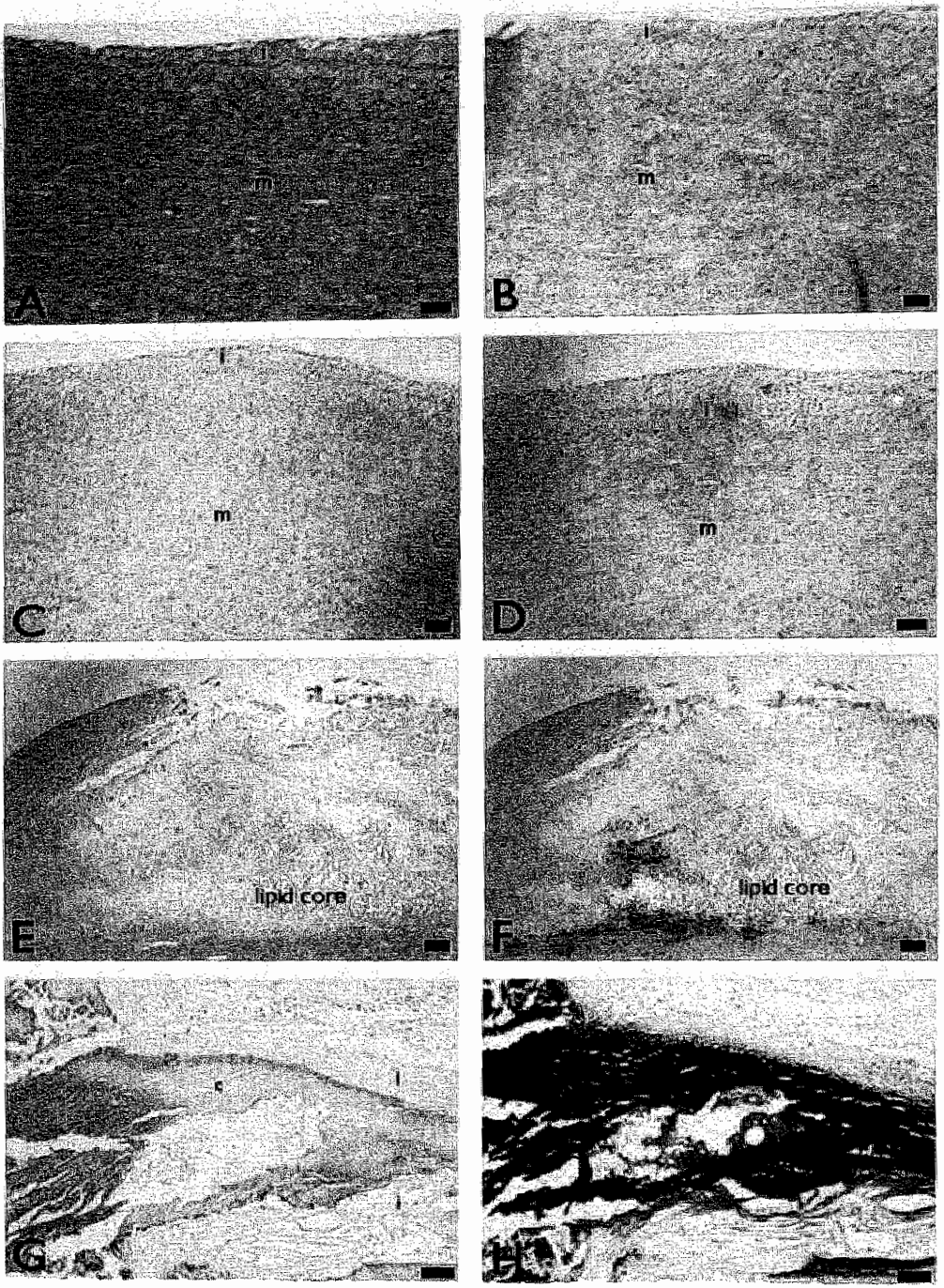

Figure 2.3. Histologkal and morphological characteristics of the plaque types. Panels a, $c_{i}$ e, and g regresent

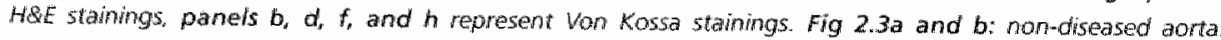
Fig $2.3 \mathrm{c}$ and d: intimal xanthoma. Fig 2.3e and fi fibrous cap atheroma. Fig $2.3 \mathrm{~g}$ and h: fithocalcific plaque.

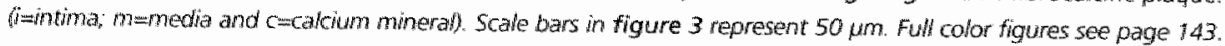




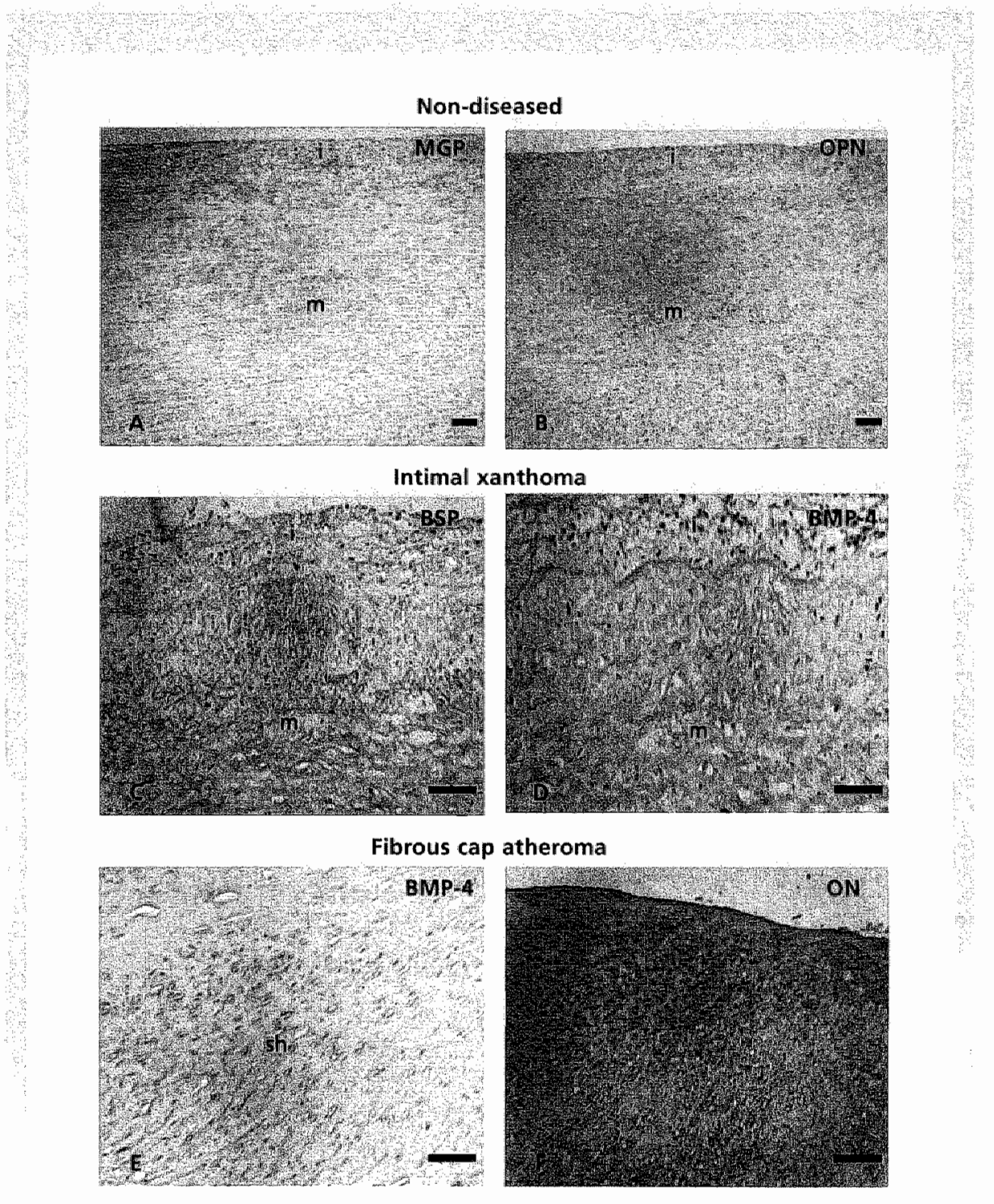

Figure 2.4. Immunohistachemical staining of a non-diseased aorta ( $a$ and b), intimal xanthoma (c and d), and fibrous cap atheroma (ie and f). Fig. $2.4 \mathrm{a}$ ard $b$ : non-diseased aorta staned with respectwely $M G P$ and OPN. Fig. 2.4C and d: intimal xanthoma stained with respectively BSP and BMP-4. Fig. 2.4e and f: fibrous cap atheroma stained with respectively $B M P-4$ and $O N$. (i=intima; $m=m e d i a$ and sh=shoulder region). Scale bars in figure $2.4 a$ and b represent $50 \mu m$, scale bars in figure $24 c$, e and frepresent 25 um and scale bar in figure $2.4 d$ represents $10 \mathrm{jm}$. Full color figures see page 144. 


\section{Fibrocalcific plaque}

This type of advanced atherosclerotic plaque is collagen rich with large areas of calcification and a necrotic core. Together with areas of calcification. we observed cortical bone structures and cells involved in bone turnover, namely chondrocyte-like cells, osteoblasts, osteocytes and osteoclasts (fig. 2.3). All bone matrix proteins examined in this study were highly expressed in these fibrocalcific lesions. Like in the fibrous cap atheroma, the medial smooth muscle cells underlying the fibrocalcific piaque showed only expression of MGP, BSP, and ON, whereas intimal smooth muscle cells expressed MGP, BSP, BMP-2, BMP-4, ON and OPG. CD68-positive macrophages surrounding the necrotic core, showed immunoreactivity of MGP, OC, BSP, BMP-4, OPN and ON. Two types of calcified structures were present in these lesions: calcium mineral deposits and lamellar bone. Around calcium mineral deposits MGP (fig. 2.5a) and OPN (fig. 2.5b) were highly expressed, whereas in the deposits BSP, OC, BMP-2 (fig. 2.5c), BMP-4. OPN and $O N$ showed immunoreactivity. Lamellar bone structures, recognized by the presence of cement lines and osteocytes within bone and osteoblasts lining the bone, showed immunareactivity of OPN (fig, 2.5d) and ON. BSP, BMP-2, BMP-4, OPN, ON, and $O P G$ (fig. 2.5e) lined the bone structures. OC was the only protein present throughout the bone matrix (fig. 2.5f). RANKL could only be demonstrated in association with the extracellular matrix (ECM) surrounding calcium deposits (fig. 2.5g). High expression of BSP. ON and OPG was seen in the few inflammatory cells present in these fibrocalcific plaques. ON was also highly expressed in the matrix vesicles present in these lesions (fig. 2.5h).

Figure 2.5. Immunohistochemical staining of a fibrocakific plaque. Fig. 2.5a: fibrocalcific plaque containing calcum mineral deposition immuno-stained with monodonal antibody against MGP (red staining). Note: Strong MGP positive staining at boundary of the mineral deposits. Fig. 2.5b: fibrocalcific plaque, containing cakium mineral deposits (c) and bone tissue (b) stained with a-OPN (red staining). OPN positive staining could be demonstrated at the boundary of the calcium mineral and bone structures (arrows). Fig. $2.5 \mathrm{c}$ fibrocakific platque containing calcium mineral deposits immuno-stained with a mouse anti-BMP-2 (red staining). BMP-2 positive staining (between arrows) could be visualised surrounding the highty cakified central area ("). Fig. 2.5d: fibrocalcific plaque, containing bone structures (b) stained with $\alpha$-OPN OPN positive staining was seen surtounding the bone structures (arrow), but also in a striping pattern within the bone varrowhead). Fig. 2.5e: fibrocalific plaque with bone formation (b) stained with goat antivoPG. OPG could be demonstrated in the osteoblasts (arrowl lining the bone structures (b) and some stromal cells farrowheady in the bone marrow (bm). Fig. 2.5f: fibrocalcific plaque stained with $\alpha$-OC. Fig. 2.5g: fibrocalcific plaque, containing calcium mineral deposits (C), immuno stained with goat anti-RAMKL. RANKL was observed in the extracellubar matrix surrounding the mineral deposits (arrow). Fig. 2.5h: fibrocalcific plaque with matrix vesictes stained with $\alpha$-ON. Scate bars in fig. $2.5 \mathrm{a}, \mathrm{c}$ and $\mathrm{h}$ represent $25 \mathrm{~mm}$, scale bars in fig. $2.5 \mathrm{~b}$, d and frepresent $50 \mathrm{um}$, scale bar in fig. $2.5 \mathrm{~g}$ represents $10 \mathrm{um}$. Full color figures see page 145 . 

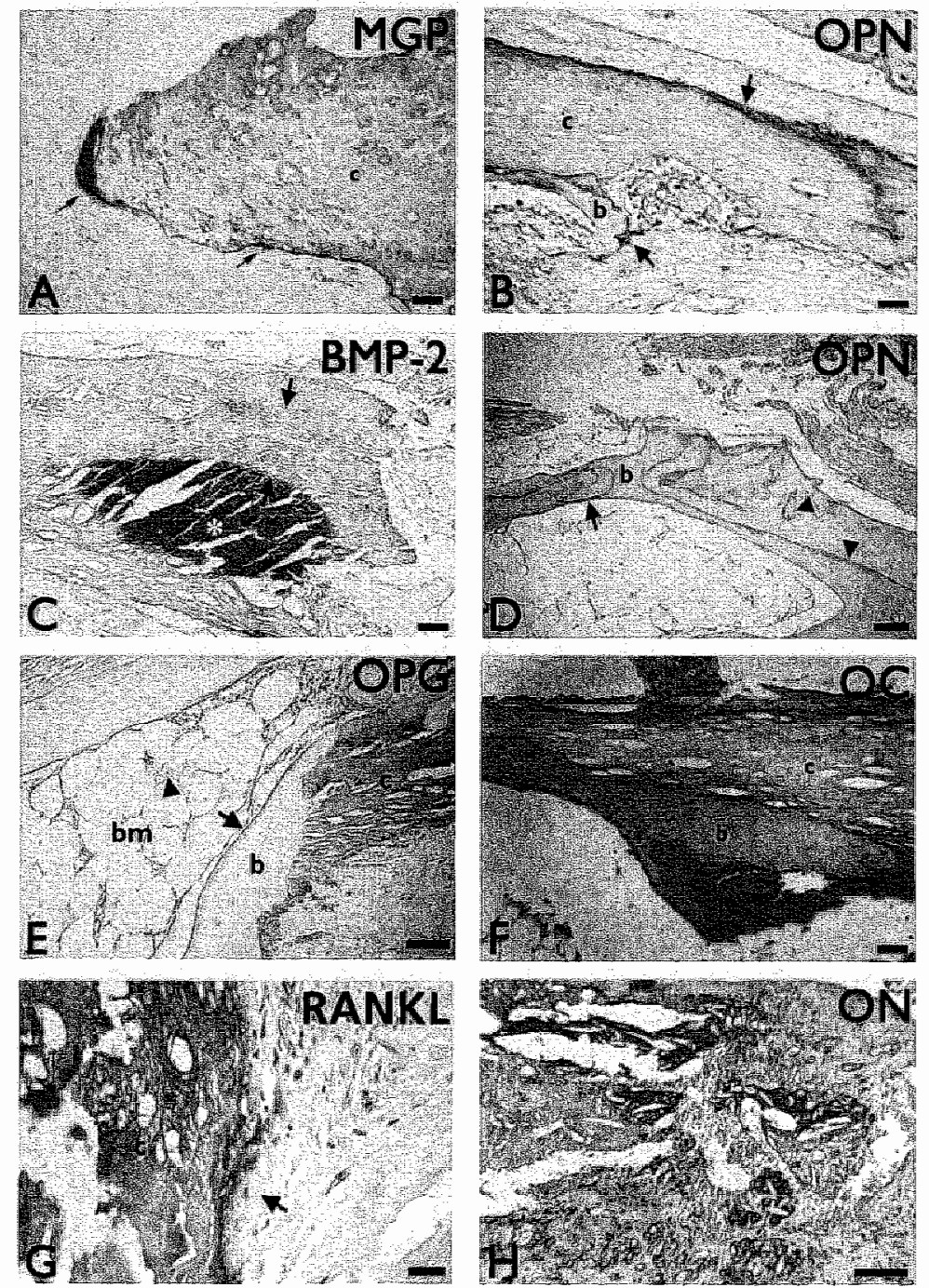


\section{In situ hybridisation}

In situ hybridisation revealed that MGP MRNA expression pattern colocalizes with the protein. In intimal xanthoma, medial vascular SMCs, adjacent to the adventitia, expressed MGP mRNA, whereas in fibrocalcific plaques, MGP MRNA was mainly present in vascular SMCs and osteoblastic cells in calcified and ossified regions in the plaque.

In situ hybridization of BMP-2 and BMP-4 in fibrocalcific plaques showed $M R N A$ expression in intimal vascular SMCS, mainly surrounding the calcified areas, and in osteoblasts, whereas mRNA expression was absent in medial vascular SMCs. This mRNA. expression pattern was comparable to immunohistochemical localization of these proteins.

In addition, in situ hybridization of OPN and ON revealed a MRNA expression profile that resembled the protein expression profile. OPN mRNA expression was present in SMCs and in bone structures of the fibrocalcific plaque, in the osteocytes and osteoblasts. ON mRNA was highily expressed in matrix-producing SMCs and in chondrocyte-like cells. For in situ hybridization results see figure 2.6 .

\section{Discussion}

In vitro and gene expression studies $5^{5,11 ; 8-2 t}$ demonstrate that human vascular calcification is a regulated process with similarities to bone modeling and remodeling. Our observations using a panel of antibodies against several bone matrix regulatory proteins support these findings and are summarised in figure 2.7. We observed that all of these bone matrix proteins were expressed in the arterial wall. One set of proteins, known to beiong to inhibitors of calcification, was present at all stages of human atherosclerosis. This suggests a continuous inhibition of calcification in the atherosclerotic vessel wall. The expression of a second set of proteins, known to belong to the activators of calcification, was restricted to advanced and calcified lesions.

Given these observations, a possible mechanism of atherosclerotic calcification is that vascullar calcification is the result of a time- and plaque-stage-restricted activation of proteins such as BMP-2, BMP-4, OPN and ON, that overrules the continuous expression of inhibitory proteins such as MGP, OC and BSP.

\section{Inhibitors of calcification (matrix Gla protein (MGP), osteocalcin (OC) and bone sialoprotein (BSP))}

Analysis of knockout mice has shown that both vitamin K-dependent, $\gamma$-carboxyglutamic acid (Gla) containing proteins, MGP and $O C$ are inhibitors of calcification ${ }^{22,23}$. MGP is found in bone, in the normal and atherosclerotic vessel wall', and in serum of patients with diabetes: Mice that lack MGP develop to term, but die within two months as a result of arterial calcification. which leads to blood vessel rupture $2,24$. Serum $O C$ is used 


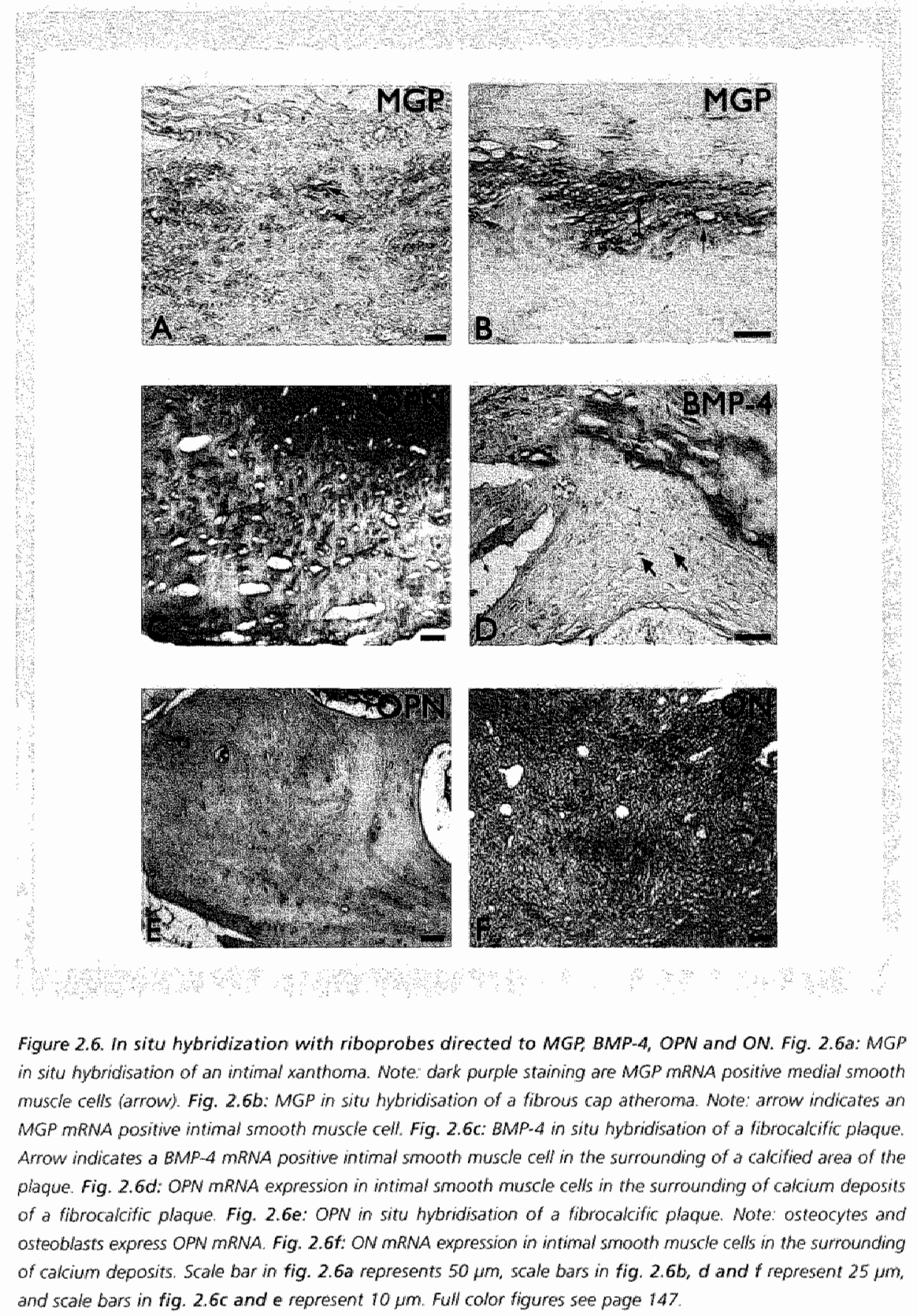

Chapher Differential expression of bone matrik neglulatory proteins in buman atherosclerotic phlaques. 


\begin{tabular}{|c|c|c|c|c|}
\hline \multirow[b]{2}{*}{ Antibody } & \multirow[b]{2}{*}{ Intimal xanthoma } & \multirow{2}{*}{$\begin{array}{l}\text { Fibrous cap } \\
\text { atheroma }\end{array}$} & \multicolumn{2}{|c|}{ Fibrocalcific plaque } \\
\hline & & & 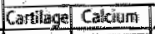 & Bnve \\
\hline MGP & - & ind & & \\
\hline oc & 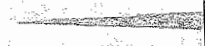 & Fin & & \\
\hline BSP & $-\operatorname{mox}=2 x$ & tras & & \\
\hline$B M P-2$ & 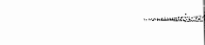 & 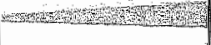 & & \\
\hline BMP-4 & 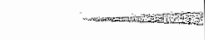 & Hrar & & $y=$ \\
\hline OPN & & - & 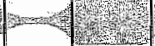 & Pasises \\
\hline ION & & 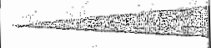 & & \\
\hline
\end{tabular}

Figure 2.7. Immunoreactivity pattern of bone matrix proteins in human non-diseased aorta, intimal xanthoma, fibrous cap atheroma and fibrocalcific plaques.

The figure represents the immuno-histochemical pattern of the bone matrix regulatory proteins MGP, OC, BSP, SMP-2, BMP-4, OPN, and ON in human atheragenesis. Fibracalcific plaques were divided into cartilage tissue, calcium deposits and bone tissue, structures that were present in these lesions. MGP. OC and BSP were present in early as well as advanced lesions, while BMP-2, BMAP-4, OPN and ON were only present in advanced plaques.

as an early marker of bone turnover" ${ }^{25}$, and is increased in women with aortic atherosclerosis ${ }^{26}$. OC-deficient mice exhibit an increased bone formation ${ }^{23}$, but have normal blood vessels. MGP and OC protein are present in calcium deposits in advanced human lesions ${ }^{27}$, which corroborates our results.

BSP is a secreted glycoprotein and contains an Arg-Gly-Asp (RGD) sequence. It is expressed in highly proliferating marrow stromal cells and cementoblasts, and might be implicated in the preferential seeding and growth of metastatic cells in bone. Elevated serum BSP is found in patients with ankylosis spondylitis? However, the proposed function of BSP as a regulator of bone mineralization has not yet been confirmed in vivo $^{30}$. The potential of BSP to nucleate hydroxyapatite ${ }^{31}$, suggests that this protein may act as an activator of calcification. However, in the present study continuous immunoreactivity of BSP in all stages of human atherosclerosis was observed, and this may suggest that BSP is also inwolved in the inhibition of arterial calcification.

\section{Activators of calcification (bone morphogenetic protein 2 and 4 (BMP-2, BMP-4), osteopontin (OPN), and osteonectin (ON))}

Two members of the transforming growth factor $\beta$ (TGFB) superfamily, BMP-2 and 
BMP-4, are secreted signalling molecules present in bone tissue. Individual BMPS are prominent at many sites during embryonic development and organogenesis. BMP-2 can induce ectopic bone and cartilage formation in adult vertebrates ${ }^{32}$. Administration of recombinant BMP-2 in animals results in ar enhancement of fracture repair" "and BMP-2 is currently being evaluated in clinical studies.

BMP-4 plays an important role in the onset of human endochondral bone formation. and a reduction in BMP-4 expression is associated with a variety of bone diseases. Expression of BMP-4 can be stimulated by anti-estrogens, but not by estrogens or other steroid hormones ${ }^{34}$. BMP-4 is expressed in human fetal osteoblast cells, and its mRNA level is increased during differentiation of ameloblasts and odontoblasts into teeth ${ }^{35}$. Although BMP-2 mRNA expression was reported to be present in vascular SMCs of advanced human atherosclerotic plaques ${ }^{36}$, we are the first to show where BMP-2 and BMP-4 proteins are localized during atherogenesis.

OPN is an acidic phosphorylated glycoprotein that binds callium and contains a RGD motif for interaction with the integrin family of cell adhesion molecules. It cam act as both a cytokine and an ECM protein ${ }^{37}$. It is expressed by chondrocytes, and found in several tissues such as brain and heart; calcified and non-calcified arterial lesions ${ }^{38}$, and in mitral valves ${ }^{39}$. In OPN mutant mice, embryogenesis occurred normally, and mice were fertile ${ }^{\text {th }}$. The mutant mice however had disorganization of matrix and alteration of collagen fibrillogenesis. This phenomenon could also be active in atherosclerosis, although no vascular phenotype was reported in these mice.

ON, a bone glycoprotein also known as SPARC (secreted protein, acidic and rich in cystein) binds tightly to hydroxyapatite and collagen. ON is a protein widely expressed in different tissues such as teeth and psammoma bodies". It is involved in cell matrix interaction, wound repair, angiogenesis, vascular permeability, cataract formation ${ }^{42}$ and carcinogenesis. ON-deficient mice have decreased bone formation and decreased osteoblast and osteoclast surface and number, which leads to a decrease in bone formation and remodeling, with a negative bone balamce that causes profound osteopenia ${ }^{43}$ and severe cataract formation. There are no data available regarding the wasculature of these mice. Immunoreactivity of OPN and $O N$ in advanced human atherosclerotic plaques was described previously" and the localization of these proteins agrees with our results. Thus, also OPN and ON may act as positive regulators of wascular calcification.

\section{Modulators of osteoclastogenesis (osteoprogerin (OPG) and receptor activator of nuclear factor- $k B$ ligand (RANKL))}

OPG, a naturally occurring protein related to the tumor necrosis factor (TNF) receptor family, is an inhibitor of osteoclast formation ${ }^{44}$. OPG is present in bone marrow stromal cells, osteoblast-like cells and osteosarcoma cells, in odontoblasts, ameloblasts and 
pulp cells in teeth, in (pre-)osteoblasts, and lining cells in bone, in endothelial cells and occasionally in osteocytes. OPG-deficient mice exhibit a decrease in total bone density with a high incidence of bone fractures ${ }^{i s}$. These mice also exhibit medial calcification of the aorta and renal arteries ${ }^{2 a}$. This corroborates with the results of a recently published study, that showed that progression of atheroscierotic calcification is associated with increased bone loss in women during menopause ${ }^{66}$. Recently, the results of the first clinical trial with OPG supported its potential as a therapeutic agent for osteoporosis. These results also suggest that OPG might play a role in the association between osteoporosis and vascular calcification. OPG also blocks pain related behaviour in mice with bone cancer and it may provide an effective treatment against pain in human bone cancer ${ }^{A \tau}$. The presence of OPG in the borders of bone structures harmonizes with its function as an inhibitor of bone resorption, most likely by inhibition of osteoclastogenesis. No immunoreactivity with $O P G$ could be demonstrated in or around calcified areas of the vessel wall, which might coincide with the arterial calcification in OPG-deficient mice.

RANKL., also known as OPGL, is a membrane-bound ligand expressed by bone marrow stromal cells and is a stimulator of osteoclastogenesis. in bone, osteoblasts/stromal cells regulate osteoclast formation by the production of cytokines like OPG and RANKL. Estrogens suppress RANKL induced osteoclast differentiation, whereas prostaglandin E2 induces expression of RANKL ${ }^{45}$. RANKL binds to RANK, a transmembrane receptor on hemopoietic osteoclast precursor cells. RANKL is also present in bone marrow stromal cells, osteosarcoma cells, odontoblasts, ameloblasts, pulp cells, in tumors associated with bone lysis and in patients with rheumatoid arthritis ${ }^{49}$. Mice with a disrupted RANKL gene show severe osteopetrosis and defects in early differentiation of $T$ and $B$ lymphocytes ${ }^{50}$. There are no data available regarding the vasculature of these mice. In the present study, RANKL was only present in the ECM surrounding the calcium mineral deposits of the plaques. This suggests that RANKL. is involved in the regulation of early mineralisation in atherosclerotic lesions.

In contrast to Schinke and Karsenty, who postulated that wascular calcification is a passive process that requires active inhibition ${ }^{24}$, the major conclusion derived from our data is that atherosclerotic calcification is an active process regulated by inhibitors and activators of calcification and bone formation. According to our data, inhibitor proteins continuously prevent calcification, whereas the restricted presence of activators provides an imbalance, finally resulting in atherosclerotic calcification. Whether bone structure formation in the arterial wall is also mediated by changes in osteoclast formation, remains to be elucidated. 


\section{Acknowledgements}

This study was financially supported by the Netherlands Heart Foundation (NHS97.113). We are grateful to Dr. LW Fisher (Bone Research Branch, National Institute of Dental Research, National Institute of Health, Bethesda, Maryland, USA) for generous gifts of antibodies. The authors thank Petra LW Aarts for expert technical assistance. 


\section{References}

1. Demer L, Watson KE, Bostrom K. Mechanism of calcification in atherosclerosis. Trends in Cardiovasc Med. 1994,4:45-49.

2. Wexter L, Brundage $B$, Crouse J, et al. Coronary artery calcification: pathophysiology. epidemiology, imaging methods, and dinical implications. Circulation. 1996;94:1175-1192.

3. Wilson PWF, Kauppita LL, ODonnell CJ, et al. Abdorninal aortic calcific deposits are an important predictor of vascular morbidity and mortality. Cinculation. 2001:103:1529-1534.

4. Janzen 1, Vuong PN. Arterial calcifications: morphological aspects and their pathologic implications. Z Kardiol 2001:90 Suppl 3:1ll6-11111.

5. Huang $H$, Virmani $R$. Younins $H$, et al. The impact of calcification on the biomechanical stability of atherosclerotic plaques. Circulation. 2001;103:1051-1056.

6. Gromholdt ML. Wagner A, Wiebe BM, et al. Spiral computed tomographic imaging related to computerized ultrasonographic images of carotid plaque morphology and histology. 1 Utrasound Med. 2001:20:451-458.

7. Doherty TM, Detrano RC. Coronary arterial calcification as an active process: a new perspective on an old problem. Caicif Tissue Int 1994;54:224-230.

8. Bostrom K, Watson KE, Stanford WP, et al. Atherosclerotic calcification: relation to developmental osteogenesis. Am J Cardiol. 1995;75:88B-91B.

9. Deneke $Y$, Langner $K$, Grewe $\mathrm{PH}_{\text {, et }}$ al. Ossification in atherosclerotic arteries. $Z$ Kardiol. 2001;90 Suppl 3:11/106-111/115.

10. Shioi A, Mori K, Jono S, et al. Mechanism of atherosclerotic calcification. Z Kardiol. 2000;89:11 75-79.

11. Bostrom $K_{x}$ Demer $L$. Regulatory mechanisms in vascular calcification. Crit Rev Eukaryot Gene Expr. 2000; 10:151-158.

12. Boyce $B F$, Hughes $D E$. Wright $K R_{r}$ et al. Recent adwances in bone biology provide insight into the pathogemesis of bone diseases. Lab invest. 1999:79:83-94.

13. Virmani $R$, Kolodgie $F D$, Burke $A$, et al. Lessors from sudden cononary death. A comprehensive morphological classification scheme for atherosclerotic lesions. Arterioscler Thromb Vasc Biol. 2000;20:1262-1275.

14. Braam L, Dissel P: Gijsbers $B_{x}$ et al. Assay for human matrix gla protein in serum. Potential application in the cardiovascular field. Arterioseter Thromb Vasc Biol. 2000;20:1257-1261.

15. Fisher LW, Stubbs JT $3 \mathrm{rd}$, Young MF. Antisera and CDNA probes to human and certain animal model bone matrix noncallagenous proteins. Acta Orthop Scand Suppl. 1995;266:61-65.

16. Breton-Gorius $J_{i}$ Clezardin $P$, Guichard J, et al. Lacalization of platelet osteonectin at the internal face of the alpha-granule membranes in platelets and megakaryocytes. Blood. 1992;79 No.4:936-941.

17. De Block M, Debrouwer D. RNA-RNA in situ hybridization using digoxigenin-labeled probes: the use of high-molecular-weight polyvinyl alcohol in the alkaline phosphatase indoxyl-nitroblue tetrazolium reaction. Anal Biochem. 1993:215:86-89. 
18. Shanahan $C M$, Proudfoot $\mathrm{D}$, Tyson $\mathrm{KL}$, et al. Expression of mineralisation-regulating proteins in association with human vascular calcification. Z Kardiol. 2000;89:11 63-68.

19. Bostrom K. Cell differentiation in vascular calcification. $Z$ Kardiol. 2000;89:11 69-74.

20. Severson ER, Ingram RT, Fitzpatrick LA. Matrix proteins associated with bone calcification are present in human vascular smooth muscle cells grown in vitro. In Vitro Cellular Developmental Biology-Animal. 1995;31:853-857.

21. Tintut $Y$, Patel 1 , Parhami $F$, et al. Tumor necrosis factor-a promotes in vitro calcification of vascular cells via the CAMP pathway. Circulation. 2000;102:2636-2642.

22. Luo $G$, Ducy $P$, Mckee MD, et al. Spontaneous calcification of arteries and cartilage in mice lacking matrix Gla protein. Nature. 1997;386:78-81.

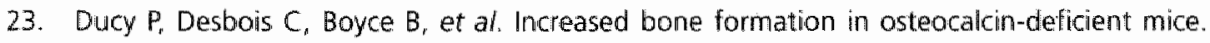
Nature. 1996;382:448-452.

24. Schinke T, Karsenty G. Vascular calcification-a passive process in need of inhibitars. Nephrol Dial Transplant. 2000; 15:1272-1274.

25. Lane NE, Sanchez $S$, Genant HK, et al. Short-term increases in bone turnover markers predict parathyroid hormone-induced spinal bone mineral density gains in postmenopausal women with glucocorticoid-induced osteoporosis. Osteoporos int. 2000;11:434-442.

26. Jie $\mathrm{KS}$, Biots $\mathrm{ML}$, Vermeer $\mathrm{C}$, et al. Vitamin $\mathrm{K}$ intake and osteocalcin levels in women with and without aortic atherosclerosis: a population-based study. Atherosclerosis. 1995;116:117-123.

27. Bini A, Mann KG, Kudryk BI, et al. Noncollagenous bone matrix proteins, calcification, and thrombosis in carotid artery atherosclerosis. Arterioscler Thromb Vasc Biol. 1999;19:1852-1861.

28. Satomura $K$, Krebsbarch $P$, Bianco $P$, et al. Osteogenic imprinting upstream of marrow stromal cell differentiation. $J$ Cell Biochem. 2000;78:391-403.

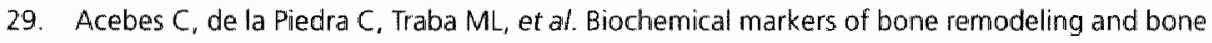
sialoprotein in ankylosing spondylitis. Clin Chim Acta. 1999:289:99-110.

30. Schinke T, Mckee MD, Karsenty $G$. Extracellular matix calcification: where is the action? Nat Genet. 1999:21:150-151.

31. Ganss B, Kim RH, Sodek 1. Bone sialoprotein. Crit Rev Oral Biol Med. 1999:10:79-98.

32. Musgrawe DS, Bosch $P_{r}$ Ghivizzani $S_{r}$ et ax. Adenowrus-mediated direct gene therapy with bone morphogenetic protein-2 produces bone. Bone 1999:24:541-547.

33. Yudell RM, Block MS. Bone gap healing in the dog using recombinant humath bone morphogenetic protein-2. I Oral Maxillafac Surg. 2000;58:761-766.

34. van den Wingaard A, Mulder WR, Dijkema $R$, et al. Antiestrogens specifically up-regulate bone morphogenetic protein-4 promoter activity in human osteoblasic cells. Mol Endocrinol. $2000 ; 14: 623-633$.

35. Sarkar L, Sharpe PT. Inhibition of Wht signaling by exogenous. Mfrzb1 protein affects molar tooth size. J Dent Res. 2000;79:920-925.

36. Shanahan CM, Cary NR, Metcalfe JC, et al. High expression of genes for calcification-regulating proteins in human atherasclerotic plaques. I Clin invest. 1994,93:2393-2402. 
37. Barry ST, Ludbrook 5B, Murrison E, et al. Analysis of the alpha4betal integrin-osteopontin interaction. Exp Cell Res. 2000;258:342-351.

38. Farrington C. Roberts 15, Heagerty AM, et al. The expression of cartilage oligomeric matrix protein, thrombospondin-1, bone sialoprotein and osteopontin in calcified and non-calcified arterial lesions. Biochem Soc Trans. 1998;26:53.

39. Canver CC, Gregory RD, Cooler SD, et al. Association of osteopontin with calcification in human mitral valves. / Cardiovasc Surg. 2000;41:171-174.

40. Liaw $\mathrm{L}$, Birk DE, Ballas $C B$, et at. Altered wound healing in mice lacking a functional osteopontin gene (spp 1). J Chin Rivest. 1998;101:1468-1478.

41. Maki M, Hirota S, Morohoshi T. Expression of osteopontin messenger RNA by macrophages in owarian serous papillary cystadenocarcinoma: A possible association with calcification of psammoma bodies. Pathol Int. 2000;50:531-535.

42. Kantorow $M$, Huang $Q$, Yang $X J$, et al. Increased expression of asteonectin/SPARC mFNA and protein in age-related human cataracts and spatial expression on the normal human lens. Mol Vis. 2000;6:24-29.

43. Delany $A M$, Amling $M$, Priemel $M$, et al. Osteopenia and decreased bone formation in osteonectin-deficient mice. J Clin Irvest. 2000; 105:915-923.

44. O'Brien EA, Williams $\mathrm{H}$, Marshail MJ. Osteoprotegerin ligand regulates osteoclast adherence to the bone surface in mouse calvaria. Biochem Biophys Res Commun. 2000;274:281-290

45. Bucay $N$, Sarosi I, Dunstan CR, et al. Osteoprotegerin-deficient mice develop early onset osteoporosis and arterial caicification. Genes Dew. 1998;12:1260-1268.

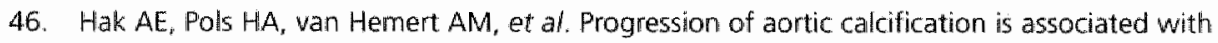
metacarpal bone loss during menopause : A population-based longitudinal study. Arterioscler Thromb Vasc Biol. 2000;20:1926-1931.

47. "Homore?" Luger NM, Sabino MAC, et al. Osteoprotegerin blocks bone cancer-induced skeletal destruction, skeltal pain and pain-related neurochemical reorganizationof the spinal cord. Nat Med: 2000;6:521-528.

48. Kanematsu M, Sato T. Takai H, et al. Prostaglandin E2 induces expression of receptor activator of nuclear factor-kappa $B$ ligand/osteoprotegrin ligand on pre $B$ cells: implications for accelerated osteoclastogenesis in trogen deficiency. J Bone Miner Res. 2000;15:1321-1329.

49. Romas E, Bakharevski O, Hards DK, et al. Expression of osteoclast differentiation factor at sites of bone erosion in collagen-induced arthritis. Arthritis Rheum. 2000;43:821-826.

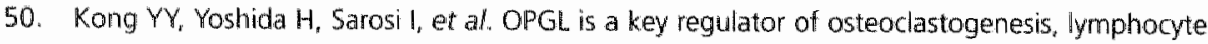
development and lymph-node organogenesis. Nature. 1999:397:315-323. 




\section{Chapter 3}

Increased expression of bone matrix regulatory proteins in leaflers of patients with a onic valve stenosis

Cherida R Dhore, Sylvia Heeneman, Jack PM Cleutjens, Robert Jan van Suylen, Cees Vermeer, Jos G Maessen and Mat JAP Daemen

Submitted 


\section{Abstract}

Increasing evidence suggests that valvular calcification is a regulated process with simlarities to developing bone. We therefore hypothesized that expression of bone matrx regulatory proteins is enhanced during calcification of aortic valves.

We performed a series of immunohistochemical stainings using antibodies directed to matrix Gla protein (MGP), osteocalcin (OC), bone sialoprotein (BSP), bone morphogenetic protein 2 (BMP-2), bone morphogenetic protein 4 (BMP-4), osteopontin (OPN), osteonectin (ON), osteoprotegerin (OPG) and receptor activator of nuclear factor-KB ligand (RANKL). Cells producing mRNAS of these bone matrix proteins were identified by non-radioactive in situ hybridization.

MGP, OC, BSP, BMP-2 and BMP-4 were present in both normal and calcified aortic valves, while the immunoreactivity of OPN and ON was restricted to valves containing calcifications or bane formation. Modulators of osteoclastogenesis (OPG and RANKL) were present in fibroblasts, smooth muscle and endathelial cells of both non-calcified and calcified aortic valves. In calcified valves OPG protein was present in chondrocytes, osteoblasts and osteocytes, while RANKL was matrix associated and highly expressed in osteoclasts and some macrophages.

Proteins involved in bone metabolism, calcification and ossification are also present in human calcified aortic valves, suggesting an active and tight molecular regulation of valvular calcification. 
Recent evidence indicates that aortic valve calcification is a well-regulated process, that involves inflammation and lipid accumulation similar to those seen in human atherosclerosis ${ }^{1-3}$. Vascular calcification is considered to be a risk factor for valvular calcification" and recently published data indicate that aortic valve calcification is indeed associated with increased risk of cardiovascular events including stroke and cardiac death ${ }^{4}$. Moreover, valvular and vascular calcifications are both considered to share similarities with skeletal bone formation.

Matrix Gla protein (MGP), osteocalcin (OC), bone sialoprotein (BSP), bone morphogenetic proteins 2 and 4 (BMP-2, BMP-4), osteopontin (OPN) and osteonectin (ON) all are involved in the regulation of skeletal bone formation. Osteoprotegerin (OPG) and its ligand (RANKL), which are involved in osteoclastogenesis, are associated with the regulation of skeletal bone remodeling. The observation that osteopontin is present in human aortic valves $^{6}$ and our recently obtained evidence that calcification in human atherosclerosis involves severall bone matrix regulatory proteins?, lead to the hypothesis that these bone matrix regulatory proteins are also expressed during valvular calcification. To further substantiate this hypothesis, we made an inventory of the mRNA and protein expression of bone matrix regulatory proteins in (non-)calcified human aortic valve leaflets.

Here we showed that all 9 bone regulatory proteins are present in human aortic valve leaflets. MGP, OC, BSP, OPG and RANKL are present in both non-calcified and calcified valves, whereas the protein expression of $O P N$ and $O N$ are restricted to calcified valves.

BMP-2 and -4 are present in endothelial cells of non-calcified valves and their enhanced expression is associated with mineralized structures in calcified valves. We conclude that human aortic valve calcification is an active process that is regulated by several molecular regulators of bone and vascular walli calcification and modeling.

\section{Methods}

\section{Patients' characteristics and tissue preparation}

Leaflets of tricuspid aortic valves were obtained from patients undergoing surgical aortic valve replacement $(n=9)$ or from autopsy $(n=3)$. Autopsy specimens were obtained from two adult men and one woman, aged 51,81 and 61 years respectively. The cause of death was cancer (2x) or rupture of an abdominal aortic aneurysm. Surgical specimens were obtained from five adult males and four adult women with an average age of 55 years (range $27-79$ ).

Aortic valve leafiet morphology was evaluated on hematoxylin and eosin (H\&E) and Elastica von Giesson (EVG) stained sections. Von Kossa, tartrate resistant acid phosphotase (TRAP) and Thionin staining were used to visualize the presence of calcification, osteoclasts and cartilage respectively. For the identification of osteoclasts, 
Cartilage and hemopoietic cells we used antibodies against cathepsin $K_{\text {, type li collagen }}$ and CD138 respectively (see immunopheno-typing).

The specimens were divided into two groups:

- Non-calcified aortic valves ( $n=6$, including 3 autopsy specimens)

- Calcified aortic vaives ( $n=6$, all surgical specimens)

\section{Immunohistochemical staining}

Paraffin sections ( $4 \mu \mathrm{m}$ ) were stained with mouse monoclonal antibodies against MGP (1:25)', or BMP-2 (1:20, Genetics Institute, Inc., Cambridge, MA, USA), goat polyclonal antibodies against BMP-4 (1:25 5anta Cruz Biotechnology, Inc., Santa Cruz, CA, USA)', OPN (1:500 LF123; gift from Dr L. Fisher), OPG (1:100 Santa Cruz Biotechnology, Inc.)', or RANKL 1:75 Santa Cruz Biotechnology, inc.)? or rabbit polyclonal antibodies against $O C$ (1:50, Anawa Trading SA, Wangen, Zürich, Switzerland)? ON (1:400 Zymed Laboratories, Inc., San Francisco, CA, USA)? or BSP $(1: 25)^{\text {. }}$. Bictinylated sheep anti mouse $\operatorname{lgG}(1: 250$. Amersham, Life Science, Little Chalfont, Buckinghamshire, UK), rabbit anti goat IgG (1:200, Dako, Glostrup. Denmark $)$ or sheep anti rabbit IgG (1:1000, Dako) were used as the secondary antibodies. After incubation with an alkaline phosphatase coupled avidin-biotin complex ( $A B C$ complex, Dako), antibodies were visualised with an alkaline substrate kit I (Vector SK-5100, Vector Laboratories, Inc., Burlingame, CA, USA), counterstained with hematoxylin and mounted. Negative controls lacked incubation with the primary antibody (fig. 3.1). Calcified atherosclerotic plaques were used as positive control for respectively MGP, BSP, BMP-2, BMP-4, ON, OPN, OPG and RANKL. Pre-treatment of calcified control sections with $3 \%$ citric acid did not affect the staining, indicating the lack of a-specific binding of the antibodies to calcium deposits" (fig. 3,2).

\section{Immunophenotyping}

Serial sections were stained with antibodies directed to CD68 (Dako, mouse monoclonal antibody) to identify macrophages, $\alpha$-smooth muscle actin (ASMA, Dako, mouse monoclonal antibody) to identify vascular smooth muscle cells, desmin (ICN, mouse monoclonal antibody) to distinguish smooth muscle cells from myofibroblasts? cytokeratin 8 (Neomarkers, mouse monoclonal antibody) to distinguish synthetic from contractile smooth muscle cells", CD3 to identify T-lymphocytes (Daka, rabbit polyclonal antibody), cathepsin K (Oncogene, monocional antibody) for osteoclast identification (fig. 3.3d), type II collagen for cartilage identification (fig. 3.3b), CD138 for hemopoietic cell identification (fig. 3.3f), or OC for osteoblast identification (fig. 3.3 ). Positive controls for CD68, ASMA, desmin, cytokeratin 8, CD3, and cathepsin K were respectively colon, aorta, heart, breast carcinoma, tonsil, and bone. 

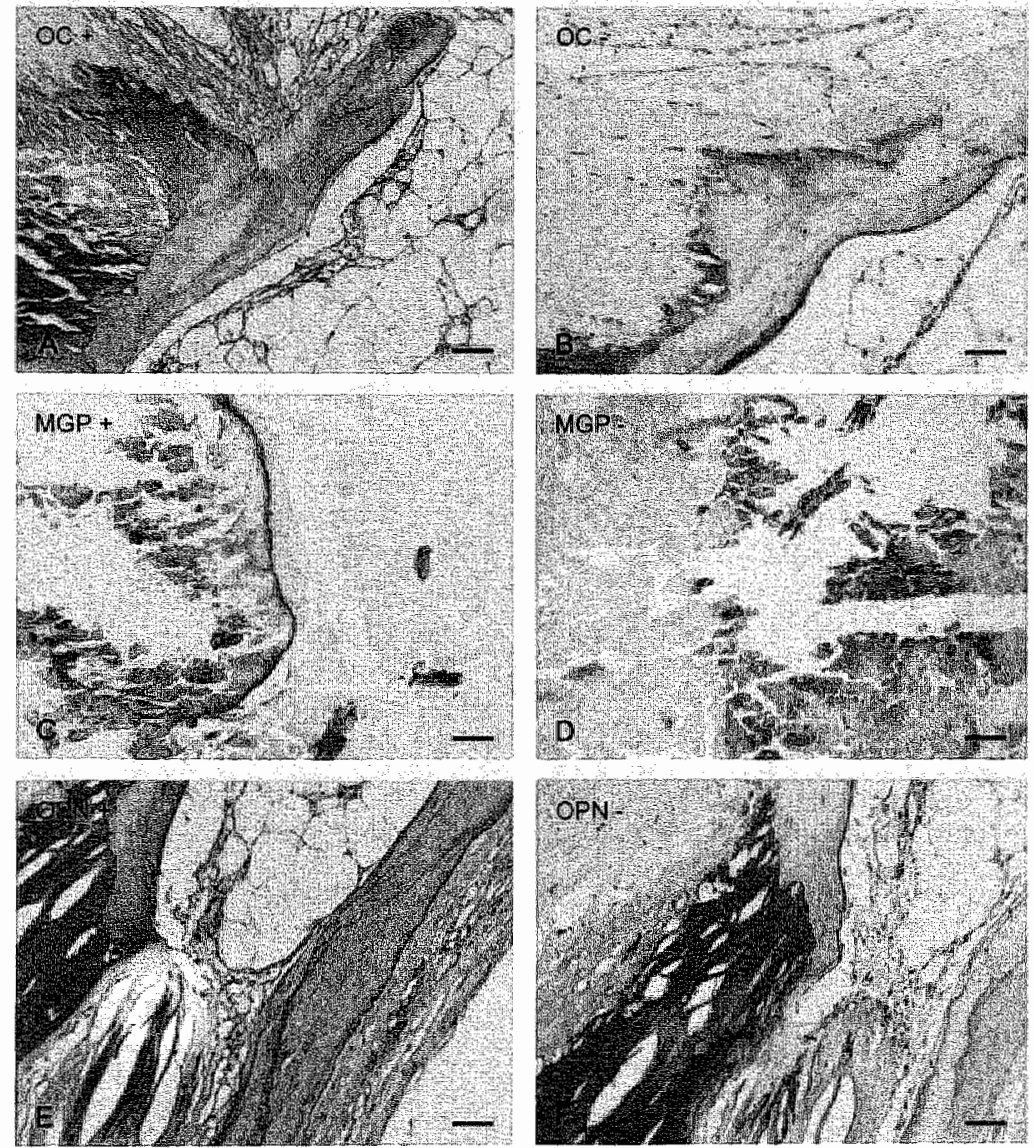

Fig. 3.1. Immunohistochemical staining of bone matrix regulatory proteins on calcified valves.

Immunohistachemistry of osteocalcin (A), matrix Glo protein (C) and osteopontin (E) and their negative controls $(B, D$ and $F)$ on human calcified artic valves. Scale bars represent 50 um. Full color figures see page 148. 


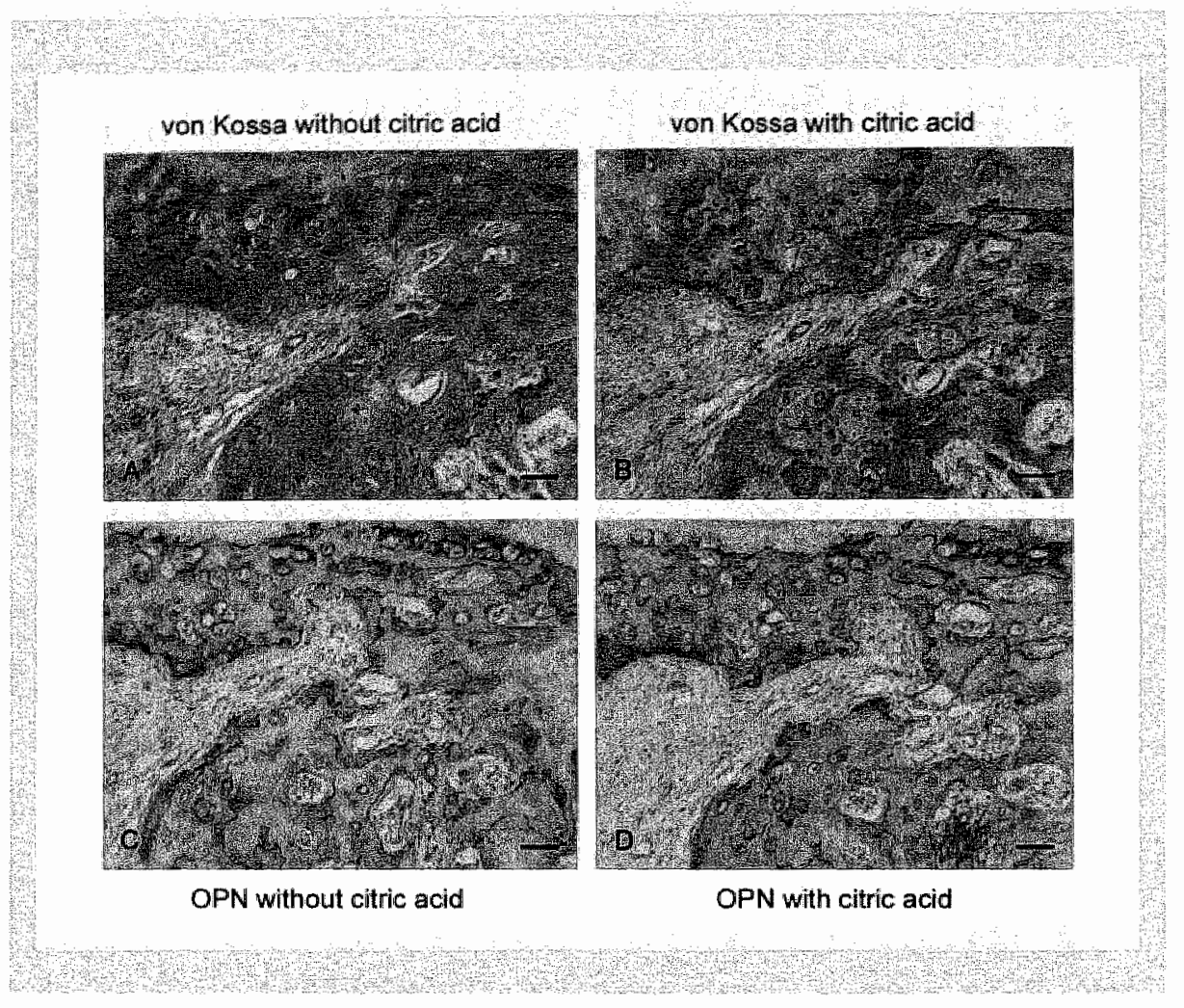

Fig. 3.2. Von Kassa staining and immunohistochemical staining of osteopontin on serial sections of at calcified aortic walve. Serial sections of a human calcified aortic vave stained with von kosia (A and $B$ ) and osteopontin ( $C$ and $D$ ) without ( $A$ and $C$ and with ( $B$ and $D$ ) citric acid pretreatment. Scale bars represent 50 um. Full color figures see page 149

For double immunohistochemistry OC, MGP, BMP-2, BMP-4, OPN, ON or BSP stained sections were incubated for 30 minutes with ASMA (1:500) or pre-treated with $0.1 \%$ pepsin (Boehringer Mannheim GmbH, Mannheim, Germany) and subsequently incubated for 30 mir, with CD3 or CD68, diluted 1:200 and 1:500 respectively. Biotin-labeled sheep anti rabbit $\lg G(1: 1000)$ or sheep anti mouse $\lg G(1: 250)$ were used as secondary antibodies. The avidir-biotin alkaline phosphatase $(1: 200)$ complex in combination with fast blue substrate $10.2 \%$ w/v fast blue-BB-salt, (5igma Chemical CO, St. Lovis, MO, USA) was used as chromogen. No counterstaining was performed.

\section{Counting and statistics}

Each single stained valve (ASMA, CD68, CD3, desmin or cytokeratin 8) was randomly divided into eight fields of $0.08 \mathrm{~cm}^{2}$, which comprise approximately $75 \%$ of total valve 

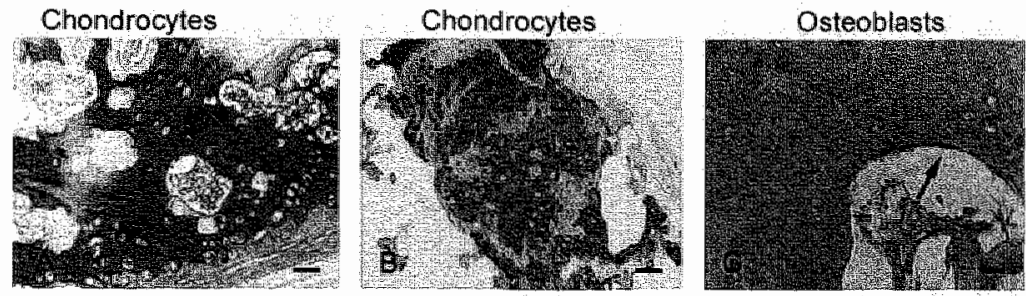

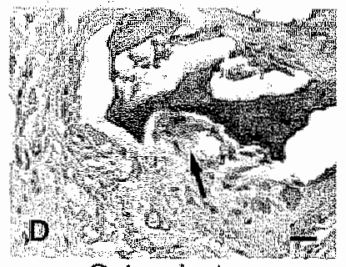

Osteoclast

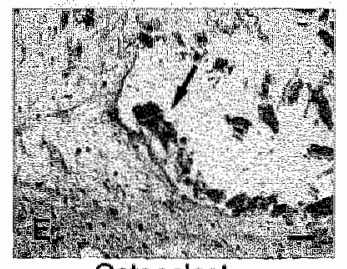

Osteoclast

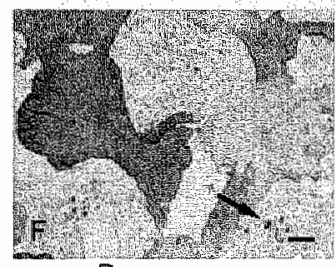

Bone marrow

Fig. 3.3 Identification of chondrocytes, osteoclasts, osteoblasts and hemopoietic cells in human calcified aortic valves by respectively thoonin staining (A), type II collagen (B), osteocalcin staining ( $\mathrm{C}$, cathepsin $K$ staining (D). TRAP staining (E) and CD138 staining (F). Scake bar in A represent $50 \mu \mathrm{m}$ and in $B, C, D, E$ and F $25 \mu \mathrm{m}$. Full color figures see page 150.
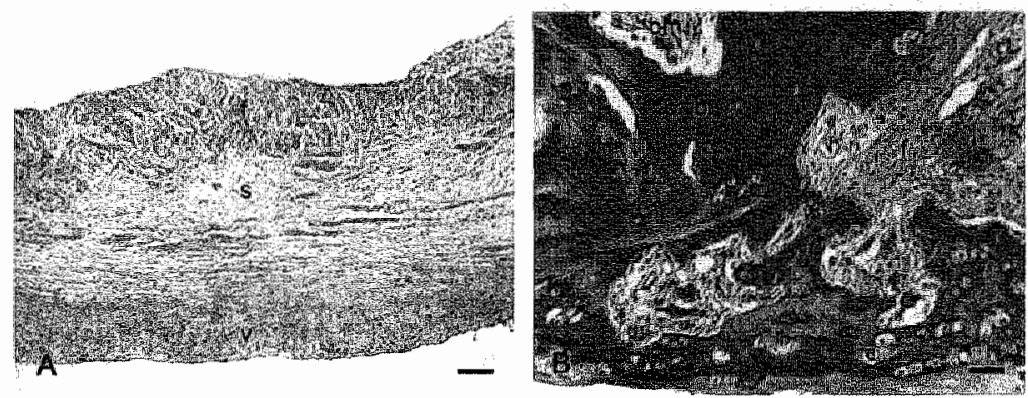

Fig. 3.4: Histological and morphological characteristics of the human aortic valve.

Fig. 3.4a: H\&E staining of a non-calcified aortic walve. The three lavers of the value are the fibrosa (I). spongiosa $(\mathrm{s})$ and wentricularis $(\mathrm{w})$. Panel b represent a valve containing calcified tissce Hike siained.

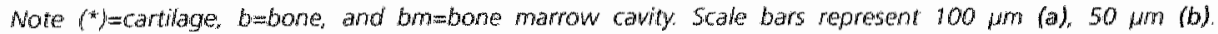
Full color figures see page 150 . 
area. All cells (positively stained and total amount) in each field were counted by one investigator (CD). The intra observer variety was $<10 \%$. Statistical analysis was performed using the Mann-Whitney $U$ test. Data are presented as means \pm SEM and values of $p<0.05$ were considered to be statistically significant.

\section{In situ hybridisation}

Sense and anti-sense digoxygenin (DIG) labeled RNA probes for MGP, BMP-2, BMP-4, and $O N$ mRNAs were transcribed from the $T 7$ promoter of pGEM3Z, following a protocol described earlier?. Parallel sections were hybridised with anti-sense and sense RNA probes. In the negative controls no probe was added to the hybridisation mixture.

\section{Protein extraction and immunoblotting}

Protein extracts were prepared from 3 non-calcified and 3 calcified aortic vales by homogenizing the leaflets in $8 \mathrm{M}$ urea. $20 \mu \mathrm{g}$ protein of each sample was separated by polyacrylamide gel electrophoresis followed by transfer to a nitrocellulose membrane (Protran, Schleicher \& Schuell). The membrane was blocked with 3\% bovine serum albumin (BSA) and then incubated with rabbit anti-OPN antibody 1:1000 (LF123; gift from $\mathrm{Dr} L$. Fisher) for 1 hour in blocking buffer. After three washes, the membrane was incubated with horseradish peroxidase-conjugated anti-rabbit lgG antibody (Cell Signaling) diluted 1:2000 for 1 hour in blocking buffer. OPN was visualized using $\mathrm{ECL}$ Western Blotting Detection Reagents (Amersham Pharmacia Biotech).

\section{Results}

\section{Aortic valve morphology}

Calcified structures were found in the fibrosa, a distinct layer of dense collagenous fibrous tissue subjacent to the endothelium of the aortic surface (fig. 3.4a). Calcified aortic valves may contain several different structures associated with bone mineralization. like amorphous calcium phosphate, cartilage and lamellar bone structures (fig. 3.4b).

Non-calcified aortic valve leaflets contain three major cell types, smooth muscle cells, myofibroblasts and fibroblasts. 5mooth muscle cells are essentially localized in the fibrosa, whereas fibroblasts and myofibroblasts are uniquely segregated in the ventricularis, a distinct layer of elastic tissue subjacent to the endothelium of the ventricular surface. Major differences were found in the cellular composition of non-calcified and calcified aortic valves (table 3.1$)$. The ventricularis of non-calcified valves (fig. 3.5a) contained less $\alpha$-smooth muscle actin positive cells than calcified valves (fig. $3.5 d)(13 \pm 5 \%$ and $33 \pm 5 \%$ respectively, $p=0.03)$. The vast majority of the ASMA positive cells in the fibrosa were negative for desmin, and can thus be classified as 
Table 3.1. Quantification of ASMA, $C D 3, C D 68$, and desmin positive cells in non-calcified and calcified aortic wallves:

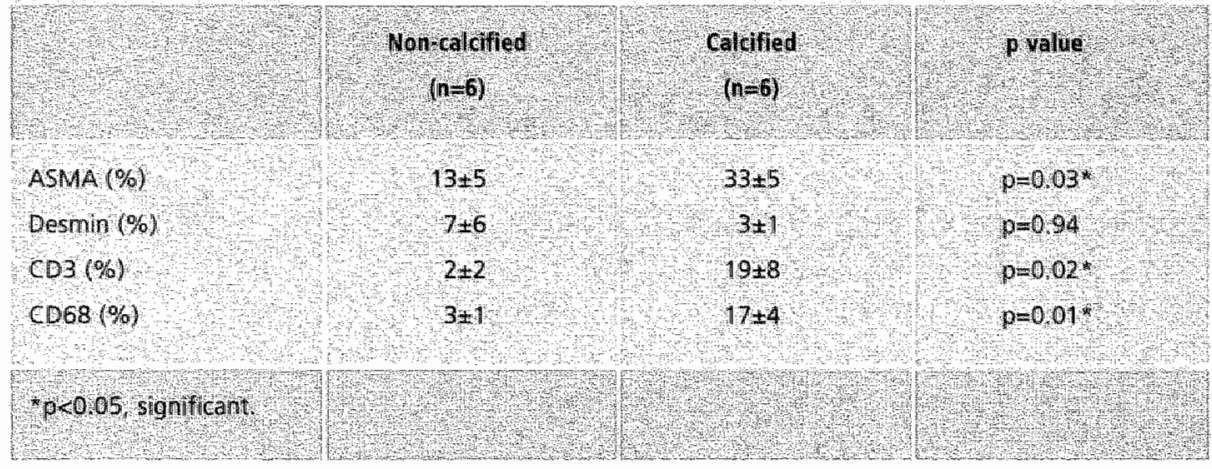

myofibroblasts. In the fibrosa of calcified aortic valves, myofibroblasts were mainly localised around the calcified structures.

There was no difference in percentage of contractile smooth muscle cells (ASMA and desmin positive, cytokeratin 8 negative) between non-calcified valves ( $7 \pm 6 \%)$ and the calcified valves $(3 \pm 1 \%, \mathrm{p}=0.94)$. Macrophages and T-cells were almost absent in non-calcified aortic valves (fig. $3.5 b$ and 3.5c), whereas both cell types were present in the surroundings of calcified structures (macrophages $3 \pm 1 \%$ versus $17 \pm 4 \%, p=0.01$ and T-cells $2 \pm 2 \%$ versus $19 \pm 8 \%, p=0.02$ ) of the aortic valves (fig. $3.5 \mathrm{e}$ and $f$ ).

\section{Non-calcified valves and bone matrix regulatory proteins}

OPN and ON were absent in non-calcified aortic valves, whereas the BMPS showed very low immunoreactivity and were expressed in the fibroblasts and endothelial cells of the ventricularis. Three bone matrix regulatory proteins (MGP OC, and BSP) showed clear immunoreactivity. MGP was present in the ventricularis and associated with elastic fibres (fig. 3.6a), while or was mainly present in the mesenchymall spongiosa, a thin layer of loose mesenchymal tissue between the fibrosa and the ventricularis (fig. 3.4a). BSP was diffusely present in all three layers of the valves, with a high expression in the myofibroblasts (fig. 3.6b) of the fibrosa and in endothelial celis. The modulators of osteoclastogenesis, OPG and RANKL, were also present in non-calcified human aortic valves (fig. $3.6 \mathrm{c}$ and d). Endothelial, smooth muscle cells and some fibroblasts in the ventricularis showed immunoreactivity with OPG, while RANKL was only present in the endothelial cells.

\section{Calcified valves and bone matrix regulatory proteins}

In contrast to non-calcified aortic valves, all bone regulatory proteins showed clear immunoreactivity in calcified aortic valves. MGP (fig. 3.7a) and BSP were observed at 
the boundaries of calcium deposits. OC was present in lamellar bone (fig. 3.7b) and bone-associated cells, such as osteoblasts and bone marrow cells, at the boundaries of amorphous calcium phosphate and in smooth muscle cells (fig. 3.8). immunoreactivity of ON and OPN was prominent in amorphous calcium phosphate depositions, especially at the borders (fig. 3.70) and in lamellae of mature bone. ON showed also immunoreactivity with chondrocyte-like cells, which were positive for ASMA. BMP-2 and BMP-4 showed no prominent expression within amorphous calcium phosphate, while the myofibroblasts surrounding these deposits showed high immunoreactivity. BMP-4 also showed immunoreactivity in the osteoblasts (fig. 3.7d).

As in non-calcified valves, both modulators of osteoclastogenesis, OPG and RANKL were present in calcified human aortic valves, especially in endothelial cells and chondrocyte-like cells, while mature chondrocytes showed only immunoreactivity with OPG (fig. 3.7e). OPG protein was further present in myofibroblasts, osteoblasts, and in the surroundings of osteoclasts. RANKL showed high immunoreactivity with osteoclasts (fig. 3.7f) and with macrophages in the surroundings of amorphous calcium phosphate.

\section{In situ hybridisation vs immunohistochemistry}

Fibroblasts present in the ventricularis of non-calcified aortic valves expressed MGP MRNA, whereas in calcified va'ves, MGP mRNA was mainly present in the surroundings of calcified and ossified regions.

BMP-2 and BMP-4 mRNA were expressed in valves in the endothelial cells (fig. 3.9a) and some myofibroblasts of non-calcified, whereas osteoblasts in calcified valves expressed both BMP-2 and BMP-4 mRNA. Immunoreactivity of BMP-4 in non-calcified valves was low (fig. 3.9b), however clearly present in endothelial cells (fig. 3.9b) and myofibroblasts (fig. 3.9c).

ON mRNA (fig. 3.9d) and protein (fig. 3.9e) were highly expressed in chondrocyte-like cells, which showed immunoreactivity with ASMA (fig. 3.9f).

The mRNA expression pattern of MGP, BMP-2, BMP-4, and ON was comparable to the immunohistochemical localisation of these proteins.

\section{Osteopontin immunoblotting}

Immunoblotting of 3 non-calcified and 3 calcified aortic valve leaflets using polyclonal antibody generated against the amino terminus of human recombinant OPN, revealed three different forms of OPN protein (fig. 3.10). In all non-calcified valves (lane 4-6) two forms were present, the native form ( $30 \mathrm{kDa}$ ) and the glycosyllated form ( $55 \mathrm{kDa}$ ). However, in two out of three calcified vales (lane 1-3) three OPN forms were detected. A $30 \mathrm{kDa}$ band of native OPN, a $55 \mathrm{kDa}$ band of giycosylated OPN and a $69 \mathrm{kDa}$ band of phosphorylated OPN, indicating that the post-translational modifications of OPN are not equal in non-calcified and calcified valves, and that only the calkified valves contain phosphorylated OPN. 


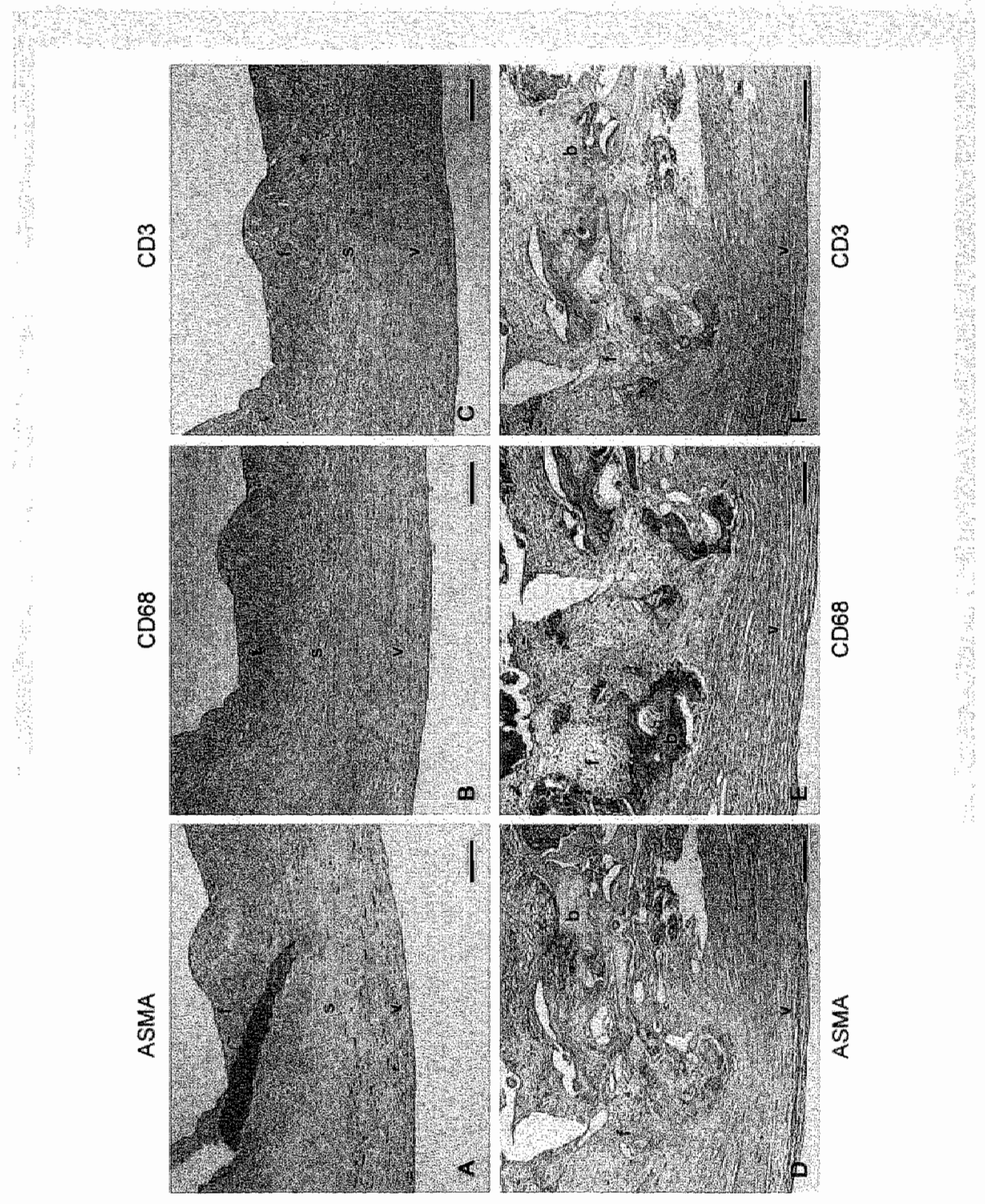

Fig. 3.5. Immunohistochemistry of ASMA, CD68 and CD3 on human aortic vales, A, B, and C: represent

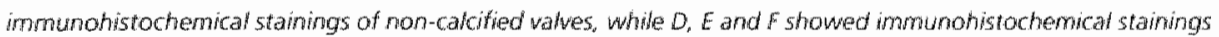

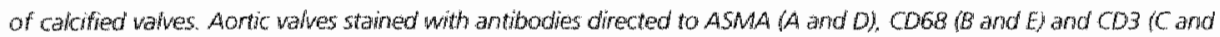
F). Note: in the calcified wabes. ASMA, CD68 and CDS positive cells (red staining) are located in the surroundings

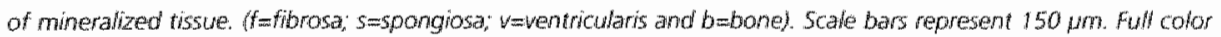
figures see page $15 \%$. 


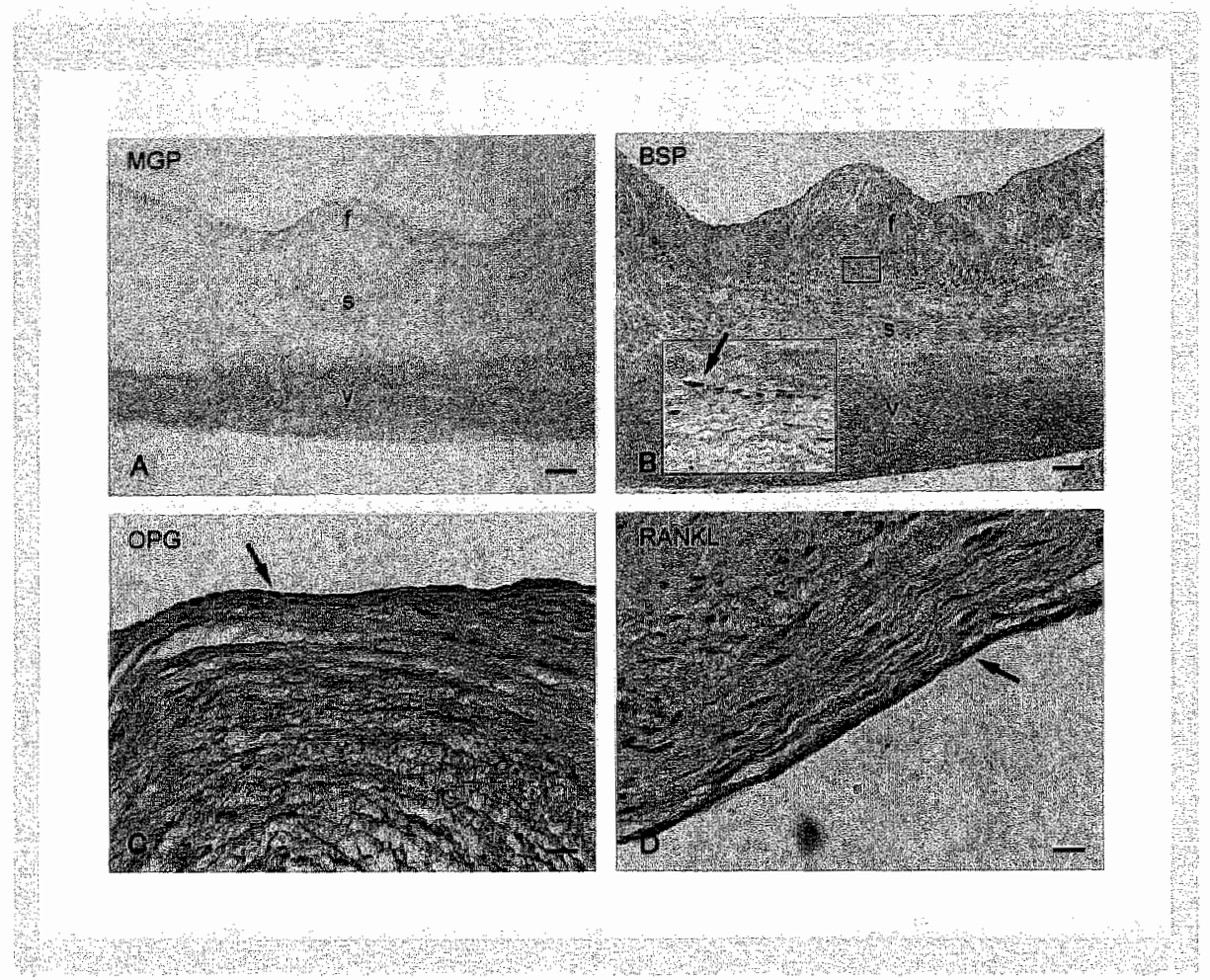

Fig. 3.6. Immunohistochemical staining of bone matrix regulatory proteins on non-calcified valves. $A$ and $B$ : non-calcified valve stained with antibodies directed to MGP (A) and BSP (B). Both proteins are present in these valves (red staining). Note: MGP is present in the ventricular layer of the walve and BSP is clear expressed in the fibroblasts (arrow and inset) in the fibrosa. $C$ and D: non-calcified valve stained with antibodies directed to OPG (C) and RANKL (D). Scale bars represent $100 \mu \mathrm{mm}(A)$ and $25 \mu \mathrm{mm}(B, C$ and $D)$. Full color figures see page 152. 

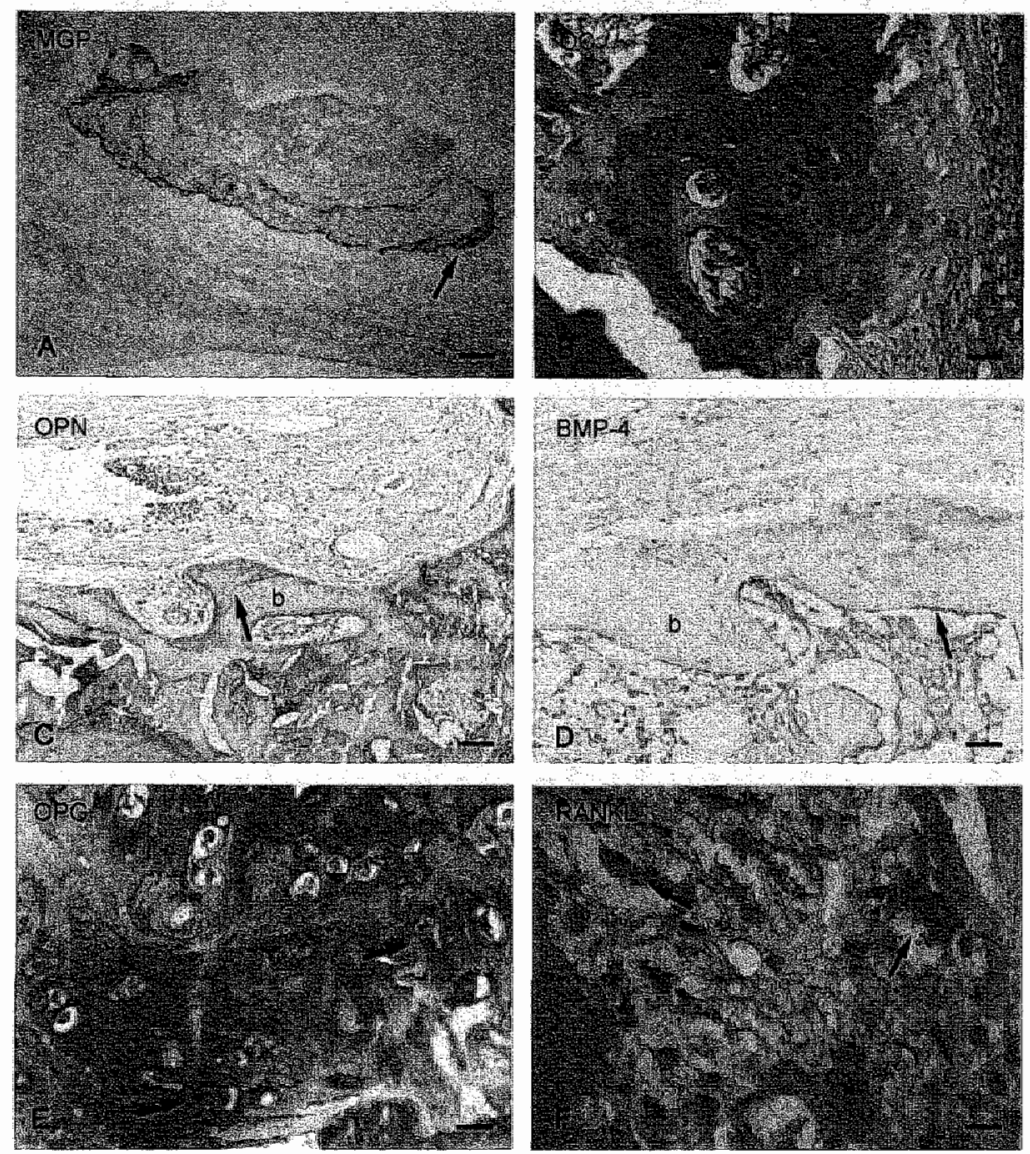

Fig. 3.7. Immunohistochemical' staining of bone matrix regulatory proteins an calcified valves. A and B: MGP. $O C$ and BSP are present in calcified aortic valves. MGP (A) showed expression (arrow) at the borders of amorphous calcium phosphate depasits, while $O C(B)$ is present in bone matrix of farneltar bone. $C$ and $D$ : in calcified walves OPN $(\mathrm{C})$ is locatised in the cement lines farrow), and BMP-4 (D) is present in the osteoblasts lining lamellar bone (arrow). Eand F: OPG (E) showed immunoreactivity in the chondrocytes (arrow) and its ligand RANKL (F) is present in osteoclasts (arrow). Scale bars represent $50 \mathrm{\mu m}$ ( $A$ and $\mathrm{Q}$ and $25 \mathrm{~km}(B, D, E$ and $F$ ). Full color figures $5 \mathrm{ee}$ page 153 


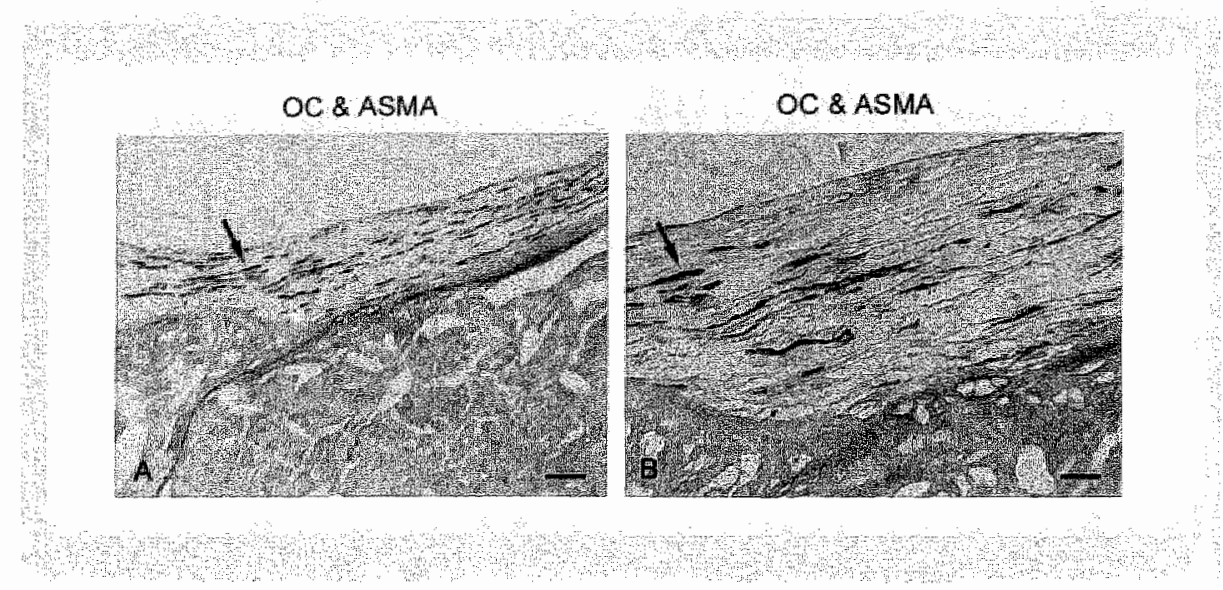

Fig. 3.8. Double immunohistochemica! staining of human calcified aortic valve with osteocalcin and ASMA (A). Note: osteocalcin is also expressed by a subpopulation of 5 mooth muscle cells. Figure $B$ represents a higher magnification. $5 \mathrm{cale}$ bar in $A$ represents $50, \mu \mathrm{m}$ and $B 25 \mu \mathrm{m}$. Full color figures see page 154.

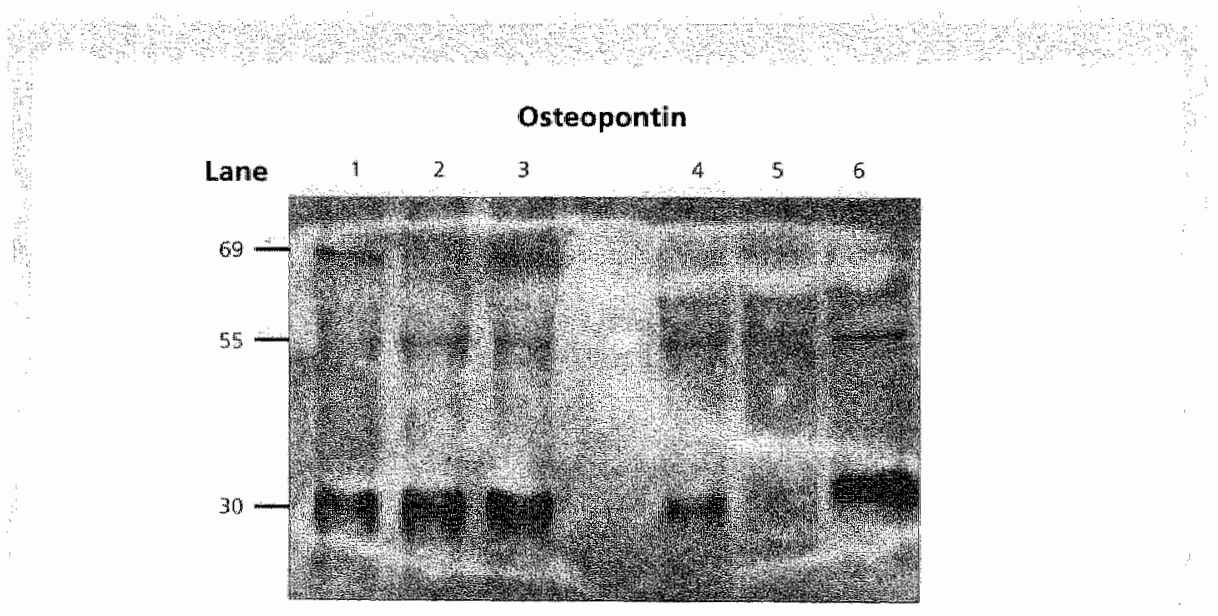

Fig. 3.10. Immumoblotting of osteopontin. Lanes $1-3$ represent $20 \mu \mathrm{g}$ of protein extracted from calcified valves, lanes 4-6 represent $20 \mu \mathrm{g}$ of protein extracted from non-calcified aartic valves. Membrane was immunostained with OPN antibody. $69 \mathrm{kDa}$ band represent phosphorlated OPN, $55 \mathrm{kDa}$ band glycosylated OPN and the $30 \mathrm{kOa}$ band native OPN. 

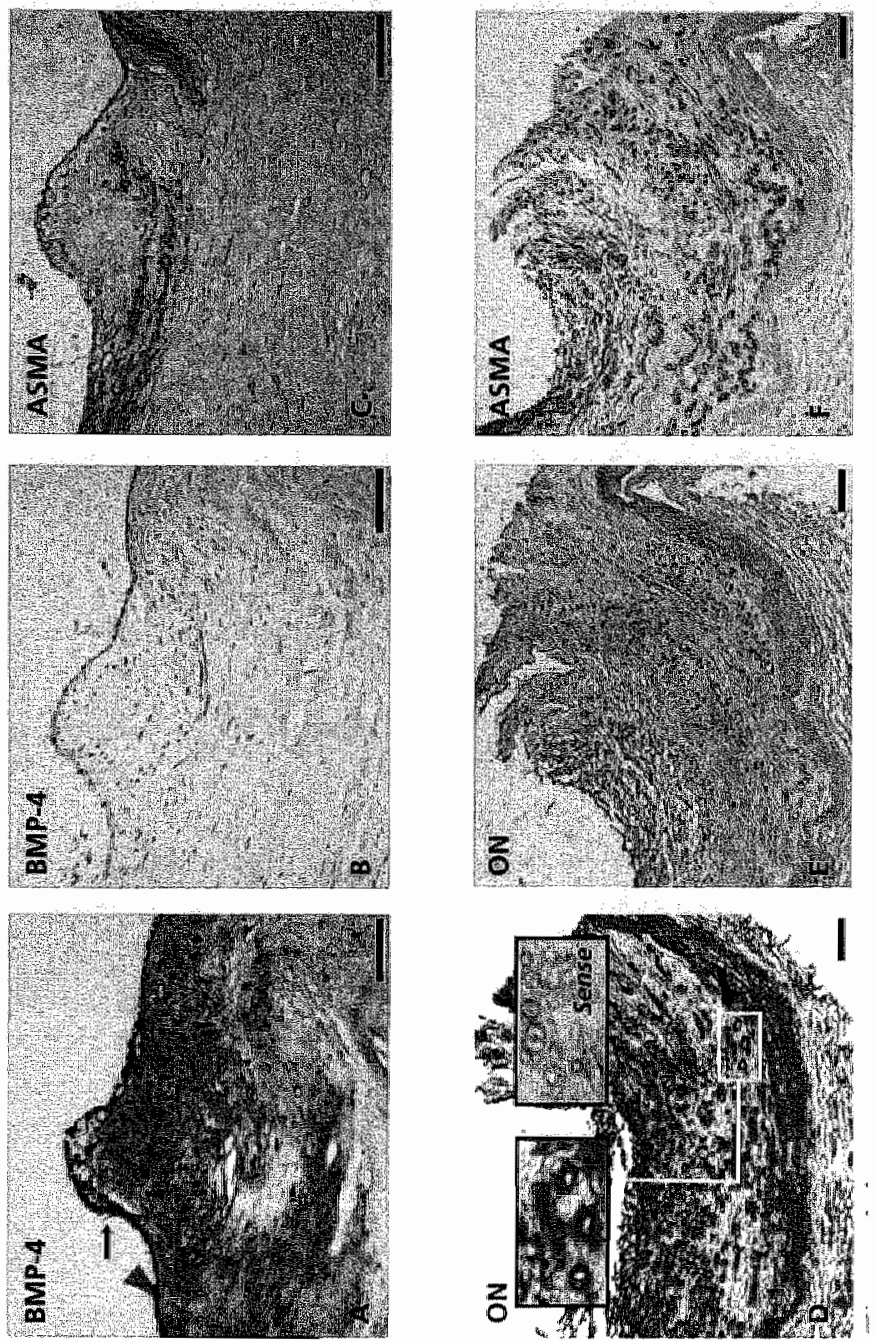

Fig. 3.9. In situ hybridisation (1SM). A, and $C$ representation of respectively 154 of BMP.4 (A), and immunohistochemistry with antibodies directed to BMPA (B) and ASMA ICA D. E and F. ISH of ON (D. left ingef is magnification of chondrocyte like cells and right inset is $15 \mathrm{H}$ of ON with sense probel, and immumohistochemistry with antbodies directed to ON (E) and ASMA (F). Note BMP-4 is present in endothelial cells (arrow). ON is present in chondroryte like cels (arrohy and inset). 5 calle bars represent $50 \mathrm{\mu m}$. Full color figures see page 155 


\section{Discussion}

The data from the present study show that the expression profile of bone matrix regulatory proteins in human heart valves is comparable to the recently described profile in human atherosclerotic plaques?. This suggests that the regulation of human aortic valve and human atherosclerotic calcification share common features, including the expression of bone matrix regulatory proteins.

To gain more insights into the possible function of the examined bone matrix regulatory proteins in valuular calcification, we compared the present data with our human atherogenesis study ${ }^{7}$ and with available data from genetically modified mice (table 3.2). We found that the immunolocalization of various bone matrix regulatory proteins in aortic valves is equal to that found in atherosclerotic plaques?. However, data from genetically modified mice models of several bone matrix regulatory proteins do not always show a clear phenotype in the aorta or aortic valve.

MGP and $O C$, both gamma carboxyglutamic acid (Gla) residues containing proteins, are activated by the vitamin $K$ dependent enzyme $\gamma$-carboxylase and subsequently bind to hydroxyapatite" in atherosclerotic plaques, MGP is expressed in SMC, macrophages, and chondrocytes. OC is highly expressed by osteoblastic cells ${ }^{12}$. MGP knockout mice have severe calcifications of their aorta" and OC-deficient mice exhibit an increased bone formation" (table 3.2). There are no data available on aortic valves in both of these models.

BSP and OPN are RGD (arginine-glycine-aspartic acid) containing glycoproteins. They both have high affinity for binding to $\alpha_{v} \beta_{3}$ integrins and might regulate cell adhesion and migration. BSP and OPN are functional in bone formation and degradation's. In the atherosclerotic plaque BSP and OPN are both present in the vascular smooth muscle cells and foam cells ${ }^{15.15}$. There are no data published on BSP knockout or transgenic mice, whereas OPN mutant mice had a disorganised matrix and alteration of collagen fibrillogenesis" (table 3.2).

Interesting is the shift in post-translational modification of OPN in calcified valves, where it is at least in part phosphorylated. Since phospharylation is necessary for its inhibitory effect on calcification as shown by Speer et al., it seems likely that OPN in calcified human valves has an inhibitory function on calcification"s.

ON, also known as SPARC (secreted protein acidic and rich in cysteine), binds to collagen and hydroxyapatite. It is involved in cell matrix interaction, wound repair, angiogenesis, vascular permeability, cataract formation ${ }^{19}$ and carcinogenesis. ON-deficient mice have decreased bone formation and decreased osteoblast and osteoclast surface and number, causing profound osteopenia ${ }^{20}$. Therefore $\mathrm{ON}$ is involved in activation of skeletal calcification. Our data show that $O N$ immunolocalization is restricted to calcified valves, and in combination with our atherosclerotic plaque data thus also involved in the activation of vascular calcification.

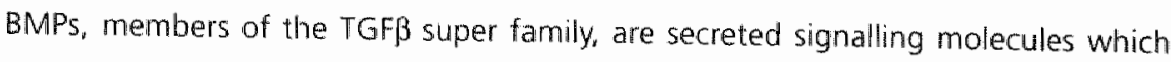


Table 3.2. Bone matrix regulatory proteins in human aortic valves and genetically modified mice models.

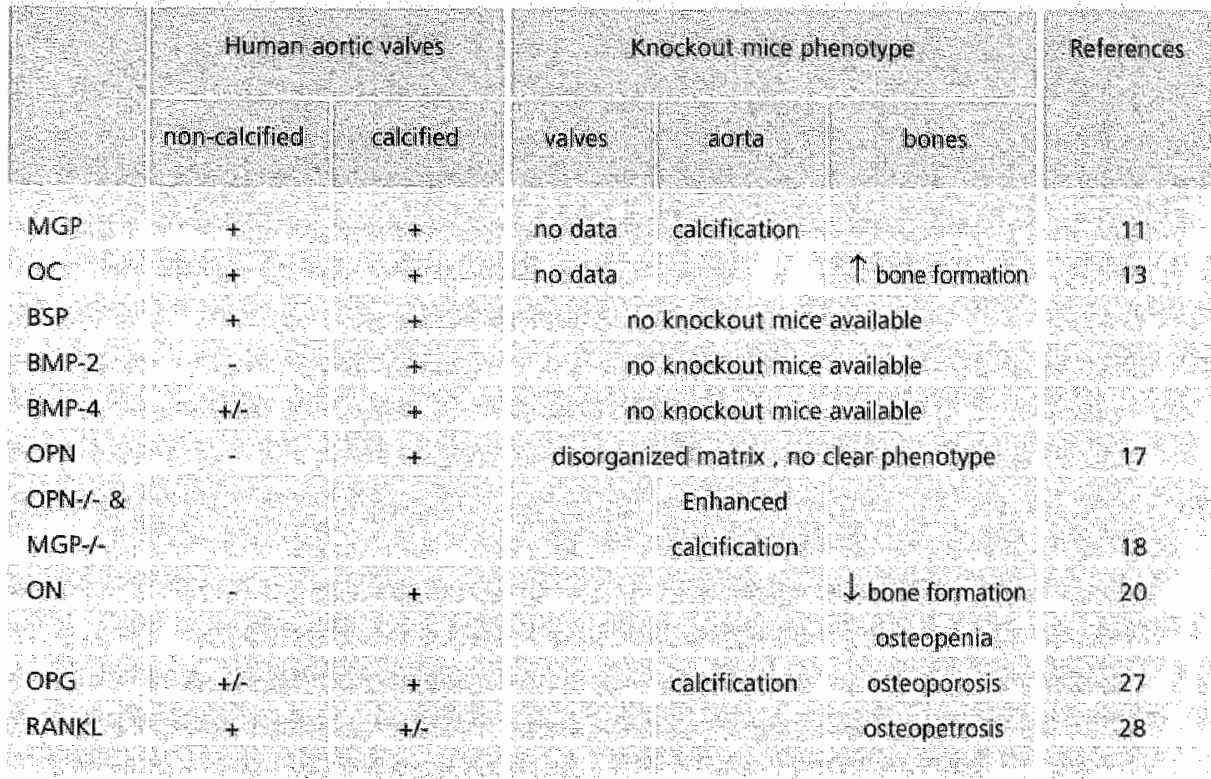

have been implicated in embryogenesis organogenesis and morphogenesis ${ }^{2 n}$. BMP-2 and BMP-4 have been shown to promote the development of bone and cartilage by inducing the differentiation of undifferentiated mesenchymal cells into the osteoblastic cells or cartilage cells, respectively2a. A reduction in expression of BMP-4 has been associated with a variety of bone diseases ${ }^{2,24}$. BMP-2 and BMP-4 proteins were recently localized in human atherosclerotic plaques 25,26 , and the present data show immunalocalization in calcified aortic valves. Since BMP-2 and -4 are essential developmental genes, genetically modified mice are not viable.

OPG is a secreted member of the tumor necrosis factor receptor gene superfamily, acts as an inmibitor of osteoclast formation and is produced by osteoblasts and osteoclasts. RANKL is an activator of osteoclast formation, but its activation is inhibited by OPG. Mice lacking OPG have severe osteoporosis and vascular calcification" while RANkL knockout mice develop severe osteopetrosis due to the absence of osteoclasts ${ }^{2 / 3}$.

Severe calcification of the human aartic valve is often followed by aortic valve replacement (AVR) surgery. Although AVR is initially successtul, in 10 to $20 \%$ of adult recipients, bioprosthetic valves become calcified within 10 years after implantation". Medication to prevent or reduce valvular calcification before or after AVR is not available yet. One possible target is lipid therapy. High levels of LDL are associated with aortic valve calcification, and lipids have been suggested to serve as a nidus for calcification, 
whereas oxidized lipids promote osteoblastic differentiation of progenitor cells ${ }^{3.5 .30}$. Moreower, delipidation of bioprosthetic valves significantly reduces their calcific degeneration, and hyperlipidemic LDL receptor null mice, fed a high fat diabetogenic diet, suffered form active induction of vascular calcification ${ }^{3 i, 22}$.

Since statins have particular benefit in both arterial calcification and osteoporosis ${ }^{31}$, and aortic valve calcification has similarities with atherosclerotic calcification and bone formation, statins may have the potential in retarding the rate of ectopic valvular calcification. Thus far, two studies described the use of statins in atherosclerotic patients and demonstrated a reduction in calcium volume score ${ }^{33}$. Mohler et al. indicated that lipid-lowering therapy is not associated with reduced aortic valve ossification", while Shavelle et al ${ }^{34}$ recently showed that patients treated with statins had a $63 \%$ lower rate of aortic valve calcium and a much smaller percentage of patients progressed to definite aortic valve calcification. Thus, lipid-lowering therapy by statins, may decrease aortic valve calcium accumulation.

Another issue that is not yet resolved, is the origin of the bone-like cells in calcified aortic valves. Circulating osteogenic stem cells have been identified, but there is no evidence that they infiltrate into aortic valves. Other studies suggested a local origin by showing that valvular SMC, pericyte-like cells and valvular cells have the capacity to calcify $^{3,1.55}$. Bone formation in the aortic valves could be initiated by the differentiation of bone marrow derived cells $5^{30}$ such as bone marrow stromal cells ${ }^{37}$ or blood mononuclear cells $s^{38}$. The knuckle epitope of BMP-2 is capable to activate the osteoprogenitor cells and stimulate calcification ${ }^{39}$, whereas also inflammatory cytokines and lipids can promote calcification ${ }^{a b}$. Since our data show the presence of $C D 138$, identifying bone marrow cells, in calcified aortic valves we agree with the initiation of bone formation by the differentiation of bone marrow derived cells.

The major conclusion derived from our data, is that human aortic valve calcification is an active process, associated with the expression of known regulators of calcification and bone modeling. The constitutive immunoreactivity of MGP, OC, BSP, and RANKL in normal aortic valves, and the enhanced immunoreactivity of BMP-2, BMP-4, OPN, ON and $O P G$ in calcified aortic valves, suggests that a shift of the balance between bone formation and bone resorption in favor of bone formation, results in aortic valve calcification. Further dissection of these molecular pathways may provide new targets for interventions in human valvular calcification.

\section{Acknowledgements}

A grant from the Netherlands Heart Foundation (NHF97.113) financially supported this studly. The authors thank Petra LW Aarts for expert technical assistance. 


\section{References}

1. Mohler ER, 3rd. Are atherosclerotic processes involved in aortic-valve calcification? Lancet. 2000;356:5:24-525.

2. Farzaneh-Far A, Proudfoot D, Shanahan $C$, et al. Vascular and valwar calcification: recent advances. Heart. 2001:85:13-17.

3. Demer $\mathrm{L}$. Cholesterol in vascullar and valvular calcification. Circulation. 2001; 104:1881-1883.

4. Pohle K, Maffert R, Ropers D, et al. Progression of aoftic valve calcification. Association with coronary atherosclerosis and cardiowascular risk factors. Circulation. 2001;104:1927-1932.

5. Mohler III ER, Gannon F, Reynolds $C_{x}$ et $a$. Bone formation and inflammation in cardiac valves. Circulation. 2001;103:1522-1528.

6. Mohler ER, 3rd., Adam LP, MCClelland P, et al. Detection of asteopontin in calcified human aortic valves. Arteriosclerosis Thrombosis and Vascular Biology. 1997;17:547-552.

7. Dhore CR, Cleutjens . PM, Lutgens $E_{\text {s }}$ et al. Differential expression of bone matrix regulatory proteins in human atherosclerotic plaques. Arteriosclerosis Thrombosis and Vascular Biology. 2001:21:1998-2003.

8. Fisher LW, Stubbs JT, 3rd., Young MF. Antisera and CDNA probes to human and certain animal model bone matrix noncollagenous proteins. Acta Orthopedica scandinavica Supplement. 1995;266:61-65.

9. Walter l. Myofibroblasts in the mucosal layer of the uterine tube. Italian Joumal of Anatomy and Embryology. 1998:103:259-266.

10. Glukhova MA, Frid MG, Koteliansky VE. Phenotypic changes of human aortic smooth muscle cells during development and in the adult wessel. Am J Physiol. 1991:261:78-80.

11. Luo G. Ducy P, Mckee MD, et al. Spontaneous calcification of arteries and cartilage in mice lacking matrix gla protein. Nature. 1997;386:78-81.

12. Martinez $P$, Moreno I, De Miguel F, et al. Changes im osteocalcin response to 1,25-dibydroxyitamin D3 stimulation and basal vitamin D receptor expression in human osteoblastic cells according: to donor age and skeletal origin. Bone. 2001;29:35-41.

13. Ducy $P$, Desbois $C$, Boyce $B$, et al. Increased bone formation in osteocalcin-deficient mice Nature 1996; 382:448-452.

14. Arai $N$, Ohya $K$, Kasugai $S$, et al. Expression of bone sialoprotein mRNA during bone formation and resorption induced by colchicine in rat tibial bone marrow cavity. Journal of Bone and Mineral Research. 1995;10:1209-1217.

15. Kkeda T, Shirasawa T, Esaki $Y$, et al. Osteopontin mRNA is expressed by smooth muscle-derived foam cells in human atheroscleratic lesions of the aorta. Journal of Clinical Investigation. 1993:92:2814-2820.

16. Shamahan CM. Cary NR, Metcalfe JC, et al. High expression of genes for calcification-regullating proteins in human atherosclerotic plaques. Journal of Clinical Investigation. 1994:93:2393-2402.

17. Liaw $\mathrm{L}$, Birk DE, Ballas CB, et al. Altered wound healing in mice lacking a functional osteoponitin gene (spp 1). Journal of Clinical Investigation. 1998;101:1468-1478. 
18. Speer MY, McKee MD, Guldberg RE, ef af Inactivation of the osteopontin gene enhances. wascular calcification of matrix Gla protein-deficient mice: evidence for osteopontin as an inducible inhibitor of vascular calcification in wivo. I Exp Med. 2002;196:1047-55.

19. Kantorow $M_{*}$ Huang $Q_{*}$, Yang $X J$, et al. Increased expression of osteonectin/SPARC MRNA and protein in agewelated human cataracts and spatial expression on the normal human lens. Molecular Vision. 2000;6:24-29.

20. Delany AM, Amling M. Priemel $M$, et al. Osteopenia and decreased bone formation in asteonectin-deficient mice. Journal of Chinical Investigation. 2000; 105:915-923.

21. Kingsley DM. What do BMPs do in animals? Clues from the mouse short-ear mutation. Trends in Genetics. 1994:10:16:21.

22. Musgrave DS, Bosch P, Ghivizzani S, et al. Adenovirus-mediated direct gene therapy with bone morphogenetic protein-2 produces bone. Bone. 1999:24:541-547.

23. Gannom $\mathrm{FH}$. Glaser D. Caron $\mathrm{R}$, et al Mast cell involwement in fibrodysplasia ossificans progressiva. Human Pathology. 2001;32:842-848.

24. Chang $B$, Smith RS, Peters $M$, et al. Haploinsufficient BMP4 ocular phenotypes include anterior segment dysgenesis with elevated intraocular pressure. BMC genetics. 2001:2:18-18.

25. Willette RN, Gu IL, Lysko PG, et al. BMP-2 gene expression and effects on human vascular smooth muscle cells. Journal of Vascular Research. 1999;36:120-125.

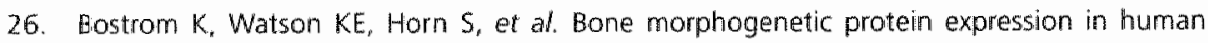
atherosclerotic lesions. Journal of Cinical investigation. 1993;91:1800-1809.

27. Bucay $\mathbb{N}_{\text {, Sarosi }}$, Dunstan $C R$, et al Osteoprotegerin-deficient mice develop early onset osteoporosis and arterial calcification. Genes and Development. 1998;12:1260-1268.

28. Kong $\mathrm{YY}$, Yoshida $\mathrm{H}$, Sarosi I, et al. OPGL is a key regulator of osteodastogenesis, lymphocyte development and lymph-node organogenesis. Nature. 1999:397:315-323.

29. Shen $M$, Marie $P$, Farge $D$, et al. Osteopontin is associated with bioprosthetic heart valve calcification in humans. C.R. Acad. Sci. Wh. 1997;320:49-57.

30. Parhami $F$. Tintut $Y$, Patel $J K$, et al. Regulation of vascular calcification in atheroscllerosis. Z Kardiol 2001,90:27-30.

31. Wailin R, Wajih N. Greenwood GT, et al. Arterial calcification: A review of mechanisms, animal models, and the prospects for therapy. Medical Research Reviews. 2001:21:274-301.

32. Bostrom $K$, Demer $L$. Regulatoy mechanisms in vascuhar calcification. Critical Reviews in Eukaryotic Gene Expression. 2000;10:151\%158.

33. Callister TQ. Raggi P. Cooil B, et al. Effect of $M M G-C O A$ reductase inhibitors on coronary artery disease as assessed by electron-beam computed tomography. $N$ Engl I Med. 1998;339:1972-8.

34. Shavelle DM, Takasu 1. Budoff MI, et al. HMG CoA reductase inhibitor (statin) and aortic valve calcium. Lancet. 2002;359:1125-6

35. Doherty MI, Ashton BA, Walsh $S$, ef al. Vascular pericytes express osteogenic potential in vitro and in vivo. Jounal of Bone and Mineral Research. 1998;13:828-838. 
36. Luria EA, Owen ME, Friedenstein Al, et al. Bone formation in organ cultures of bone marrow. Cell Tissue Res. 1987:248:449-54.

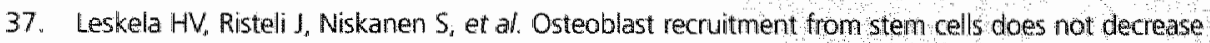
by age at late adulthood. Biochem Biophys Res Commun 2003,311,1008-13.

38. Soboleva EL, Saburova OS, Rozhkova TA. Circulating bone marrow osteodast precursors and osteodastogenesis in patients with type IIA and IB hyperlipidemias. Bull Exp Biol Med. 2001:132:890-4.

39. Saito A. Suzuki Y, Ogata $S$, et al. Activation of osteo-progenitor cells by a novell synthetic peptide derived from the bome morphogenetic protein-2 knuckle epitope. Biochim Biophys Acta. 2003,1651:60-7.

40. Demer $L L$, Tintut $Y$. Mineral exploration: search for the mechanism of vascular calcification and beyond: the 2003 Jeffrey M. Hoeg Award lecture. Arterioscler Thromb Vasc Biol. 2003;23:1739-43. Epub 2003 Sep 4. 


\section{Chapter 4}

BMP-2 induces atherosclerotic catcitication and tibrosis in cartoth artery wein grafting in hypercholesteremic Apop3" leiden mice

Cherida R Dhore, Margreet R de Vries, Sylvia Heeneman, Jack PM Cleutjens, Jos M Grimbergen, Jan Willem HP Lardenoye, Mat JAP Daemen and Paul HA Quax

In preparation 


\section{Abstract}

To study the effect of adenovirus mediated overexpression of bone morphogenetic protein 2 (BMP-2) on vascular calcification, venous interposition grafting was performed in the carotid artery of ApOE3 ${ }^{*}$ Leiden mice, fed a high cholesteral-rich diet for four weeks: After surgery, mice were intravenously injected with either $2 \times 10^{\circ}$ plaque forming units (pfu) of adenovirus carrying the BMP-2 gene (A.d.BMP-2) or control vector. 28 days after surgery, the vein grafts were dissected, processed and analyzed. In both groups the intima showed intimal thickening, foam cell accumulation, necrosis, cartilage formation and calcium mineral deposits. No difference in plaque area, relative smooth muscle cell content and cartilage were found. In the Ad.BMP-2 group the relative macrophage content showed a slight increase (from $41.0 \pm 2.6 \%$ to $50.1 \pm 3.5 \%$; $p=0.08$ ) although not significant. The area of bone formation increased substantially (from $0.0 \pm 0.0 \mathrm{~mm}^{2}$ to $0.016 \pm 0.01 \mathrm{~mm}^{20} ; \mathrm{p}=0.03$ ) and the area of calcification (from $0.01 \pm 0.006 \mathrm{~mm}^{2}$ to $0.04 \pm 0.01 \mathrm{~mm}^{2} ; p=0.06$ ) showed a tendency to increase.

Several bone matrix regulatory proteins were present in both groups, but the localization differed. In the control group these proteins were most prominent in cartilage, while in the Ad.BMP-2 treated group bone matrix regulatory proteins were highly expressed in calcified areas in the grafted vein.

In conclusion, adenoviral BMP-2 overexpression accelerates calcification and ossification in atherosclerotic lesions in vein grafts in the carotid artery in mice, which is associated with an altered bone matrix regulatory protein expression profile.

\section{Introduction}

Bone morphogenetic proteins (BMPs) play important roles in the migration of osteoblast progenitor cells, the proliferation of mesenchymal cells and their differentiation into chondrogenic and osteogenic cells.2. BMPs are able to induce endochondral bone formation at ectopic sites. A prominent feature of atherosclerosis is calcification and in calcified atherosclerotic plaques, organized bone including bone marrow may appear ${ }^{3}$. Bone morphogenetic protein 2 (BMP-2) is a highly osteoinductive protein and is present in human atherosclerotic plaques. We recently showed that besides BMP- 2 other bone matrix regulatory proteins are present in human atherosclerotic plaques. These proteins include BMP-4, matrix Gla protein, osteocalcin, osteopontin, osteonectin, osteoprotegerin and receptor activator of nuclear factor- $\mathrm{kB}$ ligand (RANKL). In addition transforming growth factor $\beta$ (TGFB), one of the main factors controlling the formation of connective tissue matrix, plays a role in endochondral bone formation, exerts similar effects as BMP-2 and is present in atherosclerotic plaques ${ }^{5,8}$. Although bone matrix regulatory proteins have a specific expression pattern in atherosclerotic plaques, data on the function of these proteins in atherosclerotic calcification are lacking. 
Since BMP-2 is a highly osteoinductive protein, involved in the differentiation into chondragenic and osteogenic cells and is present in atherosclerotic plaques we hypothesize that BMP-2 gene accelerates atherosclerotic calcification. Since a simple administration of purified, water-soluble BMP protein alone did not induce local bone formation in vivo:, we used adenovirus-mediated transfer of the BMP-2 gene.

In the present study we examined the effect of adenovirus mediated BMP-2 overexpression, using an adenoviral vector system, in the carotid artery vein graft madel in hypercholesterolemic ApoE3 ${ }^{*}$ Leiden mice". In this model in which the venous interposition is placed in the carotid artery in hypercholesterolemic ApoE3* Leiden mice, a rapid development of accelerated vein graft atherosclerosis including calcification is observed.

Four weeks after adenoviral BMP-2 administration the composition of the intima in the vein graft was studied as well as the expression profile of bone matrix regulatory proteins and TGFB. We demonstrate that BMP-2 overexpression accelerates calcification and ossification in these vein grafts.

\section{Methods}

\section{Adenoviral vectors}

An adenoviral vector encoding human BMP-2 under control of a CMV promoter was kindly provided by Dr. D. Gazit". As a control an adenoviral constructs carrying no insert (Ad.control) was used as described". For all adenovirus preparations the particle per plaque forming unit (pfu) ratio was between 15 and 20 and the titre $10^{10} \mathrm{pfu} / \mathrm{ml}$.

\section{Mice and tissue preparation}

All experiments were approved by the committee on animal welfare of TNO. Specific Pathogen-Free Transgenic APOE* 3 Leiden mice were crossbred for 18 generations with C57BL 6 mice.

Four weeks before surgery and continued after surgery, male ApoE3*Leiden mice $(\mathrm{n}=8)$, aged 8-10 weeks were fed a cholesterol-enriched high-fat diet containing $0.5 \%$ cholate (HFC: casein 20\%, choline chloride $1 \%$, methionine $0.2 \%$, cocoa butter $15 \%$, cholate $0.5 \%$, cholesterol $1 \%$, sucrose $40.5 \%$, cornstarch $10 \%$, corn oil $1 \%$, cellulose $5.1 \%$ and mineral mixture $5.1 \%$ ) to improve intestinal cholesterol uptake and suppress bile acid synthesis, both leading to increased plasma cholesterol levels. All mice received water and food ad libitum during the entire experiment.

\section{Vein graft procedure}

Venous interposition grafting was performed in the carotid artery of ApoE3*Leiden 
mice with the vena cava harvested from a donor mouse and grafted between the two ends of the right carotid artery as described beforetit Immediately after surgery, mice were intraveriously injected with $200 \mu$ of either $10^{10} \mathrm{pfu} / \mathrm{ml}$ Ad.BMP-2 or control vector. After 28 days, mice were anesthetized with Hypnorm (Bayer, $25 \mathrm{mg} / \mathrm{kg}$ ) and Dormicum (Roche, $25 \mathrm{mg} / \mathrm{kg}$ ). The venous graft was dissected and pressure-perfusion $(100 \mathrm{~mm}$ $\mathrm{Hg}$ ) was performed with $3.7 \%$ formaldehyde in $0.9 \% \mathrm{NaCl}$ (wt/vol). The venous grafts were taken out, fixed overnight in $3.7 \%$ phosphate buffered formaldehyde, dehydrated and embedded in paraffin.

Serial cross sections $(5 \mu \mathrm{m})$ were cut from the entire length of the graft.

\section{Histological stainings}

All samples were routinely stained with hematoxylin-phloxine-saffron (HPS). Weigert's elastin staining was used to visualize elastic laminae, von Kossa staining for calcium deposits, thionin staining for cartilage ${ }^{14}$, and Sirius red for collagen.

\section{Immunohistochemical staining}

Phenotyping

Smooth muscle cells were visualized by immunohistochemistry with antibodies directed to $\alpha$-smooth muscle cell actin (ASMA) (1:750 Dako), and monocytes/macrophages with antibodies directed to Mac-3 (1:200 Pharmingen).

\section{Bone modulators}

Paraffin sections were stained with goat polyclonal antibodies against BMP-2 01.50 Santa Cruz Biotechnology, Inc., Santa Cruz, CA, USA), BMP-4 (1:25 Santa Cruz Biotechnology, Inc., Santa Cruz, CA, USA), OPN (1:500 LF123; gift from Dr L. Fisher), OPG (1:200 Santa Cruz Biotechnology. Inc, Santa Cruz, CA, USA), RANKL 1:100 Santa Cruz Biotechnology, InC., Santa Cruz, CA, USA), or OC (1:400 Anawa Trading SA, Wangen, Zurich, Switzerland), or rabbit polyclonal antibodies against $O N(1: 400$ Zymed Laboratories, inc, San Francisco, CA, USA) or BSP (1:25) ${ }^{5}$, or TGF $\beta$ (1:30 R\&D Systems). For goat and rabbit polyclonal antibodies, biotinylated rabbit anti goat lgG (1:200, Dako, Glostrup, Denmark) or sheep anti rabbit IgG (1:1000, Dako) was used as secondary antibody. Sections were incubated with alkaline phosphatase coupled avidin-biotin complex (Dako) and visualised with alkaline substrate kit 1 (vector SK-5100, Vector Laboratories, Inc., Burlingame, (A, USA), counterstained with hematoxylin and mounted. Negative controls lacked incubation with primary antibody. BMP-2 specific immunohistochemistry was performed on murine liver sections. 


\section{Morphometrical analysis}

Vessel wall thickening. plaque, lumen and the calcified area, as well as the cartilage, macrophage and smooth muscle cell content were measured using a computerized morphometry system (Quantimet, Leica, The Netherlands).

\section{Statistics}

Ad.BMP-2 treated ApoE3*Leiden mice were compared with control ApoE3*Leiden mice by a nonparametric Mann-Whitney $U$ test. Data are presented as means \pm SEM and values of $p<0.05$ were considered statistically significant.

\section{Results}

\section{General}

Body weights were monitored at the day of surgery and at sacrifice. Average body weight at the day of surgery was $27.4 \mathrm{~g}( \pm 1.1)$ for the control group and $22.4 \mathrm{~g}$ $( \pm 1.1)$ for the Ad.BMP-2 group , probably due to difference (2-3 weeks) in age between the groups. At sacrifice the average body weight was $28.2 \mathrm{~g}( \pm 1.0)$ for the control group and $25.0 \mathrm{~g}( \pm 1.8)$ for the Ad.BMP-2 treated animals. No significant change in body weight in the control group between surgery and sacrifice was registered, $p=0.38$. The Ad.BMP-2 group showed significant enhancenent in body weight between surgery and sacrifice, $p=0.02$ ).

To check adequate BMP-2 gene expression after intravenous injection of the adenovirus, we performed a BMP-2 specific staining of the liver in which BMP-2 protein expression is normally absent. 28 days after surgery, liver cells of the Ad.BMP-2 treated mice showed immunoreactivity while the liver cells of the control mice showed no immunoreactivity (fig. 4.1a and b), indicating that BMP-2 expression is induced by adenowiral administration.

\section{Plaque morphology}

Total vessel area $\left(1.5 \pm 0.2 \mathrm{~mm}^{2}\right.$ versus $\left.1.7 \pm 0.2 \mathrm{~mm}^{2} ; p=0.20\right)$, plaque area $\left(1.1 \pm 0.2 \mathrm{~mm}^{2}\right.$ versus $\left.1.4 \pm 0.2 \mathrm{~mm} 2 ; p=0.34\right)$ and lumen area $\left(0.34 \pm 0.05 \mathrm{~mm}^{2}\right.$ versus $0.26 \pm 0.08 \mathrm{~mm}^{3} ; p=0.49$ ) were not different in the Ad. BMP-2 versus the control group (fig. $4.2 a$ and $b$ ). There was no difference in relative SMC content ( $26.5 \pm 7.4 \%$ versus $28.3 \pm 2.8 \% ; \mathrm{p}=0.89$ ) between the Ad.BMP-2 and the control group. However, the area of non-osseous calcification $\left(0.04 \pm 0.01 \mathrm{~mm}^{2}\right.$ versus $0.01 \pm 0.06 \mathrm{~mm}^{2}$; $p=0.06)$ and the area of ectopic bone formation $\left\langle 0.016 \pm 0.01 \mathrm{~mm}^{2}\right.$ versus $0.0 \pm 0.0 \mathrm{~mm}^{2}$, $p=0.03$ ) (fig. $4.2 \mathrm{C}$ ) was enhanced in the Ad.BMP-2 treated mice versus the controls. The relative amount of macrophages $(50.1 \pm 3.5 \%$ versus $41.0 \pm 2.6 \% ; p=0.08)$, was not 


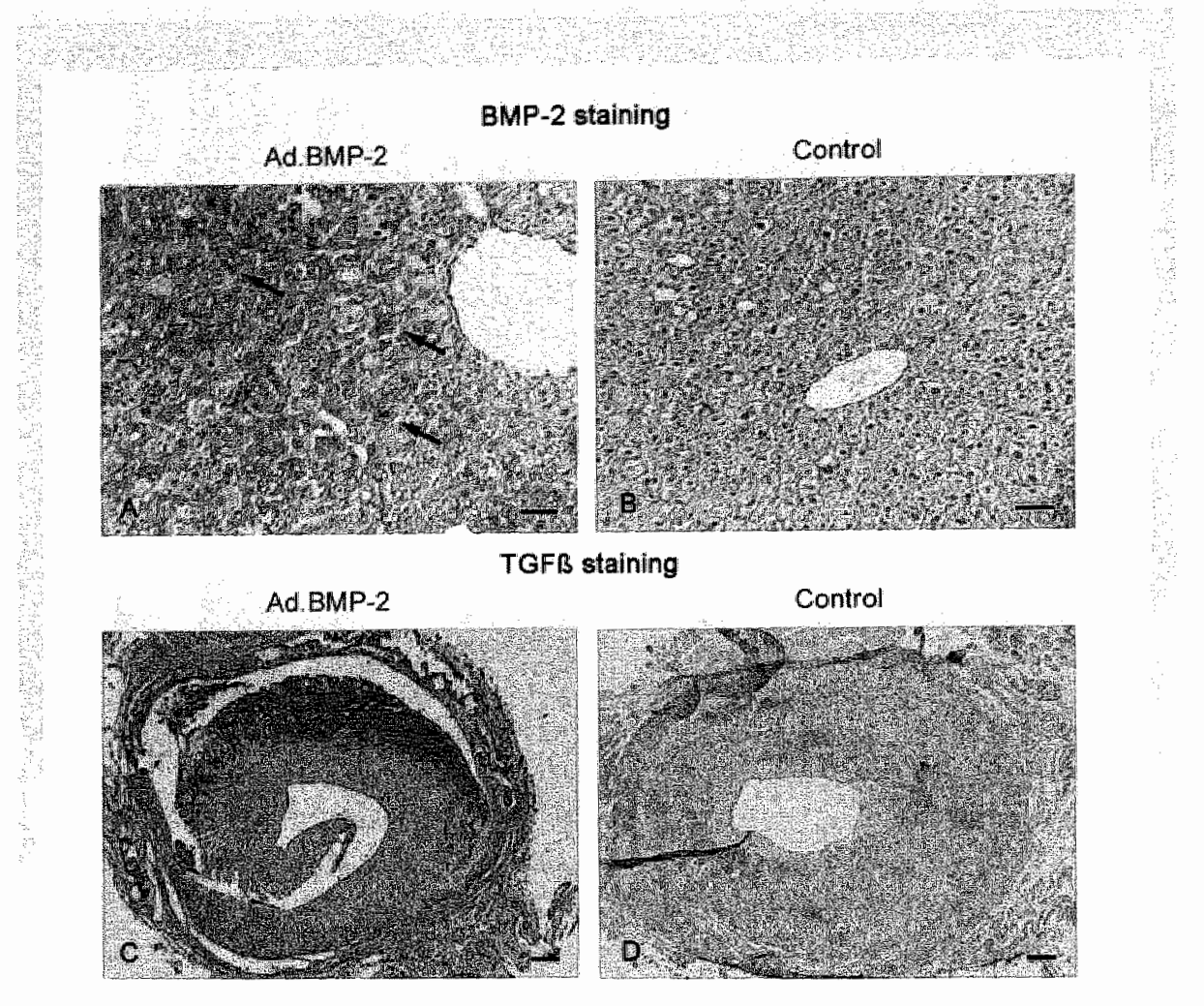

Fig. 4.1. Cross-sections of the liver of respectively Ad. BMP-2 treated mouse (A) and a control mouse (B) stained by imnunohistochemistry with a polyctond antbody directed to BMP-2. A. BMP-2 is wisualized jin red. Arrows

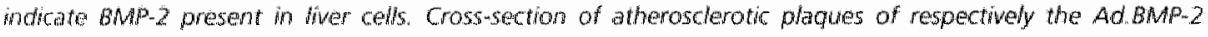
breated group (C) and the control growp (D) staned for $7 G F B$ (visualized in red). Note: TGFB was hardly present in the contial graup (Fig. 4.1D) and clearly erhanced in the AdBMp.2 group, whith TGFB located

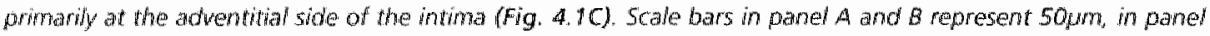
C and D 100 mm. Full color tigures sea page 156 

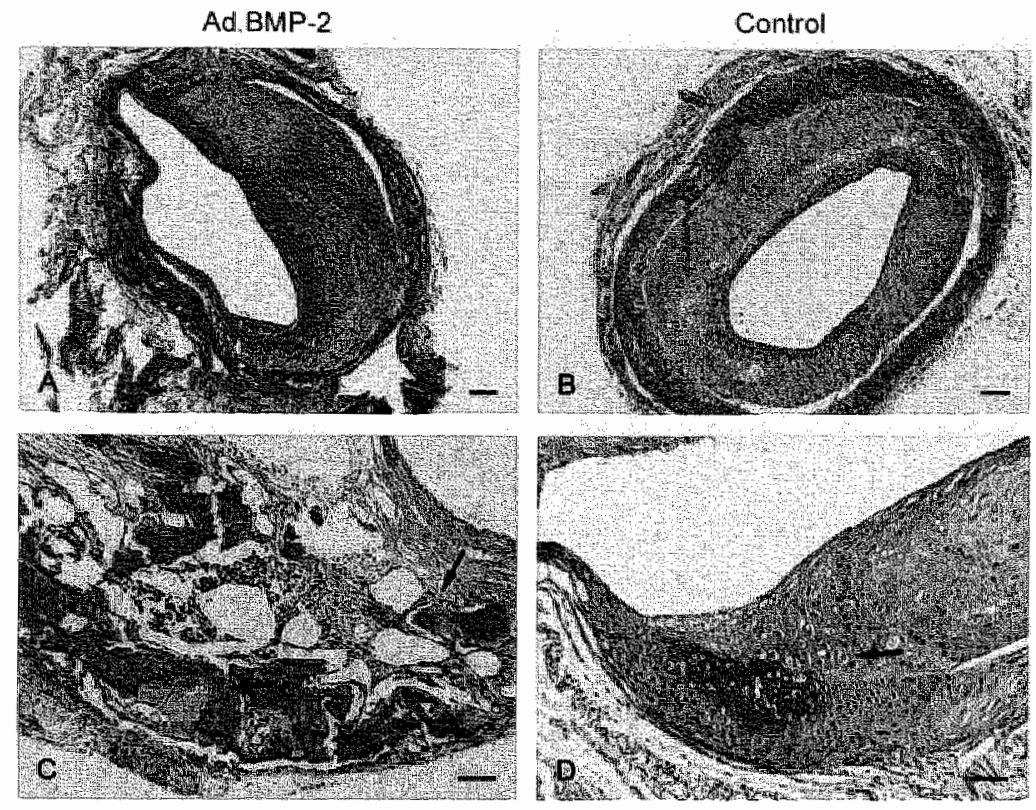

Thionin staining

Ad.BMP-2

Control
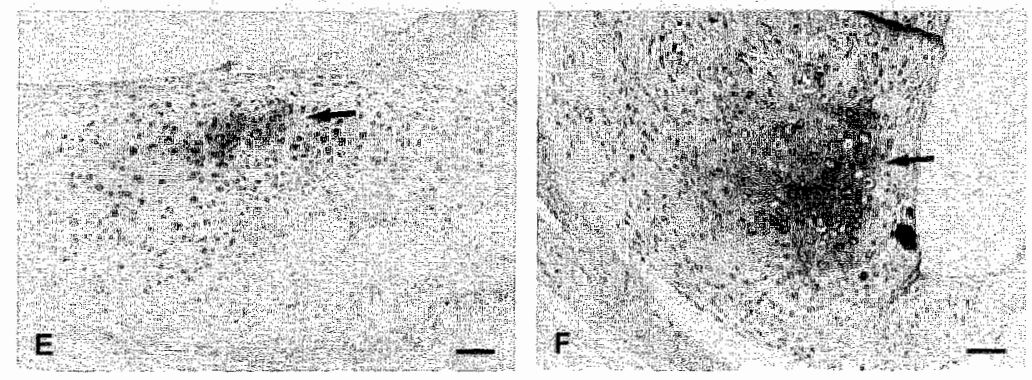

Fig. 4.2. Cross-sections of a vein graft of respectively the Ad, BMP-2 treated group (A and $O$ ) and the controt group $(B$ and $D$ ). There was no difference in total vessel area, plaque areat and lumen area berween the Ad. BMP.2 treated mice (A) and the controls $(B)$. However, the area of non-ossious calcification and ectopic bone formation was enhanced in the Ad.BMP-2 treated mice (C) versus the controls (D). Arrow in panel $C$ indicate ecropic bone formation. Arrow in panel D indicate cartilage

Cross-sections of atherosderotic plaques in AdBMP-2 treated mouse (E) and controt mowse (F) containing non-cakiffed cartilage. Cartilage is wisualized in purple by a thionin staining (arrowh. Scale bars in panel A and $B$

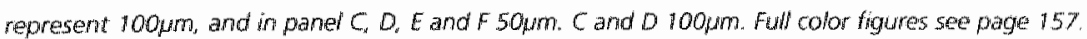




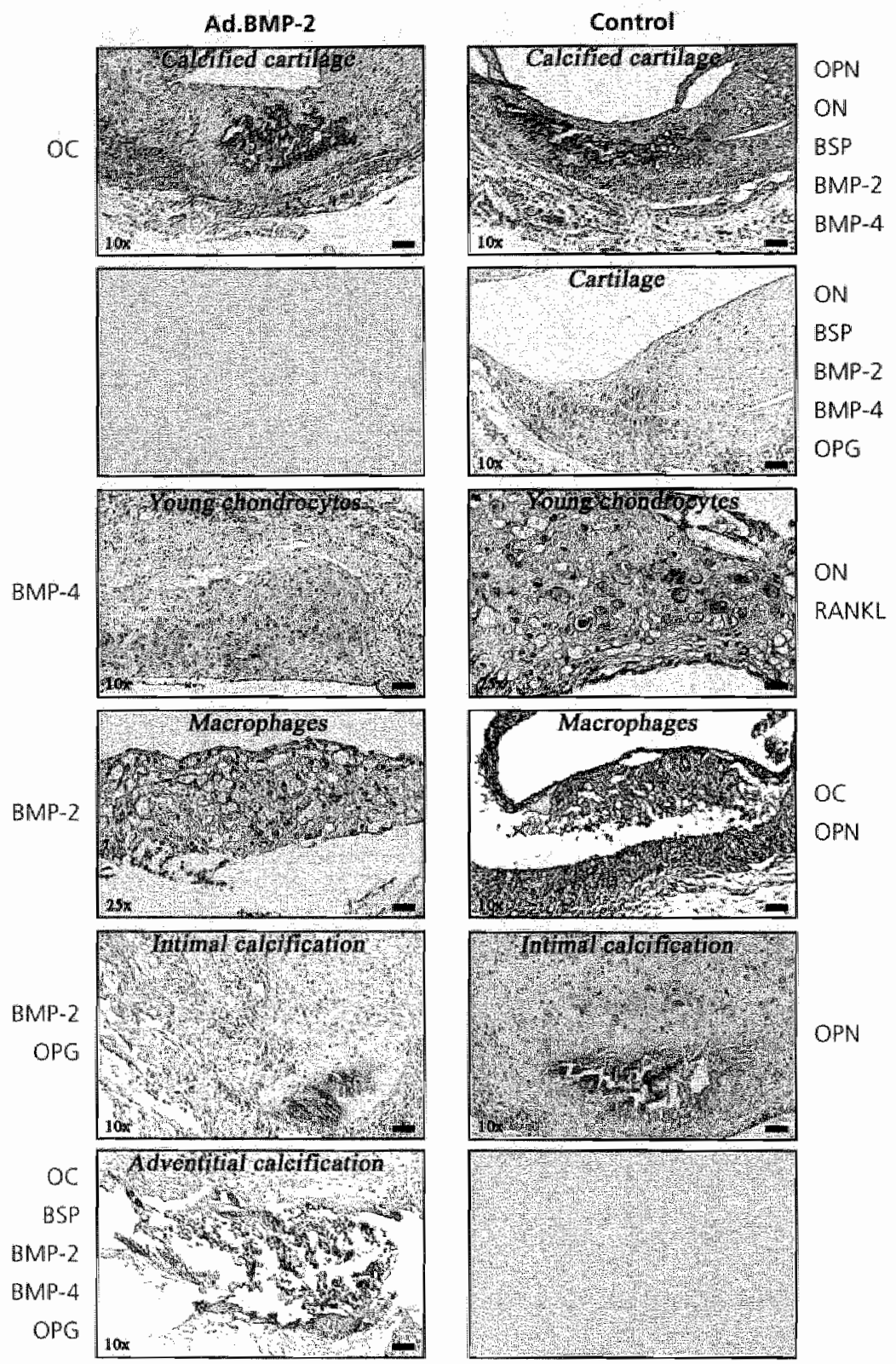


Fig: 4.3. Cross-sections of atherosclerotic plaques in both the Ad BMA-2 treated group llet panels) and the control group (right paneds). Postive staining was visualized in red.

In the Ad BMP-2 treated group only osteocakin was present in calcified cartitage BMP-4 in joung chondrocytes, EMP-2 in the macrophages, BMP-2 and osteoprotegerin in intimal calcification and in adventitial caicificationlossification fwe proteins showed immunoneactiwity (BMP.2. BMP-4, osteocalcin, BSP and osteoprotegerin. In the control group BMP-2. BMP-4, BSP and osteonectin whe prasent in both calcifed cartilage and non-calcified cartilaga. Osteopontin was present in calcifted cartilage. white osteoprotegun

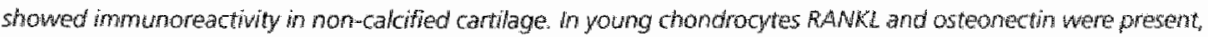
in macrophages osteopontin and osteocalcin and in intimal calcification ony osteopontin was expnessed. scate bars in panels with $70 x$ magnification represent 50 wm. and in panels with $25 x$ magnification 20 wn. Full color pigures see page 158.

changed in plaques of the Ad.BMP-2 group. There was no difference in the area of cartilage between the Ad.BMP-2 and the control group $\left(0.49 \pm 0.18 \mathrm{~mm}^{*}\right.$ versus 0.25 $\pm 0.15 \mathrm{~mm}^{2} ; p=0.3$ ) (fig. 4.2d), although non-calcified cartilage was present in only one of the Ad.BMP-2 treated mice versus four of the control mice (fig. $4.2 e$ and f). Non-calcified cartilage, calcified cartilage and amorphous calcification were located in the shoulder regions in the intima and at the adventitial side of the plaque. However ectopic bone formation which was only present in the Ad.BMP-2 group, was restricted to the adventitial side of the plaques.

Collagen content was measured on Sirius Red stained sections. These measurements revealed no significant difference in collagen content between the Ad.BMP-2 group and the controls $(12.4 \pm 6.1 \%$ versus $12.9 \pm 2.4 \% ; p=1.0)$. However, all plaques of the Ad.BMP-2 treated mice contained enhanced TGFB protein expression compared to the control mice after histological analysis.

\section{Expression profile of bone matrix regulatory proteins}

Immunohistochemistry with bone matrix regulatory proteins revealed a clear shift of protein expression profile in atherosclerotic plaques of Ad.BMP-2 treated mice versus the controls.

In the wein grafts of the controls, the majority of bone matrix regulatory proteins were expressed in chondrocytes and in non-calcified and calcified cartilage in the intima, as is summarized in figure 4.3. In the vein grafts of the Ad.BMP-2 treated group, the expression profile of the majority of bone matrix regulatory proteins had shifted to areas of calcification and bone formation in the intima and the adventitial side of the vein.

Immunohistochemistry with TGFB didn't show a clear shift in localization of the protein. However, TGFB was hardly present in the control group (fig. 4.1d) and clearly enhanced in the Ad.BMP-2 group, with TGFB located primarily at the adventitial side of the intima (fig. 4.1 $\mathrm{C}$. 


\section{Discussion}

Bone morphogenetic proteins are potent bone inducers that act through specific receptors located on the cell surface of responding mesenchymal cells, promote proliferation and differentiation of these cells into the osteoblastic lineage ${ }^{25.35}$, and initiate endochondrall bone formation. It has been well established that BMP-2 can induce ectopic bone formation both in wivo and in vitro. Adenovirus mediated overexpression of the BMP-2 gene and direct injection of recombinant human BMP-2 are able to induce ossification in vitro ${ }^{\text {th }}$ and in the musculature ${ }^{1 / 9}$ of several animal models. BMP-2 is also involved in other processes like vascular remodeling". We previously showed that BMP-2 expression is enhanced in calcified human atherosclerotic plaques and calcified aortic valve leaflets $5^{5}$.

The present study demonstrates that BMP-2 overexpression accelerates atherosclerotic calcification in the carotid artery vein graft model after intravenous injection of an adenowirus carrying the BMP-2 gene. This model is known for its development of advanced atherosclerotic plaques, including calcification within 28 days ${ }^{30}$. The vein grafts of Ad.BMP-2 treated mice showed an enhancement in bone formation and a tendency in enhancement of calcification. Strikingly, the amount of non-calcified cartilage seems to be reduced in the Ad.BMP-2 treated mice. Bone morphogenetic proteins are known to induce both endochondral (through cartilage intermediate) and direct (intramembranous) bone formation, however our data suggest that intramembranous bone formation was enhanced after Ad BMP-2 treatment.

The expression profile of several bone matrix regulatory proteins (BMP-2, BMP-4. BSP, OC, OPN, ON, OPG and RANKL) was influenced by overexpression of BMP-2. The main observation was a shift from expression in cartilage tissue in controls to intimal and adventitial calcification of the Ad.BMP-2 treated group. This suggests an intermediate role of other bone matrix regulatory proteins in the BMP-2 induced acceleration of vascular calcification.

A number of different growth tactors have been identified to influence bone growth. collagen synthesis, and fracture repair both in vitro and in vivo ${ }^{2 x}$, including TGF $\beta$ and BMPs ${ }^{3,27}$, both members of the TGF $\beta$ supertamily. Like BMPs, TGF $\beta$ is known for its role in development, proliferation, differentiation and extracellular matrix biology. and is important in matrix remodelling and collagen synthesis ${ }^{25}$. Lutgens et al. and Mallat et al. described that inhibition of TGFB in murine atherosclerotic plaques reduces plaque stability partly due to the reduction of the amount of fibrosis. In the present study we showed that adenovirus mediated overexpression of BMP-2 induces a more fibrous plaque with an enhanced TGF 3 protein expression. The induction of collagen was also seen in several cell lines transfected with the BMP-2 gene B $^{n}$. The cells produced more BMP-2, which causes an upregulation of alkaline phosphatase activity, osteocalcin, osteopontin and type 1 collagen ${ }^{3: 3}$. It has also been described" that BMP-2 is able to 
induce scar formation and fibrosis in fetal wound healing. These data suggest a key role for BMP-2 in the development of a stable plaque phenotype.

The results from our study may have important dinical implications. Recent pre-clinical experiments have served the idea that BMP-2 will be a useful therapeutic agent, acting to induce new bone formation at sites of bone injury in osteoporotic patients. Mostly BMP-2, a secreted protein, was placed on a matrix or collagen sponge, and implanted at the site of bone fracture healing. Since osteoporosis is associated with atherosclerotic calcification ${ }^{32}$, systemic treatment with BMP-2 in order to reduce osteoporosis may enhance vascular calcification.

In conclusion, atherosclerotic plaques of Ad.BMP-2 treated mice have accelerated calcification and ossification, a pro-fibrotic phenotype and an altered bone matrix regulatory protein expression profile. This suggests that BMP-2 is an active regulator of atherosclerotic plaque calcification and fibrosis in the murine carotid artery vein graft model.

\section{Table 4. 1 .}

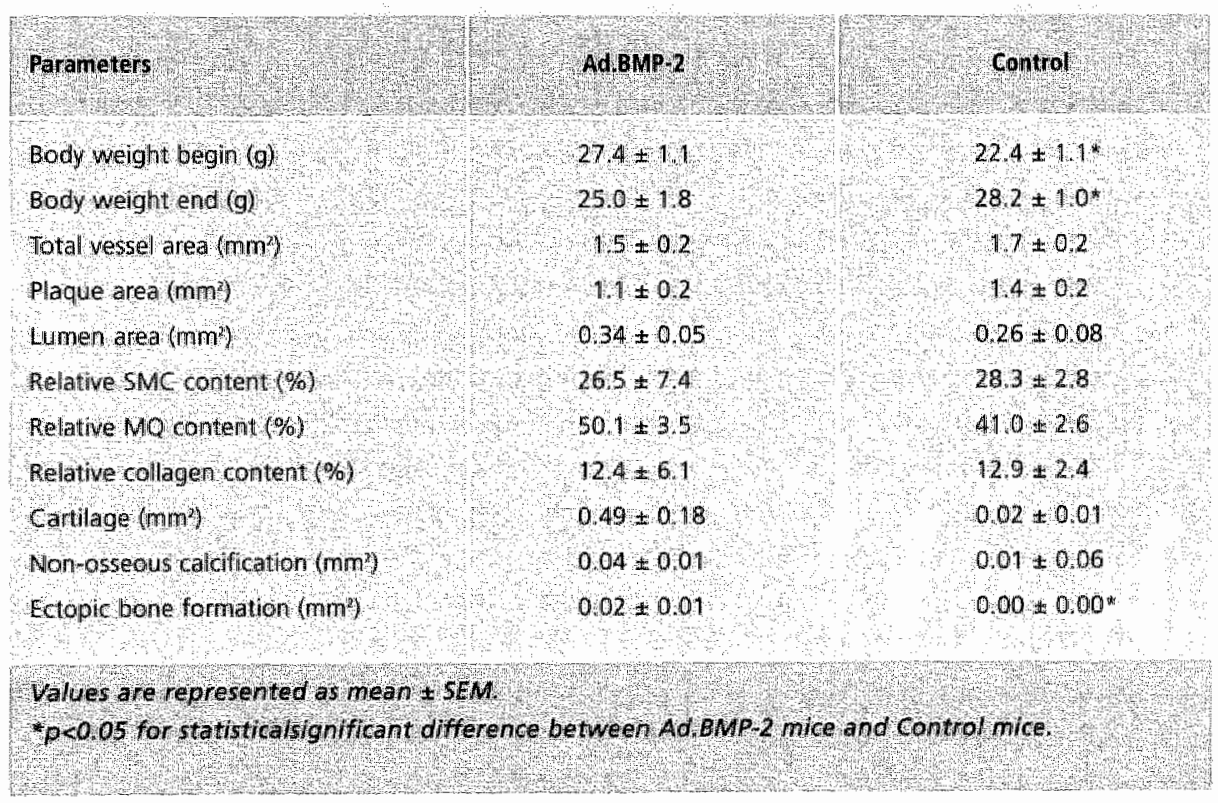




\section{References}

1. Uusitalo $H_{*}$ Hiftunen $A_{4}$ Ahonen $M$, et al. Induction of periasteall callus formation by bone morphogentetic protein- 2 employing adenovirus-mediated gene delivery. Matrix Biology. $2001: 20: 123-127$.

2. Eerola I, Uusitalo $H$, Aro $H$, et al. Production of cartilage collagens during metaphyseal bone healing in the mouse. Matrix Biol. 1998;17:317-20.

3. Deneke $Y$, Langner $K$, Grewe $\mathrm{PH}$, et al. Ossification in atherosclerotic arteries. Zeritschrift fur Kardiologie. 2001;90 Suppl 3illt106-11/115.

4. Bostrom $\mathrm{K}$, Watson $\mathrm{KE}$, Horn $\mathrm{S}_{\mathrm{x}}$ et ad. Bone morphogenetic protein expression in human atherosclerotic lesions. Journal of Clinical Investigation. 1993;91:1800-1809.

5. Dhore $C K$, Cleutiens JPM, Lutgens $\mathrm{E}$, et al. Differential expression of bone matrix regulatory proteins in human atherosclerotic plaques. Arteriosclerosis Thrombosis and Vascular Biology. 2001:21:1998-2003.

6. Lutgens $E$, Daemen MI. Transforming growth factor-beta: a local or systemic mediator of plaque stability? Circ Res. 2001;89:853-5.

7. Mallat Z. Gojova A, Marchiol-Foumigault $C$, et al. Inhibition of transforming growth factor-beta signaling accelerates atherosclerosis and induces an unstable plaque phenotype in mice. Circ Res 2001;89:930-4.

8. Jeziorska M. Transforming growth factor-betas and CD 105 expression in calcification and bone formation in human atheroscleratic hesions. Z Kardiol. 2001;90:23-6.

9. Laurencin CT, Lane JM. Poly(lactic acid) and poly(glycolic acid): Orthopaedic surgery applications. In: Brighton CT, Friedlaender GE, Lane JM, eds. Bone formation and repair. Mfinois: Rosemont: $1994: 325-340$.

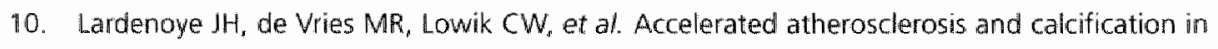
vein grafts: a study in APOE 3 Leiden transgenic mice. Circ Res. 2002;91:577-84.

11. Turgeman $G$, Pittman DD, Muller $R$, et al. Engineered human mesenchymal stem cells: a novel platform for skeletal cell mediated gene therapy. J Gene Med. 2001;3:240-51.

12. Quax PH, Lamfers ML. Lardenoye ith, et at. Adenoviral expression of a urokinase receptor-tarigeted protease inhibitor inhibits neointima formation in murine and human blood vessels, Circulation. 2001:103:562-9.

13. Zou $Y$, Dietrich $H$, Hu $Y$, et al. Mouse model of wenous bypass graft arteriosclerosis. Am J Pathol. 1998:153:1301-10.

14. Bulstra SK, Drukker J, Kuijer $R$, et al. Thionin staining of paraffin and plastic embedded sections of cartilage. Biotech Histocherm. 1993;68:20-8.

15. Iten Dijke $P_{x}$ Yamashita $H_{*}$ Sampath TK, et al. Identification of type I receptors for osteogenic protein- 1 and bone morphogenetc protein-4. I Biol Chem. 1994;269:16985-8.

16. Urist MR, DeLange RJ. Fineman GA. Bone cell differentiation and growth factors. 5cience. $1983,220: 680-6$.

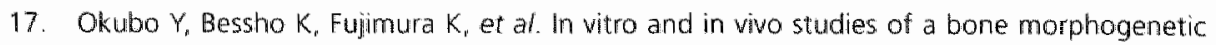
protein-2 expressing adenoviral vector. $J$ Bone Joint Surg Am. 2001:83-A Suppl 1:599-104. 
18. Musgrave DS, Basch $\mathbb{P}$, Ghivizzani $S$, et al. Adenowirus-mediated direct gene therapy with bone morphogenetic protein-2 produces bone. Bone. 1999:24:541-547.

19. Okubo $Y$, Bessho $K$. Fujimura $K$, et al. Expression of bone morphogenetic protein- 2 via adenoviral vector in $\mathrm{C} 2 \mathrm{C} 12$ myoblasts induces differentiation into the osteoblast lineage. Biochemical and Biophysical Research Communications. 1999;262:739-743.

20. Gonda K. Nakaoka T, Yoshimura K, et al. Heterotropic ossification of degenerating rat skeletal muscle induced by adenowirus-mediated transfer of bone morphogenetic protein-2 gene. Journal of Bone and Mineral Research. 2000;15:1056-1065.

21. Willette RN, Gu IL, Lysko PG, et al. BMP-2 gene expression and effects on human vascular smooth muscle cells. Journal of Vascular Research. 1999;36:120-125.

22. Linkhart TA, Mohan S, Baylink DJ. Growth factors for bone growth and repair: IGF, TGF beta and BMP. Bone. 1996;19:15-125.

23. Wang EA, Rosen $V_{\text {"D }}$ Alessandro 15 , et al. Recombinant human bone morphogenetic protein induces bone formation. Proceedings of the National Academy of Sciences U.S.A. $1990 ; 87: 2220-2224$.

24. Wozmey $I M$, Rosen $V$. Bone morphogenetic proteiry and bone morphogenetic protein gene family in bone formation and repair. Clinical Ortopaedics and Related Research. $1998 ; 346: 26-37$.

25. Amento EP, Ehsani $N$, Palmer $H$, et al. Cytokines and growth factors positively and negatively regulate interstitial collagen gene expression in human vascular smooth muscle cells. Arterioscler Thromb. 1991:11:1223-30.

26. Mallat $Z$, Tedgui A. The role of transforming growth factor beta in atherosclerosis: novel insights and future perspectives. Curr Opin Lipidol. 2002;13:523-9.

27. Takuwa $Y$, anse $C$, Wang $E A$, et al. Bone morphogenetic protein-2 stimulates alkaline phosphatase activity and collagen synthesis in cultured osteoblastic cells, MC3T3-E1. Biachem Biophys Res Commun. 1991;174,96-101.

28. Cheng SL, Lou I. Wright NM, et al. In vitro and in vivo induction of bone formation using a recombinant adenoviral vector carrying the human BMP-2 gene. Calcif Tissue lot. 2001;68:87-94.

29. Huang W. Rudkin GH, Carlsen B, et al. Owerexpression of BMP-2 modulates morphology, growth, and gene expression in osteoblastic cells. Exp Cell Res. 2002:27.4:226 34.

30. Tare RS, Oreffo RO, Clarke NM, et al. Pleiotrophin/Osteoblast-stimulating factor 1: dissecting its diverse functions in bone formation. J Bone Miner Res. 2002:17:2009-20.

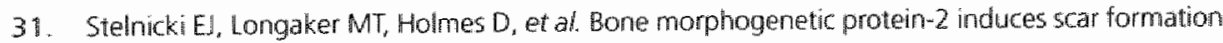
and skin maturation in the second trimester fetus. Plast Reconstr Surg. 1998;101:12-9.

32. Tintut $Y$. Demer LL. Recent advances in multifactorial regullation of vascular calcification. Curr Opin Lipidol. 2001:12:555-60. 



\section{Chapter 5}

A thrul generation bisphosphonate, risedronatse, has mo erfect on the deveropment of aherosterosis in Apoc-/ mice in doser that aftect bone densing

Cherida R Dhore, Piet PMM Geusens, Bert van Rietbergen, Kitty Schapira, Marion Gijbels, Jack PM Cleutjens and Mat JAP Daemen

Submitted 


\section{Abstract}

Bisphosphonates, pyrophosphate analogs, are potent inhibitors of bone resorption. At the cellular level the target of bisphosphonate-action is the osteoclast, the bone resorbing cell. At the molecular level enzymes in the chollesterol bicsynthesis pathway were shown to be inhibited by bisphosphonates. A third generation nitrogen containing bisphosphonate risedronate is used clinically for the treatment of postmenopausal osteoporosis. Since in older women osteoporosis and atherosclerosis are correlated and atherosclerotic calcification shares molecular pathways with bone formation we hypothesized that risedronate, according to its mechanism of action, could reduce vascular calcification at doses effective on bone density and microarchitecture. We therefore used a mouse model of atherosclerosis and subcutaneously injected ApoE-/ mice with different dosages $\left(5 \mu \mathrm{g} . \mathrm{kg}^{-1}\right.$. injection-' or $25 \mu \mathrm{g} . \mathrm{kg}^{-1}$, injection- $\left.{ }^{\prime}\right)$ of risedronate twice a week. We used two different starting ages ( 5 and 29 weeks old mice) and two different types of diet (Western type and normal chow). Results revealed that risedronate had no effect on the development of atherosclerosis in ApoE-1- mice at doses that had significant effects on bone density and microarchitecture.

\section{Introduction}

Bisphosphonates are nonhydrolyzable analogs of pyrophosphate and like pyrophosphate have the ability to bind to bone mineral and hydroxyapatite crystals. $\mathrm{N}$-containing bisphosphonates are non-metabolized potent inhibitors of osteoclastic bone resorption and inhibit farnesyl-diphosphate synthase, an enzyme in the mevalonate pathway. This results in inhibition of posttranslational prenylation, which is necessary for appropriate anchoring of small glutamyl transpeptidases such as Rho, Ras, Rac and Rab to the osteoclast membrane. This inhibits the regulation of membrane ruffling and apoptosis in the osteoclast, ${ }^{2}$. N-containing bisphosphoriates such as the pyridiny" bisphosphonate risedronate have been successfully used in the treatment of postmenopausal osteoporosis ${ }^{3,4}$ and Paget's disease ${ }^{5.5}$. Since in older women osteoporosis and atherosclerosis are correlated and atherosclerotic callification shares molecular pathways with bone formation we hypothesized that bisphosphonates would reduce vascular calcification. We therefore examined the chronic effects of the third generation, $\mathrm{N}$-containing bisphosphonate risedronate on atherosclerotic calcification in a mouse model of atherosclerosis. First risedronate was tested in a prevention set-up in which treatment began at 5 weeks of age and continued for 24 weeks. Because treatment of osteoporosis mainly starts at an older age when atherosclerotic calcification may already be present, we also studied the effect of risedronate in older ApoE-1-mice that had already developed calcified atherosclerotic lesions (regression set-up). In this part of the study a high $(25 \mu \mathrm{g} / \mathrm{kg})$ and low $(5 \mu \mathrm{g} / \mathrm{kg})$ dose of risedronate was used as well as two different diets, normal chow and Western type diet. 


\section{Materials and Methods}

\section{Animals}

Male ApoE -/- mice on a C57Bl6 background were obtained from ffa Credo (Lyon. France). All animal work was approved by the institutional committee for whe weltare of laboratory animals of the University of Maastricht and was performed in compliance with the Dutch government guidelines. Mice were kept in accordance with standard animal care requirements of the University of Maastricht, housed 5 to 6 per cage with free access to food and water, and maintained on a 12-hour light-dark cycle. Thee experiments were performed: prevention Western type diet (pWT) $(n=48\rangle_{\text {, regression }}$ Western type diet $(r W T)(n=45)$ and regression normal chow diet ( NC) $(n=31)$. Mice in the prevention WT and the regression WT received a WT diet $10.21 \%$ cholesterol, Hope Farms), beginning at week 5 of age until the end of the experiment, while mice of the regression NC diet experiment were kept on NC from week 5 atter birth.

Body weights were measured at the beginning and at the end of the expermentat period.

\section{In vivo treatment of anilmals with drug}

All mice were injected subcutaneously twice a week with $200 \mu \mathrm{L}$ of with either risedronate (kindly provided by P\&GP) diluted in phosphate buffered saline (PBS) or phosphate buffered saline (PBS), alone as a control. In the prevention WT experiment injections began at 5 weeks of age and continued for 24 weeks. The dose of

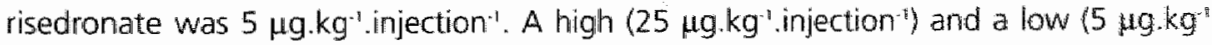
.injection ${ }^{1}$ ) dose of risedronate was given in the regression WT experiment, which began at 29 weeks of age and continued for 12 weeks. A control group received PBS injections for 12 weeks. In the last experiment risedionate was given at a dose of $5 \mu \mathrm{g} \mathrm{kg}^{-1}$. injection ${ }^{-1}$ for 12 weeks starting 35 weeks of age (regression NC experiment). All experimental groups are represented in table 5.1 and table 5.2 .

Table 5.1

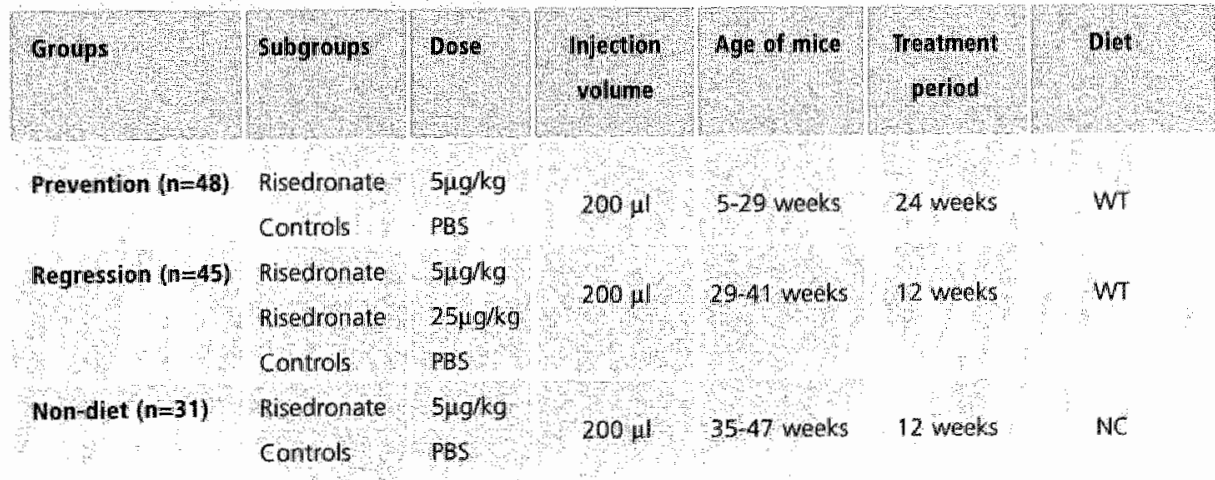


Table 5.2

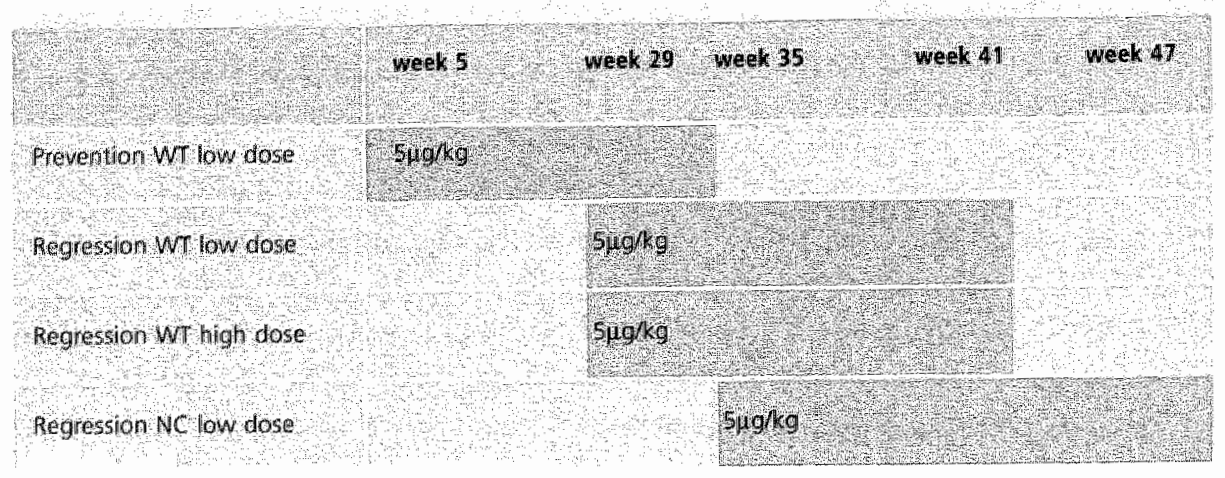

The risedronate dose used is in the same range of two recent published articles. Nakamura et al. used a dose of $10 \mu \mathrm{g} . \mathrm{kg}^{-1}$.day ${ }^{\prime}$ s.c. for 30 days and showed effects of risedronate treatment on bone formation and bone resorption in mice. This dose of $70 \mu \mathrm{g} . \mathrm{kg}^{-1}$. Week' is comparable to the close of $50 \mu \mathrm{g} . \mathrm{kg}^{3}$. week ${ }^{-1}$ used in the present study. Shimshi et al. used a dose of $6 \mathrm{mg} \mathrm{p.o.} \mathrm{twice} \mathrm{weekly} \mathrm{for} 8$ weeks in ApoE-/ mice, which corresponds with the human-equivalent dose of $0.3 \mathrm{mg} . \mathrm{kg}^{\prime}$. day" and showed effects of risedronate treatment in plaques.

\section{Tissue preparation}

Mice were sacrificed after a 24 -hour fasting period. Blood $(0.5$ to $1.0 \mathrm{~mL})$ was obtained from the right cardiac ventricle, mixed with $50 \mu \mathrm{L} 0.5 \mathrm{M} \mathrm{EDTA}$, centrifuged at $1500 \mathrm{rpm}$ for $10 \mathrm{~min}$ and plasma was stored at $-80^{\circ} \mathrm{C}$ until lipoprotein analysis. The arterial tree was perfused through a catheter inserted into the left ventricular apex for 3 minutes with PBS, followed by 3 minutes with $10 \%$ phosphate-buffered formalin $(\mathrm{pH} 7.4)$, both containing $0.1 \mathrm{mg} / \mathrm{mL}$ sodium nitroprusside (Sigma) ${ }^{\text {ns }}$. The aortic arch, including its main branch points (brachiocephalic trunk, left common carotid artery, and left subclavian artery) was embedded longitudinally in paraffin and cut into $\sim 40$ sections. A series of twenty $4 \mu \mathrm{m}$-thick sections, which represented the central area of the arch with an intact morphology of the complete arch and branch points, were used for analysis (see further, histological and morphometric analysis).

\section{Lipid Profile}

For the assessment of lipid profiles at the end of the experiments, standard enzymatic techniques, automated on the Cobas Fara centrifugal analyzer (Hoffmann-La Roche), were used. Total plasma cholesterol and HDL were measured by using kit No. 073663 5 and kit No. 543004 (Hofmann-La Roche), total glycerol was measured by using kit 
No. 337-40 A/337-10B (Sigma Chemical $\mathrm{Co}$ ) and free glycerol was measured by using kit No. 0148270 (Hoffmann-La Roche). Standardized mouse serum (Precipath) was used as an internal standard. LDL was calculated by the equation: total cholesterol -[(total glycerol-free glycerol)/2.2]- $\mathrm{HDL}$.

\section{Evaluation of Systemic Effects}

In each experimental group twenty organs (brain, lung, heart, thymus, liver, spleen. kidneys, stomach, intestine, pancreas, bone (skull, femur), adrenal glands, bladder, skin, prostate, seminal vesicle, salivary glands, lymph nodes and tonsil) were excised from 4 randomly selected risedronate treated (prevention WT low dose group) and 4 control mice. Analysis was performed by light microscopy on $4 \mu \mathrm{m}$ sections stained with hematoxylin and eosin.

\section{Histological and Morphometric analysis}

For histological analysis of atherosclerosis, 4 sections of the complete aortic arch including the main branch points $(20 \mu \mathrm{m}$ apart) were stained with hematoxylin and eosin (fig. 5.1a and b). Atherosclerotic lesions were classified by light microscopy, based on histological criteria, according to the classification by Virmani". The number of atherosclerotic plaques, the presence or absence of lipid cores, chondroid and calcification were determined. Lawson staining (modified Elastica von Giesson, Verhoef staining), which exclusively stains the elastic laminae, was used to delineate the internal elastic lamina, to permit an easier distinction between media and intima. Four Lawson-stained sections (20 $\mathrm{mm}$ apart) were used for morphometrical analysis. All morphometrical parameters were determined using a microscope coupled to a computerized morphometry system (Quantimet 570, Leica, The Netherlands). Plaque area excluding the underlying media was measured for each individual plaque, and measurements of chondroid and calcified area were performed. To facilitate the detection of calcified areas in the plaques, two sections $(28 \mu \mathrm{m}$ apart) were stained with Von Kossa. The relative collagen area (the percentage of area that stained positively for Sirius Red)(fig. $5.7 \mathrm{c}$ and d) was determined for each atherosclerotic plaque using the same morphometric system.

\section{Immunohistochemistry:}

Antibodies directed to $\alpha$-smooth muscle actin (ASMA ${ }^{\text {kic }}$ monoclonal antibody, 1:500; Sigma), Mac3 (1:30, Pharmingen) (fig. 5. 1e and f) and CD3 (A0452 polydonal antibody, 1:200; Dako) were used to identify smooth muscle cells, macrophages and T-cells respectively. The relative $\alpha$-smooth muscle actin area was determined by dividing the ASMA-positive area by total plaque area using the morphometric system. To determine the relative amounts of macrophage and T-lymphocyte content in an 


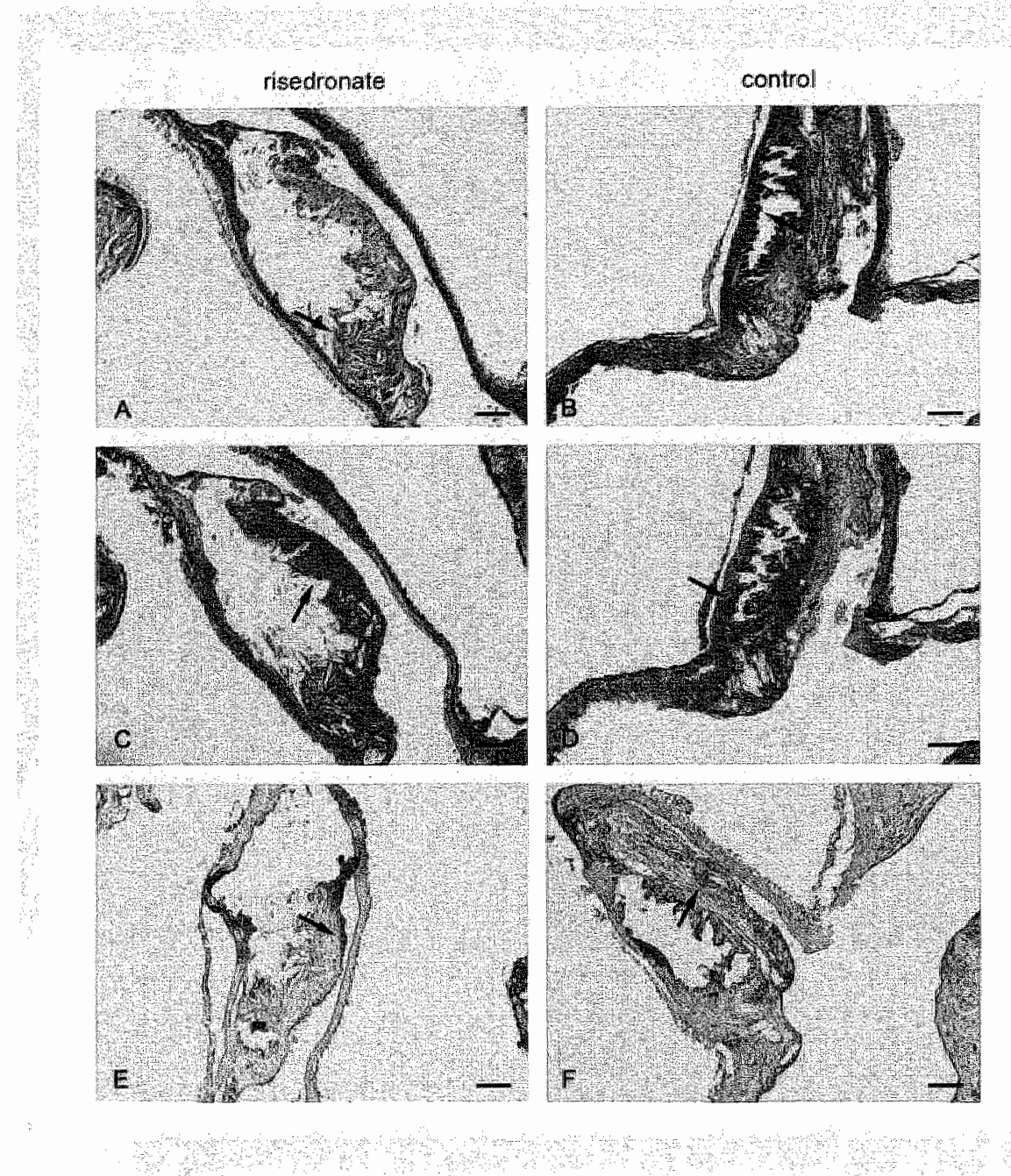

Fig. 5.1. Cross-5ections of the first branch (right carotid artery) of the aortic arch of respectively a risedronale treated mouse ( $a, c$ and e) and a control mouse (b, $d$ and $D$ stamed with H\&E (and b), sirus Red for the derection of collagen (c and d) and with monoclonal antibody directed io Mac 3 for the detection od macrophages (e and 1). arrow indicate cholestero cystak. b: arrow indicate calcification. $c$ and d: collagen is visualized in red. e and f: arrows indicate macrophages, wisualized iny red. Full color figures see page 160. 


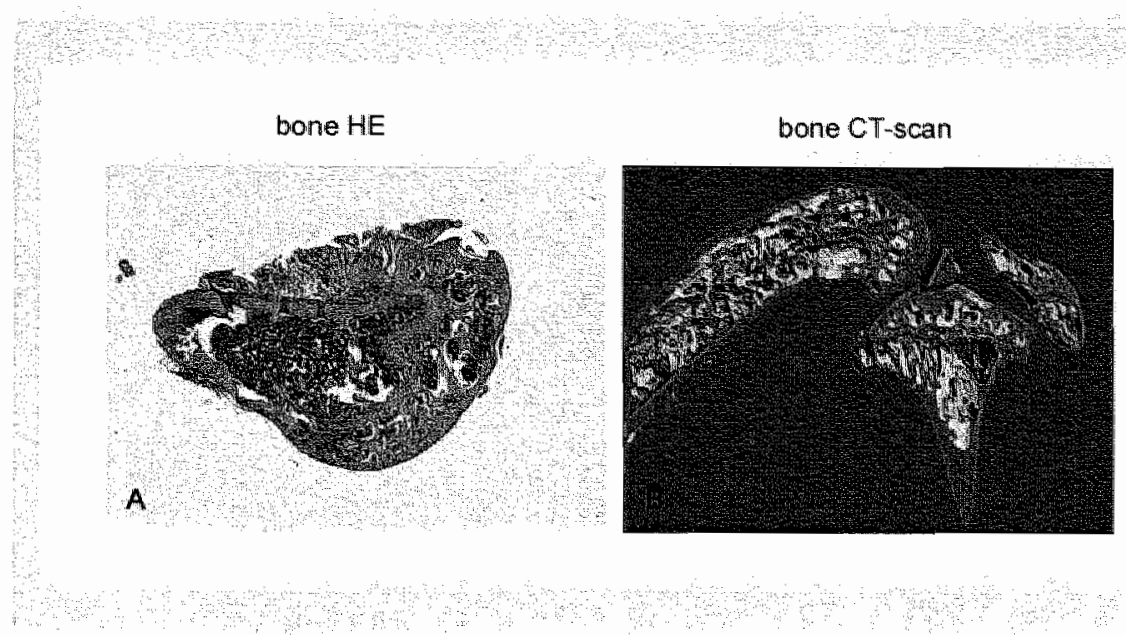

Fig. 5.2. Crossimections of a femw H\&E stained (a) and a three-dimentional microuCT scan of the left leg ffemur, knee joint and tibia) (b). Full color figures see aage 161.

atherosclerotic plaque, the number of Mac3- or CD3-positive cells in the lesion was divided by the total number of cells in the entire atherosclerotic plaque.

The expression profile of bane morphogenetic protein 2 (BMP-2), osteoprotegerin (OPG) and receptor activator of nuclear factor-KB (RANKL) were sudied with antibodies directed to BMP-2 (1:12.5, Santa Cruz), OPG (1:200, Santa Cruz) and RANKL (1:100, Santa (ruz). Incubation of the primary and secondary antibodies was performed using standard procedures. After incubation with an alkaline phosphatase-coupled avidin-biotin complex ( $\mathrm{ABC}$ complex, Dako), antibodies were visualised with an alkaline substrate kit I (Vector SK-5100, Vector Laboratories, Inc., Burlingame, CA, USA). Sections were counterstained with hematoxylin and mounted with coverslips. The primary antibody was omitted in negative contrals. Each staining was performed on one section per mouse.

\section{Bone structural measurements:}

After the mice were sacrificed, bones of the left leg (fermur, knee joint and tibia) were extracted, stored in PBS and frozen at $-20^{\circ} \mathrm{C}$. A micro-CT 5Canner ( $\mu$ CT80, 5canco Medical $A G$, Bassersdorf, Switzerland) was used to produce three-dimensional reconstructions of the distal femurs at an isotropic resolution of 10 microns (fig. 5.2). A volume of interest (VOI) was selected that comprises the trabecular bone in the femoral epiphysis. After thresholding the images, structural parameters were determined for this VOI using the Scanco 3D evalwation software. Parameters inciuded in this study 
are bone volume fraction (BV/TV), trabecular number (Tb.N), trabecular thickness (Tb. Th) and trabecular spacing (Tb.Sp).

\section{Statistical analysis}

All data are expressed as mean \pm SEM. Means between groups were compared by the use of the non-parametric Mann-Whitney $U$ test, and data were considered statistically significant at $p<0.05$.

\section{Results}

\section{General}

In the prevention (pWT low dose) experiment 3 out of 24 risedronate and 1 out of 24 PB5 treated animals died. In the regression (rWT high and low dose) experiment no risedronate treated animals died while 3 out of 19 PBS treated animals died. In the regression normal chow (NNC low dose) experiment no animals died. In all three experiments, the starting body weights were not different between treated and control groups (table 5.3). Risedronate treatment induced a small (<10\%) loss of body weight but only in the normal chow (PNC low dose) experiment (risedronate group: body weight decreased from $35.0 \pm 0.6 \mathrm{~g}$ to $31.7 \pm 0.6 \mathrm{~g} ; \mathrm{p}=0.001$, controls: body weight loss from $35.7 \pm 0.7 \mathrm{~g}$ to $33.7 \pm 0.7 \mathrm{~g} ; \mathrm{p}=0.58$ ).

The atherogenic Western type diet resulted in a doubling of cholesterol, triglycerides and LDL plasma levels. Treatment with risedronate had no effect on this increase in lipoprotein levels. Similarly in the normal chow (rNC low dose) experiment risedronate did not affect plasma lipoprotein levels.

\section{Toxicology}

Histological analysis of all 20 organs did not reveal any differences between PBS and risedronate treated animals in any of the experiments.

\section{Bone}

Bone measurements revealed that risedronate treatment in the prevention WT low dose group (pWT low dose) and in the regression WT low dose group ( $\mathrm{WWT}$ low dose) has effects on bone parameters, however in the regression WT high dose (rWT high dose) there were no differences. In the PWT low dose group, volume fraction, trabecular numbering and thickness were increased, while trabecular spacing was decreased. Risedronate treatment in the regression WT low dose group (rWT low dose) showed an increase in trabecular thickness and a reduction in trabecular spacing. Risedronate treatment in the regression NC low dose group (NNC low dose) had no effect on the various bone parameters (table 5.4). 


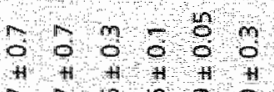

in m $\rho \circ$ o 9

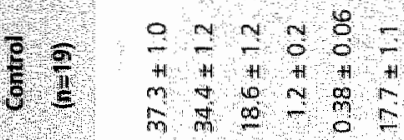

9.

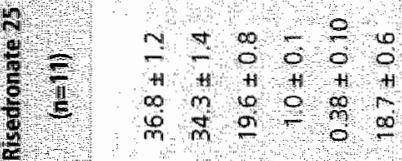

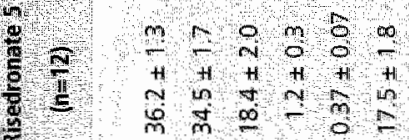

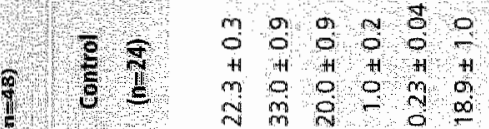

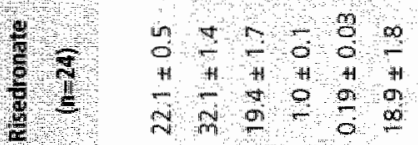

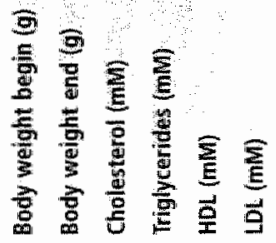

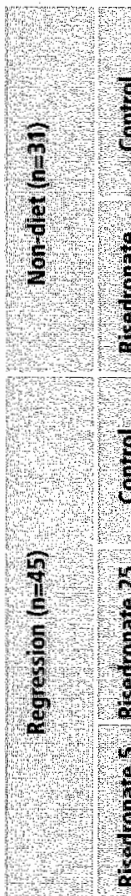

$\begin{array}{llll}3 & 9 & 8 & 8 \\ 0 & 0 & 8 \\ 0 & 4 & 0 & 0\end{array}$ 용

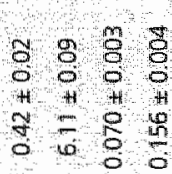

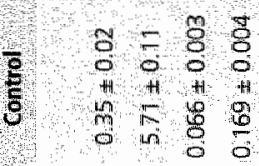

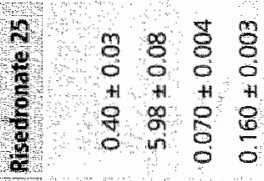

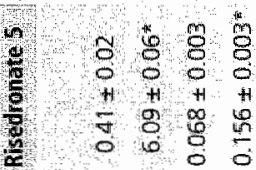

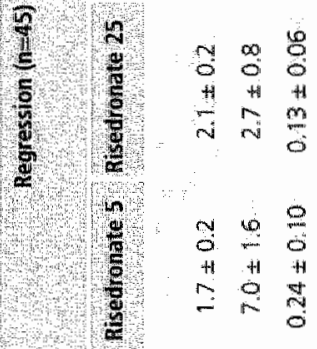

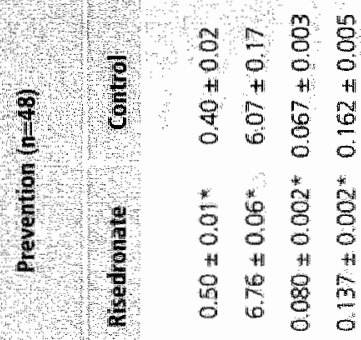
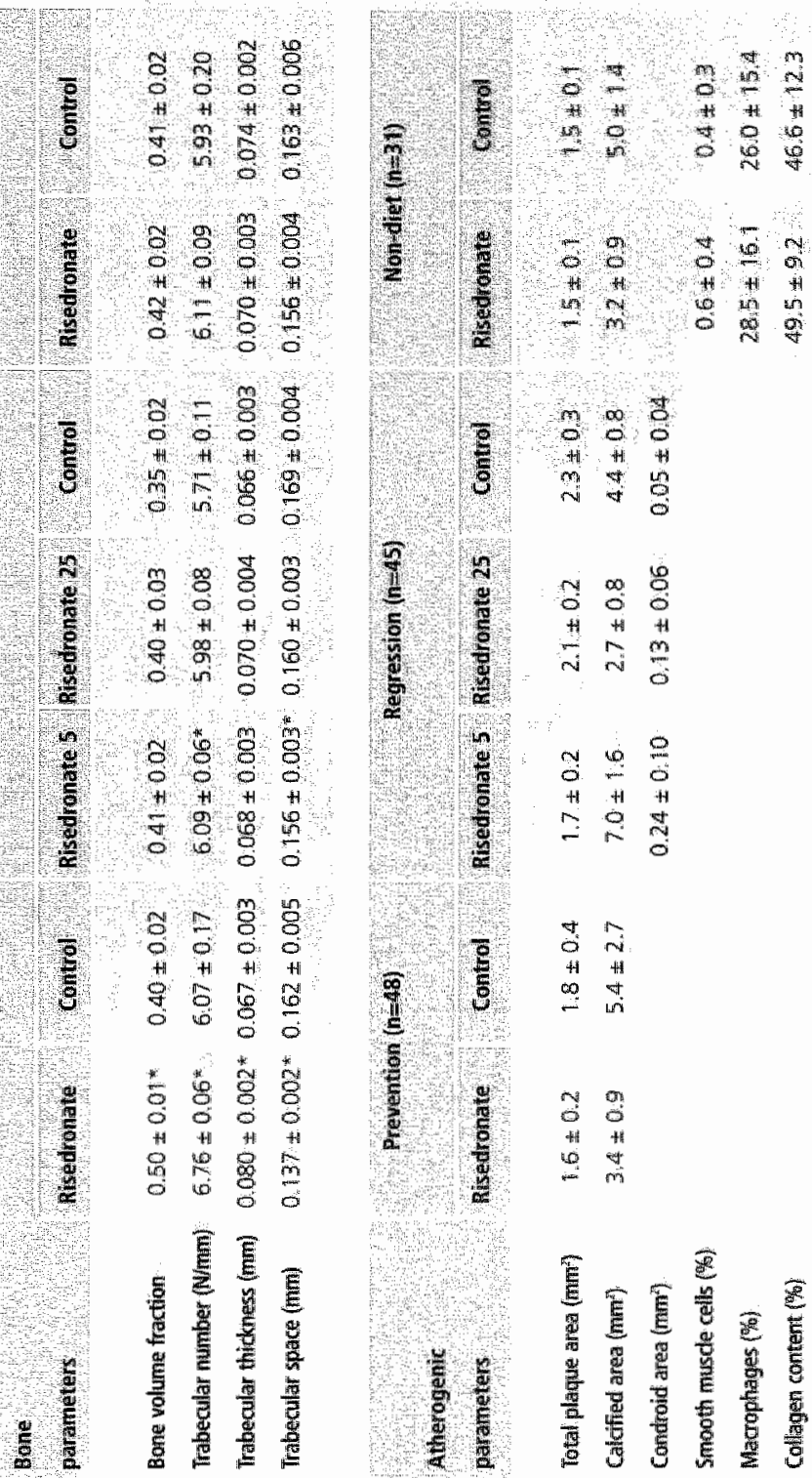

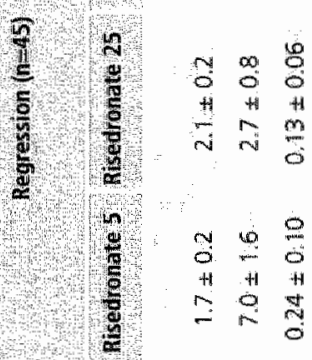
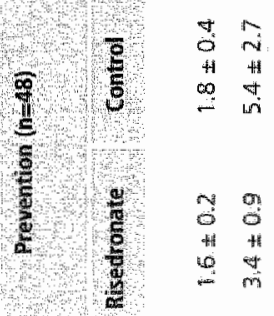

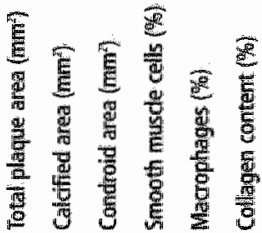




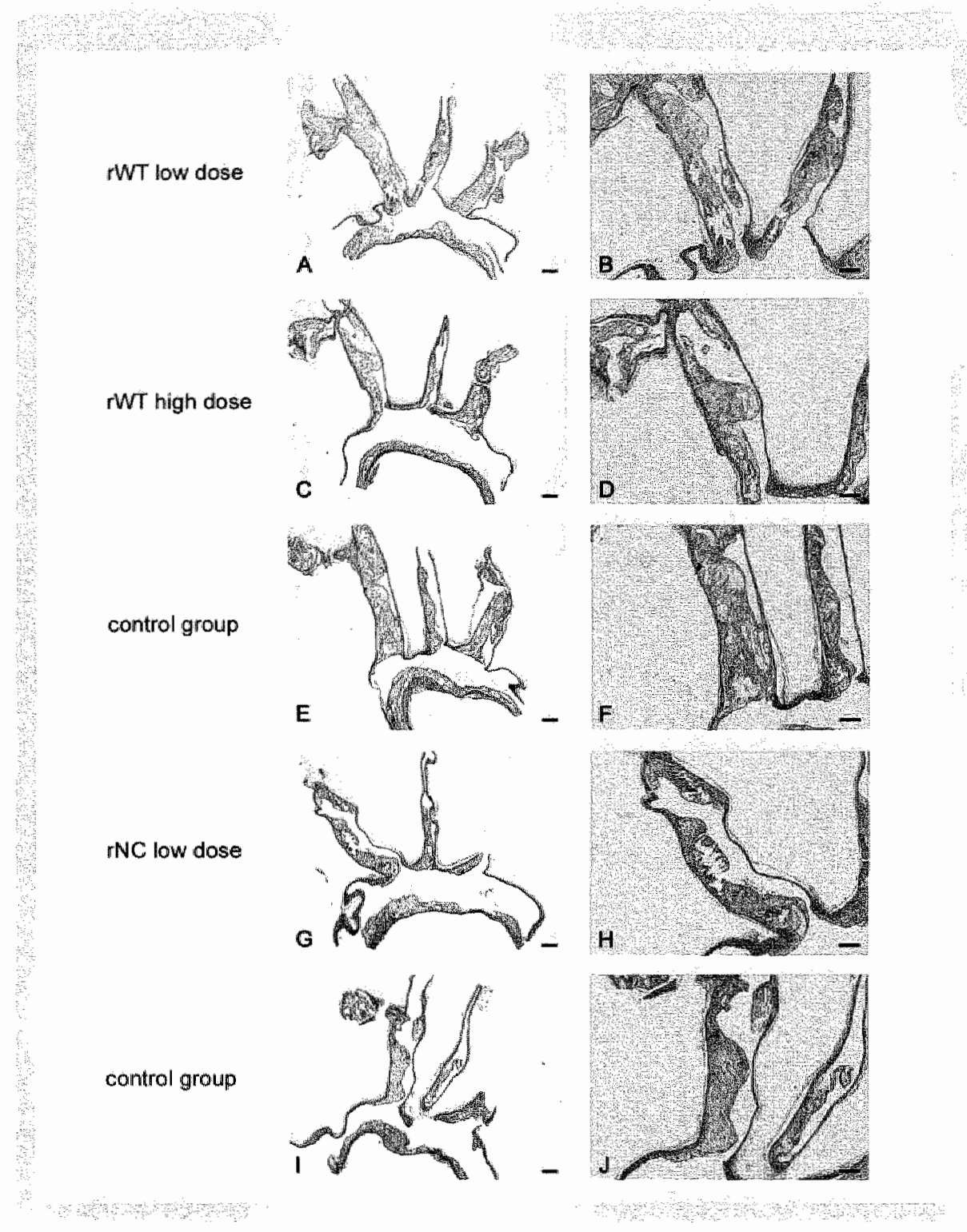

Fig. 5.3. Cross-sections of the complete aortic anch including the main branch points (a, $c, e_{n} g$ and i) and a higher magnification of the first branch (right carotid artery) (b, $d, f, h$ and $j$ ) of various groups and

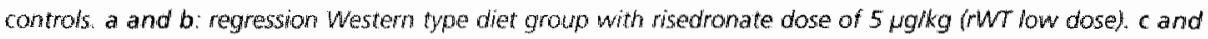
d. regression Western type diet group with risedronate dose of $25 \mu \mathrm{kg} k \mathrm{~kg}$ (FT high dose) and f: control group for the regression Western type diet experment. $g$ and hi regression normal chow group with risedronate dose of

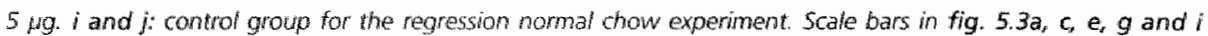
represent $300 \mathrm{um}$, and in fig. $5.3 \mathrm{~b}, \mathrm{~d}, \mathrm{f}$ h and the scale bars represent $200 \mathrm{\mu m}$. Full color figures see page 162 . 


\section{Atherosclerosis}

All atherosclerotic lesions in the aortic arch of mice in the prevention ( $\mathrm{pWT}$ low dose), regression (IWT high and low dose) and normal chow (NNC low dose) experiments were analyzed (table 5.5).

Risedronate at a dose of $5 \mu \mathrm{g} / \mathrm{kg}$ had no effect on total plaque area. This was true for the prevention ( $\mathrm{pWT}$ low dose) and regression ( $r W T$ low dose) experiment (Western type diet) and the normal chow ( $\mathrm{NC}$ low dose) experiment. Similary the high dose of $25 \mu \mathrm{g} / \mathrm{kg}$ in the rWT high dose experiment did not affect total plaque area. Detailed phenotypic analysis of the plaque did not show any differences between control and risedronate treated groups (fig. 5.3). The percentage of macrophages, smooth muscle cells and collagen was not different. Chondroid and calcified area in the plaque were also not affected by risedronate treatment in any of the four groups.

\section{Immunohistochemistry}

Evaluation of sections, immunohistochemically stained with antibodies directed to BMP-2, OPG and RANKL (fig. 5.4) revealed expression of all three bone related proteins in atherosclerotic plaques of ApoE-/- mice. Expression of BMP-2 was mainly present in and around calcium mineral deposits in the plaques. Especially hypertrophic chondrocytes and calcifying chondrocytes showed BMP-2 expression, although BMP-2 was also present in some SMC in areas surrounding calcification. Like BMP-2, OPG and RANKL were also present in hypertrophic chondrocytes and calcifying chondrocytes. Additional, OPG showed immunoreactivity with endothelial cells in plaques. BMP-2, OPG and RANKL were present in both, risedronate treated animals and controls of all experimental groups. Distribution of these proteins were not effected by risedronate administration, in either the prevention WT experiment, the regression WT experiment or in the regression $\mathrm{NC}$ experiment.

\section{Discussion}

Risedronate, at doses that affected BMD and protected bone microarchitecture, had no effect on amorphous vascular calcifications. As no ectopic bone formation was detected in this animal model, the effect on ectopic bone formation could not be documented. The main findings of the present study are that chronic treatment with two different doses of the $\mathbb{N}$-containing bisphosphonate risedronate has no effects on atherosclerotic lesion instability, development and regression in ApoE-\% mice. Risedronate had no effects in mice fed a normal chow diet nor on mice fed an atherogenic Western type diet. Detailed phenotypical analysis of the atherosclerotic lesion, including quantification of the area of calcification in the plaque, did not yield 

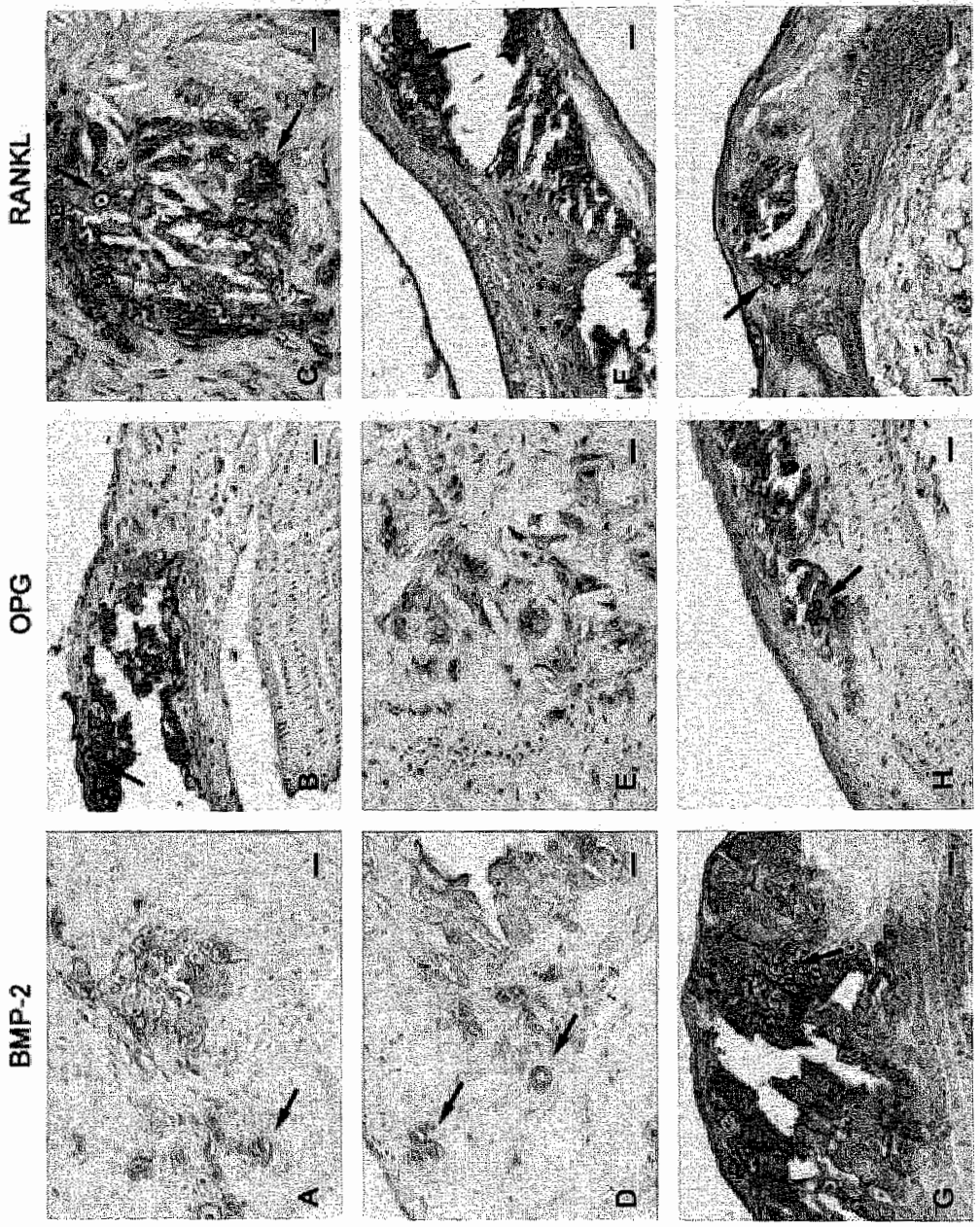

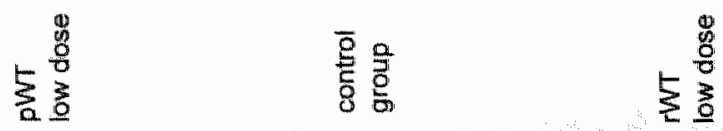

Fig. 5.4. Immumohistochemical staining of three bone matrix reguatory proteins (BMP-Z, OPG and RANKL) on murime atherosclerotic plaques of wariows experimemal groups. a, b and crepresent atherosclerotic plaques

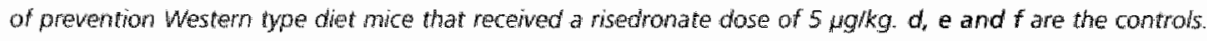
9. hand itepresent atherosichotic plaques of regression Western type diet mice that received a risedromate dose of $5 \mathrm{Hg} k \mathrm{~kg}$. The left panels are immunohistochemically staned with BMP-2. the middle panels with oPG and the right panels whth RANK. Fositive staining was wisualized in red. Mainly the chondrocytes (arrows) are positively staned for alle thee bone matrix proteins. Scale bars represent 20 m. Full color figures see page 163 . 


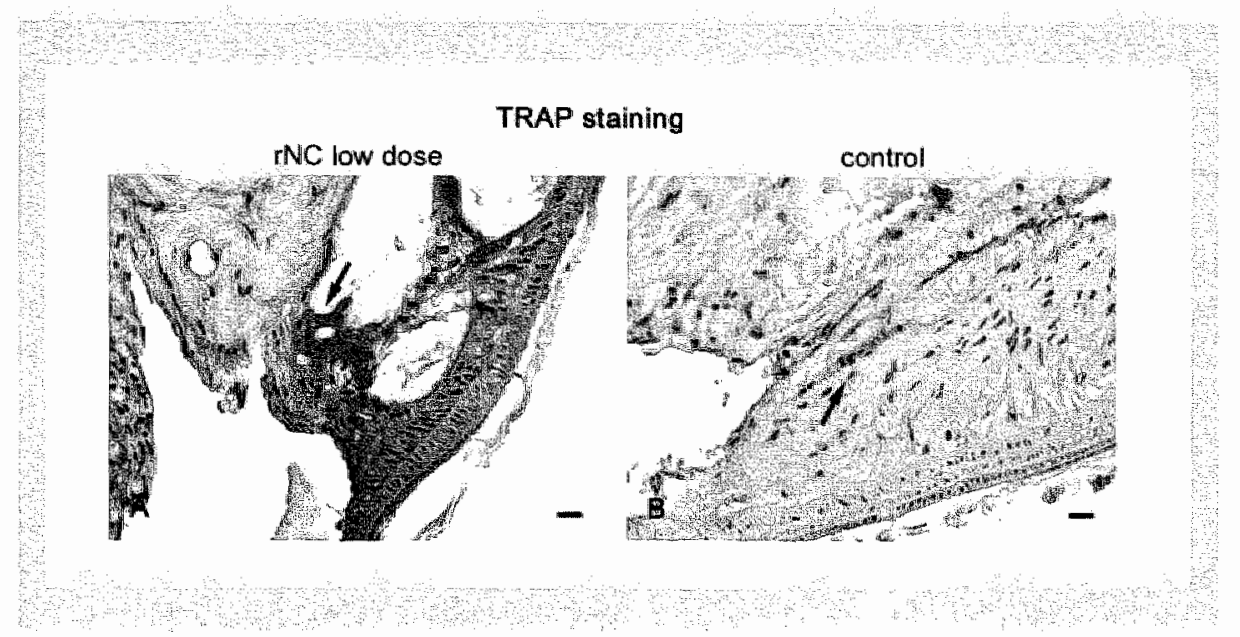

Fig. 5.5. Trap staining for the identification of osteoclasts. A singhe osteoclast farrowy present in an atherosclerotic plaque of the regression NC experiment (fig. 5.5a) and in the accessory controf groun (fig. 5.5b). Positive staining is visualized in brown. Scale bars represent $20 \mathrm{~mm}$. Full color figures see page 164.

any differences between risedronate and PBS treated animals, in either in the normal chow or Western type diet fed animals. Plasma lipoprotein levels increased with the high fat diet, but were unaffected by bisphosphonate treatment. Furthermore, a five-fold higher dose of risedronate did not result in any significant changes in plaque development, while protecting bone.

These findings are in accordance with several studies in humans which showed absence of effect of treatment with bisphosphonates on atherosclerosis lesion formation and progression using alendionate ${ }^{52}$ and ibandronate ${ }^{13}$. However, other studies in humans demonstrated possible negative effect of bisphosphonates on atherosclerosis" 1.4. 15. Shimshi et al. demonstrated that ApoE / mice treated with alendronate and risedronate had an increased risk of plaque rupture. There ane severall possibilities to explain these results. First of all the dose of risedronate might have been too low to have any effects on vascular calcifications. However, published data on risedronate administration in mice and rats ${ }^{15}$ resulting in a dose response relation ${ }^{*}$ indicate that we have used an appiropriate dose regimen. For instance Nakamura et al described that risedronate treatment in OPG $/$ - mice (10 $\mu \mathrm{g} \cdot \mathrm{kg}^{\prime}$. day " for 30 days) showed effects on bone resorption and bone formation ${ }^{8}$. Boyce et al. reported that one year of risedronate treatment in a dose of $5 \mu \mathrm{\mu g} . \mathrm{kg}^{\prime}$.day "subcutaneously administered for 1 week followed by 3 weeks without treatment enhanced bone density after ovariectorny" Lin et al. showed that risedronate increased bone density in rats in a dose regimen of $5 \mu \mathrm{g} / \mathrm{kg}$ "day" sc twice a week for 60 days". In a bone metastasis model in nude mice 
(approximately $20 \mathrm{~g}$ ) risedronate sc at a dose of $200 \mu \mathrm{g} \mathrm{kg}^{-1}$. day-i for 28 days slowed or inhibited the development of bone metastasis ${ }^{18}$. A proof of concept study on vascular calcification showed that the bisphosphanates ibandronate and alendronate in an oral dose of $50 \mu \mathrm{g} \cdot \mathrm{kg}^{1}$ day and $1000 \mu \mathrm{g} \cdot \mathrm{kg}^{-8}$. day for 14 and 28 days completely inhibited vascular calcification in the warfarin induced medial calcification rats ${ }^{19}$. However, these doses where higher then used in dinical practice and the warfarin model is different from the currently studied model, in that it results in ectopic bone formation in the blood vessels. Furthermore, evidence that we used the appropriate dose was revealed by the increase in bone mineral density observed after low dose risedronate treatment.

Another possibility is that chronic inhibition of the mevalonate pathway by risedronate induced counter-regulatory pathways that reduce calcification. Possible candidates are the downregulation of BMP-2, OPG and upregulation of RANKL. Immunohistochernical analysis of BMP-2, OPG and RANKL protein expression in the different treatment groups do not support this hypothesis since the expression of all three proteins appeared not to be regulated by chronic risedronate administration.

A third possibility is that the high fat diet may have overruled the possible effects of risedronate. This is unlikely, however since the drug did not have an effect in animals receiving a normal chow diet.

A fourth possibility to explain the negative finding of this study is that the proposed mechanism whereby bisphosphonates enhance bone density and microarchitecture, which is by the inhibition of osteoclasts, does not occur in atherosclerotic lesions in mice. We and others have shown the presence of osteoclasts in human atherosclerotic lesions which colocalize with lamellar bone structures ${ }^{72.26,21}$, suggesting that these osteoclasts are associated with the transition of caleified cartilage into lamellar bone. Thus far, no published data are available on the presence of osteoclasts in atherosclerotic plaques in mice. However, we found a single osteoclast present in an atherosclerotic plaque of the regression NC experiment and in the accessory control group (fig. 5.5). Unilke in human plaques, lamellar bone structures have never shown in advanced atherosclerotic plaques of ApoE- $/$ - mice. The fact that lamellar bone is absent and osteoclasts appear sporadically present in atherosclerotic plaques of ApoE-f-mice suggests that our negative results in mice can not be extrapolated to humans. Risedronate had little effect on the bone structure in the regression groups. Significant changes in bone structural parameters were found in the regression WT low dose group, the changes were within the expected range (10-20\% for TB/BV). This can be explained by the fact that the animals in the regression groups were older (29 to 41 weeks) than the animals in the prevention WT low dose group ( 5 to 29 weeks). These younger animals have a higher bone turnover during their growth. A significant increase in bone density and structural quality (as expressed by increased trabecular thickness and number and 
reduced trabecular spacing) was found, however, for the prevention group. A possible explanation for this finding is that the bones in these animals are still in a growth process, which includes osteoclastic activity. Inhibition of osteoclastic activity by risedronate, at this stage might hinder the removal of surplus bone that can exist during growth". Inhibition of bone removal results in a higher bone mass in these mice.

Suppression of osteoclasts in bone might alter bone matrix regulatory proteins in bone and in atherosclerotic plaques. However, our data revealed no altered protein expression profile of BMP-2, OPG or RANKL.

The association of osteoporosis with vascular calcification has been widely reported ${ }^{23-27}$. Thus far only two articles were published on the effect of bisphosphonates on arterial calcification in osteoporotic patients. One small pilot study indicated that oral alendronate administration did not accelerate the rate of coronary artery calcification ${ }^{12}$. However Tanko et al. ${ }^{2 A}$ recently described the effect of bisphosphonates on aortic calcification in osteoporotic patients, and concluded that a 3-year treatment with effective doses does not pose any altering in vascular calcification. Our data show that risedronate did not affect vascular calcification in atherosclerotic lesions of ApoE- $/$ - mice.

In conclusion these findings indicate that risedronate treatment has a positive effect on bone mineral density and bone microarchitecture but does not alter atherosclerotic vessel wall plaque progression or calcification. 


\section{References}

1. Benford HL, McGowan NW, Heltrich MH, et al. Visualization of bisphosphonate-induced caspase-3 activity in apoptotic osteodlasts in vitro. Bore. 2001:28:465-73.

2. Cummings $\$ \mathbb{R}$, Bauer DC. Do statins prevent both cardiovascular disease and fracture? Jama. 2000;283:3255-7.

3. Harris $S T$, Watts NB, Genant HK, et al. Effects of risedronate treatment on vertebral and nonvertebral fractures in women with postmenopausal osteoparosis: a randomized controlled trial. Vertebral Efficacy With Risedronate Therapy (VERT) Study Group. Jama. $1999 ; 282: 1344-52$.

4. MCClung MR, Geusens P, Miller PD, et al. Effect of risedronate on the risk of hip fracture in elderly wormen. Hip Intervention Program Study Group. N Engl I Med. 2001:344(5):333-340.

5. Brown JP, Chines AA, Myers WR, et al. Improvement of pagetic bone lesions with risedronate treatment: a radiologic study. Bone, 2000;26:263-7.

6. Hosking DJ, Eusebio RA, Chines AA. Paget's disease of bone: reduction of disease activity with oral risedronate. Bone. 1998;22:51-5.

7. Dhore CR, Cleutjens JPM, Lutgens $E$, et al. Differential expression of bone matrix regulatory proteins in human atheroscleratic plaques. Arteriosclerosis. Thrombosis and Vascular Biology. 2001:21:7998-2003.

8. Nakamura $M$, Udagawa $N$, Matsuura $S$, et al. Osteoprotegerin regulates bone formation through a coupling mechanism with bone resorption. Endocrinology 2003;144:5441-9. Epub 2003 Sep 18.

9 Shimshi $M$, Abe $E$, Fisher $E A$, et al. Bisphosphonates induce inflammation and rupture of atherosclerotic plaques in apolipoprotein-E null mice. Biochem Biophys Res Commun. 2005;328(3):790-793.

10. Lutgens $E$, Daemen $M$, Kockx $M$, et ad. Atherosclerosis in APOE*3-Leiden transgenic mice: from proliferative to atheromatous stage. Circulation. 1999;99:276-83.

11. Vimani $R$, Kolodgie FD, Burke AP, et d. Lessons from sudden coronary death. A comprenensive morphological classification scheme for atherosclerotic lesions. Arteriasclerosis Thrombosis and Vascular Biology. 2000;20:1262-1275.

12. Hill JA, Goldin JG, Gjertson D, et al. Progression of coronary artery calcification in patients taking alendronate for osteoporosi5. Acad Radiol. 2002:9:11:48-52.

13. Tanko $L B$, Qin $G$, Alexandersen $P$, et al. Effective doses of ibandronate do not influence the 3-year progression of aortic calcilication in elderly osteoporotic women. Osteoporos int. $2004: 10: 10$.

14. Goldstein MR. Bisphosphonate therapy and vascular calcification. Jama. 2000:283(4): 1424-1425.

15. Goldstein MR. Long-term therapy for postmenopausal asteoporosis: stronger bones but weaker arteries. Circulation. 1999;100(4):446-447. 
16. Lin BY, Jee WS, Ma YF, et al. Effects of prostaglandin $E 2$ and risedronate administration on cancellous bone in older female rats. Bone. 1994; 15:489-96.

17. Boyce RW. Wronski TJ, Ebert DC, et al. Direct stereological estimation of three-dimensional connectivity in rat vertebrae: effect of estrogen, etidronate and pisedronate following ovariectomy. Bone 1995;15:209-13.

18. Sasaki $A$, Boyce $B$, , Story $B$, et al. Bisphosphonate risedronate reduces metastatic human breast cancer burden in bone in nude mice. Cancer Res. 1995;55:3551-7.

19. Price PA, Faus SA, Williamson MK. Bisphosphonates alendronate and ibandronate inhibit artery calcification at doses comparable to those that inhibit bone resorption. Arteriosclerosis Thrombosis and Vascular Biology. 2001:21:817-824.

20. Jeziorska M, McCollum C, Wooley DE. Observations on bone formation and remodeling in adwanced atherosclerotic lesions of human carotid arteries. Wirchows Arch. 1998:433:559-565.

21. Hunt $J$, Fairman $R$, Mitchell ME, et al. Bone formation in carotid plaques: a clinicopathological study. Stroke. 2002;33:1214-9.

22. Tanck E, Hommingla J, van Lenthe GH, et al. Increase in bone volume fraction precedes architectural adaptation in growing bone. Bone. 2001;28:650-4.

23. Ouchi $Y$, Akishita M, de Souza AC, et al. Age-related loss of bone mass and aortic/aortic walve calcification-peevaluation of recommended dietary allowance of calcium in the elderly. Ann N Y Acad Sci. 1993:676:297-307.

24. Banks $\mathrm{LM}_{\star}$ Lees $\mathrm{B}$, MacSweeney JE, et al. Effect of degeneratiwe spinal and aortic calcification on bone density measurements in post-menopausal women: links between osteoporosis and cardiovascular disease? Eur J Clin Invest. 1994;24:813-7.

25. Sugihara $N$. Matsuzaki $M$. The influence of severe bone loss on mitral annullar calcification in postmenopausal osteoporosis of elderly Japanese women. Jpn Circ 1. 1993;57(1):14-26.

26. Boukhris $\mathrm{R}$, Becker $\mathrm{KL}$. Calcification of the aorta and osteoporosis. A roentitgenogiraphic study. Jama. 1972:219:1307-11.

27. Dent CE, Engelbrecht HE Godfrey RC. Osteoporosis of lumbar vertebrae and calcification of abdominal aorta in women living in Durban. Br Med J. 1968:4:76.9. 



\section{Chapter 6}

General discussion 
In this thesis we investigated aspects of the molecular regulation of vascular calcification. We hypothesized that bone matrix regulatory proteins that are associated with skeletal bone formation are also involved in the initiation and progression of vascular calcification. We further hypothesized that enhanced BMP-2 gene expression accelerates atherosclerotic caleification and ossification and that bisphosphonates reduce valscular calcification.

The main conclusions derived from the studies are that both atherosclerotic and aortic valve calcifications are indeed actively regulated processes involving bone matrix regulatory proteins. This regulation involves both activators and inhibitors of calcification and bone formation. We also conclude that BMP-2 is one of the major active regulators of vascular calcification and that in an atherosclerotic mouse model bisphosphonates have no influence on vascular calcification when given in a dose that enhances bone density. 


\section{Active stimulation and inhubition of vascular calcification}

Many studies revealed that vascular smooth muscle cells and pericytes have the potential to undergo osteogenic differentiation ${ }^{i-4}$. While our studies clearly show active regulation of vascular calcification including activators and inhibitors, schinke described another model of vascular calcification. He described that the passive deposition of calcium phosphates in the arterial wall could only occur when active inhibitors of calcification were no longer able to prevent precipitations, thus proposing an active inhibition model. A third model is described by Price and colleagues. They reasoned that since vascular calcification is linked to osteoporosis, calcium and phosphate concentrations in the blood are enhanced, which stimulates the formation and growth of crystal nuclei in the arterial wall. Soft tissue calcification is promoted by crystal nuclei generated at sites of bone resorption that travel via the blood and occasionally lodge in soft tissue structures. The observation that reduction of bone resorption by bisphosphonates has no effects on serum levels of free calcium and phosphate, but reduces arterial medial calcification by inhibiting the release of a complex of calcium phosphate mineral and MGP from bone into the blood, does not support a strictly passive model. In fact, these data support the active inhibition model described by Schinke. Our data suggest not only active inhibition but alsa active stimulation of vascular calcification.

Giachelli? described that the uptake of inorganic phosphate by SMC that were exposed to inorganic phosphate levels similar to those seen in patients with end stage renal disease (>1.4 mmol/L) is facilitated by mediation of the sodium dependent phosphate co-transporter type III, Pit-1. Pit-1 aiso induces the expression of Cbfa-1 in these aortic SMC, resulling in an enhanced expression of osteogenic markers and calcification of wascular cells ${ }^{8}$. These results indicate that Cbfa-1, a bone matrix regulatory protein, is stimulated by inorganic phosphate levels, which can indirectly induce vascular calcification. They also suggest that the increased risk for vascular calcification in patients with end stage renal disease may be explained by such an active model, rather than the simple precipitation of calcium and phosphate as suggested in the passive model. Vattikuti et al. suggested that tissue calcium phosphate deposition may serve as a metabolic stressor that induces BMP-2, thereby enhancing calcification". This points to the importance of bone matrix regulatory proteins, such as BMP-2, besides calcium and phosphate serum levels in the regulation of vascular calcification. Thus also recent data from several other laboratories suggest an active regulation of vascular calcification rather than a passive precipitation of calcium and phosphate in the vessels. This active regulation involves at least active inhibition and most probably also active stimulation.

Vascular calcification is not only regulated by bone matrix regulatory proteins, but also involves mechanisms of skeletal bone formation as demonstrated in chapters 2 and 3 of this thesis, where we described cartilage, matrix wesicles and lamellar bone 
formation in calcified human atherosclerotic plaques and aortic valves. The finding that in human atherosclerotic lesions mature bone tissue is frequently anchored to amorphous mineralized matrix ${ }^{10}$, resembling intramembranous ossification, suggests that amorphous mineral matrix serves as a scaffold for mature bone formation even in atherosclerotic plaques. The chondrocytes that form the cartilage in the vessel wall are thought to align to calcified amorphous mineral deposits ${ }^{1.32}$. Both chondrocytes and calcified amorphous mineral deposits form nuclei for endochondral ossification". One of the candidate regulators of both intramembranous and endochondral vascular ossification is BMP-2.

\section{Molecular regulation of vascular calcification}

\subsection{BMP-2, an important active regulator of vascular calcification}

BMP-2 is an osteoinductive protein, which induces intramembranous bone formation via Msx-2 upregulation but also endochondral bone formation and neovascularisation via Cbfa-1 upregulation". Based on the data described in chapter 4 we conclude that atherosclerotic calcification and ossification are accelerated by BMP-2 and associated with an altered bone matrix regulatory protein expression profile illustrated by an upregulation of BMP-4, OC, OPG, OPN and a downregulation of RANKL. This is supported by data from Bächner et al. They demonstrated that multipotent mouse embryonic cells, also known as vascular progenitor cells ${ }^{14}$ when stimulated with BMP-2 differentiate along osteogenic and chondrogenic lineages ${ }^{15}$. Moreover, BMP-2 can potently induce the expression of Cbfa-1, Sox-9 and Msx-2, transcription factors that are upregulated in the calcified vasculature ${ }^{4.15,17}$ (fig. 6.1). In diabetes Cheng et al. provided evidence that aortic myofibroblasts respond to BMP-2/Msx-2, resulting in medial calcification independent of $\mathrm{Cbfa}-1^{18}$. In atherosclerotic calcification however, the Cbfa- 4 dependent endochondral assification appears to predominate since in plaques Cbfa-1 gene expression is much higher than Msx-2 gene expression".?

Besides these direct effects of BMP-2 on vascular calcification it also has indirect effects by altering the expression of other bone regulatory proteins (fig. 6.2). Cellular transfection with BMP-2 $2^{20}$ causes an upregulation of alkaline phosphatase activity, osteocalcin, osteopontin and type I collagen ${ }^{21.23}$. Expression of two other bone matrix regulatory proteins BMP-4 and BSP is enhanced after BMP-2 induction in rat calvarial

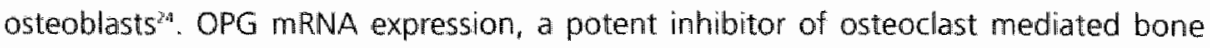
resorption is produced by osteoblasts and is present in human atherosclerotic plaques. Its expression is stimulated by BMP- $2^{25}$. BMPs play a critical role in bone remodeling and maintenance of the structural integrity of the skeletal system, due to their ability to induce osteoblastic differentiation ${ }^{25}$. The inhibitory effect of MGP on BMP-2 is 


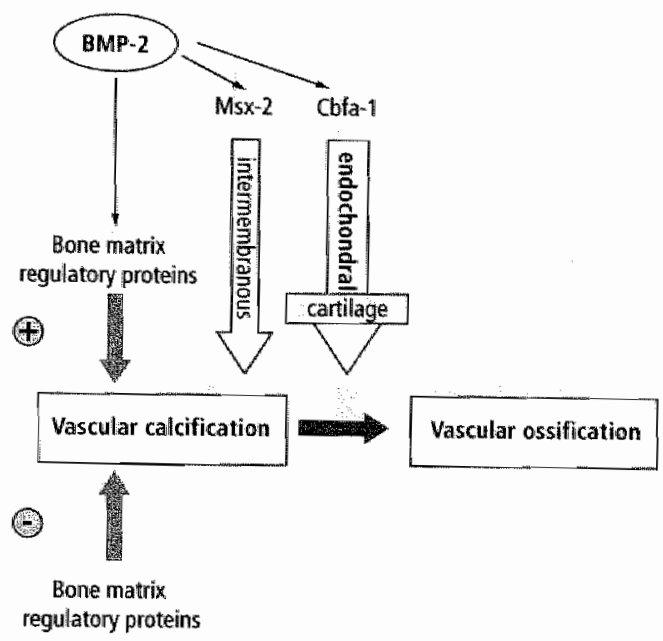

Fig. 6.1 The role of BMP-2 vascular calcification.

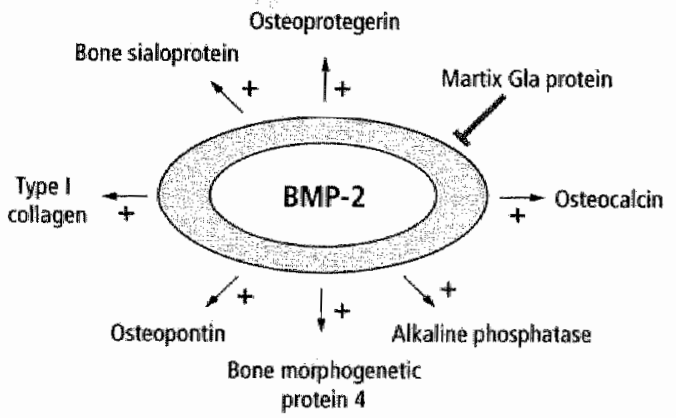

Fig. 6.2 The role of BMP 2 on bone matrix regulatory proteins

concentration dependent". Since BMP-2 has both direct and indirect effects, we consider BMP-2 as a major activator of vascular calcification.

\subsection{Possible novel regulators of vascular calcification}

To identify possible novel regulators of vascular calcification we performed a DNA micro-array experiment, using a DNA micro-array with 8000 human genes spotted in duplo (Clontech). We compared the expression protiles of human non-calcified fibrous 
cap atheromas and fibrocalcific plaques. After hybridization, about $10 \%$ of the spotted genes were differentially expressed. We selected four differentially expressed bone associated genes for further validation, bone morphogenetic protein 3 (BMP-3). cartilage linking protein 1 (CRTL-1), craniofacial developmental protein 1 (CFDP-1), and cysteine knot superfamily 1 (Cktsfi-b1). While the DNA array revealed an upregulation of BMP-3 and CRTL-1 in non-calcified plaques and an upregulation of CFDP-1 and Cktsf-1-b1 in calcified plaques, quantitative Real Time PCR on non-calcified fibrous cap atheromas, fibrocalcific plaques and on human non-calcified and calcified aortic valves showed a significant upregulation of onlly BMP-3 in both human fibrous cap atheromas (fig. 6.3.a) and non-calcified aortic valves (fig. 6.3b). BMP-3 is a member of the transforming growth factor $\beta$ superfamily, and known as a negative regulator of bone density. Daluiski et al, showed that BMP-3 is an antagonist of osteogenic BMP5. BMP-3 inhibits BMP-2 mediated induction of Msx-2 and blocks BMP-2 mediated differentiation of osteoprogenitor cells into osteoblast ${ }^{28}$. BMP-3 knockout mice are viable and show increased trabecular bone density, however no vascular or valvular phenotype was reported ${ }^{29}$. The upregulation of $\mathrm{BMP}-3$ in non-calcified atherosclerotic plaques and aortic valves is in accordance with our earlier findings of the expression of inhibitors of calcification in non-calcified tissues (chapter 2 and 3). The enhanced expression of BMP-3 might inhibit the differentiation of vascular cells into osteogenic cells, resulting in the active inhibition of calcification and ossification in atherosclerotic plaques and aortic valves.

\section{Vascular calcification: good or bad?}

The deposition of solid calcified areas in atherosclerotic lesions occurs predominantly in advanced lesion ${ }^{30}$, with only speckled deposits in early lesions ${ }^{31}$. This indicates that the presence of solid calcified deposits is an indicator of advanced atherosclerotic disease and represents an increased risk for end stage organ damage ${ }^{3 x}$. Yet there has been a large debate in the literature on the effect of calcification on the stability of the plaque. Others stated that plaque calcification would further stabilize the plaque ${ }^{10.33}$, because soft plaques are more prone to rupture than calcified plaques ${ }^{36,35}$. Echomorphologic studies indicate that echolucent and ukerated atherosclerotic plaques are associated with a higher risk for ischemic cerebrovascular events, whereas echo-dense plaques are more prevalent in asymptomatic plaques ${ }^{35.37}$. It has also been proposed that the presence of both hard and soft tissue in the plaque makes it more vulnerable. That the presence of calcification in coronary atherosclerosis has been associated with a less favorable prognosis is supported by several studies. Autopsy studies have shown that calcification increases the risk of myocardial infarction independently of age ${ }^{32}$. Niskanen 

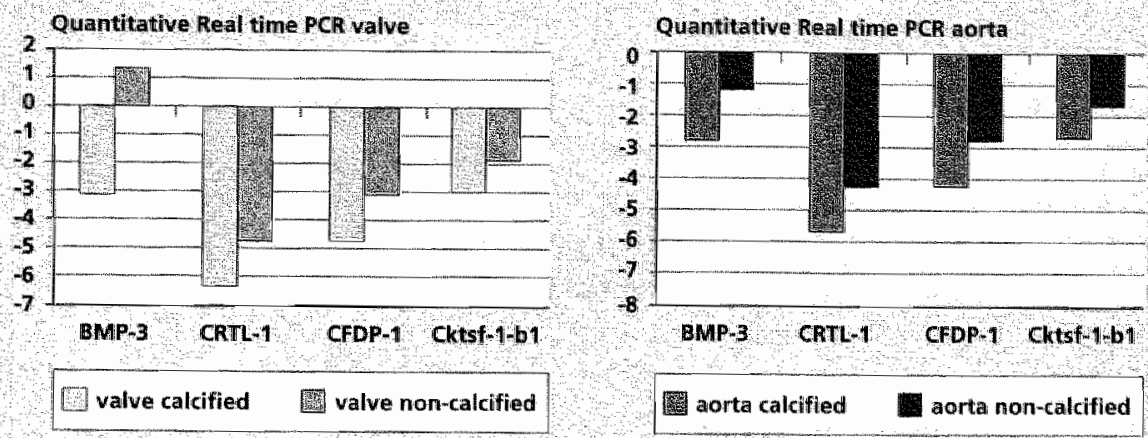

Fig. 6.3

et al. showed that calcification in peripheral vascular lesions increases the likelihood of ischemia. Vascular calcification has also been documented in patients with clinically significant coronary artery disease ${ }^{3 a}$ and it is a sensitive and specific predictor for future cardiac events ${ }^{39}$. Coronary calcification contributes to plaque rupture ${ }^{40}$ by increasing the stress at the interface of calcified and compliant structures in the arterial wall.

Thus the presence of calcification in the plaque increases the heterogeneity of the tissue and thereby the likelihood of rupture. Flanking calcification may function as an anchor on an individual plaque, reducing circumferential stress and the likelihood of subsequent rupture ${ }^{33}$. Shear stress increases at the edges of the calcified segment of the adjacent plaque, increasing the propensity for rupture ${ }^{4 !}$.

\section{Is regression of calcification in atherosclerotic lesions possible?}

Considering that vascular calcification is a risk factor, one has to find targets to prevent or reduce vascular calcification. The increased understanding of the molecular regulation of vascular calcification may provide novel possible targets for regression of vascular calcification. Because of the reciprocal effects of some factors on vascular and bone cells, one might be able to reduce both atherosclerotic calcification and osteoporosis. In the mouse, a bisphosphonate, risedronate inhibits both osteoclast function ${ }^{42,213}$ and cholesterol synthesis ${ }^{\text {sa }}$, but has no effect on vascular calcification as described in chapter 5, at least in the dose and model tested. Thus far, only limited data on the efficacy of bisphosphonates in the treatment of atherosclerosis are available in the literature ${ }^{45}$. Recently Tanko et al. ${ }^{46}$ described the effect of bisphosphonates on aortic calcification in osteoporotic patients, and concluded that a 3-year treatment with 
effective doses does not pose any altering in vascular calcification.

As bisphosphonates, statins interfere with the mevalonate cholesterol biosynthesis pathway, albeit at a different point. Statins also have reciprocal effects on vascular and bone cells. Treatment with statins has been shown to reduce vascular calcification in humans ${ }^{a, n}$. These effects are associated with reduced serum lipid levels. Bea and colleagues demonstrated a significant $56 \%$ reduction in vascular calcification. independent of the lipid lowering effect of statins ${ }^{49}$. They also showed that statins have stabilizing effects on advanced atherosclerotic lesions. Whether stabilization of advanced plaques is due to the reduction of vascular calcification is still unclear.

In vitro, statins have bone forming potential by increasing the synthesis of BMP-2 by osteogenic progenitor cells: $5^{50}$. They also substantially reduce the risk of bone fractures in older women ${ }^{51}$. Studies are ongoing to examine the effects of statins in treatment of osteoporosis ${ }^{\mathrm{s} 2}$.

A major protein capable of inhibiting BMP-2, and thus vascular calcification, is MGP. MGP contains Gla residues that are activated by vitamin $K^{5 i}$. Jie et al. demonstrated that in postmenopausal women, the presence of atherosclerotic calcification in the abdominal aorta is associated with a marginal vitamin $K$ status ${ }^{54}$. Warfarins are vitamin $K$ antagonists and used in anti-coagulation therapy in cardiac patient $5^{55}$. Warfarins induce vascular calcification by blocking vitamin $K$ and hence MGP thereby reducing the inhibition of BMP-2 activity ${ }^{2 x}$, However, the warfarin induced vascular calcification can also be inhibited by osteoprotegerin, that is also regulated by BMP-25:5.3 Thus, in the active regulation of vascular calcification, the BMPs are key molecules.

BMP-3, which we identified in our micro-array, might also have therapeutic potential in inhibiting the progression of vascular calcification. Whether it has reciprocal effects on vascular-and bone cells is not known yet and its capacity to reduce calcification in plaques is still elusive. However, BMP-3 might be beneficial in preventing vascular calcification by inhibiting BMP-2.

\section{Limitations of the study}

In this thesis we showed that valvular and vascular calcifications are actively regulated by both active inhibitors and active stimulators (chapter 2 and 3 ). Since these studies were designed to be descriptive, we did not perform molecular interventions with these regulators of vascular calcification, except for BMP-2. This key molecule was used to determine the effects on vascular calcification in mice (chapter 4). However, interventions with the other regulators of vascular calcification would be elusive and most suited to further dissect the molecular pathways inwolved.

A second limitation is the choice to use small animal models for in vivo interventions 
(chapter 4 and 5). With the use of mouse models, we restricted the passibility to investigate vulnerability of the plaques, since these are rather limited, if not absent in mice. The use of larger animal models, such as the rabbit will enable to study the role of vascular calcification in plaque vulnerability. Another limitation of the use of mice is the apparent lack of lamellar bone structures and the paucity of osteoclasts in advanced lesions, which may reduce the effectiveness of therapeutic interventions such as bisphosphonates that act on osteoclasts.

Randomized clinical studies will be necessary to translate the findings of our animal studies to humans. 


\section{References}

1. Doherty MJ, Ashton BA, Walsh $S$, et al. Vascular pericytes express osteogenic potential in vitro and in vivo. Joumal of Bone and Mineral Research. 1998; 13:828-838.

2. Canfield AE, Doherty M!, Wood AC, et al. Role of pericytes in vascular calcification: a review. Zeitschrift fur Kardiologie. 2000,89:11 20-27.

3. Demer $L L$, Tintut $Y$. Mineral exploration: search for the mechanism of vascular calcification and beyond: the 2003 Jeffrey M. Hoeg Award lecture. Arterioscler Thromb Vasc Biol. 2003:23:1739 43 . Epub 2003 Sep 4.

4. Bostrom $K$, Watson $K E$, Horn 5 , et al. Bone morphogenetic protein expression in human atherosclerotic lesions. Joumal of Clinical Investigation. 1993;91:1800-1809.

5. Schinke T, Mckee MD, Karsenty G. Extracellular matix calcification: where is the action? Nature Genetics. 1999:21:150-151.

6. Price PA, Faus SA, Williamson MK. Bisphosphonates alendronate and ibandronate inhibit artery calcification at doses comparable to those that inhibit bone resorption. Arteriosclerosis Thrombosis and Vascular Biology. 2001;21:817-824.

7. Giachelli CM. Wascular calcification: in vitro evidence for the role of inorganic phosphate. J Am Soc Nephrol. 2003; 14:5300 4.

8. Jono 5. Mckee MD. Murry CE, et al. Phosphate regulation of vascular smooth muscle cell calcification. Circulation Research. 2000;87:E10-E17

9. Vattikuti $R$, Towler $D A$. Osteogenic regulation of vascular calcification: an early perspective. Am J Physiol Endocrinol Metab. 2004;286:E686-96.

10. Hunt JL, Fairman R, Mitchell ME, et al. Bone formation in carotid plaques; a clinicopathological study. Sroke. 2002;33:1214-9.

11. Qiao $\mathrm{HH}_{x}$ Mertens RB, Fishbein MC, et al. Cartilaginous metaplasia in calcified diabetic peripheral wascular disiease: morphologic evidence of enchondral ossification. Hum Pathol. 2003;34:402.7

12. Hadjisky P, Donev S. Renais J, et af. Cartilage and bone formation in arteriah wall. 1 . Morphological and histochemical aspects. Basic Res Cardiol 1979:74:649-62.

13. Karsenty G. Minireview: Transcriptional Control of Osteoblast Differentiation. Endocrinology. $2001 ; 142: 2731-2733$.

14. Hirschi KK, Rohovsky SA, DAmore PA. PQGF, TGF- $\beta$, and heterotypic cell-cell interactions mediate endothelial cell-induced recruitment of $1071 / 2$ cells and their differentiation to a smooth muscle fate J Cell Biol. 1998;141805-14.

15. Băchner $D$, Ahrens $M$, Schröder $D$, et al. Bimp-2 downstream targets in mesenchymal development identified by subtractive cloning from recombinant mesenchymal progenitors (C3H10T1/2). Developmental Dyramics. 1998:213:398-41\%.

16. Lee $\mathrm{KS}$. $\mathrm{Km} \mathrm{H} /$, $\mathrm{i} \mathrm{QL}$, et al. Runx2 is a common target of transforming growth factor $\beta 1$ and bone morphogenetic protein 2, and cooperation between Runx.2 and 5 mad 5 induces osteoblast-specific gene expression in the pluripotent mesenchymal precursor cell line C2C12. Mol Cell Biol. 2000;20:8783-92. 
17. Kramer J, Hegert C, Guan K, et al. Embryonic stem cell-derived chondrogenic differentiation in vitro: activation by BMP-2 and BMPw4, Mech Dev. 2000:92:193-205.

18. Cheng SL, Shao JS, Charlton-Kachigian N, et al. MSX2 promotes osteogenesis and suppresses adipogenic differentiation of multipotent mesenchymal progenitors. I Biol Chem. 2003:278:45969-77. Epub 2003 Aug 18.

19. Tyson $\mathrm{KL}$, Reynolds $\mathrm{JL}$, McNair $\mathrm{R}$, et al. Osteorchondrocytic transcription factors and their target genes exhibit distinct patterns of expression in human arterial calcification. Arterioscler Thromb Vasc Biol. 2003;23:489-94.

20. Takuwa $Y$, Ohse $C$, Wang $E A$ et al. Bone morphogenetic protein- 2 stimulates alkaline phosphatase activity and collagen synthesis in cultured osteoblastic cells, MCBT3-E1. Biochem Biophys Res Commun. 1991:174:96-101.

21. Cheng SL, Lou J, Wright NM, et al, In witro and in vivo induction of bone formation using a recombinant adenoviral vector carrying the human BMP-2 gene. Calcif Tissue Int. 2001;68:87-94.

22. Huang $W$. Rudkin GH, Carlsen $B$, et al. Overexpression of BMP-2 modulates morphology. growth, and gene expression in osteoblastic cells. Exp Cell Res. 2002;274:226-34.

23. Tare RS, Oreffo RO, Clarke NM, et al. Pleiotrophin/Osteoblast-stimulating factor 1: dissecting its diverse functions in bone formation. J Bione Miner Res. 2002:17:2009-20.

24. Chen D. Harris MA, Rossini $G$, et al. Bone morphogenetic protein 2 (BMP-2) enhances BMP-3, $B M P-4$, and bone cell differentiation marker gene expression during the induction of mineralized bone matrix formation in cultures of fetal rat calvarial osteoblasts. Calcified Tissue International. 1997;60:283-290.

25. Hofbauer LC, Dunstan CR, Spelberg $T C_{r}$ et al. Osteoprotegerin production by human osteoblast. lineage cells is stimulated by vitamin $D$, bone morphogenetic protein- 2 , and cytokines. Biochemical and Biophysical Research Communications. 1998;250:776-781.

26. Wang EA, Rosen $V$, D'Alessandro JS, et al. Recombinant human bone morphogenetic protein induces bone formation. Proceedings of the National Academy of Sciences U.S.A. 1990;87:22:20-2224.

27. Zebboud AF, Imura M, Bostrom K. Matrix GLA protein, a regulatory protein for bone morphogenetic protein-2. J Biol Chem. 2002;277:438:84.

28. Daluiski $A_{n}$ Engstrand T, Bahamonde ME, et al. Bone morphogenetic protein-3 is a negative regulator of bone density. Nature Genetics. 2001:27:84-88.

29. Bahamonde ME, Lyons KM. BMP3: to be or not to be a BMP. J Bone loint Surg Am. 2001; 83-A Suppl 1:556-62.

30. Stary $H C$, Chandler $A B$, Dinsmore RE, et al. A definition of advanced types of atherosclerotic llesions and a histological classification of atherosclerosis. A report from the Committee on Vascular Lesions of the Council on Arteriosclerosis. American Heart Association. Arteriosiclerosis Thrombosis and Vascular Biology. 1995; 15:1512-1531. 
31. Stary $H C$. The sequence of cell and matrix changes in atherosclerotic lesions of coronary arteries in the furst forty years of life. Eur Heart 1 , 1990; 11:3-19.

32. Beadenkopf WG, Daoud AS, Love BM. Calcification in the coronary arteries and its relationship to arteriosclerosis and myocardial infarction. American Joumal of Rontgenology. $1964: 92: 865-871$.

33. Huang $H$, Virmani $R$, Younins $H$, et at. The impact of calcification on the biomechanical stability of atherosclerotic plaques. Circulation. 2001;103:1051-1056.

34. Johnson IM, Kennelly MM, Decesare D, et al. Natural history of asymptomatic carotid plaque. Arch Surg. 1985;120:1010-2.

35. Mathiesen EB, Bonaa $\mathrm{KH}$, Joakimsen $\mathrm{O}$. Echolucent plaques are associated with high risk of ischemic cerebrovascular events in carotid stenosis: the tromso study. Circulation. $2001 ; 103: 2171-5$.

36. Sabetai MM, Tegos TJ. Nicolaides AN, et al. Hernispheric symptoms and carotid plaque echomorphology. J Vasc Surg. 2000;31:39-49.

37. Nordestgaard $\$ G$, Gronholdt ML, Sillesen $H$. Echolucent rupture-prone plaques. Curr Opin Lipidal. 2003;14:505-12.

38. Bostrom K. Demer LL. Regulalory mechanisms in vascular calcification. Critical Reviews th Eukaryotic Gene Expression. 2000; 10:151-158.

39. Wayhs $\mathrm{R}$, Zelinger A, Raggi P. High coronary artery caicium scores pose an extremelly elevated risk for hard events. I Am Coll Cardiol, 2002:39:225 30.

40. Sharma 5K, Israel DH, Kamean JL, et al. Clinical, angiographic, and procedural determinants. of major and minor coronary dissection during angioplasty. American Heart Jounal. $1993: 126: 39-47$

41. Richardson PD, Davies MJ Influence of plaque configuration and stress distribution on fissuring of coronary atherosclerotic plaques. The lancet. 1989;0ctober:941-944.

42. Reszka A, Halasy-Nagy $\mathrm{MM}_{\mathrm{A}}$, Masarachia PJ, et al. Bisphosphonates act directly on the osteodlast to induce caspase cleavage of mst1 kinase during apoptosis. A link between inhibition of the mevalonate pathway and regulation of an apoptosis-promoting kinase. I Biol Chem. 1999;27434967.73.

43. Russell RG. Rogers Mu, Frith $J C$, et al. The pharmacology of bisphosphonates and new insights into their mechanisms of action. J Bone Miner Res. 1999:14:53-65.

44. Amin D. Comell SA, Gustatson SK, et al. Bisphosphonates used for the treatment of bone disorders inhibit squalene synthase and cholesterol biosynthesis. LLipid Res. 1992;33:1657-63.

45. Yitalo $R$. Bisphosphonates and atherosclerosis. General Pharmacology 2002;35:287-296.

46. Tanko LB, Qin $G$, Alexandersen $P$, et al. Effective doses of ibandronate do not influence the 3-year progression of aortic calcification in elderly osteoporotic women. Osteoporos int. 2004:10:10.

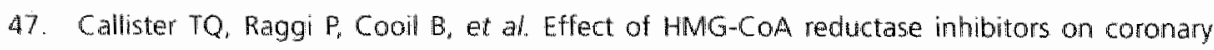
artery disease as assessed by electron-beam computed tomography. $N$ Engt / Med. 1998;339:1972-8. 
48. Budoff $\mathrm{MJ}$, Lane $\mathrm{KL}$, Bakhsheshi $\mathrm{H}$, et al. Rates of progression of coronary calcium by electron beam tomography. Am J Cardíl. 2000 86 8-11.

49. Bea $F$. Blessing $E$, Bennett $B_{\text {s }}$ et al. Simvastatin promotes atherosclerotic plaque stability in apoE-deficient mice independently of lipid lowering. Arteriosider Thromb Vasc Biol. $2002 ; 22: 1832-7$.

50. Mundy G, Garrett R, Harris 5 , et al. Stimulation of bone formation in witro and in rodents by statins. Science. 1999;286:1946-1949.

51. Chan $\mathrm{KA}_{\mathrm{r}}$ Andrade $\mathrm{SE}$, Boles $\mathrm{M}_{\mathrm{r}}$ et al. Inhibitors of hydroxymethylglutary/-coenzyme A reductase and risk of fracture among older women. Lancet. 2000;355:2185-8.

52. Rejnmark L, Buus NH, Vestergaard P, et at. Effects of simvastatin on bone turnover and BMD: a 1-year randomized controlled trial in postmenopausal osteopenic women. I Bone Miner Res. 2004: 19:737-44. Epub 2004 Feb 16.

53. Vermeer $C$. Ganma carboxyglutamate containing proteins and the vitamin $K$ dependent carboxylase. Biochemical Journal. 1990;266:625-636.

54. Jie KS, Bots ML, Vermeer $C$, et al. Vitamin $K$ intake and osteocalcin levels in women with and without aortic atherosclerosis: a population-based study. Atherosclerosis. 1995; 116:117-123.

55. Williams BR, Kim J. Cardiovascular drug therapy in the elderly: theoretical and practical considerations. Drugs Aging. 2003;20:445-63.

56. Demer LL. Tintut Y, Parhami F. Novel mechanisms in accelerated vascular calcification in renal disease patients. Curr Opin Nephrol Hypertens. 2002;11:437-43.

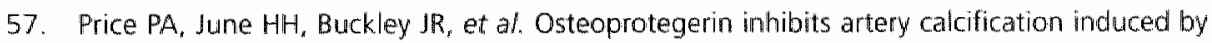
warfarin and by vitamin D. Arterioscler Thromb Vasc Biol. 2001:21:1610-6.

58. Wan $M$, Shi $X$, Feng $X$, et al. Transcriptional mechanisms of BMP-induced Osteoprotegerin gene expression. The Journal of Biological Chemistry. 2001;267:10119-10125. 
$\therefore \quad \therefore$ 


\section{Summary}

Atherosclerosis is a chronic inflammatory disease that affects the inner layer (intima) of mainly large arteries. It is a disease characterized by several stages, starting at the first decade of life and progressing with age. As the primary cause of myocardial infarction. stroke and ischemia of the extremities, atherosclerosis is responsible for about $50 \%$ of all deaths in the western society. The etiology of atherosclerotic disease is multifactoriat, and both hereditary and environmental factors accelerate atherosclerosis. Atherosclerotic plaques can lead to clinical manifestations by blocking the blood flow in the vessel or by thrombus formation. The different stages of atherosclerosis are morphologically well described; plaques responsible for blockade of the blood flow are mainly large and stable, while the thrombus forming plaques are ruptured, eroded or show calcified nodules. Vascular calcification in the intima is invariably associated with. and is a prominent feature of atherosclerosis. Disturbances in lipid metabolism, male sex, and hypertension aggravate atheroscierotic calcification. Calcification in plaques decreases vessel elasticity, and augments plaque brittleness. Atheroselerotic calcification is not restricted to large arteries, and can also occur in leaflets of aortic valves. Aortic value calcification is associated with increased risk of cardiovascular events including stroke and cardiac death.

In the field of vascular calcification two main questions have been raised. The first question is whether atherosclerotic calcification stabilizes or destabilizes the plaque. The second question is whether vascular calcification is a passive, or active regulated process. Although the association of vascular calcification with atherosclerosis has been noted for centuries, its, regulation has been largely ignored, because of the prevailing view that calcification was merely a degenerative, passive process of calcium phosphate precipitation that only occurs in end-stage atherosclerosis and simply signifies dying cells. By the discovery that bone-associated genes can be expressed in the vessel wall. it has become clear that vascular calcification may not be a passive process, but may be actively regulated. In this thesis we focus on the question whether vascular calcification is a passive or active regulated process and how vascular calcification is regulated.

Calcified atherosclerotic plaques can contain osteogenic elements such as bone cells, cartilage, calcium mineral, lamellar bone, nucleation sites (matrix vesicles) and bone regulatory proteins. The presence of these elements and the discovery that two bone matrix regulatory proteins, OPN and BMP- 2 were present in human atherosclerotic plaques, demonstrate that atherosclerotic calcification has high similarity with bone calcification. Since bone calcification is regulated by more bone matrix proteins than only OPN and BMP-2, we hypothesized that other bone matrix proteins are also present in human atherosclerotic calcification, both in the vessel wall and aortic valve leaflets. In the second part of this thesis interventions with BMP-2, a highly osteo-inductive protein and one of the first bone matrix proteins described in atherosclerotic plaques, and bisphosphonates, drugs used in the treatment of 
osteoporosis were performed in mouse models of atherosclerotic calcification. We hypothesized that enhanced BMP-2 gene expression accelerates atherosclerotic calcification and ossification and that bisphosphonates reduce vascular calcification.

In chapter 2 we examined the protein expression of 7 bone matrix regulatory proteins and 2 modulators of osteoclastogenesis in all stages of human atherosclerosis. We abserved that all these bone matrix proteins are expressed in the arterial wall. One set of proteins, known to belong to inhibitors of calcification, was present in all stages of human atherosclerosis. This suggests a continuous inhibition of calcification in the atherosclerotic vessel wall. The expression of a second set of proteins, known to belong to the activators of calcification, was restricted to advanced and calcified lesions. From this study we conclude that vascular calcification is actively regulated by both, inhibitors and activators of calcification.

Recent evidence indicates that aortic valve calcification is a well-regulated process that involves inflammation and lipid accumulation similar to those seen in human atherosclerosis. Vascular calcification is considered to be a risk factor for valvular calcification and recently published data indicate that aortic valve calcification is indeed associated with increased risk of cardiovascular events. Moreover, valvular and vascular calcifications are both considered to share similarities with skeletal bone formation. We therefore examined and described in chapter 3 the protein expression of 7 bone matrix regulatory proteins and 2 modulators of osteoclastogenesis in both non-calcified and calcified aortic valves. Our data showed that the expression profile of bone matrix proteins in human aortic valves is comparable to the in chapter 2 described profiles in 'ruman atherosclerotic plaques.

According to our data described in chapter 2 and 3, inhibitory proteins continuously prevent calcification, whereas the restricted presence of activators provide an imbalance, finally resulting in vascular and/or valvular calcification.

One of the activators of vascular calcification is BMP-2. BMP-2 is a member of the TGFB super family, and is a potent inducer of bone formation and the first osteo-inductive protein found in atherosclerotic plaques. Since BMP-2 is highly osteo inductive, enhances proliferation and differentiation of osteogenic cells, and is present in atherosclerotic plaques we examined the intervention of BMP-2 gene expression on the atherosclerotic calcification process in chapter 4 . Our data revealed not only that enhanced BMP-2 gene expression accelerated calification and ossification in atherosclerotic plaques, but that enhanced BMP-2 gene expression also caused an altered bone matrix regulatory protein expression profile. 
Another intervention we performed with bisphosphonates, a drug used for the treatment of osteoporosis, and is described in chapter 5. Therefore we used the $\mathbb{N}$-containing bisphosphonate, risedronate in an atherosclerotic mouse model. Our data showed that risedronate enhanced bone mineral density of skeletal bones, but had no influence on the initiation and regression of atherosclerotic calcification in mice.

In chapter 6 we summarize and discuss the data presented in the experimental chapters and provide some novel thoughts on the regulation of vascular calcification and on possibilities to intervene in this process.

The main conclusions derived from the studies described in this thesis are that both atherosclerotic and aortic valve calcifications are indeed actively regulated processes involving bone matrix regulatory proteins. This regulation involves both activators and inhibitors of calcification and bone formation. Furthermore, we conclude that BMP-2 is one of the major active regulators of vascular calcification, and that in an atherosclerotic mouse model bisphosphonates have no influence on vascular calcification when given in a dose that enhanced bone density. 


\section{Samenvatting}

Atherosclerose (aderwerkalking) is een chronische systemische aandoening die de binnenste laag (intima) van woornamelijk de grote slagaders aantast. Kenmerkend voor deze ziekte zijn de verschillende stadia, beginnend in het eerste decennium van ons leven en verergerend naarmate men ouder wordt. Atherosclerose is de belangrijkste oorzaak van een hartinfarct, herseninfarct en beperkte bloedvoorziening in de extremiteiten en is hierdoor verantwoordelijk woor ongeveer $50 \%$ van alle sterfgevallen in de Westerse samenleving. De oorzaak van atherosclerose is multi-factorieel. Zawel erfelikke als omgevingsfactoren versnellen de vorming wan atheroscherose. Atherosclerotische plaques kunnen leiden tot klinische verschijnselen doordat de bloedstroom in een bloedvat door de plaque geblokkeerd wordt of omdat er een bloedstolsel ontstaat. De verschillende stadia van atherosclerose zijn morfologisch goed beschreven; plaques verantwoordelijk voor de blokkade van de bloedstroom zijn woornamelijk groot en stabiel, terwijl de bloedstolsel vormende plaques geruptureerd (gescheurd) of geêrodeerd zijn, of gecalcificeerde (verkalkte) structuren vertonen. Vaatwerkalking in de intima is niet alleen geassocieerd met atherosclerose, het is ook een belangrijk kenmerk van atheros/cerose. Veranderingen in vetstofwisseling, het mannelijk geslacht en hoge bloeddruk dragen bij aan het ontstaan van atherosclerotische verkalking. Verkalking in plaques vermimdert de elasticiteit van het bloedvat, verhoogt de breekbaarheid van de plaque en leidt tot een toegenomen risico voor het ruptureren wan de plaques gedurende dotteren. Atherosclerotische verkalking beperkt zich niet tot de grote slagaders, het kan ook woorkomen in de aortakleppen. Aortaklepverkalking is geassacieerd met een toegenomen risico voor hart- en vaataandoeningen inclusief herseninfarcten en hartstilstand.

In het onderzoeksgebied van vaatverkalking zijn twee belangrijke vragen aan de orde. De eerste wraag is of atherosclerotische verkalking de plaque stabilliseert of destabiliseert. De tweede vraag is of vaatverkalking een passief of een actief gereguleerd proces is. Hoewel de associatie tussen vaatverkalking en atherosclerose al eeuwen geleden gemaakt is, heeft men zich nooit verdiept in de regulatie ervan, omdat men dacht dat werkalking een degeneratief, passief proces van calciumfosfaat neerslag was dat alleen voorkwam in het laatste stadium wan atherosclerose als gevolg van een ophoping van dode cellen. Door de ontdekking dat bot geassocieerde genen tot expressie kunnen komen in de vaatwand, is het duidelijk geworden dat vaatverkalking niet zomaar een passief proces is, maar dat het mogelijk actief gereguleerd wordt.

Verkalkte atherosclerotische plaques kunnen bot gerelateerde elementen bevatten zoals botcellen, kraakbeen, calciummineraal, volledig uitgegroeid bot, aamhechtingsplaatsen woor botvorming en bot regulerende eiwitten. Door de aanwezigheid van deze elementen en door de ontdekking dat er twee botmatrix regulerende eiwitten, OPN en BMP-2 aanwezig zijn in humane atherosclerotische plaques weet men nu dat atherosiclerotische verkalking grote overeenkomsten vertoont 
met botverkalking. Doordat botverkalking gereguleerd wordt door meer botmatrix eiwitten dan alleen OPN en BMP-2, hebben wij de hypothese opgesteld dat andere botmatrix eiwitten ook aanwezig zijn in humane atherosclerotische verkalking, zowel de vaatwand als im aortakleppen. In het tweede deel van dit proefschrift worden twee interventie studies beschreven. De ene interwentie is gedaan met BMP-2, een krachtig botvorming inducerend eiwit en tevens een van de eerste botmatrix eiwitten beschreven in atherosclerotische plaques. De andere interventie met bisfosfonaten, een medicijn gebruikt voor de behandeling van osteoporose (botontkalking). Beide interventies zijn uitgevoerd in een muismodel dat atherosclerotische verkalking ontwikkelt. Onze hypothese was dat een verhoogde BMP-2 genexpressie zorgt voor een versnelde atherosclerotische verkalking en botvorming en dat bisfostonaten watverkalking kunnen verminderen.

In hoofdstuk 2 hebben we gekeken naar de eiwit expressie van 7 botmatrix regulerende eiwitten en 2 modulatoren van osteoclastagenese (vorming van botafbraak cellen) in alle stadia van atherosclerose. We hebben geobserveerd dat al deze botmatrix eiwitten tot expressie komen in de vaatwand. Eén set eivitten, behorend tot de remmers van verkalking, was aanwezig in alle stadia van atherosclerose. Dit suggereert een continue remming van verkalking in de atherosclerotische vaatwand. De expressie van een tweede set van eiwitten, behorend tot de activatoren van verkalking. was beperkt tot de vergevorderde en verkalkte plaques. Uit de resultaten van deze studie concluderen wij dat vaatverkalking actief gereguleerd wordt door zowel remmers als activatoren van werkalking.

Recent bewijs geeft aanwijzingen dat aortaklepverkalking een goed gereguleerd proces is met aanwezigheid van ontsteking en vetophoping in overeenstemming met humane atherosderose. Vaatwerkaking wordt beschouwd als een risicofactor voor klepwerkalking en recentelijk gepubliceerde data wijzen in de richting dat aortaklepverkalking weldegelijk geassocieerd is met een verhoogd risico op hart- en vaataandoeningen. Bovendien vertonen zowel klep- als vaatverkalkingen grote overeenkomsten met skeletale botvorming. Daarom hebben we in hoofdstuk 3 de eiwit expressie van 7 botmatrix regulerende eiwitten en 2 modulatoren van osteoclastogenese onderzocht en beschreven in zowel niet verkalkte als verkalkte aortakleppen. Onze data laten zien dat het eiwit expressiepatroon in de humane aortakleppen vergelijkbaar is met het in hoofdstuk 2 beschreven eiwitpatroon in humane atherosclerotische plaques.

volgens onze data beschreven in hoofdstuk 2 en 3, zijn het de remmende eiwitten die continu woorkomen dat er verkalking plats vindt, terwijl de beperkte aanwezigheid wan de activatoren zorgen voor een disbalans, die uiteindelijk resulteert in vaat-en/ of klepverkalking. 
Eén van de activatoren van vaatwerkalking is BMP-2. BMP-2 behoord tot de TGF $\beta$ superfamilie, en is een krachtige aandrijver van botvorming en het eerst botinducerende eiwit dat gevonden is in atherosclerotische plaques. Omdat BMP-2 zo sterk osteo-inductief is, zorgt voor versnelde deling en differentiatie van osteogene (bot) cellen, en omdat BMP-2 aanwezig is in atherosclerotische plaques hebben we in hoofdstuk 4 de effecten van een toegenomen BMP-2 genexpressie op het atherosclerotische verkalkingproces beschreven. Onze data tonen aan dat een verhoogde BMP-2 genexpressie niet alleen maar leidt tot versnelde verkalking en botworming in atherosclerotische plaques, maar ook een veranderd botmatrix regulerend eiwit expressiepatroon veroorzaakt.

De effecten van de interventie met bisfosfonaten, een medicijn dat gebruikt wordt bij de behandeling van osteoporose (botontkalking): wordt beschreven in hoofdstuk 5 . We hebben hiervoor het $\mathrm{N}$-bevattende bisfosfonaat risedronate gebruikt in een atherosclerotisch muismodel. Uit de resultaten van deze studie blijkt dat risedronate wel zorgt voar een verhoogde botdichtheid van skeletbeenderen, maar geen invloed heeft op zowel het ontstaan van als het terugdringen van verkalkte atherosclerotische plaques in muizen.

In hoofdstuk 6 worden de bevindingen die beschreven worden in de experimentele hoofdstukken samengevat en bediscussieerd. Dit laatste hoofdstuk verschaft ook een aantal nieuwe gedachten over de regulatie van vaatverkalking en over de mogelijkheden om in dit proces in te grijpen.

De hoofdconclusies wan de studies die in dit proefschrift worden beschreveri zijn dat zowel atherosclerotische verkalking als ook aortaklepverkalking wel degellik actief gereguleerde processen zijn waarbij botmatrix regulerende eiwitten betrokken zijn. Bif deze regulatie zijn zowel de activatoren als ook de remmers van verkalking en botvorming betrokken. Bovendien concluderen we dat BMP-2 eén van de belangrijkste actieve regulatoren is van vaatverkalking, en dat behandeling met bisfosfonaten in een atherosclerotisch muismodel géen invloed heeft op vaatverkalking, hoewel de gegeven dosis wel zorgt voor een verhoging van de botdichtheid van de skeletbeenderen. 


\section{Dankwoord}

Mat, I juni 1998 ben ik bij jou op de afdeling begonnen om mijn promotie onderzoek te doen. Nu, precies. 7 jaar later is het dan eindelijk zover. Het was zeker niet de bedoeling om er zo lang over te doen, maar soms komen er orverwachte dingen op je weg. Toen ik bij jou met de mededeling kwam dat ik tandheelkunde erbij zou gaan doen, was je sprakeloos. Volgens mij is dit de enige keer geweest dat je even niet wist wat je moest zeggen. Er is een moment geweest dat ik de indruk kreeg dat jij dacht dat ik het niet zou affonden. Maar hier is dan eindelijk het resultaat. Mat, ik heb jou in de afgelopen jaren leren kennen als iemand die heel goed in stat is om mensen te motiveren. Soms probeerde je nieuwe tactieken uit, maar je had al gauw in de gaten dat je tegen mij beter eerlijk kunt zijn (ook bij minder positieve dingen). In het begin zagen we jou nog wel eens op het lab, maar de laatste jaren zat dat er niet meer in. Nee, wij moesten keer op keer heen en weer naar jouw kamer lopen. Heel vaak had jij het erg druk, maar toch vond jij altijd weer een paar minuutjes om te luisteren. Mat, voor mij ben jif een hele behulpzame promotor geweest.

Jack, als co-promotor heb jij het niet altijd gemakkelijk gehad met mij. lk wilde graag alles zelf doen en ontdekken. Toch heb ik vaker jouw hulp in moeten roepen. Zeker in het begin toen ik door de microscoop nog niet precies het onderscheid tussen de verschillende structuren en celtypen kon maken. Je hebt mij ook vaker uit de brand geholpen met computerprogramma's, de quantimed, en de fotomicroscoop. Maar vooral de laatste periode van mijn promotieonderzoek heb jij mij goed geholpen. Als ik thuis weer eens een foto nodig had van een coupe die te vinden was op de bovenste plank van mij oude werkplek, ging jij op zoek naar de coupe, maakte de foto ('s) en stuurde mij die of per e-mail of via de post op. Dan kon ik weer verder zonder naar Maastricht te reizen. Dit heeft mij veel tijd bespaard. Ook bij het nakijken van de door mij geschreven artikelen liep iij zorgvuldig alle referenties na. Bedank woor de puntjes op de i, Jack!

Elly, dankzij jou was het elke keer weer mogelijk om een werkbespreking met Mat te hebben op een voor ons geschikt tijdstip. Ook alle regeldingetjes waren woor jou geen enkel probleem en hebben mij enorm geholpen. Cor, als wij in dezelfde trein zaten hadden we altijd leuke gesprekken over mijn onderzoek. Het laatste jaar gingen de gesprekken echter vaker over tandheelkunde dan over mijn onderzoek. Ik moest jou telkens weer uitleggen waarom tandheelkundige zorg nou echt zoveel geld moet kosten. Natuurlijk kan ik de dames wan het secretariaat (Ingrid, Karin, Cyriel, Peggy, Audry en Patricia) niet vergeten. Altijd was het weer leuk om bij jullie binnen te lopen hoewel ik regelmatig de weg kwijt was omdat jullie dan een andere werkplek hadden.

Aan alle kamergenootjes die ik heb gehad heb ik leuke herinneringen. Het begon met Esther L. Esther C en Saskia Robert-Offermann, ik hoop niet dat jullie erg moe zijn geworden wan al mijn vragen. Na het vertrek van Saskia is Sylwia gekomen. Sylvia, aan jou heb ik echt alles kunnen vragen en kunnen bespreken, zelfs tot op het alleriaatste 
moment. Ook als er wat woor mij gedaan moest worden op hel lab, regelde jij dat allemaal zonder anderen voorrang te geven omdat dat onderzoek "belangrijker" was. Ik vond het erg leuk dat jij ook bent gaan paardrijden, maar het wordt nu echt de hoogste tijd dat ik weer een keertje kom kijken, en dan natuurlijk ook naar je huis in Belgiê. Syl, bedankt dat je altijd tijd voor mij had en elke keer dat ER op de televisie is zal ik aan jou denken.

Samen met Esther $C$ ben ik verhuisd naar de naastgelegen kamer. Esther $C$, schrijven zoals jij zal mij nooit lukken, maar jouw tips hebben mij wel heel goed op weg geholpen. Later is Ann-Pascale (annie-pascallie) erbuj gekomen. AP, jij bent altijd de rustige factor bij ons op de kamer gebleven. Je was een zeer prettige collega om mee samen te werken en ik hoop dat je onderzoek uitstekend blift lopen. Heel veel succes en jou Belgische accent is helemaal niet zo erg hoor. Na het vertrek van Esther $C$ is Birgit achter mij komen zitten. Door de komst van Birrie de best is het niet rustiger geworden op onze kamer. Birgit, ik heb heel erg veel plezier met jou gehad, zowel op de kamer als op het lab. Onze gezamenlijke uitstapjes via het koffiezetapparaat naar het lab waren telkens weer even zoeken naar ontspanning. Het lab heeft het zo nu en dan moeten ontgelden. Birgit en Esther L, ik zal onze trip naar de Rocky Mountains noojt vergeten. Toch was het echt een leeuw die ik de weg zag oversteken en de vos die we in het echt gezien hebben staat mooi op de foto! Birgit dankzij jou wiebel enkels, Esther jij als dokter en ik ais degene die zuinig met het drinkwater omgat waren we zelfs buiten ons werk om een uitstekend team.

De kamer van de "nieuwe" AlO's was, zoals voor velen, bekend een kippenhok. Marjo, Judith, Kitty, Suzanne, Linda en Natasja, altijd was het gezellig op even met jullie over het vorderen van het onderzoek te praten. Behalve voor Dr Marjo is het nu jullie beurt. Heel veel succes!

Kitty, wij zijn ongeveer tegelikk begonnen bij Pathologie, maar hebben niet veel samengewerkt. Maar als ik jouw advies nodig had, was je beschikbaar met jou schat aan kennis en ervaring. Kitty, heel veel succes met alles! Manon, niet altijd alleen maar werken hè!

De vele uren die ik op het lab het doorgebracht waren onvergetelijk. Ik zal het echt gaan missen. Ik wil bij voorbaat alle mensen van het lab bedanken woor al het werk en vooral jullie a anwezigheid als ilk weer eens iets nodig had, of met een vraag kwam, ook de naastgelegen labs. Guido altijd weer een rare situatie om over te schakelen naar het Nederlands zodra we door de poort van pathologie liepen. Degenen van ons eigen lab bedank ik natuurlijk ook. Ron, het was jammer dat je al snel na mijn komst wegging. maar Intervet is een witermate geschikte vervanging. Loes, Monique en Wendy, inmiddels ook niet meer werkzaam bij de cardio's, bedankt voor de leuke tijd. Wendy, ik hoop dat je het nu wel naar je zin hebt. Anique, ik kan nu eindelijk een groot deel van mijn 
spullen opruimen. Ine en Coby, al zag ik jullie niet zo waak omdat jullie altijd enorm druk met coupes bezig waren op het ander lab. Ruben en Barry, eindelijk jongens op het lab. Jullie waren een perfect duo. Ruben, de puppy kalender hangt nog steeds. De data kloppen miet meer maar de puppies zijn nog steeds een genot om naar te kijken. Barry, jou E-mail adres en telefoonnummer zal bewaren zodat ik je altild kan bereiken als er weer eens iets met mijn computer is. Meestal weet jij een heel eenvoudige oplossing. Anouk, na het vertrek van vele collega's ben iij de vaste kracht op het lab. Anouk, bedankt voor het "quantimetten" en succes met alle experimenten! Petra "jij hebt erg veel labwerk woor mij gedaan. Het was zeer aangenaam om i.p.w. twee handen, over vier handen te beschikken. Ondanks dat het genotyperen van de transgene muizen jou niet altijd vrolijk maakte, deed jij het elke keer weer zonder te mopperen (ik voelde mij wel schuldig hoor!). Ook de in situ hybidisaties roepen in elk geval bij mij, geen vrolijke gedachten op, maar jij kwam telkens weer met coupes die mij positief stemde. Dit heb ik erg weten te waarderen. Petra, hartelijk bedankt voor de enorm leuke samenwerking. En..... ik ben blij dat jij mijn paranimf wil zijn.

Mensen die ik zeker niet mag wergeten zijn de pathologen (Robert-Jan, Adriaan, Ton e alle anderen die ik vergeten ben), de "farmacologen" (Agnieszka ik zal jou op concours nog wel tegen komen, Nicole, Jack. Peter), de "mannen" van biochemie (Henri, Leon, Barry en Cees), en de "cardiologen" (Bianca, Alexandra, Denny en Henny)

De samenwerking met Leiden en P\&G hebben beide een mooi hoofdstuk in het proefschrift opgeleverd. Margreet, bedankt voor alle experiment en Paul bedankt woor het kritisch nalezen van het manuscript. Prof Piet Geusens, bedankt voor alle informatie over osteoporose en vasculitis en natuurlijk het fantastische congres in Madrid.

In de periode dat ik elke dag naar Maastricht kwam met de trein heb ik vele uren in dit vervoersmiddel doorgebracht. Eerst vanuit Boxmeer en later vanuit Tegelen (opstapplaats Reuver). In de trein heb ik vele mensen leren kennen, maar Anita, jij bent mijn echte treingenootje. Met z'n tweetjes zijn we heel vaak op en neer naar Maastricht gegaan. Later zijn ook Bart en Bianca met grote regelmaat met ons meegegaan. "s Morgens hadden we elkaar meestal niet zo heel veel te vertellen, 's middags dalarentegen was altijd woldoende stof om over te kletsen. Ook was het zo nu en dan nodig om eventjes met $z^{\prime} n$ tweetjes de stad in te gaan om met volle tassen huiswaarts te keren. Bart, jammer dat we elkaar niet meer zo vaak spreken, maar de mail is toch een prefect medium om over vanalles op de hoogte te blijven.

Bianca, jij ging bijna altijd met Anita en mij naar Maastricht, behalve dinsdag en woensdag. Dinsdag ging jij altijd met de auto om dat je dan heel vroeg werkbespreking had. Omdat jij in Belfeld woont, konden we ook vaker carpoolen. De leuke gesprekken die wij hadden zal ik niet wergeten. Ook onze discussies, niet alleen over het werk, maar natuurlijk ook over paarden. 
Voor ik in Maastricht ben begonnen heb ik bij Intervet in Boxmeer een enorme leuke tijd gehad. Ik heb daar hele mooie herinneringen aan. Zelfs als ik nu nog wel eens daar binnenlcop is iedereen nog even aardig. Er zijn een paar mensen die ik extra wil bedanken. Paul, on met jou te beginnen. bijna alles wat ik de op het lab heb gedaan qua experimenten) heeft zijn oorsprong bij jou. Toen ik na mijn stage bij jou ben gaan werken heb je mij zo vrij gelaten dat ik heel veel zelf heb kunnen ontdekken. Als ik er echit niet meer uitkwam en geen ideeën/mogelijkheden meer had, dan belde ik jou of liep even langs. Jij wist mij elke keer weer te verbazen met het scala aan ideeên/ mogelijkheden die jij nog woorhanden had. Daarna ging ik dan snel weer verder om "op tijd" naar huis te gaan. Paul "door jou oplettendheid ben ik geen analist gebleven. en toch AlO geworden. Nog bedankt voor de vacature toentertijd!

Lisette, eerst even koffie drinken en kletsen om daarna snel aan de slag te gaan. zo begon elke morgen voor ons. Een van de overeenkomsten tussen ons is het Baculo-virus expressie systeem. Jij werkt nu nog steeds met dit zeer weilige systeem, terwijl ik er na mijn stage nooit meer iets mee gedaan heb, behalve als jij op vakantie was. In de jaren dat we samen het kantoortje deelden zijn we behalve collega's ook vriendinnen geworden. Helaas zien we elkaar niet meer zo heel valak, maar de kapper (Luci) is dan weer een perfecte gelegenheid om af te spreken. De planning om het mountainbiken weer op te pakken hebben we erin weten te houden, aileen laat de uitvoering nog te wensen over. Lisette en Pieter, we moeten nu toch echt afspreken om te gaan fietsen, en daarna heerlijk te eten met een goed glas wijn erbij.

Natuurlijk zijn er nog mensen bij Intervet (ik denk oa aan John, Stefan, Henk, Wies, Christa, Pleter van Gelder en Ennie) die zich arvragen wanneer ik nou eindelijk klaar ben met dat proefschrift. Paul en Lisette, daar kunnen jullie nu eindelijk een duideliik antwoord op geven.

Mijn paranimien Petra en Marja, geweldig dat jullie deze taak op jullie willen nemen. Petra, als team bestaande uit jou en mij hebben we met vier handen veel werk verricht. Dit is eén van de redenen dat er zoveel kleurenplaatjes in mijn proefschrift staan. Altijd was er tijdens onze experimenten door tijd voor een geintje. Marja, doordat jil mij liet zien wat het was om te gaan promoveren wilde ik dat ook (en war ben jij zoal mee bezig?). Jij bent echt een voorbeeld voor mij geweest. Het heeft even geduurd maar eindelijk is het dan zover. Het boekje is af en jij, zoals afgesproken. paranimf.

Karin, de lay-out en de buttenkant van het boekje zijn van jou hand. Enorm veel werk heb je ermee gehad, onder andere omdat ik toch wel een pietje precies ben. Gelukkig heb ik (als de photoshop-koningin) jou kunnen helpen met de figuren. Het proefschrift ziet er schitterend uit. Karin heel erg bedankt voor alle uren die je erin gestoken hebt, en nu is het niet meer nodig om op een oude krant met een fles whisky op kantoor te overnachten! 
Wim en Joke, nu ik klaar ben met mijn promotie zal ik vast niet meer zoveel haast hebben. De wervelwind zal nu gaan liggen en ik denk dat de paarden dit ook als minder stressvol zullen ervaren. Jullie beiden heel erg bedankt voor alle plezier die ik altijd bij jullie beleef.

Anita, als beste vriendin mag jij niet ontbreken in mijn dankwoord. Na mijn vertrek uit Boxmeer heeft mijn keuze om in Nijmegen te gaan studeren evoor gezorgd dat ik toch met regelmat even bij jou op de koffie kon komen. Ik ga er vanuit dat deze regelmaat na 3 juni in frequentie zal toenemen. Anita, bedankt dat jij er altijd bent voor mij.

Mijn ouders will ik natuurlijk ook bedanken. Mama, jij hebt tijdens mijn drukke jaren in Maastricht ervoor gezorgd dat mijn huishouding enigszins op orde was (misschien lukt het mij wel om het nu zelf op orde te houden). En mama, hopelijk zien jullie mij nu wat vaker. Papa, hier is dan eindelijk het resultaat. Je hebt er wel even op moeten wachten, maar nu heb je eindelijk de mogelijkheid om het hele boekje door te spitten. Misschien een mooi moment om eens vanachter die computer uit te komen. Mama en Papa, bedankt dat jullie altijd weer achter alle keuzes van mij gestaan hebben.

Marcel, jij hebt het reeds vele jaren te voorduren gehad met mij. Ik denk dat daar nu wel verandering in komt. Wen er maar vast aan, ik zal vast een heleboel energie over hebben. Ondanks dat ik nogal eens tegen jou zei: "jij denkt dat alles zo gemakkelijk gaat" begreep ik echt wel dat jij het goed bedoelde. Héel erg bedankt dat je er altijd was en iklaar stond voor mij. Marcel, ik heb het maar getroffen met jou!!!! 


\section{Curriculum Vitae}

\section{Cherida Dhore}

29 July 1971

Born in "s Gravenhage

\section{Education}

$1984-1990$

HAVO-B, Den Hulster, Venlo.

1990-1995

BSC (HLO) at the Hogeschool of Utrecht, Utrecht.

$2002-\ldots$

Dental School at the University Medical Centre Nijmegen.

\section{Research positions}

$1995-1998$

Molecular Biological Research Technician at the Department of Virological Research, Intervet International BV, Boxmeer.

1998-2003

PhD student at the Department of Pathology (CARIM). Maastricht University.

\section{Full articles}

Cherida R. Dhore, Jack PM Cleutjens, Esther Lutgens, Kitty ByM Cleutjens, Piet PMM Geusens, Peter JEHM Kitslaar, Jan HM Tordoir, Henri MH Spronk, Cees Vermeer and Mat JAP Daemen. Differential expression of bone matrix regulatory proteins in human atherosclerotic plaques. Arteriosclerosis Thrombosis and Vascular Biology. 2001. $21(12)$ : 1998-2003.

Cherida R Dhore, Jack PM Cleutjens, Robert Jan van Suylen, Cees Vermeer, Jos G Maessen, Mat JAP Daemen. Increased expression of bone matrix regulatory protems in leaflets of patients with aortic valve stenosis. (Submitted)

Cherida $R$ Dhore, Margreet $R$ de Vries, Sylvia Heeneman, Jack PM Cleutjens, Jos M van Grimbergen, Jan Willem HP Lardenoye, Mat IAP Daemen, Paul HA Quax. BMP- 2 induces atherosclerotic calcification and fibrosis in carotid artery vein grafting in hypercholesterolemic ApoE3*Leiden mice. (In preparation) 
Cherida R Dhore, Piet PMM Geusens, Bert wan Rietbergen, Kitty Schapira, Marion Gijbels, Jack PM Cleutjens, Mat JAP Daemen. A third generation bisphosphonates, Risedronate has no effect on the development of atherosclerosis in ApoE- mice in doses that affect bone density. (Submitted)

J.H.P. Lardenoye, M.R. de Vries, C.W.G.M. Löwik, Q. Xu, C.R. Dhore, I.P.M. Cleutjens, V.W.M. van Hinsbergh, J.H. wan Bockel, P.H.A. Quax. Accelerated atherosclerosis and calcification in vein grafts: a study in ApoE*3 Leiden transgenic mice. Circ Res. 2002. $91: 577-584$.

L.J. schurgers, P.E.P. Dissel, H.M.H. Spronk, B.A.M. Soute, C.R. Dhore, J.P.M. Cleutjens and $C$. Vermeer. Role of vitamin $K$ and vitamin $K$-dependent proteins in vascular calcification.

2. Kardiol. 2001.90 (Suppl 3): 11//57-11/63.

Hesselink W, Sondermeijer $P$, Pouwels $H$, Verblakt $E$, Dhore $C$. Vaccination of cats against feline imunadeficiency virus (FIV): a matter of challenge. Vet Microbiol. 1999. $69(1-2): 109-110$.

\section{Abstracts}

C. Dhore, J. Cleutjens, S.van der Linden, M. Daemen, P. Geusens. Identification of osteoprotegerin and osteoprotegerin-ligand in calcified atherosclerotic lesions. Bone. $2001.28(5): 5118$.

C. Dhore, J. Cleutjens, J. Maessen and M. Daemen. Increased expression of bone matrix regulatory proteins in human degenerative valvular aortic disease. Arteriosclerosis. Thrombosis and Vascular Biology. 2001. Abstract P258. 21 (4): 702. New investigator award.

C. Dhore, J. Cleutjens, P. Kitslaar, H. Spronk, C. Vermeer and M. Daemen. Enhanced expression of proteins involved in bone formation in advanced atherosclerotic plaques. Arteriosclerosis, Thrombosis and Vascular Biology. 2000 . Abstract P221.

C. Dhore, J. Cleutjens, P. Kitslaar, I. Tordoir, B. Soute, C. Vermeer and M. Daemen. Osteocalcin and matrix gla protein deposition is enhanced in human atherosclerotic plaques. The FASEB Journal. 1999. 13 (4): Abstract A203. 
L.A.J.L.M. Braam, P. Dissel, H. Spronk, R. Houben, B.A.M. Soute, B.L.M.G. Gijsbers, M.J.A.P. Daemen, I.P.M. Cleutjens, C.R. Dhore, K. Hamulyák, C. Vermeer. Development and evaluation of an enzyme-linked immuno sorbent assay (Elisa) for circulating matrix gla-protein. Thrombosis and Haemostasis Supplement. 1999. Abstract A760. 


\section{Full color figures}
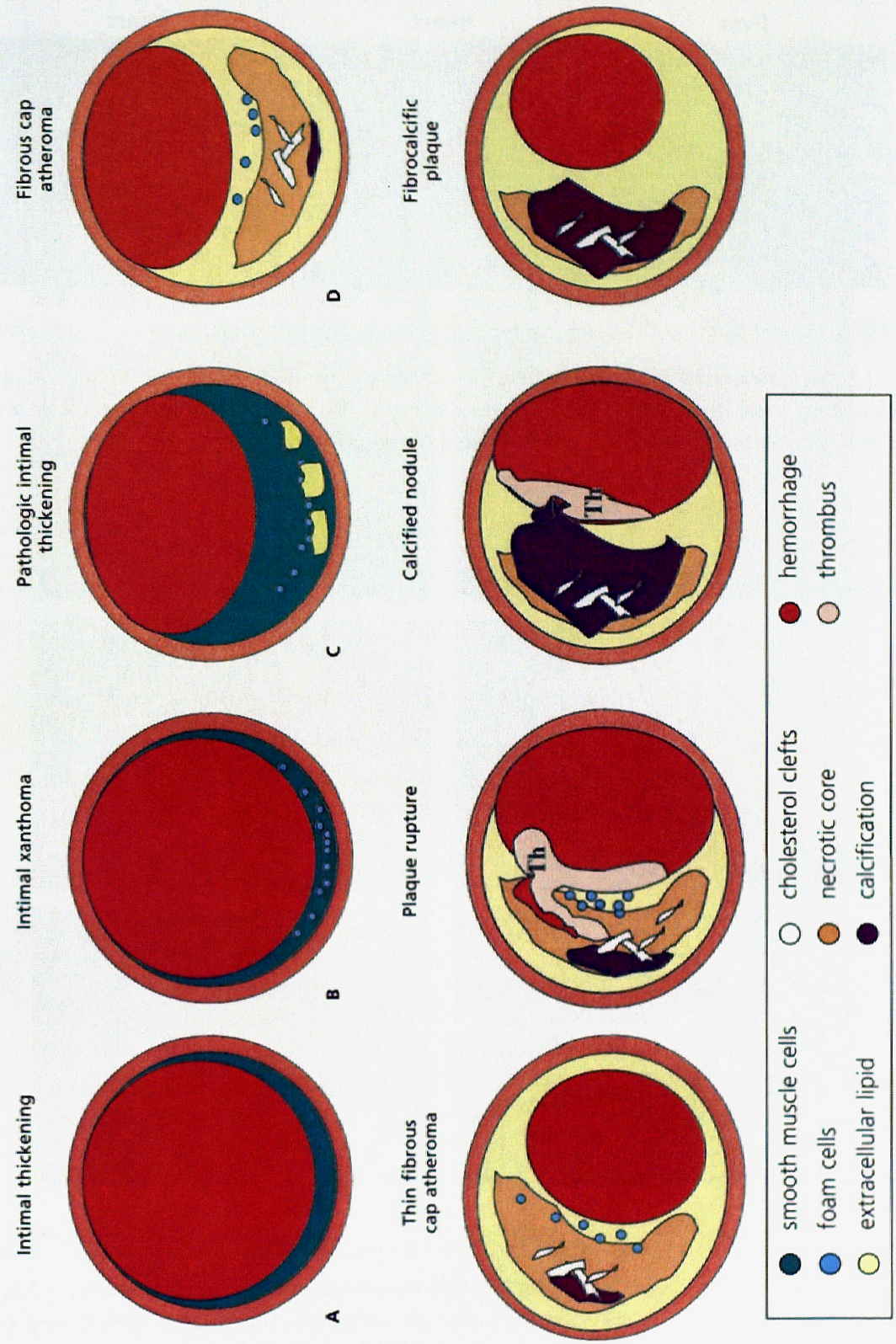

Figure 1.2 Classification of atherosclerotic plaques 

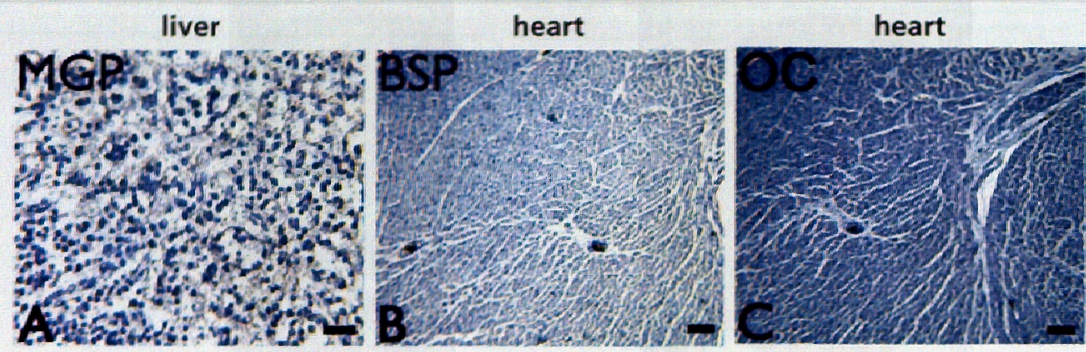

Figure 2.2. Immunohistochemical staining. Negative controls for the antibodies directed to MGP, $O C$ and BSP. Fig. 2.2a: human liver stained with $\alpha$-MGP. Fig. $2.2 b$ and $c$ : human heart stained with respectively $\alpha-O C$ and $\alpha-B S P$. Note: positive staining is red. Scale bars in figure 2 represent $50 \mu \mathrm{m}$. 

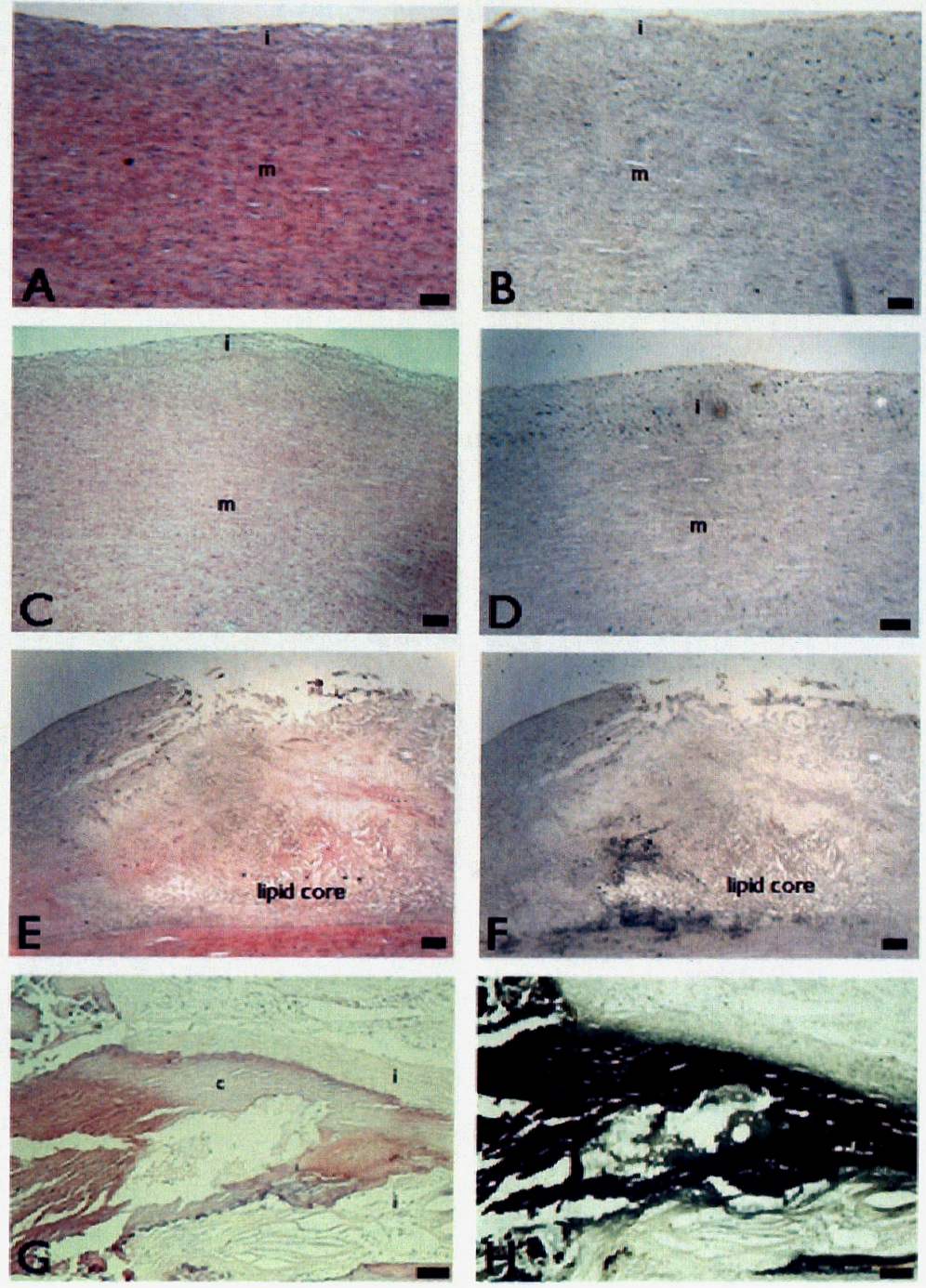

Figure 2.3. Histological and morphological characteristics of the plaque types. Panels a, $c, e$, and g represent H\&E stainings, panels $b, d, f$, and $h$ represent Von Kossa stainings. Fig 2.3a anid b: non-diseased aorta. Fig $2.3 \mathrm{c}$ and $d$ : intimal xanthoma. Fig 2.3e and f: fibrous cap atheroma. Fig $2.3 \mathrm{~g}$ and $\mathrm{h}$ : fibrocalcific plaque. ( $i=$ intima: $m=$ media and $c=$ calcium mineral). Scale bars in figure 3 represent $50 \mu \mathrm{m}$. 

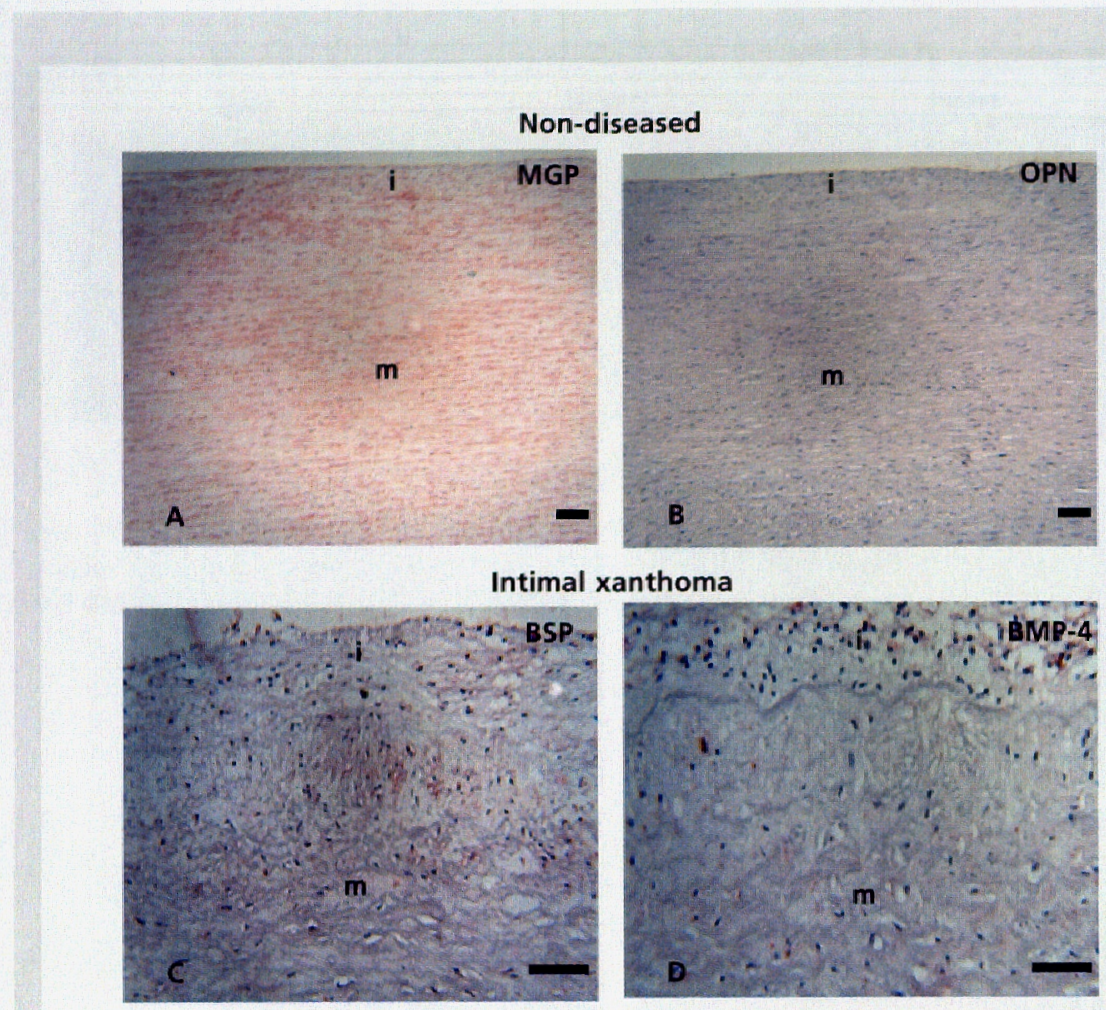

Fibrous cap atheroma
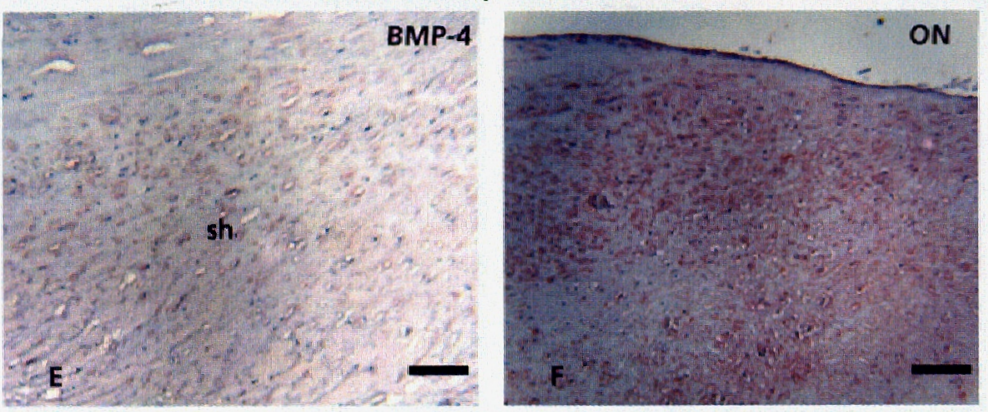

Figure 2.4. Immunahistochemical staining of a non-diseased aorta ( $a$ and b), intimal xanthoma ( $c$ and $d$ ), and fibrous cap atheroma (e and f). Fig. 2.4a and b: non-diseased aorta stained with respectiveiy MGP and OPN. Fig. 2.4C and d: intimal xanthoma stained with respectively BSP and BMP-4. Fig. $2.4 \mathrm{e}$ and $f$ : fibrous cap atheroma stained with respectively BMP-4 and ON. (i=intima; $m=$ media and $s h=$ shoulder region). Scale bars in figure $2.4 \mathrm{a}$ and b represent $50 \mu \mathrm{m}$, scale bars in figure $2.4 \mathrm{c}$, e and $\mathrm{f}$ represent $25 \mu \mathrm{m}$ and scale bar in figure $2.4 d$ represents $10 \mu \mathrm{m}$. 

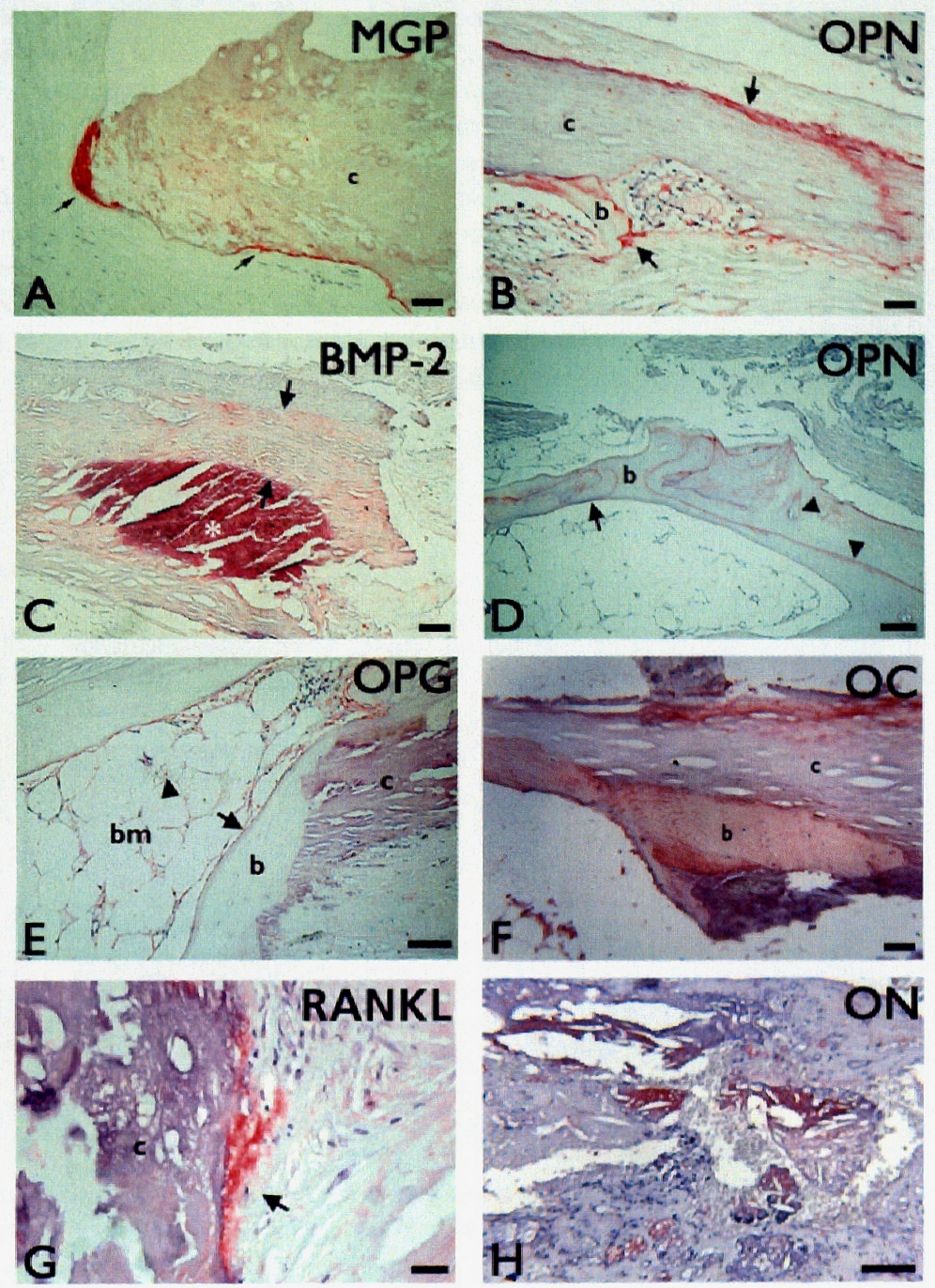
Figure 2.5. Immunohistochemical staining of a fibrocalcific plaque. Fig. 2.5a: fibrocalicific plaque containing calcium mineral deposition immuno-stained with monoclonal antibody against MGP (red staining). Note: Strong MGP positive staining at boundary of the mineral deposits. Fig. 2.5b: fibrocalcific plaque, containing calcium mineral deposits (c) and bone tissue (b) stained with $\alpha$-OPN (red staining). OPN positive staining could be demonstrated at the boundary of the calcium mineral and bone structures (arrows). Fig. 2.5c: fibrocalcific plaque, containing calcium mineral deposits immuno-stained with a mouse anti-BMP-2 (red staining). BMP-2 positive staining (between arrows) cauld be wisualised surrounding the highly calcified central area (*). Fig. 2.5d: fibrocalcific plaque, cantaining bane structures (b) stained with $\alpha$-OPN. OPN positive staining was seen surrounding the bone structures (arrow), but also in a striping pattern within the bone (arrowhead). Fig. 2.5e: fibrocalcific plaque with bone formation (b) stained with goat anti-OPG. OPG could be demonstrated in the asteoblasts (arrow) lining the bone structures (b) and some stramal cells (arrowhead) in the bone marrow (bm). Fig. 2.5f: fibrocalcific plaque stained with $\alpha$-OC. Fig. $2.5 \mathrm{~g}$ : fibrocalcific plaque, containing calcium mineral deposits (c), immuno stained with goat anti-RANKL. RANKL was observed in the extracellilar matrix surrounding the mineral deposits (arrow). Fig. 2.5h: fibrocalcific plaque with matrix vesicles stained with $\alpha$-ON. Scale bars in fig. $2.5 \mathrm{a}, \mathrm{c}$ and $\mathrm{h}$ represent $25 \mu \mathrm{m}$, scale bars in fig. $2.5 \mathrm{~b}$, d and frepresent $50 \mu \mathrm{m}$, scale bar in fig. $2.5 \mathrm{~g}$ represents $10 \mu \mathrm{m}$. 

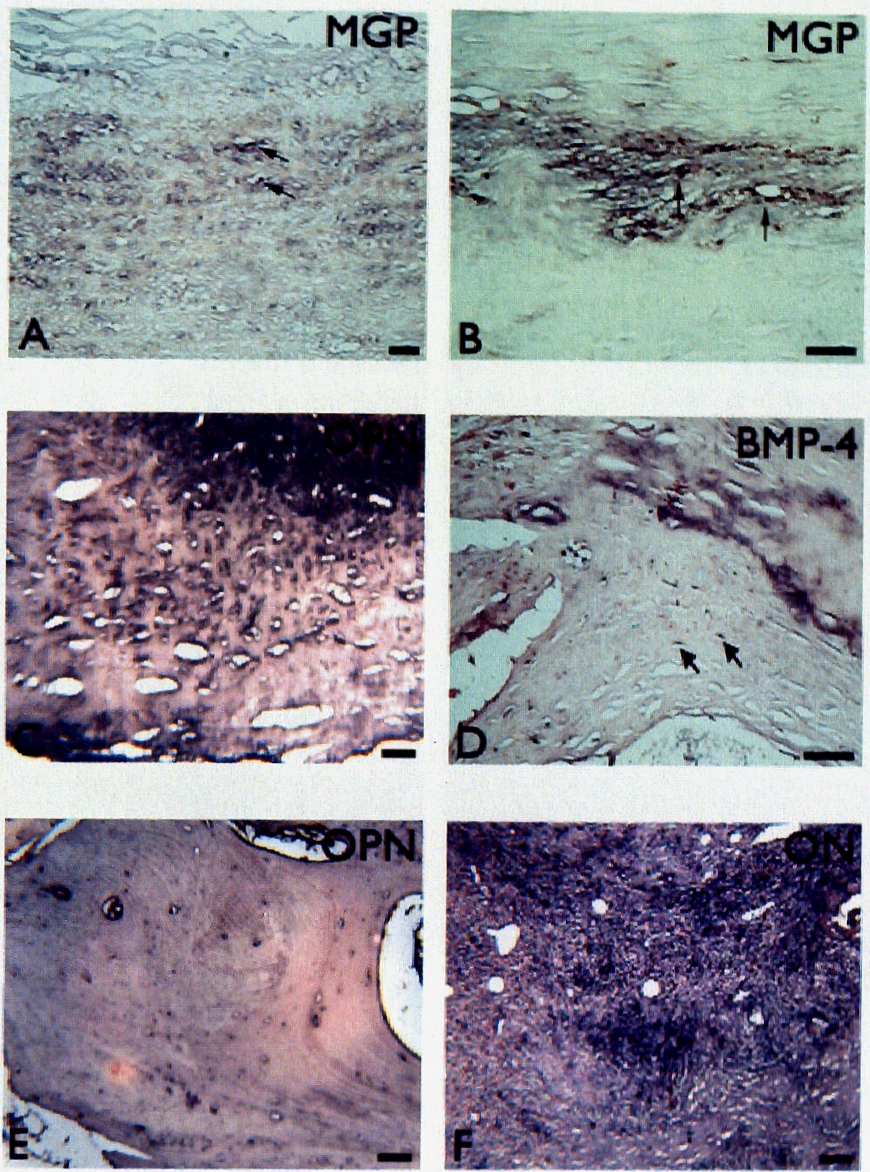

Figure 2.6. In situ hybridization with riboprobes directed to MGP, BMP-4, OPN and ON. Fig. 2.6a: MGP in situ hybridisation of an intimal xanthona. Note: dark purple staining are MGP MRNA positive medial smooth muscle cells (arrow). Fig. 2.6b: MGP in situ hybridisation of a fibrous cap atheroma. Note: arrow indicates an MGP MRNA positive intimal smooth muscle cell. Fig. 2.6c: BMP-4 in situ hybridisation of a fibrocalcific plaque. Arrow indicates a BMP-4 MRNA positive intimal smoath muscle cell in the surrounding of a calcified area of the plaque. Fig. 2.6d: OPN MRNA expression in intimal smooth muscle cells in the surrounding of calcium deposits of a fibrocakific plaque. Fig. 2.6e: OPN in situ hybridisation of a fibrocalcific plaque. Note: osteocytes and osteoblasts express OPN mRNA. Fig. 2.6f: ON mRNA expression in intimal smoath muscle cells in the surrounding of calcium deposits. Sicale bar in fig. 2.6a represents $50 \mu \mathrm{m}$, scale bars in fig. 2.6b, d and frepresent $25 \mu \mathrm{m}$, and scale bars in fig. $2.6 \mathrm{c}$ and e represent $10 \mu \mathrm{m}$. 

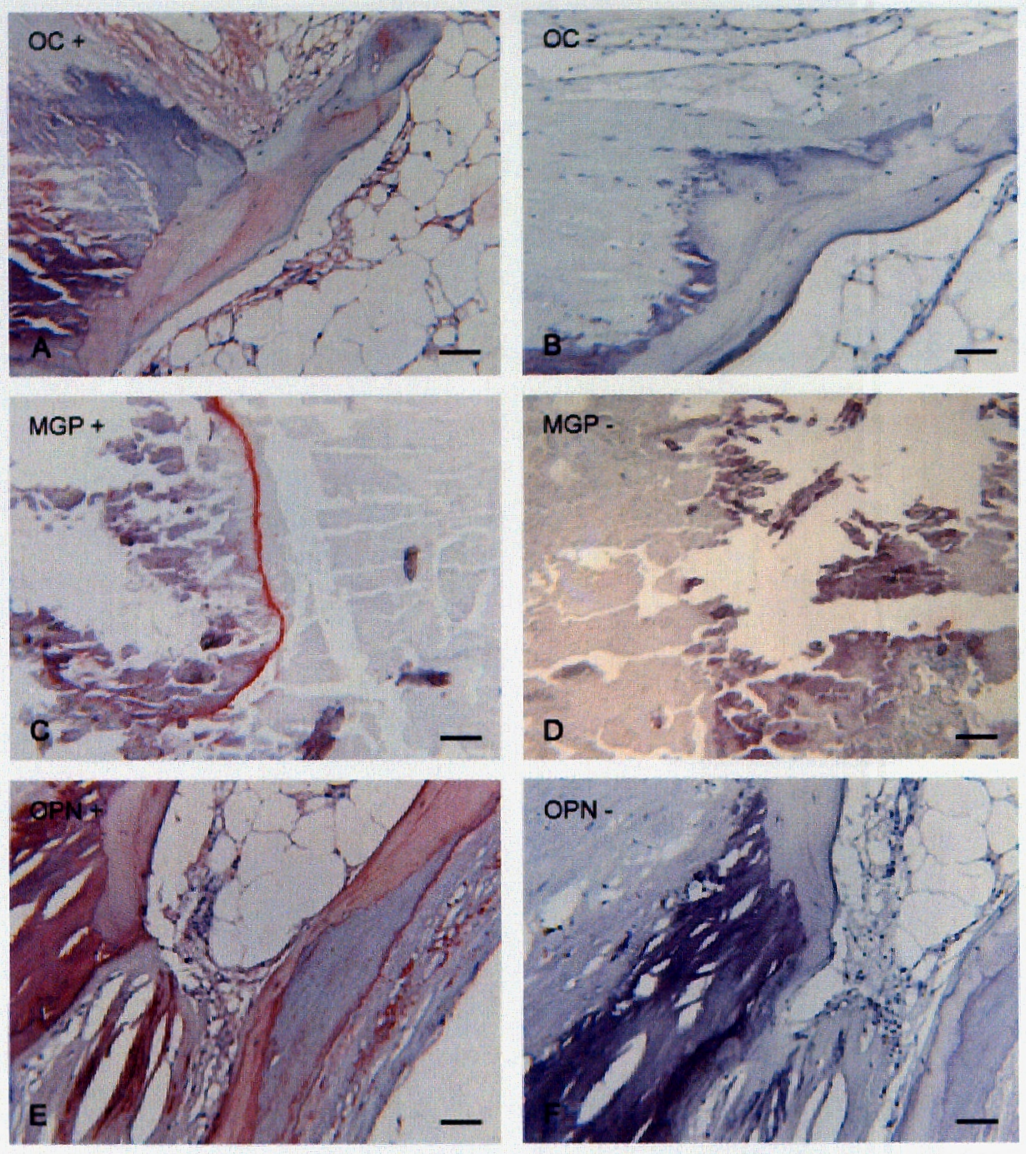

Fig. 3.1. Immunohistachemical staining of bone matrix regulatory proteins on calcified valves. Immunohistochemistry of osteocalcin (A), matrix Gla protein (C) and osteopontin (E) and their negative controls. ( $B, D$ and $F)$ on human calcified aortic valves. Scaie bars represent $50 \mu \mathrm{m}$. 


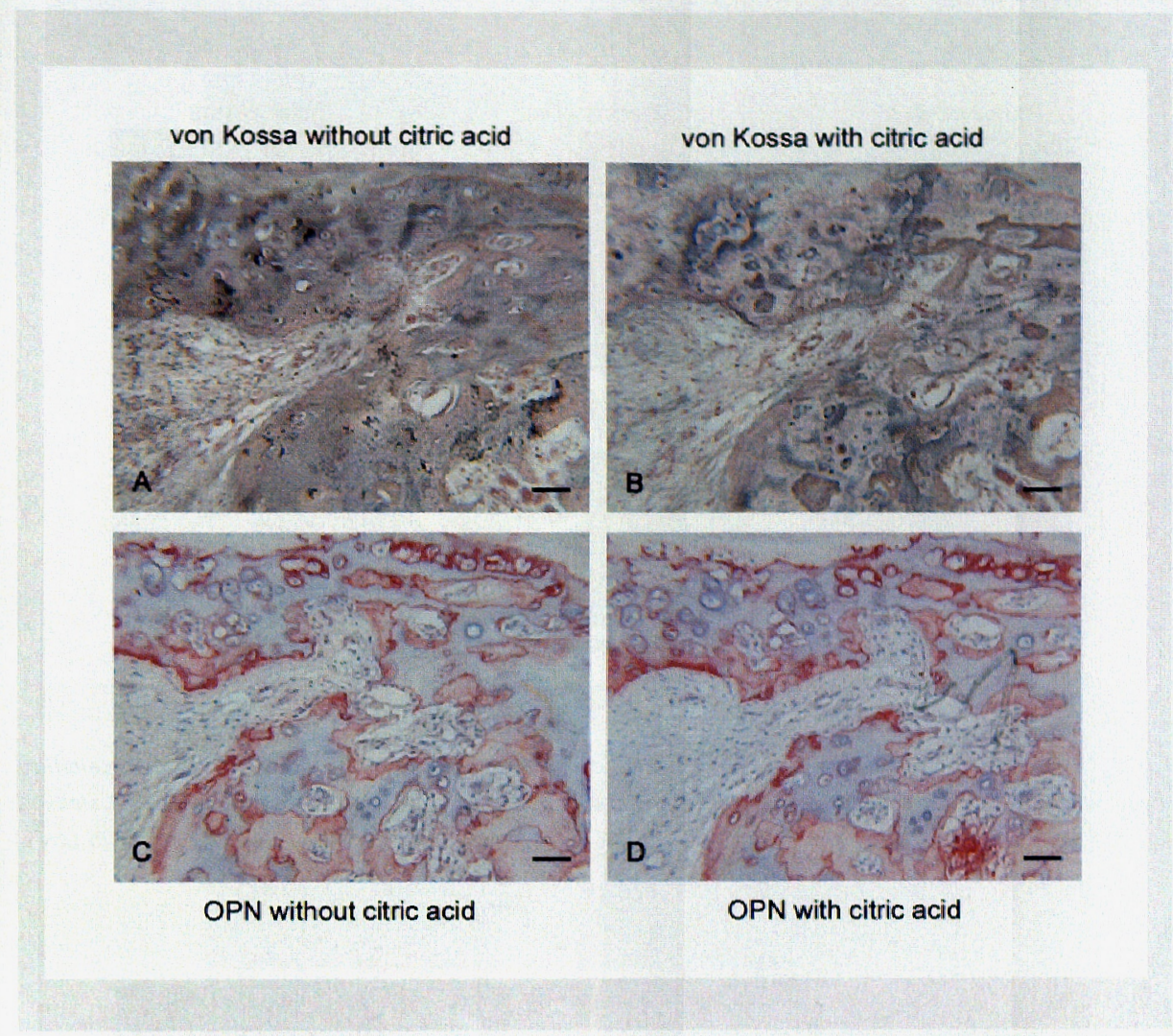

Fig. 3.2. Von Kassa staining and immunohistochemical staining of osteopontin on serial sections of a calcified aortic valve. Serial sections of a human calcified aortic valve stained with Von Kossa (A and B) and osteopontin ( $C$ and $D$ ) without ( $A$ and $C$ ) and with $(B$ and $D$ ) citric acid pretreatment. 5 cale bars represent $50 \mu \mathrm{m}$. 


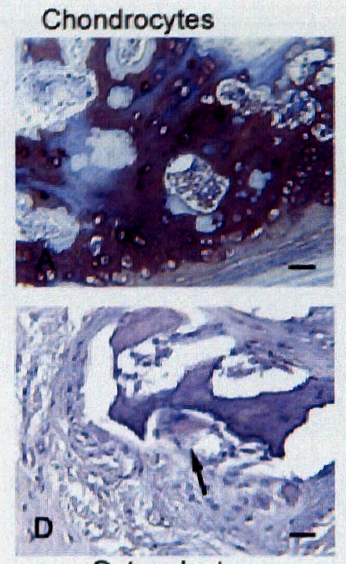

Osteoclast
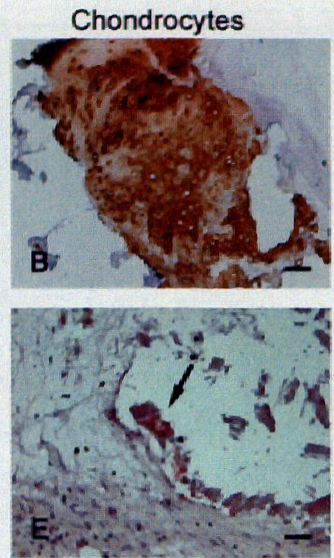

Osteoclast
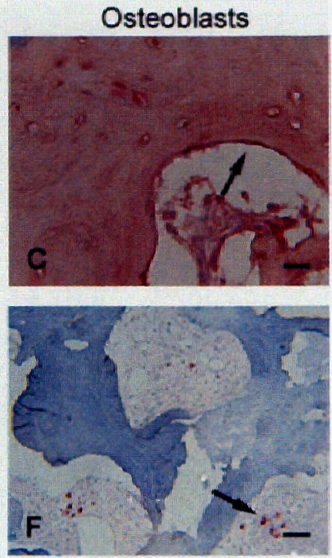

Bone marrow

Fig. 3.3 Identification of chondrocytes, osteoclasts, osteoblasts and hemopoietic cel/s in human calcified aortic valves by respectively thionin staining (A), type I/ collagen (B), osteocalcin staining (C), cathepsin $K$ staining (D). TRAP staining ( $E$ ) and CD138 staining (F). Scale bar in A represent $50 \mu \mathrm{m}$ and in $B, C, D, E$ and $F 25 \mu \mathrm{m}$.

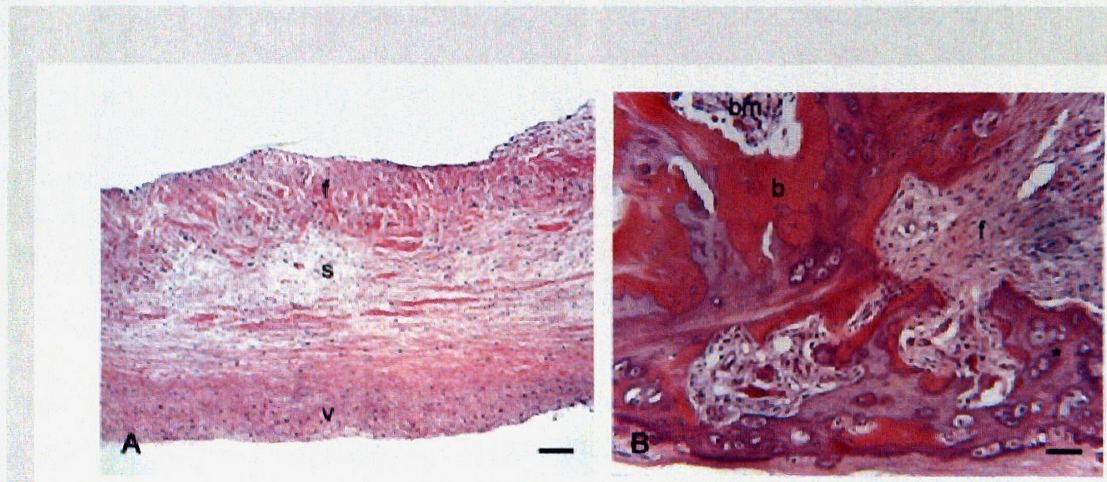

Fig. 3.4: Histological and morphological characteristics of the human aortic valve.

Fig. 3.4a: H\&E staining of a non-cakiffied aortic valve. The three layers of the valve are the fibrosa (f), spongiosa ( $s$ ) and ventricularis ( $v$ ). Panel b represent a valve containing calcified tissue H\&E stained. Note $\left(^{*}\right)=$ cartilage, $b=b o n e$, and bm=bone marrow cavity. Scale bars represent $100 \mu \mathrm{m}(\mathrm{a}), 50 \mu \mathrm{m}(\mathrm{b})$. 

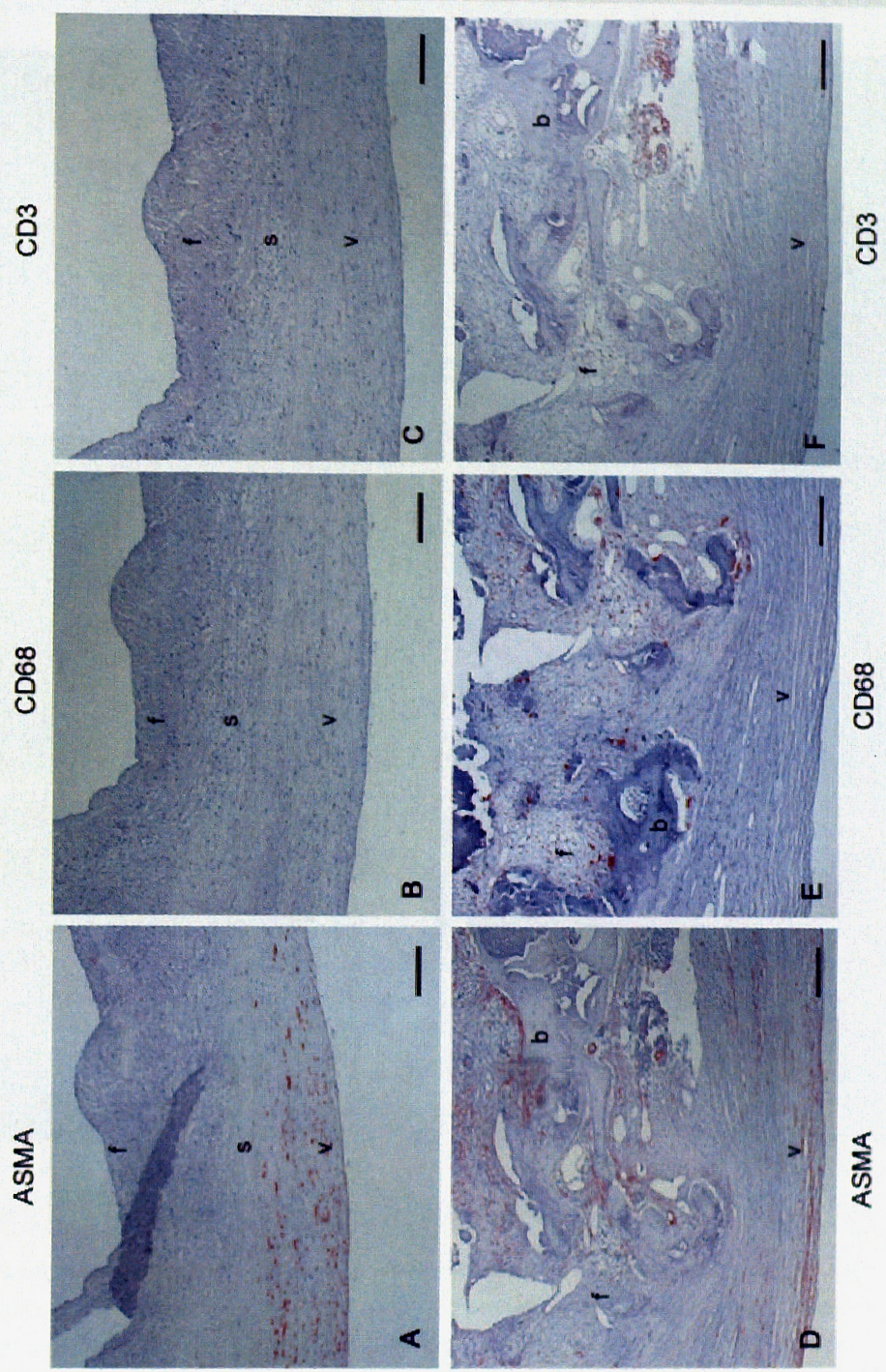

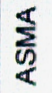

Fig. 3.5. Immunohistochemistry of ASMA, CD68 and CD3 on human aortic vales. A, $B$, and C: represent immunohistochemical stainings of non-calcified walves, while $D$, E and $F$ showed immunahistochemical stainings of calcified valves. AOrtic valves stained with antibodies directed to ASMA (A and D), CD68 (B and E) and CD3 (C and F. Nate: In the calcified valves ASMA, CD68 and CD3 positive cells (red staining) are located in the surroundings of mineralized tissue. ( $f=$ fibrosa; $s=s p o n g i o s a ; ~ v=v e n t r i c u l a r i s ~ a n d ~ b=b o n e)$. Sicale bars represent $150 \mu m$. 

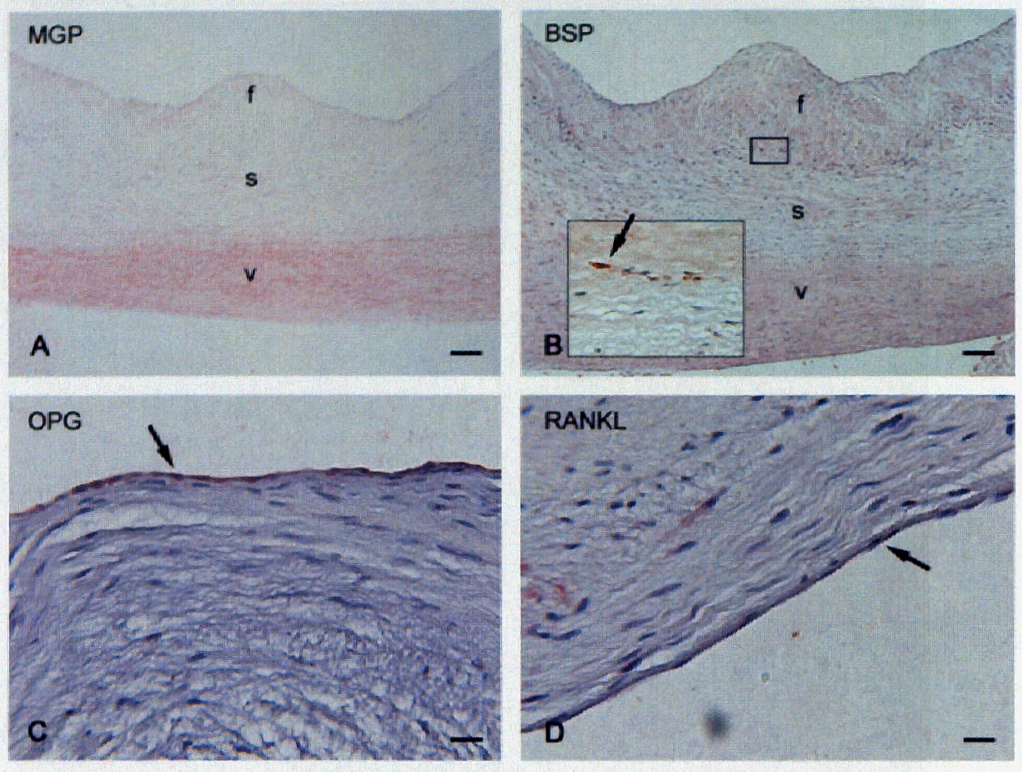

Fig. 3.6. Immunohistochemical staining of bone matrix regulatory proteins on non-calcified valves. $A$ and $B$ : non-calcified valve stained with antibodies directed to MGP $(A)$ and BSP (B). Both proteins are present in these valves (red staining). Note: MGP is present in the ventricular layer of the valve and BSP is clear expressed in the fibroblasts (arrow and inset) in the fibrosa. $C$ and $D$ : non-calcified valve stained with antibodies directed to OPG (C) and RANKL (D). Scale bars represent $100 \mu \mathrm{m}(\mathrm{A})$ and $25 \mu \mathrm{m}$ (B, C and D). 

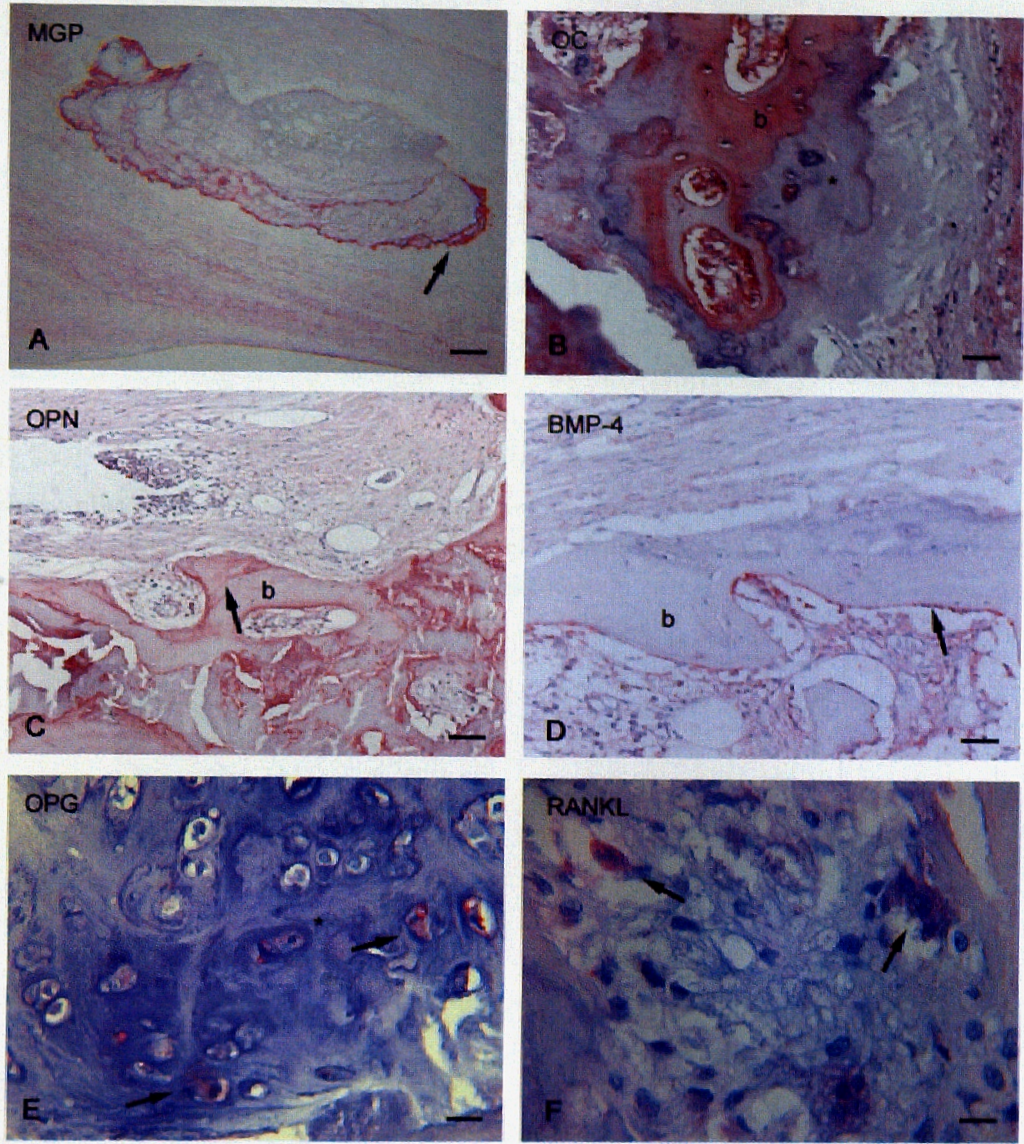

Fig. 3.7. Immunohistochemical staining of bone matrix regulatory proteins on calcified valves. A and B: MGP. OC and BSP are present in calcified aortic valves. MGP (A) showed expression (arrow) at the borders of amorphous calcium phosphate deposits, while $O C(B)$ is present in bone matrix af lamellar bone. $C$ and $D:$ In calcified valves OPN ( $C$ ) is localised in the cement lines (arrow), and BMP-4 (D) is present in the osteoblasts lining lamellar bone (arrow). E and F: OPG (E) showed immunoreactivity in the chondrocytes (arrow) and its ligand RANKL (F) is present in osteoclasts (arrow). Scale bars represent $50 \mu \mathrm{m}$ ( $A$ and $C$ ) and $25 \mu \mathrm{m}(B, D, E$ and $F$ ). 


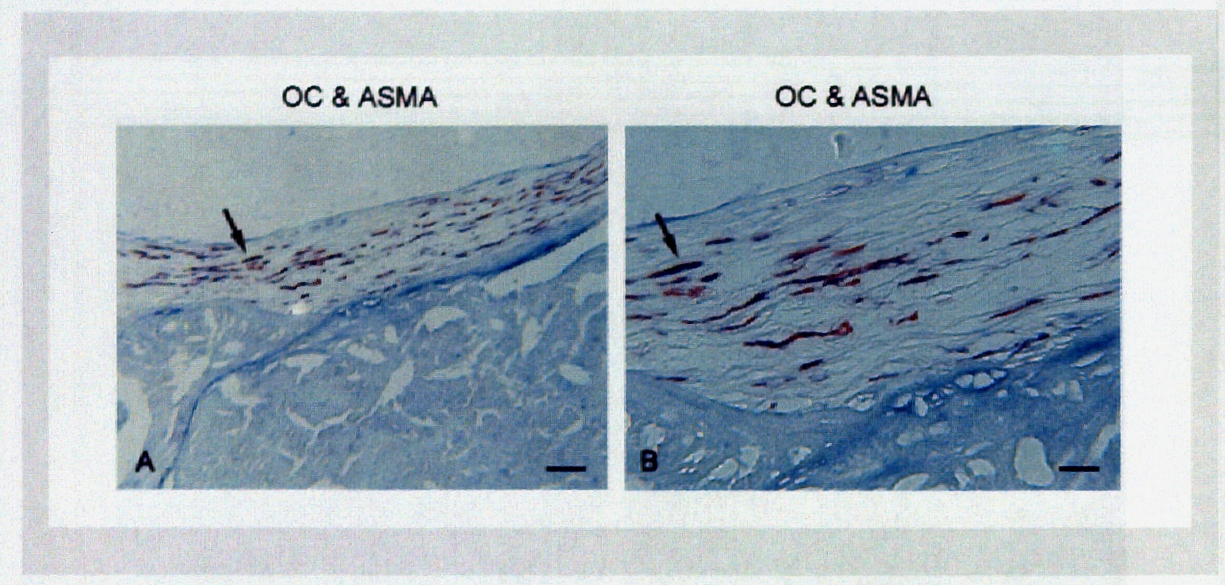

Fig. 3.8. Double immunohistochemical staining of human calcified aortic valve with osteocalcin and ASMA (A). Note: osteocalcin is also expressed by a subpopulation of smooth muscle cells. Figure $B$ represents a higher magnification. Scale bar in A represents $50 \mu \mathrm{m}$ and B $25 \mu \mathrm{m}$. 


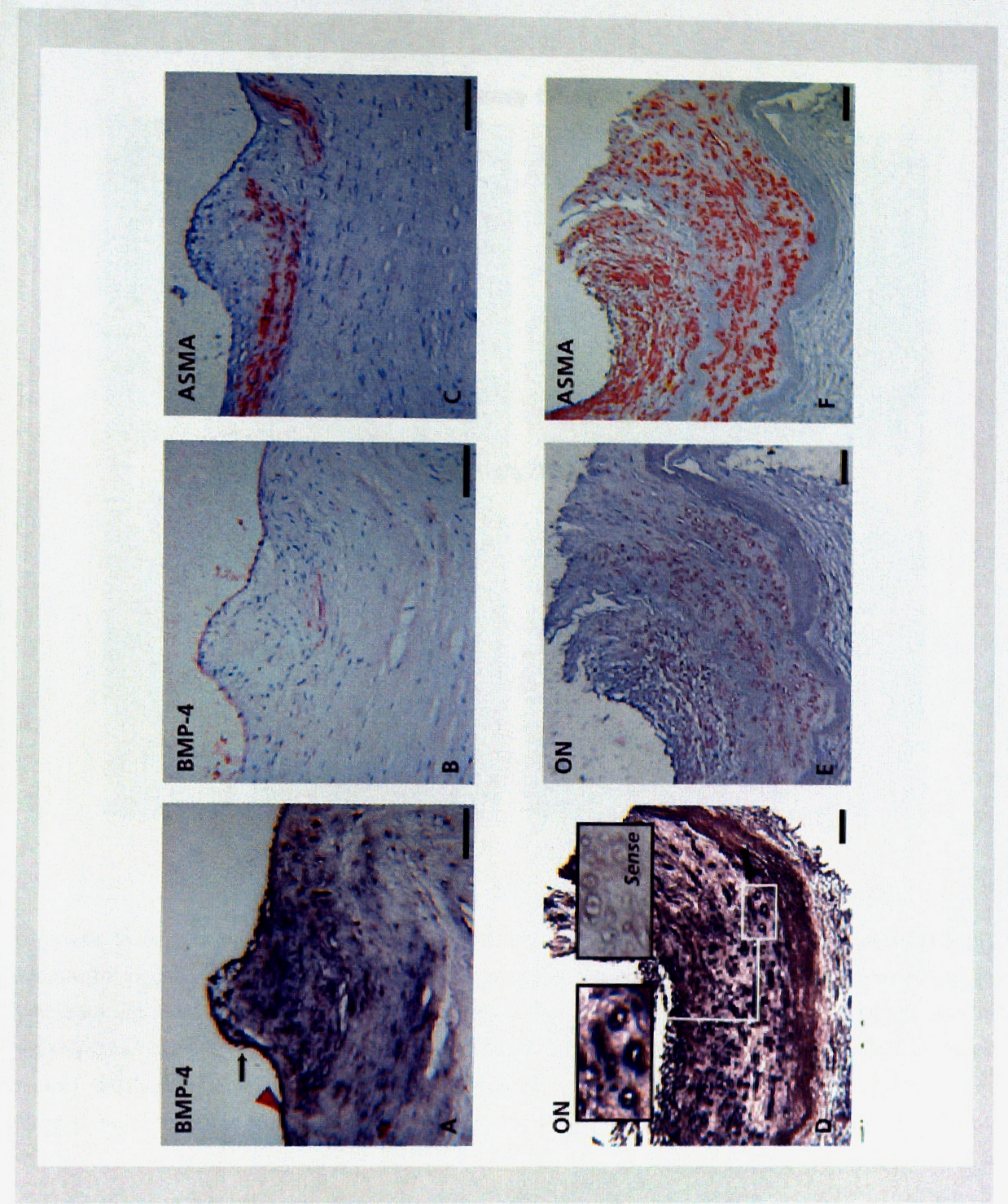

Fig. 3.9. In situ hybridisation (ISH). $A, B$ and $C$ : representation of respectively ISH of BMP-4 (A), and immunohistochemistry with antibodies directed to BMP-4 (B) and ASMA (C). D, E and F; ISH af ON (D) left inset is magnification of chondrocyte like cells and right inset is ISH of ON with sense probe), and immunohistochemistry with antibodies directed to ON (E) and ASMA (F). Note: BMP-4 is present in endothelial cells (arrow). ON is presient in chondrocyte like cells (arrow and inset). Scale bars represent $50 \mu \mathrm{m}$. 


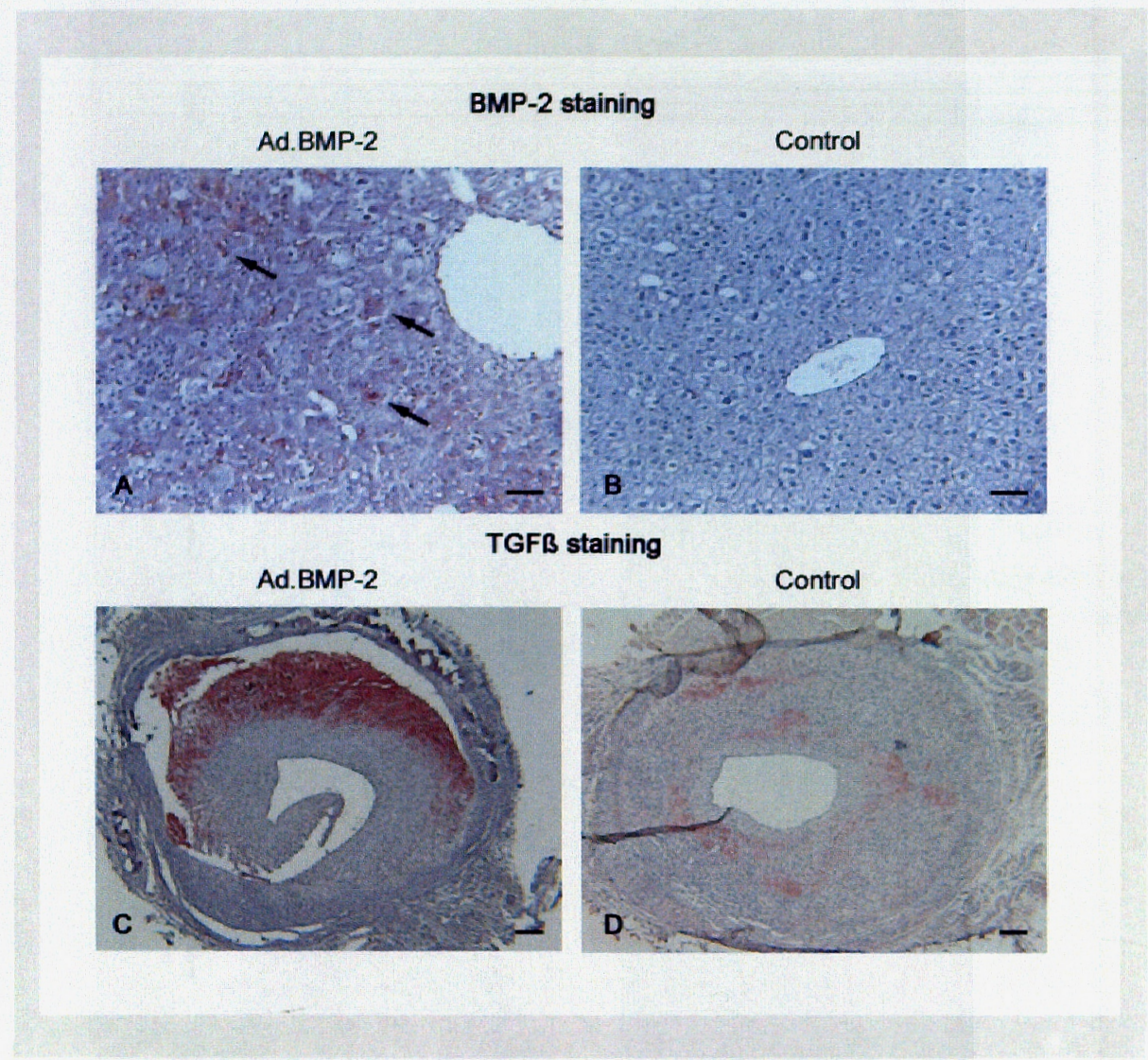

Fig. 4.1. Cross-sections of the liver of respectively a Ad. BMP-2 treated mouse $(A)$ and a control mouse (B) stained by immunohistochemistry with a palyclonal antibody directed to BMP-2. A. BMP-2 is visualized in red. Arrows. indicate BMP-2 present in liver celis. Cross-section of atherosclerotic plaques of respectively the Ad.BMP-2 treated group ( $C$ ) and the control group (D) stained for TGFB (visualized in red). Note: TGFB was hardly present in the control group (Fig. 4.1D) and clearly enhanced in the Ad.BMP-2 group, with TGFB located primarily at the adventitial side of the intima (Fig. 4.1C). Scale bars in panel $A$ and $B$ represent 50 mm, in panel $C$ and $D$ rooum. 


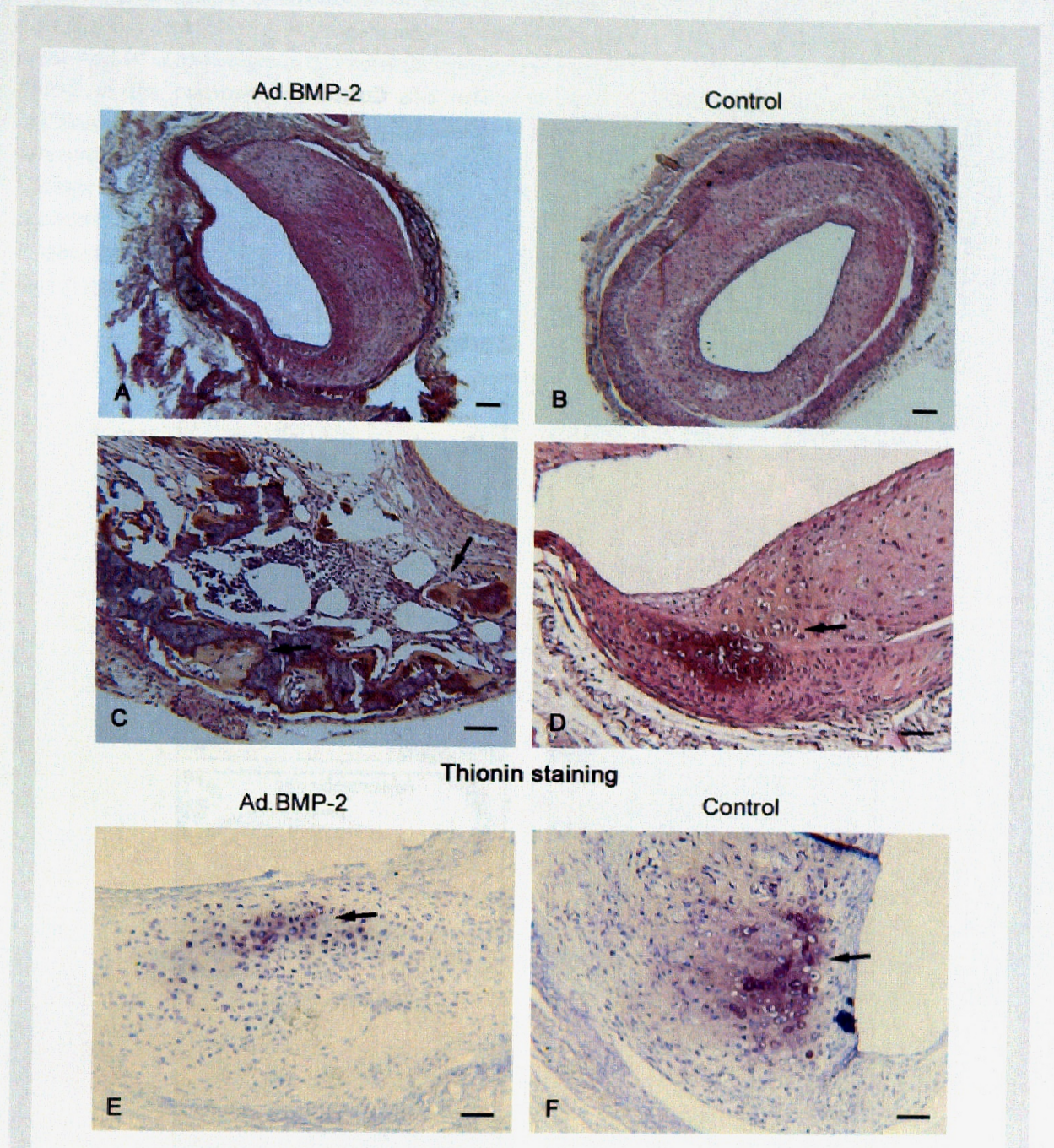

Fig. 4.2. Cross-sections of a vein graft of respectively the Ad.BMP-2 treated group (A and $C$ ) and the cantrol group $(B$ and $D)$. There was no difference in total vessel area "plaque area and lumen area between the Ad.BMP-2 treated mice (A) and the controls (B). However, the area of non-ossious calcification and ectopic bone formation was enhanced in the Ad.BMP-2 treated mice $(C)$ versus the controls $(D)$. Arrow in panel $C$ indicate ectopic bone formation. Arrow in panel $D$ indicate cartilage.

Cross-sections of atherosclerotic plaques in Ad.BMP-2 treated mouse (E) and control mouse (F) containing non-calcified cartilage. Cartilage is visualized in purple by a thionin staining (arrow).

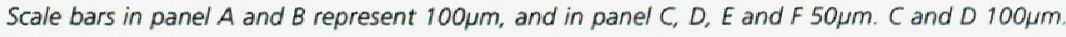




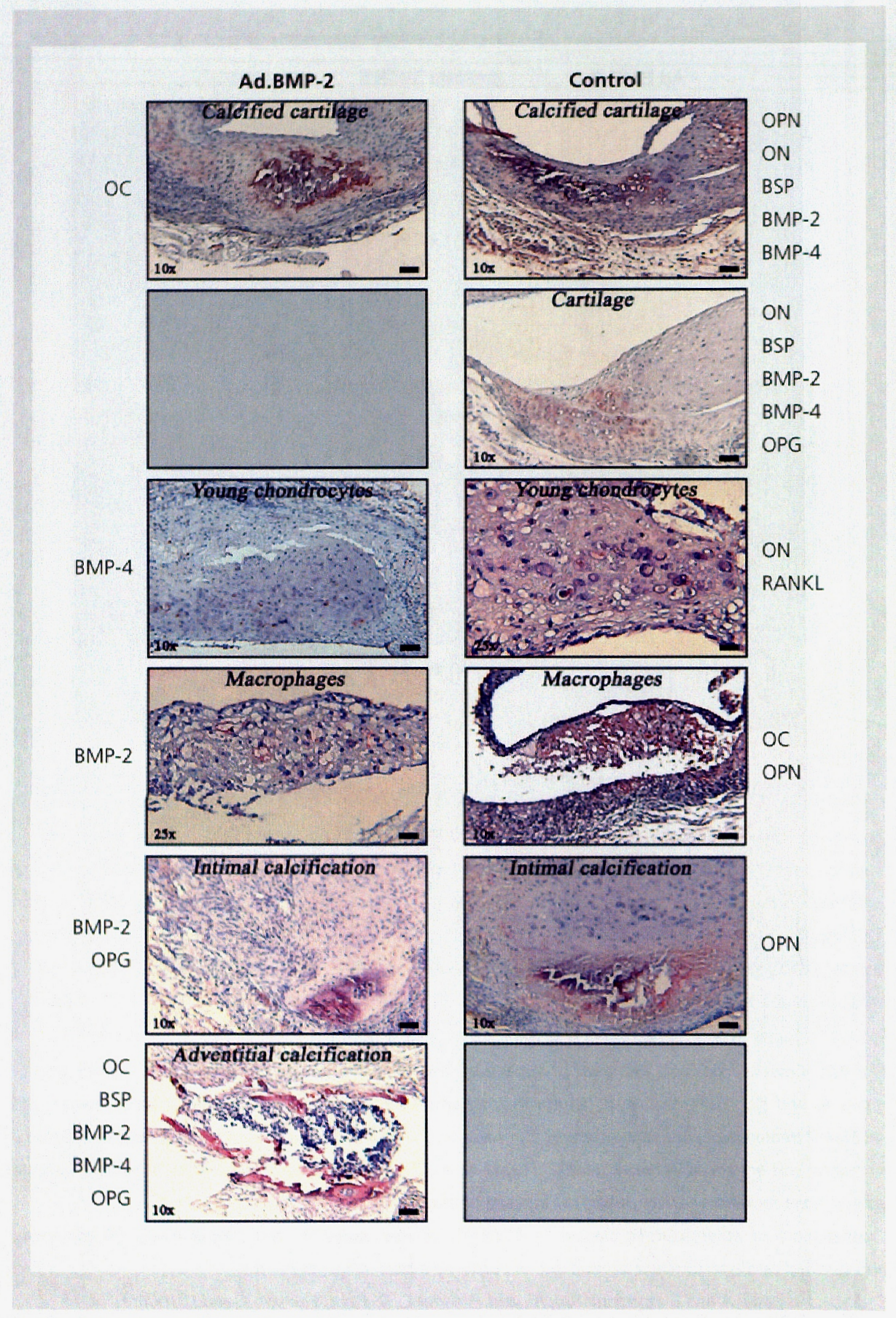


Fig. 4.3. Cross-sections of atherosclerotic plaques in both the Ad.BMP-2 treated group (left pane/s) and the control group (right panels). Positive staining was visualized in red.

In the Ad.BMP-2 treated group only osteocalcin was present in calcified cartilage, BMP-4 in young chondrocytes, $B M P-2$ in the macrophages, $B M P-2$ and osteoprotegerin in intimal calcification and in adventitial calcification/ossification five proteins showed immunoreactivity (BMP-2, BMP-4, osteocalcin, BSP and osteoprotegerin. In the control group BMP-2, BMP-4, BSP and osteonectin were present in both calcified cartilage and non-calcified cartilage. Osteopontin was present in calcified cartilage, while osteoprotegerin showed immunoreactivity in non-calcified cartilage. In young chondrocytes RANKL and osteonectin were present, in macrophages osteopontin and asteocalcin and in intimal calcification only osteopantin was expressed. Scale bars in ponels with $10 x$ magnification represent $50 \mu m$, and in panels with 25x magnification 20um. 


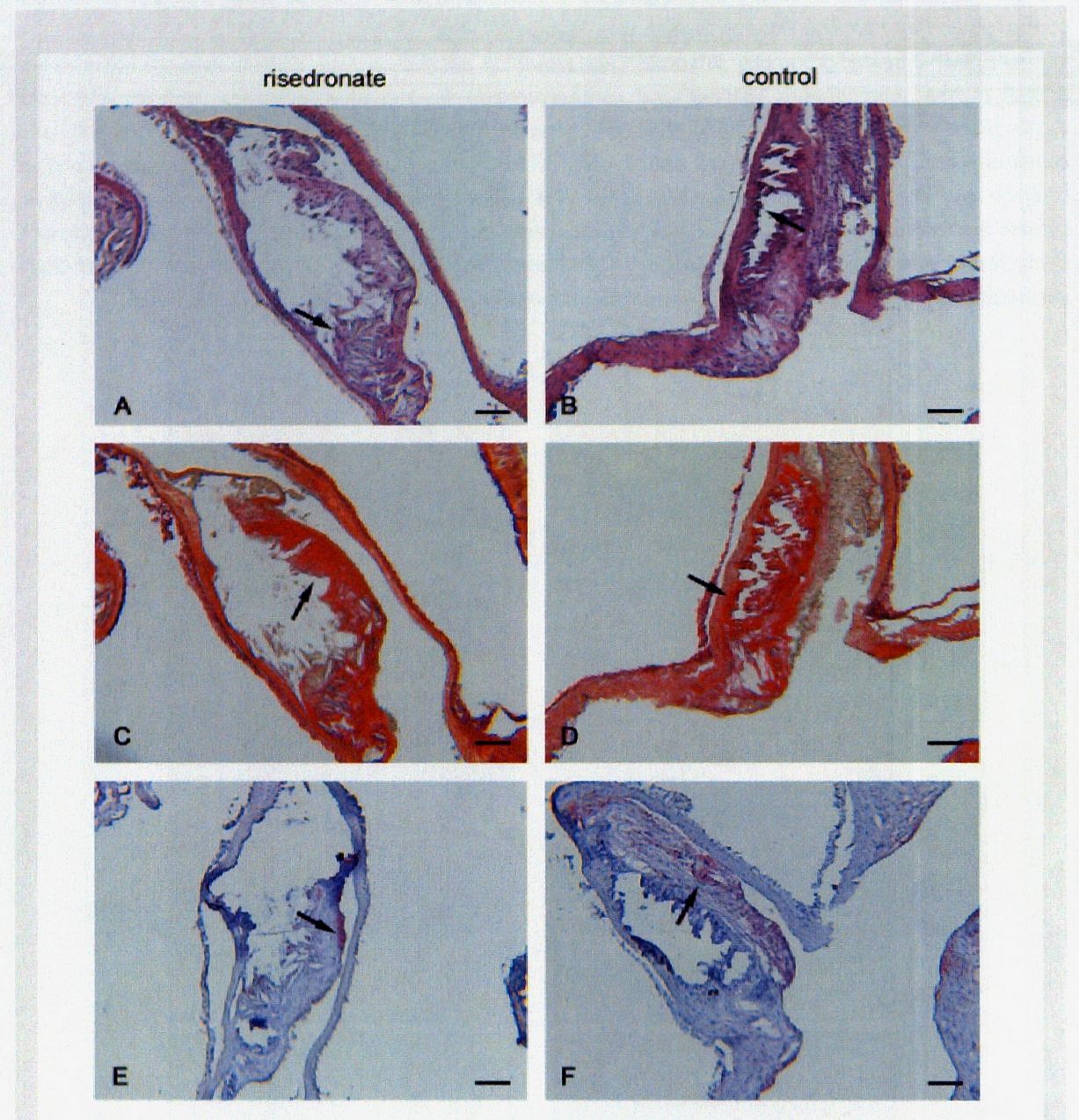

Fig. 5.1. Cross-sections of the first branch (right carotid artery) of the aortic arch of respectively a risedronate treated mouse ( $a, c$ and $e$ ) and a control mouse ( $b, d$ and $f$ ) stained with H\&E ( $a$ and $b$ ), Sirius Red for the detection of collagen ( $\mathrm{c}$ and $d$ ) and with a monoclonal antibody directed to Mac3 for the detection od macrophages (e and $)$ ). a: arrow indicate cholesterol crystals. b: arrow indicate calcification. $c$ and $d$ : collagen is visualized in red. $e$ and $f$ : arrows indicate macrophages, visualized in red. 


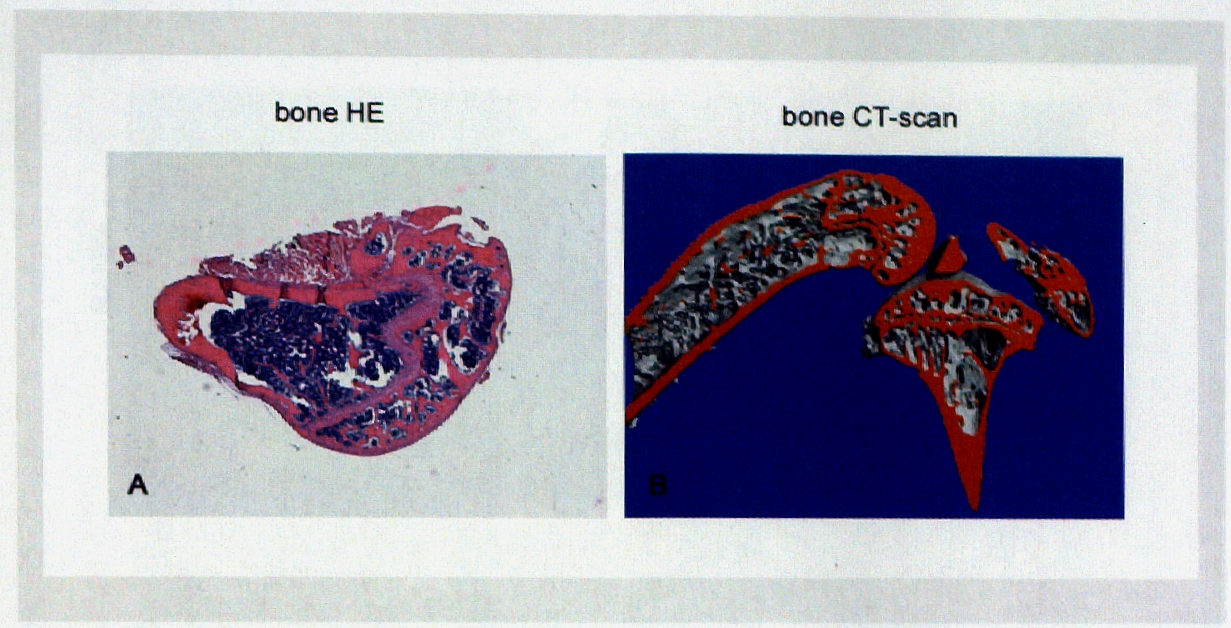

Fig. 5.2. Cross-sections of a femur H\&E stained (a) and a three-dimentional micro-CT scan of the left leg (femur, knee joint and tibia) (b). 


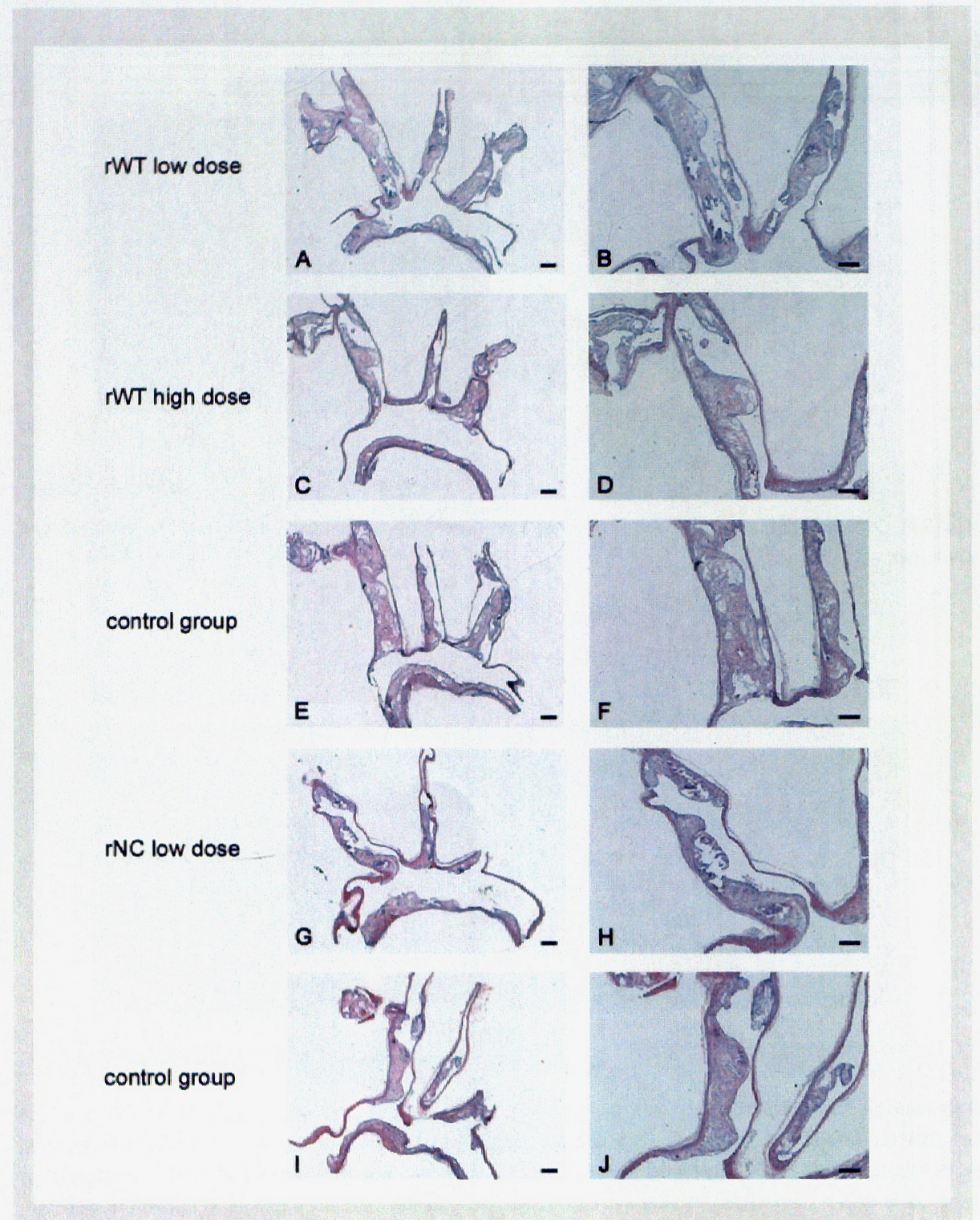

Fig. 5.3. Cross-sections of the complete aortic arch including the main branch points $\left(a, c, e_{x} g\right.$ and i) and a higher magnification of the first branch (right carotid artery) ( $b, d, f, h$ and $j$ ) of various groups and controls. $a$ and b: regression Western type diet group with risedronate dose of $5 \mu \mathrm{g} / \mathrm{kg}$ ( $\mathrm{rWT}$ low dose). c and d: regression Western type diet group with risedronate dose of $25 \mu \mathrm{g} / \mathrm{kg}$ (rWT high dose). e and f: contro/ group for the regression Western type diet experiment. $g$ and h: regression normal chow group with risedronate dose of $5 \mu \mathrm{g} . i$ and $j$ : control group for the regression normal chow experiment. Scale bars in fig. 5.3a, c, e,g and i represent $300 \mu \mathrm{m}$, and in fig. $5.3 \mathrm{~b}, \mathrm{~d}, \mathrm{f}, \mathrm{h}$ and $j$ the scale bars represent $200 \mu \mathrm{m}$. 


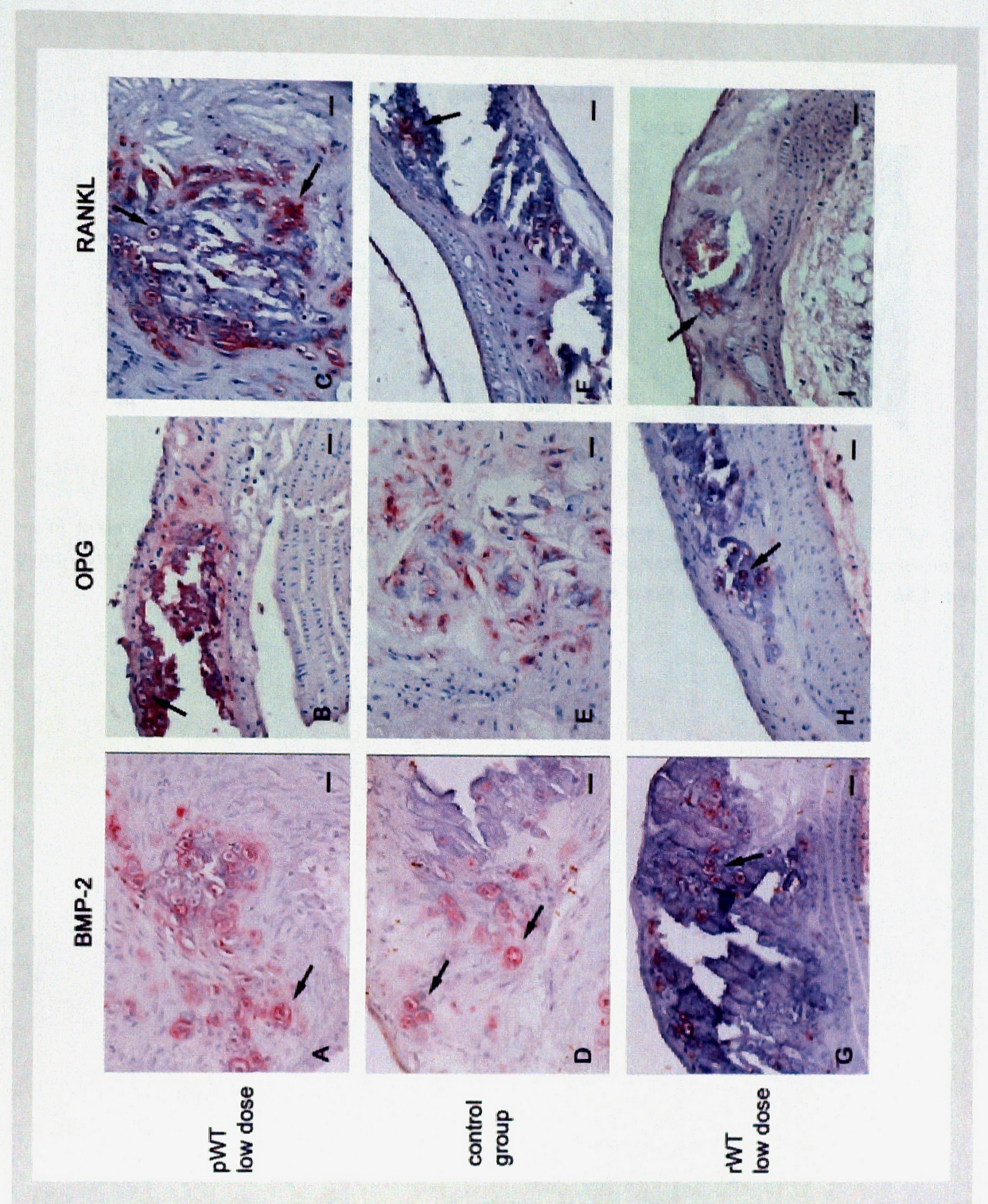

Fig. 5.4. Immunohistochemical staining of three bone matrix regulatory proteins (BMP-2, OPG and RANKL) on murine atherosclerotic plaques of various experimental groups. $a$, $b$ and $c$ represent atherosclerotic plaques of prevention Western type diet mice that received a risedronate dose of $5 \mu \mathrm{g} / \mathrm{kg} . \mathrm{d}$, e and $f$ are the controls. g, th and i represent atherosclerotic plaques of regression Western type diet mice that received a risedronate dose of $5 \mu \mathrm{g} / \mathrm{kg}$. The left panels are immunohistochemically stained with BMP-2, the middle panels with OPG and the right panels with RANKL. Positive staining was visualized in red. Mainify the chondrocytes (arrows) are positively stained for alle three bone matrix proteins. Scalle bars represent $20 \mu \mathrm{m}$. 


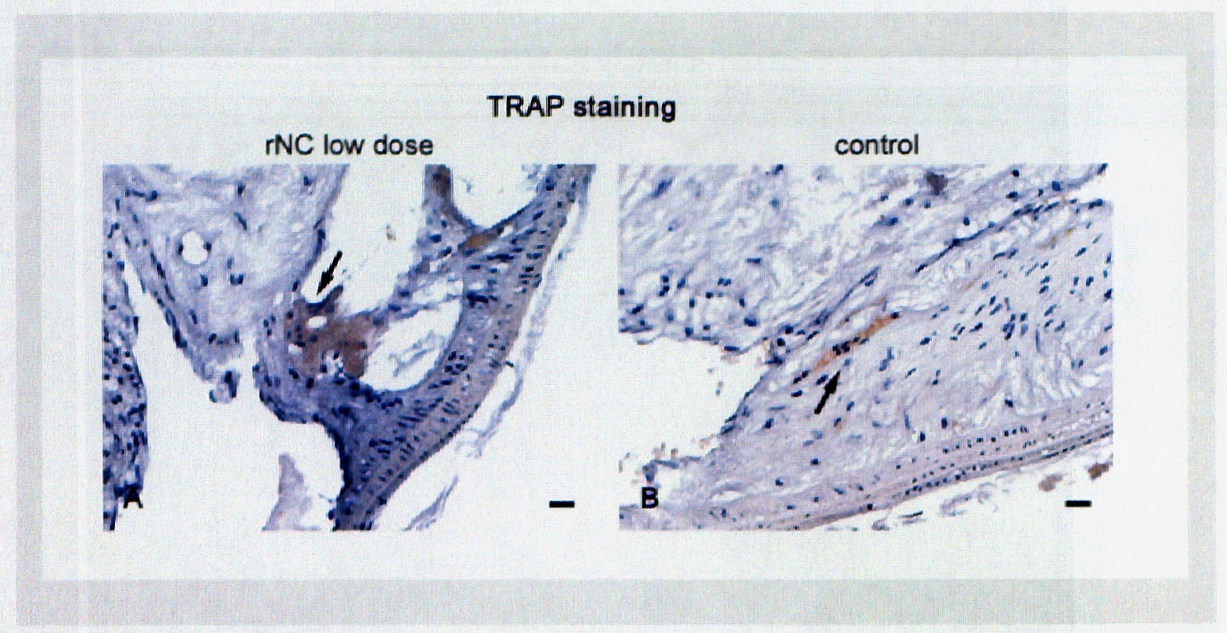

Fig. 5.5. TRAP staining for the identification of osteoclasts. A single osteoclast (arrow) present in an atherosclerotic plaque of the regression NC experiment (fig. 5.5a) and in the accessory control group (fig. 5.5b). Positive staining is visualized in brown. Scale bars represent $20 \mu \mathrm{m}$. 